\title{
THREE ESSAYS ON STOCK EXCHANGE DEMUTUALIZATION AND MERGERS
}

by

Kobana Abukari, B.Sc., M.A., M.M.S.

A thesis submitted to the Faculty of Graduate and

Postdoctoral Affairs in partial fulfilment of the requirements for the degree of

Doctor of Philosophy

in

Management

Carleton University

Ottawa, Ontario

(C) 2015

Kobana Abukari 


\section{ABSTRACT}

The increased competition in the stock exchange industry, intensified by globalization and technological advancements, has motivated a number of changes in the stock exchange industry including demutualization and mergers. This thesis studies stock exchange demutualization and mergers in three separate but related essays. Essay one ${ }^{1}$ investigates the stock market and product market effects of stock exchange mergers, which have been facilitated by demutualization. We find that shareholders of targets and shareholders of the combined exchanges realize significant positive abnormal returns. Additionally, we find that shareholders of competitors from countries in the same geographical region and competitors at the same stage of development also realize significant abnormal returns. We also find that on the product market, the merging exchanges increase their market share and experience reductions in bid-ask spreads while rivals experience decreased market share and increased bid-ask spreads. We contend that stock exchange mergers have resulted in significant wealth creation on the stock market and substantial value creation on the product market for the merging entities.

Essay two examines the market quality implications of stock exchange demutualization. We find that exchanges undertaking demutualization (especially developed stock exchanges) achieve significant reductions in transaction costs and volatility. Although the demutualized exchanges see improvements in market quality, a controlled group of mutual rival stock exchanges have experienced increases in spreads and volatility in the post-demutualization period, and have, as a result, seen deterioration in market quality. Essay three explores the market power consequences of stock exchange mergers. We find that stock exchange mergers have not resulted in the exercise of market power. Instead, the mergers have led to efficiency gains for the merging exchanges and efficiency losses for rivals.

Our findings are insensitive to several robustness checks.

\footnotetext{
${ }^{1}$ Essay one has been accepted for publication in the Journal of Financial Studies.
} 


\section{ACKNOWLEDGEMENTS}

Undertaking and completing this thesis would have been impossible had it not been for the invaluable help, support and contributions of many people. I would therefore like to take this opportunity to express my sincere thanks and appreciation to the selfless help of the many individuals who contributed immensely to this thesis. I would first and foremost like to thank Professor Isaac Otchere, my thesis supervisor, for his unparalleled guidance, assistance, encouragement and friendship during the entire thesis process. Professor Otchere has diligently and patiently guided me through several drafts and the successful completion of the thesis. Admittedly, without Professor Otchere's insightful direction, thoughtful suggestions and reasoned answers to my never-ending questions, this thesis would probably not have seen the light of day. Professor Otchere, thank you immensely for your extraordinary help on all facets of the thesis and academic life. I am eternally indebted to you for everything.

The thesis has benefited significantly from the invaluable input of my thesis committee. In this regard, I would like to thank Professor Howard Nemiroff for the insightful comments, suggestions and support. I would also like to thank Professor Sana Mohsni for the valuable comments, suggestions and encouragement. My sincere thanks also go to Professor Gady Jacoby for the invaluable input, insights, comments, suggestions and for being on my thesis committee. My thanks also go to Professor Shantanu Dutta for the valued comments, suggestions and for agreeing to be part of the committee.

Several other professors have helped me on this journey and I would like to offer my sincere thanks to them. First, I sincerely thank Professor Vijay Jog for his invaluable help and friendship over the years and for guiding me through the comprehensive examination phase. Professor Roland Thomas has tremendously helped me with statistics and modeling over the years. Accept my sincere thanks, Professor Thomas, for all your help. My thanks also go to Professor Alex Ramirez, Professor Uma Kumar and Professor Ernest Kwan for the help and guidance during the $\mathrm{PhD}$ program. 
Thanks to Greg Schmidt for the friendship and all the help with my hardware and other computing needs. I would also like to thank my friends and colleagues Anant Rege and Jayant Pandit for help with data transformation. Thanks to Phil Zhu and Erin Oldfold for the friendship and all the help on the thesis. I would like to acknowledge and thank Mr. Herbie Skeete at Mondo Visione for taking it upon himself to collect demutualization dates for stock exchanges for which I could not find the dates. I would also like to thank Ms. Eleanor Penistone at the World Federation of Exchanges and several individuals from a number of stock exchanges for their help with the collection of the demutualization dates. Thanks to Namawu Alolo and Mutako Alolo for the help over the years. Special thanks also go to Sue Khosla and the late Dev Khosla for providing me with a home away from home.

Last, but not the least, I would like to thank my family for their love, support and sacrifices. Sincere thanks go to my wife Sahada and to my boys Kataali, Timalma and Wunyiko. Sincere thanks also go to my mom and siblings for always being there for me. I dedicate this thesis to the memory of my beloved dad and sister.

I acknowledge the financial support from Carleton University during my $\mathrm{PhD}$ studies. 


\section{TABLE OF CONTENTS}

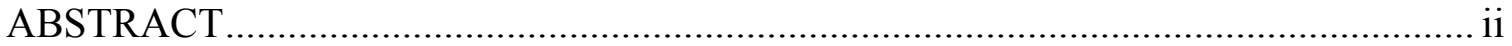

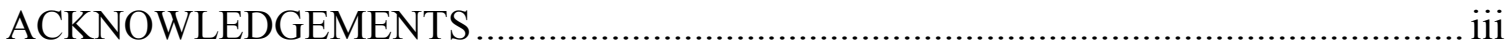

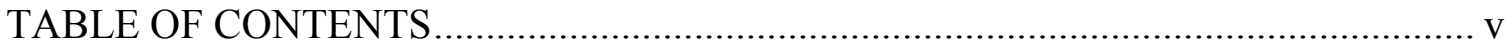

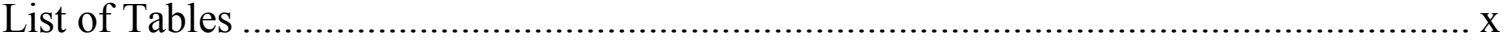

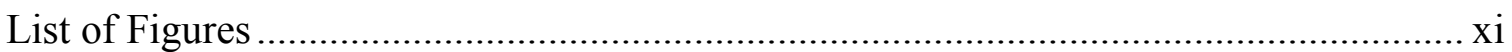

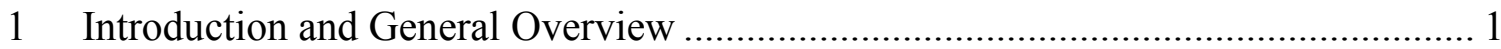

1.1 Introduction ....................................................................................................

1.2 Overview and Trends in the Stock Exchange Industry .................................................. 12

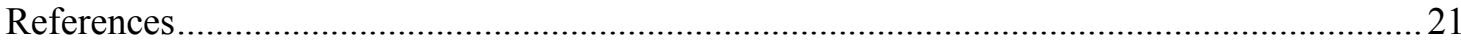

2 Essay One: Stock and Product Markets Effects of Stock Exchange Mergers ........... 24

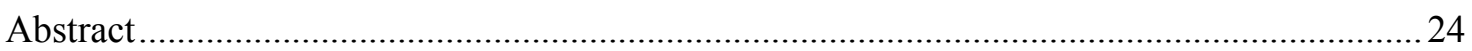

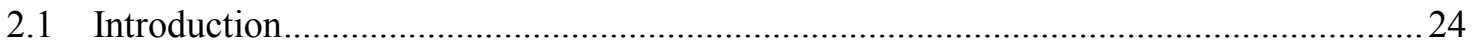

2.1.1 Benefits of Study ........................................................................................... 32

2.1.1.1 Contributions of Essay to the Academic Community …...................... 33

2.1.1.2 Importance of Study to Investors........................................................ 33

2.1.1.3 Corporate Policy Implications of Study ………………….................. 33

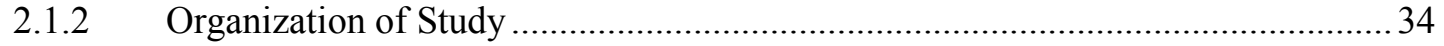

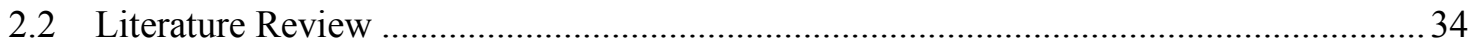

2.2.1 Literature on Stock Exchange Mergers.................................................................. 35

2.2.2 Summary of the Literature on Mergers and Acquisitions ........................................39

2.2.3 Concerns raised about Stock Exchange Mergers ..................................................... 41

2.3 Research Questions and Hypotheses ……………………............................................. 43

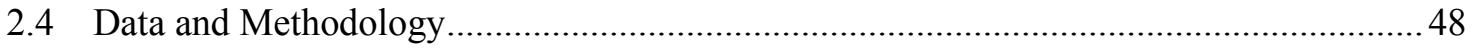

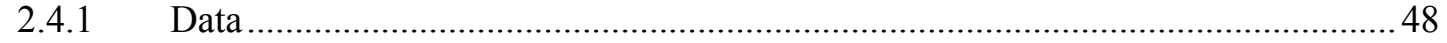

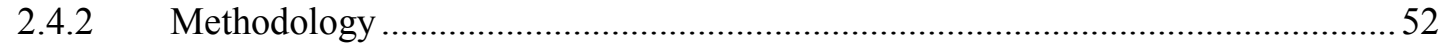

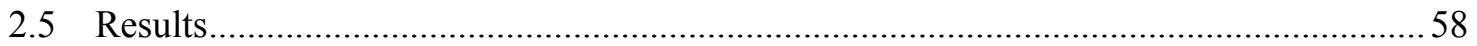

2.5.1 Stock Market Impacts of Mergers.......................................................................58

2.5.1.1 Pooled Results of All Mergers.......................................................... 58

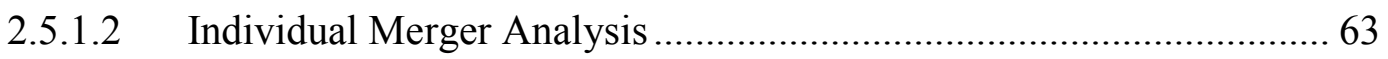

2.5.1.2.1 Stock Market Performance of Merging Companies.......................... 63 
2.5.1.2.2 Stock Market Reaction of Competitors to the Merger

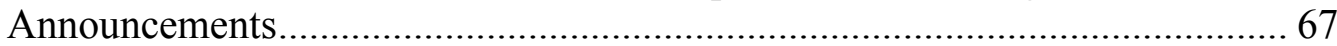

2.5.1.3 Effects of Control Variables ........................................................... 70

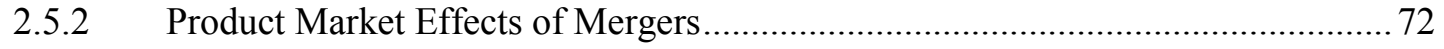

2.5.3 Effects of the Mergers on Bid-Ask Spreads........................................................79

2.5.3.1 Short-Term Analysis of Bid-Ask Spreads .......................................... 81

2.5.3.1.1 Univariate Tests of Means and Medians ......................................... 81

2.5.3.1.2 Bid-Ask Spreads SUR Regression Equations .................................. 83

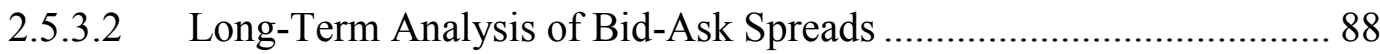

2.5.3.2.1 Long-Term Trends in Bid-Ask Spreads ......................................... 88

2.5.3.2.2 Univariate Tests of Means and Medians ........................................ 90

2.5.3.2.3 Bid-Ask Spreads SUR Regression Equations .................................. 91

2.5.3.3 Influence of Other Factors on Bid-Ask Spreads................................. 93

2.5.4 Robustness Tests ..........................................................................................

2.5.4.1 Volatility as Measure of Market Quality ……………………….......... 95

2.5.4.2 Calendar Time Market Share Analysis................................................ 97

2.5.4.3 Other Robustness Tests ................................................................. 99

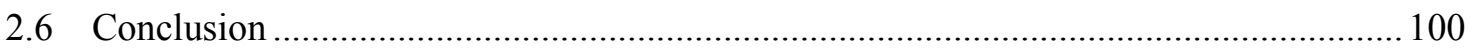

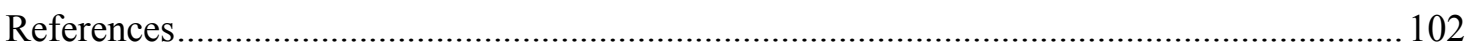

Appendix 1A: General Literature on Mergers and Acquisitions ………………………….... 109

3 Essay Two: Stock Exchange Demutualization and Market Quality......................... 118

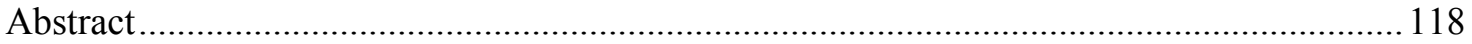

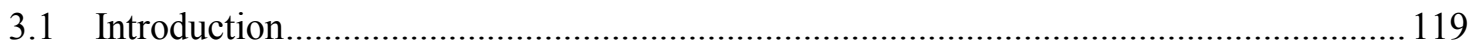

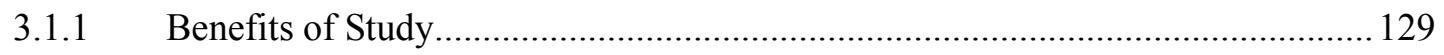

3.1.1.1 Contributions of Study to Academia …………................................ 129

3.1.1.2 Importance of Study to Investors.................................................... 129

3.1.1.3 Policy Implications of Essay ....................................................... 130

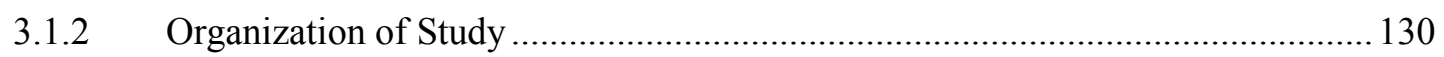

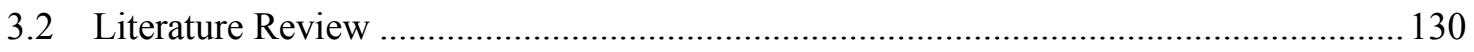

3.2.1 Literature on Stock Exchange Demutualization ………...................................... 131

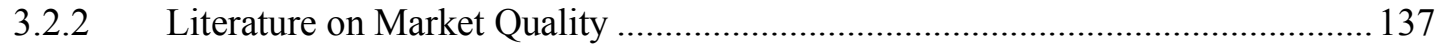

3.2.2.1 The Many Factors Impacting Market Quality ................................... 137

3.2.2.2 Measures of Market Quality .......................................................... 138

3.2.2.2.1 Measures of Liquidity ……………………................................. 139 
3.2.2.2.1.1 Measures of the Cost Dimension of Liquidity .................................. 140

3.2.2.2.1.2 Measures of the Trading Volume Dimension of Liquidity................. 142

3.2.2.2.1.3 Measures of the Market Impact Dimension of Liquidity.................... 142

3.2.2.2.2 Measures of Execution Speed ..................................................... 142

3.2.2.2.3 Measures of Volatility and Price Efficiency .............................. 143

3.2.2.3 Concerns Raised about Demutualization and Market Quality .......... 144

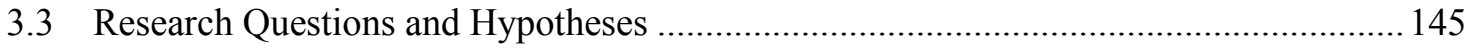

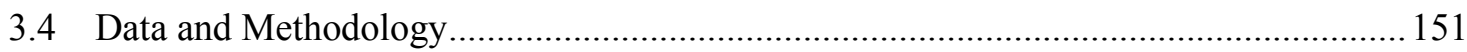

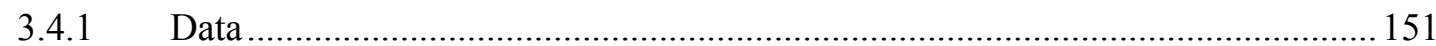

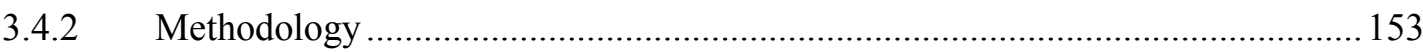

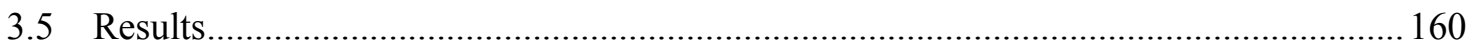

3.5.1 Descriptive Statistics and Correlations .............................................................. 161

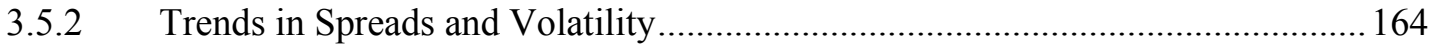

3.5.3 Univariate Analysis of the Impact of Demutualization on Market Quality ......... 171

3.5.4 Multivariate Analysis of Stock Exchange Demutualization ................................ 176

3.5.4.1 Separate Effects of Exchange Demutualization .............................. 176

3.5.4.2 Combined Effects of Exchange and Developed Exchange

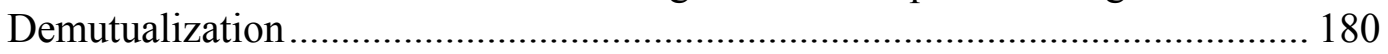

3.5.4.3 Effects of Technology on Market Quality ...................................... 182

3.5.4.4 Effects of Other Variables on Market Quality................................. 184

3.5.5 Short Term Effects of Exchange Demutualization on Market Quality .................. 186

3.5.6 Yearly and Long Term Effects of Exchange Demutualization ............................ 187

3.5.7 Exchange Demutualization and Subsequent IPO.............................................. 190

3.5.8 The Size Effects of Exchange Demutualization.................................................... 193

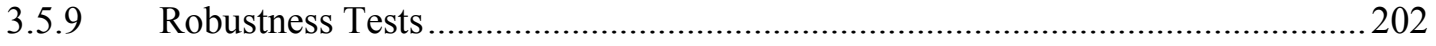

3.5.9.1 Traditional Firm-Level Analysis ................................................. 202

3.5.9.2 High-minus-low as an Alternative Measure of Risk ........................ 204

3.5.9.3 Alternative Specifications.................................................... 205

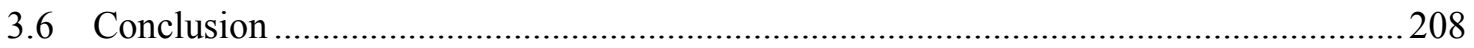

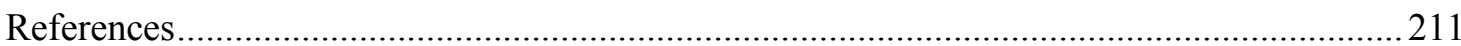

Appendix 2A: List of Demutualized and Mutualized Stock Exchanges.................................219

4 Essay Three: Stock Exchange Mergers and Market Power................................... 221

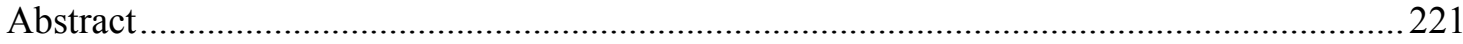

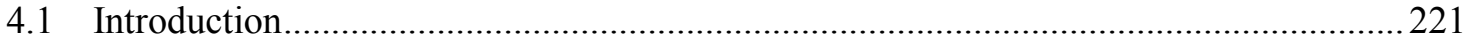




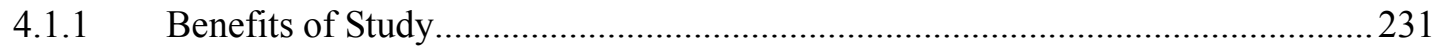

4.1.1.1 Contributions of Study to Academic Community ........................... 231

4.1.1.2 Policy Implications of Study ....................................................... 231

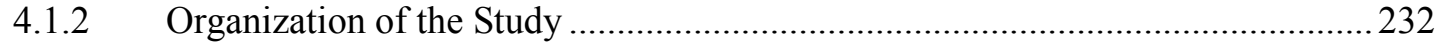

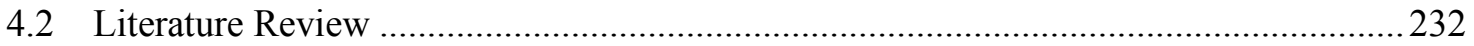

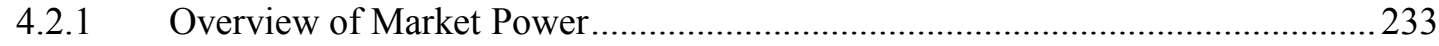

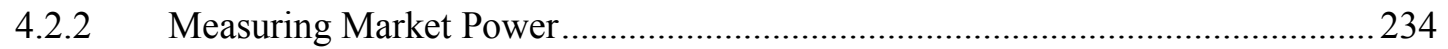

4.2.2.1 Structure-Conduct-Performance (SCP) Tests ................................. 234

4.2.2.1.1 The Herfindahl-Hirschman Index ............................................. 236

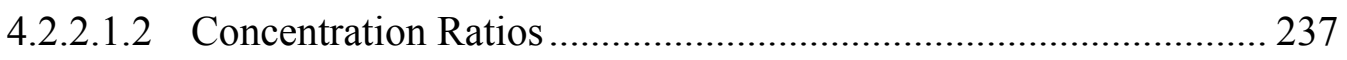

4.2.2.1.3 Dynamic Measures of Market Structure ..................................... 237

4.2.2.1.4 Firm Level SCP Measures of Market Power .............................. 238

4.2.2.1.4.1 Market Share...................................................................................... 238

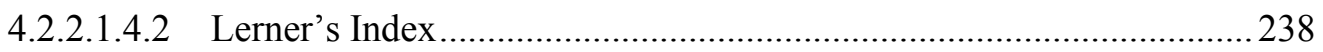

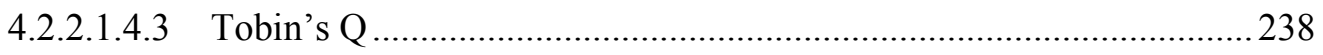

4.2.2.2 New Empirical Industrial Organization (NEIO) Models ................. 239

4.2.2.2.1 Markup Test ............................................................................... 239

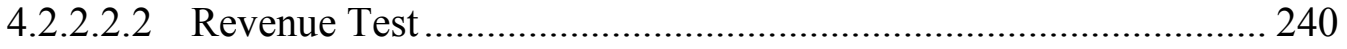

4.2.3 Market Power in the Banking Industry …........................................................ 240

4.2.4 Mergers and Market Power in the Airline Industry ..............................................24

4.2.5 Market Power in Insurance and Thrift Industries ................................................245

4.2.6 Market Power Studies in Other Industries .......................................................... 247

4.2.7 Potential Benefits of Market Power ........................................................................249

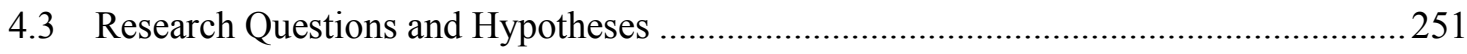

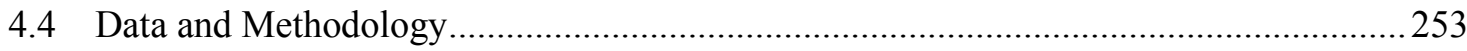

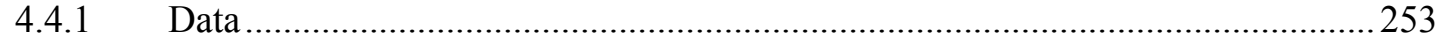

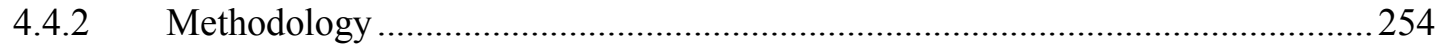

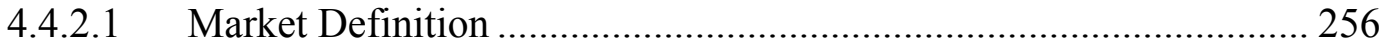

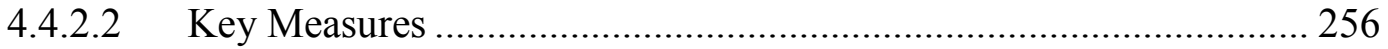

4.4.2.3 Univariate Analysis Approach....................................................... 258

4.4.2.4 Multivariate Analysis Approach................................................... 258

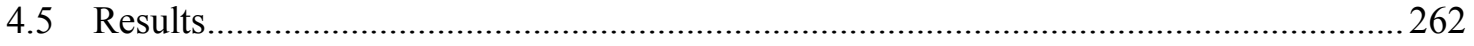

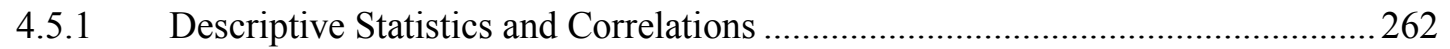

4.5.2 Univariate Analysis of Market Power.................................................................265 
4.5.2.1 Trend Analysis of Concentration and Profit Measures .................... 265

4.5.2.2 Pre- and Post-Merger Market Power Analysis ............................... 267

4.5.3 Multivariate Analysis of Market Power............................................................... 268

4.5.3.1 Market Power Effects in the Absence of Efficiency Measures ......... 268

4.5.3.2 Incorporating Efficiency Measures in Market Power Analysis......... 270

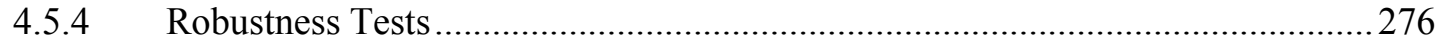

4.5.4.1 Using Yearly (instead of Monthly) Data ....................................... 276

4.5.4.2 Not Skipping a Year Following Merger Completion Dates .............. 278

4.5.4.3 Using ROE as an Alternative Measure of Profitability .................... 280

4.5.4.4 Pretax ROA - An Alternative Definition of ROA .......................... 282

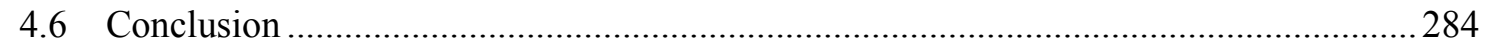

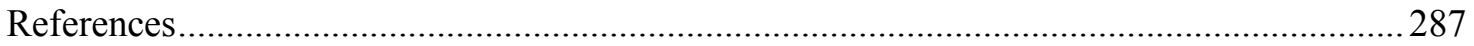

5 Summary, Conclusions and Policy Implications ................................................ 295 


\section{List of Tables}

Table 2.1 - Summary Information about the Sample Mergers........................................ 48

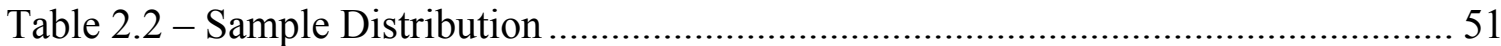

Table 2.3 - Pooled Stock Market Results ......................................................................... 59

Table 2.4 - Stock Market Performance of Merging Companies ...................................... 63

Table 2.5 - Stock Market Performance of Competitors/Rivals ............................................ 68

Table 2.6 - Combined Mergers Regression Results with Control Variables .................... 71

Table 2.7 - Event Time Market Share Results ............................................................... 73

Table 2.8 - Tests of Mean and Median Bid-Ask Spreads for All Mergers ...................... 82

Table 2.9 - Bid-Ask Spreads SUR Regression Equations.................................................. 84

Table 2.10 -Tests of Long-Term Mean and Median Bid-Ask Spreads ............................ 90

Table 2.11 - Long Term Bid-Ask Spreads SUR Regression Equations............................ 91

Table 2.12 - Calendar Time Market Share Results .......................................................... 97

Table 2.13 - Other Robustness Tests........................................................................... 99

Table 3.1 - Descriptive Statistics and Pearson Correlations ............................................ 161

Table 3.2 - Univariate Tests of Means and Medians..................................................... 172

Table 3.3 - Separate Effects of Exchange and Developed Exchange Demutualization. 176

Table 3.4 - Combined Effects of Exchange and Developed Exchange Demutualization

Table 3.5 - Effects of Demutualization on Market Quality over Time ......................... 187

Table 3.6 - Demutualization, IPO and Market Quality ................................................... 191

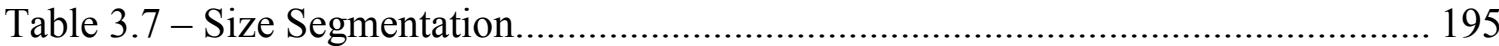

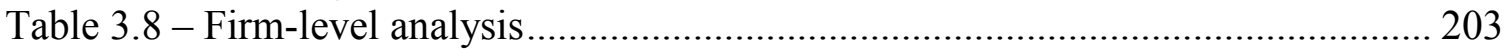

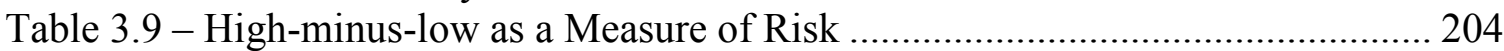

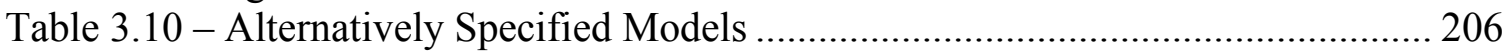

Table 4.1 - Descriptive Statistics and Pearson Correlations ………………………...... 263

Table 4.2 - Univariate Tests of Means and Medians...................................................... 267

Table 4.3 - Market Power Effects without controlling for Efficiency Effects ............... 269

Table 4.4 - Efficiency and Market Power Effects of Exchange Mergers ....................... 270

Table 4.5 - Efficiency and Market Power Effects using Yearly Data............................. 276

Table 4.6 - Efficiency and Market Power Effects without Skipping a Year.................. 278

Table 4.7 - Efficiency and Market Power Effects using ROE ……………………….... 280

Table 4.8 - Efficiency and Market Power Effects using Pretax ROA............................. 282 


\section{List of Figures}

Figure 1.1 - Top 10 Exchanges based on 2005 Average Monthly Value of Share Trading

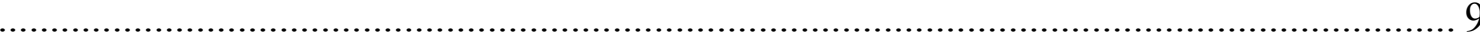

Figure 1.2 - Percent of Foreign Firms listed on Stock Exchanges in Americas .............. 15 Figure 1.3 - Stock Exchange Industry Current Business Environment and Thesis Scope19 Figure 2.1 - Overview of the General M\&A Literature ……………………................ 41

Figure 2.2 - Long-Term Trends in Bid-Ask Spreads .................................................... 89

Figure 2.3 - Long-Term Trends in Price Volatility ......................................................... 96

Figure 3.1 - Dimensions and Measures of Market Quality ........................................... 139

Figure 3.2 - Quoted Spreads of Firms listed on Demutualized and Mutualized Exchanges

Figure 3.3 - Effective Spreads of Firms listed on Demutualized and Mutualized

Exchanges 167

Figure 3.4 - Standard Deviation of Firms listed on Exchanges .................................... 169

Figure 3.5 - High-minus-low of Firms listed on Demutualized and Mutualized Exchanges

Figure 3.6 - Quoted Spreads of Small- and Large-cap Stocks listed on Demutualized and Mutualized Exchanges

Figure 3.7 - Quoted Spreads of Small- and Large-cap Stocks listed on Developed Demutualized and Mutualized Exchanges

Figure 3.8 - Standard Deviation of Small- and Large-cap Stocks listed on Demutualized and Mutualized Exchanges

Figure 3.9 - Standard Deviation of Small- and Large-cap Stocks listed on Developed

Demutualized and Mutualized Exchanges.... 198

Figure 4.1 - Stock Exchange Industry Concentration and Profit 265 


\section{Introduction and General Overview}

\subsection{Introduction}

By providing a marketplace for buyers and sellers of companies' stocks and also establishing the conduit for the transfer of risk capital from sellers to buyers, stock exchanges play a significant role in the allocation of resources in market economies. Traditionally, these all-important roles were performed by stock exchanges that had been organized as government or member owned mutual/cooperative/not-for-profit organizations. With physical location and geographical nearness being vitally important for stock trading in the past, stock exchanges were imbued with some monopoly power. However, advances in technology have broken down geographical barriers and enabled investors to trade in stocks virtually - effectively dampening the monopoly power stock exchanges had hitherto enjoyed and increasing the level of competition in the stock exchange industry. In addition to the technological advancements, other factors including globalization, liberalization and integration have also contributed to the intensification of competition in the industry.

In the face of the new competitive realities in the industry, stock exchanges are seeing, among other things, the need for managerial latitude in decision making as paramount in order to be able to effectively respond to the competitive threats. Since the mutual form of organization is deemed to be stifling and constraining, a number of stock exchanges have demutualized and others have gone a step further to self-list themselves and become publicly traded companies (Otchere and Abou-Zied, 2008). For instance, from being nonexistent prior to 1993, stock exchange demutualization has become so widespread 
that it grew to about $63 \%$ (among the members of the World Federation of Exchanges) by 2002 and further grew to about 80\% by 2007 (Otchere, 2006, Oldford and Otchere, 2011). Another important way that stock exchanges are responding to the increased competition has been the pervasive use of mergers (especially cross-border mergers) to increase their geographical reach beyond their own national boundaries. In 2007, for example, a number of high profile stock exchange mergers were completed including the merger between the New York Stock Exchange (NYSE) and Euronext.

Since stock exchange demutualization and mergers (especially cross-border mergers) are recent phenomena dating back only about a couple of decades, the literature on stock exchange demutualization and mergers is still developing. But this developing literature is mostly concentrated on a number of areas (in the form of mostly theoretical exposes) including stock exchange governance (e.g. Hart and Moore, 1996; Pirrong, 1999; Aggarwal, 2002); competition (e.g. Di Noia, 1999; 2001; Santos and Scheinkman, 2001; Pagano and Padilla, 2005; Faulconbridge et al., 2007); trading mechanisms (e.g. Jain, 2003; 2005); and, economies of scale (e.g. Malkamäki, 1999). From an empirical perspective, only a few studies have investigated the product market and stock market effects of stock exchange mergers (e.g. Arnold et al., 1999; Nielsson, 2009; Hasan et al., 2012) and the performance effects of stock exchange demutualization and initial public offerings (e.g. Aggarwal, 2002; Krishnamurti et al., 2003; Mendiola and O’Hara, 2003; Otchere, 2006; Otchere and Abou-Zied, 2008; Oldford and Otchere, 2011). Our understanding of important aspects of stock exchange mergers and demutualization is still very limited. In particular, our understanding of the stock market and product market 
benefits of stock exchange mergers, the market power implications of stock exchange mergers and the impact of stock exchange demutualization on market quality is limited because of the small number of studies that have explored these issues. This study fills this gap by exploring, in three independent but related essays, the stock market and product market effects of stock exchange mergers, the market quality implications of stock exchange demutualization and the market power consequences of stock exchange mergers.

Several reasons motivate our study of stock exchange demutualization and mergers. First, a number of competitive forces including technological advancements, liberalization and globalization are reducing entry barriers in the stock exchange industry and stock exchanges are now faced with intense competition. In Canada for example, low entry barriers in recent years have led to the establishment of a number of alternative trading systems (e.g. Bloomberg Tradebook Canada, Chi-X Canada, Liquidnet Canada and Omega) that compete with the TSX (Toronto Stock Exchange) for order flow. To deal with the increased competition, stock exchanges are making significant strategic, tactical and operational changes. The first response that most stock exchanges have adopted to help deal with the increased competition in the industry has been to convert from a member-owned mutual structure to a for-profit demutualized structure. The expectation is that when stock exchanges demutualize, the for-profit objective will drive them to undertake measures that will increase order flow to the exchange. Some examples of actions that demutualized stock exchanges are undertaking to increase order flow include providing incentives and subsidies to market makers to use their trading systems (Lee, 
2002) and investing in technology (Krishnamurti et al., 2003). The increased order flow will increase liquidity and improve the price discovery process - thereby improving market quality by, among other things, decreasing the cost of transacting (e.g. bid-ask spreads), making prices more efficient (e.g. by reducing volatility) and improving the speed of order execution. While Krishnamurti et al. (2003) demonstrate that transaction costs are lower on the demutualized National Stock Exchange than on the mutualized Bombay Stock Exchange and Otchere (2006) shows that bid-ask spreads decrease following the demutualization of the Australian stock exchange, these findings are country specific and may have limited generalizability to other countries. There are important questions on the market quality effects of stock exchange demutualization that still remain unanswered. For instance, will demutualization lead to improvements in market quality for stock exchanges in other countries and regions? In other words, are the preliminary results documented by these country specific studies generalizable to other countries? Given that market quality is a multifaceted concept, are other dimensions of market quality (e.g. execution speed and volatility) improving or is it only the cost dimension of market quality (as measured by bid-ask spreads) that is seeing improvements as a result of stock exchange demutualization? Examining these unanswered questions on the market quality implications of stock exchange demutualization is thus one important factor motivating this study. Answering these unanswered questions will be important to the academic and professional communities. Answers to these questions will extend the academic literature by providing new evidence on the market quality effects of stock exchange demutualization in a multicountry context. Professionals can use answers to these questions in a number of ways. 
Managers of stock exchanges can use the results to inform their decisions on whether or not to demutualize. Investors can use the findings to determine the types of stock exchanges (e.g. mutualized vs. demutualized) that have lower costs of transacting which can be useful in deciding where to trade.

Second, mergers and acquisitions are also becoming a key strategy that stock exchanges are using to help deal with the increased competition. However, although there is over a century of evidence on mergers and acquisitions (Martynova and Renneboog, 2008), it is still imperative to understand stock exchange mergers and acquisitions because stock exchanges are not ordinary firms. Stock exchanges are special firms because they are marketplaces for the transfer of risk capital and as such, they play important roles in national as well as international financial market development. As Di Noia (2001) notes, a stock exchange is not just a firm but is also a marketplace for the trading of financial instruments and is also a broker-dealer gathering and executing trading orders. Due to their special nature, when stock exchanges merge, the effects of such mergers are far more reaching and could impact listed firms and investors ${ }^{2}$ and the operations and efficiency of the whole stock market - unlike other mergers involving ordinary firms. Also, there have been a number of theoretical arguments as well as some predictions and conjectures advanced in the literature about the effects of stock exchange mergers and acquisitions. Among other things, stock exchange mergers are expected to improve the competitive position of the merging exchanges and lead to an increase in order flow and liquidity. The improved liquidity could lead to a decrease in the cost of transacting -

\footnotetext{
${ }^{2}$ For instance, the mergers could improve liquidity and reduce bid-ask spreads - which will be beneficial to listed firms and investors.
} 
which benefits not just the exchange but also investors and listed firms. The consolidation of order flow is also expected to result in network externalities and economies of scale (Pagano, 1989; Malkamäki, 1999) - which could reduce transaction costs. However, if the competitive position of exchanges involved in mergers improves, this could put rivals at a competitive disadvantage. The competitive disadvantages can become more pronounced when the mergers lead to the creation of super exchanges (such as NYSE Euronext) with significant operations in important global markets such as North America and Europe. Because of the potential global reach of such super exchanges, when transaction costs on these super exchanges are reduced, the effects may extend beyond rivals in one country or even one region. Rivals across the globe may suffer significantly when investors begin to migrate their order flow to these super exchanges in order to enjoy lower transaction costs. Important questions that therefore merit exploration include the impact of such mergers on order flow to rivals, how rivals are reacting and responding and whether or not some competitors are responding better than others. Thus, unlike the competitive effects of ordinary mergers that are focused on just the firms involved, looking at the effects of stock exchange mergers on rivals will provide better insights into the far reaching impacts of these mergers on not just the exchanges but also on investors - in terms of how investor order flow is affected. For these reasons, it is important to examine the effects of stock exchange mergers on not just the merging entities but also the effects of the mergers on rival exchanges. And although Arnold et al. (1999), Nielsson (2009) and Hasan et al. (2012) have examined some aspects of stock exchange mergers, a number of important issues that still remain unaddressed can benefit from further research. Some unanswered questions that merit researching into include 
determining in a multi-country and multi-merger context, (i) the markets' perceptions of the value of the mergers, and hence the stock price reactions of not only the merging firms but also rivals; (ii) the extent to which the mergers have led to an increase in order flow for the merging entities and whether or not any increased order flow is drawn from rivals; and, (iii) the impacts of the mergers on the cost of transacting on the merging stock exchanges and rival stock exchanges - which is very important to investors since decreases (increases) in transaction costs means they are paying less (more) to transact on the exchanges. This thesis aims to address these unanswered questions.

Third, synergy is an often cited reason for mergers and acquisitions. However, there are several sources from which synergy can come - including synergy from efficiency gains and synergy from the exercise of market power. While some have argued that stock exchange mergers will lead to efficiency improvements, others have conjectured that the mergers and acquisitions happening in the industry would lead to increased concentration that could dampen competition and lead to the exercise of market power - which may be detrimental to investor welfare. Our objective is to provide empirical evidence on these important questions.

Finally, stock exchanges contribute significantly to the development of nations, and this realization has led a number of countries to establish stock exchanges as national monopolies. Given the important role that stock exchanges play in global development, we are also motivated to research and understand the ramifications of the current changes in the industry - which could help shape the industry's future development and direction. 
Guided by the above motivations, we structured this thesis into three separate but interrelated essays. Essay one examines six recent financial exchange mergers to ascertain the stock market and product market implications of these mergers. Since stock exchange mergers are relatively new, our choice of the six stock exchange mergers is based on the need to examine, in detail, mergers that have had transformational effects on the industry. To this effect, we require that the merger must involve a player with 2005 (i.e. year before the start of our sample period) average monthly value of share trading of at least US\$100 billion. It is our view that exchanges with average monthly value of share trading below US\$100 billion are not big enough to likely have effects on competitors in the industry. Figure 1.1 shows the top 10 stock exchanges based on average monthly value of share trading in 2005 .

We also impose the additional condition that the merger be consummated between 2006 and 2008. The decision to analyze only mergers consummated between 2006 and 2008 is to allow us to perform long term market share analysis (i.e. 3 years before and 4 years after each merger) using data from the World Federation of Exchanges (WFE) website (http://www.world-exchanges.org/statistics/monthly-reports). And since the WFE changed the way it calculates some variables in 2002, the earliest date that we can get comparable data for the variables of interest is 2003. 
Figure 1.1 - Top 10 Exchanges based on 2005 Average Monthly Value of Share Trading

This figure shows the top 10 stock exchanges based on the average monthly value of share trading (in USD) in 2005. The data is the average of monthly 2005 value of shared trading downloaded from the WFE. Since we are selecting mergers between 2006 and 2008 , we rank the stock exchanges based on their average monthly value of share trading the year before the start of the sample period.

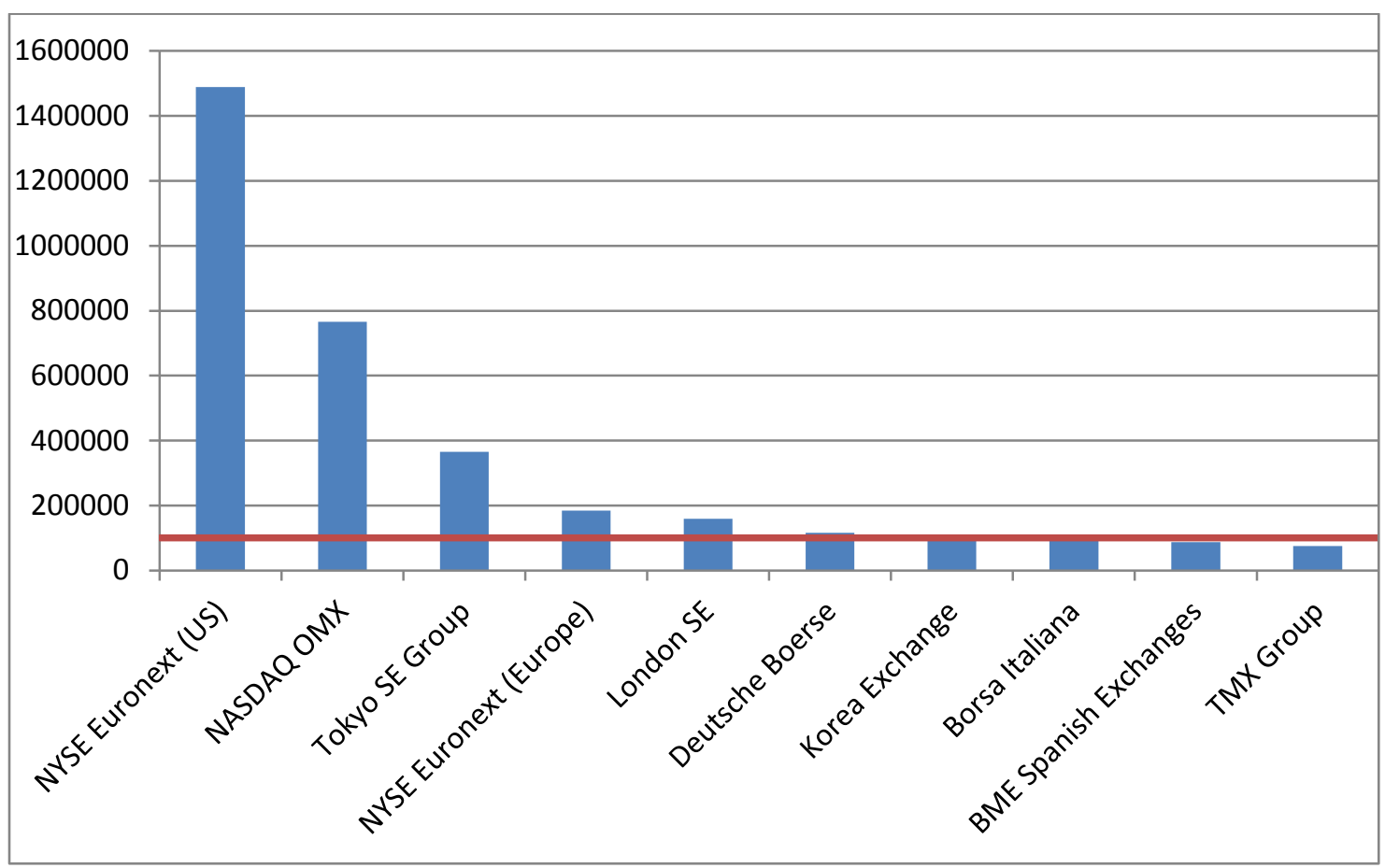

Applying the above criteria resulted in our sample of six stock exchange mergers. The six mergers are the NYSE-Euronext merger, the NASDAQ-OMX merger, the London Stock Exchange (LSE)-Borsa Italiana (BI) merger, the Deutsche Boerse-International Securities Exchange Holdings, Inc. (ISE) merger, the NYSE-Archipelago merger and the Chicago Mercantile Exchange's (CME) merger with the Chicago Board of Trade (CBOT).

Essay one explored the wealth implications of these stock exchange mergers by examining the short-run abnormal returns (around the merger announcements) to shareholders of the merging and non-merging stock exchanges. We find that shareholders of targets and shareholders of the combined exchanges realize significant abnormal 
returns. Additionally, we find that shareholders of competitors from countries in the same geographical region and competitors at the same stage of development also realize significant abnormal returns. Essay one also (directly) explored the synergy implications of the mergers by analyzing the long-term product market (i.e. market share) impacts of the mergers on the merging as well as the non-merging exchanges. Our results indicate that the merging exchanges achieved significant increases in market share of about $0.9 \%$ in the post-merger completion period. This increased market share, we find, came at the expense of rivals who lost, on average, a significant $0.1 \%$ in market share in the postmerger completion period. Finally, to determine the implications of these mergers on the cost of transacting in the stock exchange industry (which benefits investors and listed firms), we analyzed the impact of the mergers on bid-ask spreads and find that in both the short term and long term, the merging exchanges experienced reductions in bid-ask spreads while rivals experienced increased bid-ask spreads. These findings support the contention that the stock exchange mergers have resulted in significant wealth creation on the stock market and considerable value creation on the product market for the merging entities.

Market quality is profoundly important to stock exchanges and the expectation is that the recent demutualizations in the stock exchange industry would positively impact market quality since the profit motive will propel demutualized stock exchanges to undertake actions that will increase order flow and liquidity - which will reduce bid-ask spreads and volatility - and improve market quality. Improving market quality directly benefits investors and listed firms since that will reduce the cost of transactions on the stock 
exchange. Essay two investigated the extent to which stock exchange demutualization has led to improvements in market quality. We find that exchanges undertaking demutualization (especially developed stock exchanges) achieve significant improvements in market quality in the five years following the completion of the demutualization. While the demutualized stock exchanges achieved significant reductions in transaction costs and volatility (two important dimensions of market quality), a controlled group of mutualized rival stock exchanges which have not undertaken demutualization experienced increases in spreads and volatility, and have, as a result, seen deterioration in market quality.

Although there are several sources of gains from mergers and acquisitions, efficiency gains and market power gains have dominated the discussion over the years. Bhattacharyya and Nain (2011) for instance acknowledge the long-standing dichotomous debate on the motives of mergers (especially horizontal mergers) in the finance and economics literatures, observing that while firms undertaking horizontal mergers ordinarily cite expected improvements in productive efficiencies as the key rationale for merging, antitrust authorities normally express concerns over the potentiality of increase in market power as a result of mergers. And while efficiency gains are favorably perceived, gains resulting from market power are frowned upon because of their potentially detrimental effects on consumer welfare (generally in the form of higher prices and/or restricted output). Essay three assessed the market power implications of the six stock exchange mergers we studied in essay one. We find that stock exchange mergers have not led to the exercise of market power. In addition to finding that industry 
concentration levels have not significantly increased (and do not influence exchanges' profitability) in the post-merger period, we also find that the profit rate of the merging exchanges in the post-merger period is largely influenced by efficiencies in revenue generation and cost management. We also find that non-merging rival exchanges suffer efficiency losses in the post-merger period. One important implication of our findings is that there is no immediate need for regulatory agencies to be concerned about stock exchange mergers leading to the exploitation of market power to the detriment of consumer welfare.

The remainder of this thesis is organized as follows. We present a general overview of the trends in the stock exchange industry in the next section. Following that, the next three sections are dedicated to the three essays. For each essay, we first present an introduction and review the relevant literature. We next discuss the research questions/hypotheses and then provide a synopsis of the data and methodology. The results are presented next and the final section of each essay is the conclusion of the essay. The overall summary and conclusions section finalizes the thesis.

\subsection{Overview and Trends in the Stock Exchange Industry}

Several definitions of stock exchanges have been provided in the extant literature. Arnold et al. (1999) maintain that stock exchanges are firms that compete on a number of related dimensions including liquidity provision and price discovery. Pirrong (1999) notes that a stock exchange provides a trading infrastructure, enforces trading rules and adjudicates 
disputes between traders. Michie (2001) defines a stock exchange as a market where specialized intermediaries buy and sell securities under a common set of rules and regulations through a closed system dedicated to that purpose. Di Noia (2001) offers three views of a stock exchange, viz.:

- the stock exchange as a market (i.e. a stock exchange is an organized market for the trading of securities);

- the stock exchange as a firm (i.e. a view concentrating on the production side, and perceiving a stock exchange as a firm that creates a market in financial instruments); and,

- the stock exchange as a broker-dealer (i.e. an exchange is an intermediary among intermediaries; the exchange gathers trading orders and supplies the way of executing them).

The various definitions demonstrate the important roles played by stock exchanges. Indeed, stock exchanges have been closely linked to the development of national and even international financial centers (Faulconbridge et al. 2007), and have traditionally been organized as government or member owned mutual/cooperative/not-for-profit organizations. Stock exchanges have, in the past, enjoyed some monopoly power. Otchere (2006) for example asserts that until recently, most stock exchanges have "enjoyed national monopoly status caused partly by indirect barriers that prevented local investors from investing in equities outside the national exchange" (pp. 926). Di Noia (1999) also contends that stock exchanges were firms with a great degree of monopoly power in dealing with their customers while Malkamäki (1999) asserts that a stock 
market is an example of a type of firm that has been a local monopoly in most countries. Clearly, with the earlier mutual form of organization and the monopoly power that stock exchanges enjoyed, the stock exchange industry, until recently, was described as a stable business environment with little or no competition. Lately, however, the business environment of stock exchanges has become increasingly competitive. A confluence of factors has coalesced to negate the local monopoly power of exchanges, and consequently, stock exchanges are now moving "to a new era marked by competition" (Kokkoris and Olivares-Caminal, 2008, pp. 838). The competition in the stock exchange industry is coming from multiple fronts - including competition among the exchanges themselves (i.e. competition from within) and competition between exchanges and electronic communications networks (ECNs).

With respect to competition among the stock exchanges themselves (i.e. competition from within), cross-listing of securities on different stock exchanges has increased the level of competition among the stock exchanges. Also, with deregulation of financial markets and advances in technology, trading on stock exchanges remotely has meant that investors are not limited to trading in stocks on stock exchanges that are geographically proximate. These factors have contributed to the increased competition among the exchanges. Figure 1.2 - which graphs the percentage of foreign firms listed on stock exchanges in the Americas region of the WFE members - highlights the increasing competition among stock exchanges. 
Figure 1.2 - Percent of Foreign Firms listed on Stock Exchanges in Americas

The percentage of foreign firms listed on stock exchanges in the Americas region from 2003 to 2012 is presented in Figure 1.2. The number of firms (domestic and foreign) data was downloaded from the WFE website and the percentages calculated from that data.

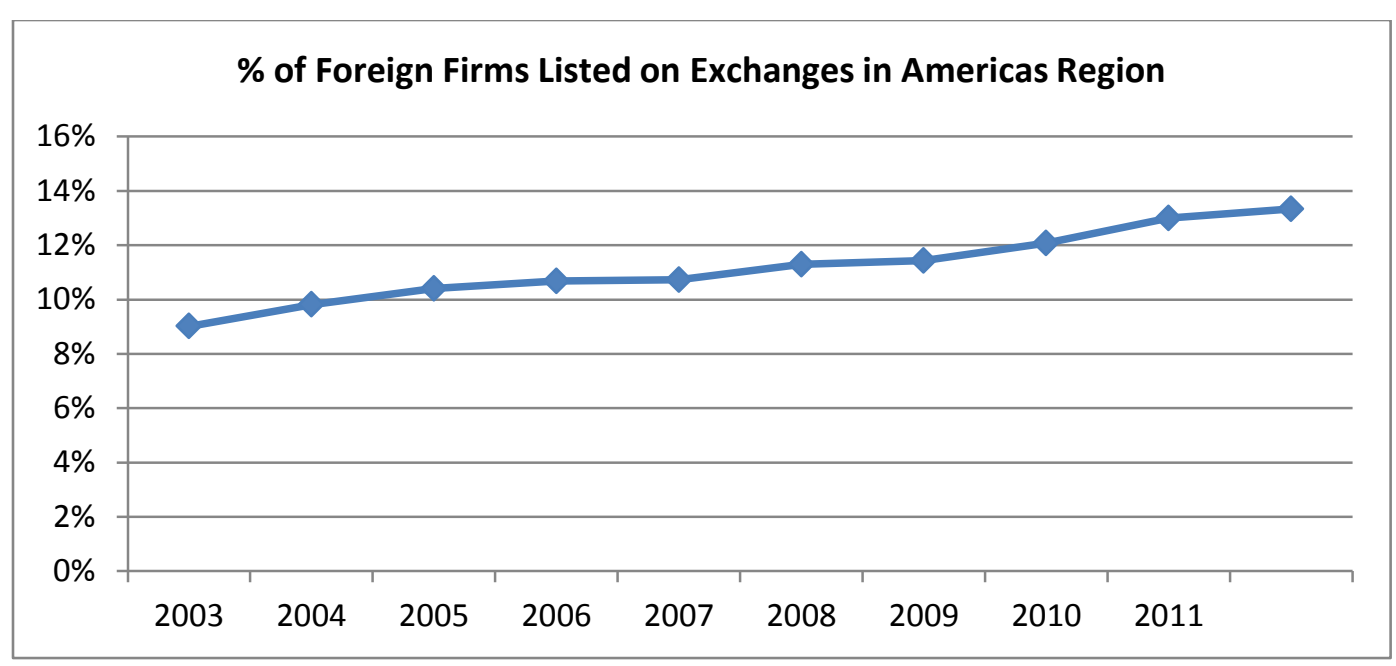

While in 2003 only about $9 \%$ of foreign firms were listed on stock exchanges in the Americas region, the proportion has grown steadily and by 2012 , about $13.3 \%$ of the firms listed on these stock exchanges are foreign. Our choice of the Americas region to illustrate the increasing competition in the industry is based on the fact that the stock exchanges in this region are fairly representative of the universe of stock exchanges. Indeed, the region has some of the most advanced stock exchanges (e.g. NYSE Euronext) as well as emerging stock exchanges (e.g. Bermuda Stock Exchange). In addition to the competition from within, there is competition between stock exchanges and ECNs - in part due to advancements in technology and liberalization. In the US (e.g. Instinet/Inet, Archipelago, Bloomberg Tradebook), Canada (e.g. Bloomberg Tradebook Canada, Chi-X Canada, Omega), Europe (e.g. BATS Chi-X Europe) and around the world (e.g. Chi-X Australia, Chi-X Japan), ECNs are competing with traditional stock exchanges for order flow. Euromoney (2011) noted that in just three years, Chi-X Europe overtook Deutsche Boerse and NYSE Euronext in market share of European equity trading, and that its 
volumes grew by $80 \%$ to more than $\$ 1.5$ trillion in 2010 . In fact, Lee (2002) refers to ECNs as MONSTERs or market-oriented new systems for terrifying exchanges and regulators largely because of their role in intensifying the level of competition in the stock exchange industry. By allowing investors to trade directly in stocks, ECNs weakened the traditional stock exchange model that had hitherto been based on issuers having to issue stocks through intermediaries and investors having to buy stocks through intermediaries. Pagano et al. (2002) and Foucault and Parlour (2004) have, among others, alluded to the unprecedented levels of competition in the stock exchange industry.

Several authors have offered various reasons for this state of affairs. Di Noia (1999) cites the integration of markets and evolution of technology as some of the factors impinging on the monopoly position that exchanges previously enjoyed. Chemmanur and Fulghieri (2006) highlight the global integration of capital markets which has led to an increase in the number of listing venues available to firms and a growing number of firms taking advantage of the increase in listing venues to list their equity outside their country of origin - as resulting in unprecedented competition for listings among exchanges. Faulconbridge et al. (2007) talk about the virtualization of stock exchanges resulting from advances in technology that has provided the capability to trade from a location physically remote from the site of an exchange - as driving forces behind the increased competition. Otchere and Abou-Zied (2008) argue that the increasing internationalization of financial markets and advances in technology have reduced access barriers and have set national stock exchanges in direct competition with each other and with electronic communications networks (ECNs). Jain $(2003 ; 2005)$ also discussed the increased 
competition from automated trading through ECNs by noting their popularity and the considerable market share of trading volumes they are capturing from traditional floorbased stock exchanges. The author submits that over $80 \%$ of the world's exchanges (101 of 120 sample countries) have introduced some form of electronic-screen-based trading mechanism with automatic execution and that many of these exchanges ( 85 of the 101) have abolished the floor trading mechanism. Ramos and von Thadden (2008) talk about the two-sided competition that exchanges are subject to - competition for the listing of firms and competition for investors - as contributory factors. The authors note that with the advent of cross-listings of European firms on the NYSE and NASDAQ, competition among stock exchanges "went global in the 1990s" (Ramos and von Thadden, 2008, pp. 285).

With the current competitive environment, stock exchanges need to respond effectively (and quickly) to the competitive threats to ensure continued success. Hart and Moore (1996) contend that the success of exchanges in responding to change is likely to depend in large measure on their organizational structure. Stock exchanges around the world are therefore beginning to see their mutual form of organization as becoming inadequate in the current highly competitive business environment. Otchere (2006) offers a theoretically well-grounded explanation of the current turbulence in the stock exchange industry and the inability of the mutual form of organization to deal with this competition. Citing the economic disturbance theory, the author argues that recent shocks to the industry - including globalization, technological developments, regulatory changes and increased competition - have exposed the shortfalls of the mutual form of 
organization. Otchere (2006) leans on agency theory to argue that organizational structures that inhibit efficiencies and restrict private benefits (e.g. the mutual form of organization) leave exchanges with no option but to reorganize.

The recognition that the old member-owned structure fails to provide the flexibility and the financing needed to compete in today's competitive environment (Aggarwal, 2002) is, not surprisingly, motivating some stock exchanges to start abandoning their traditional mutual structures. Figure 1.3 summarizes some of the current changes occurring in the industry and the strategies that stock exchanges are adopting to cope in the current business environment. 
Figure 1.3 - Stock Exchange Industry Current Business Environment and Thesis Scope

This figure summarizes the current competitive forces affecting the stock exchange industry and the (largely governance related) responses stock exchanges are adopting to withstand the increased competition. This thesis examines two of the governance responses (i.e. demutualization and mergers) but uses firms in the other groups of the governance continuum as control samples.

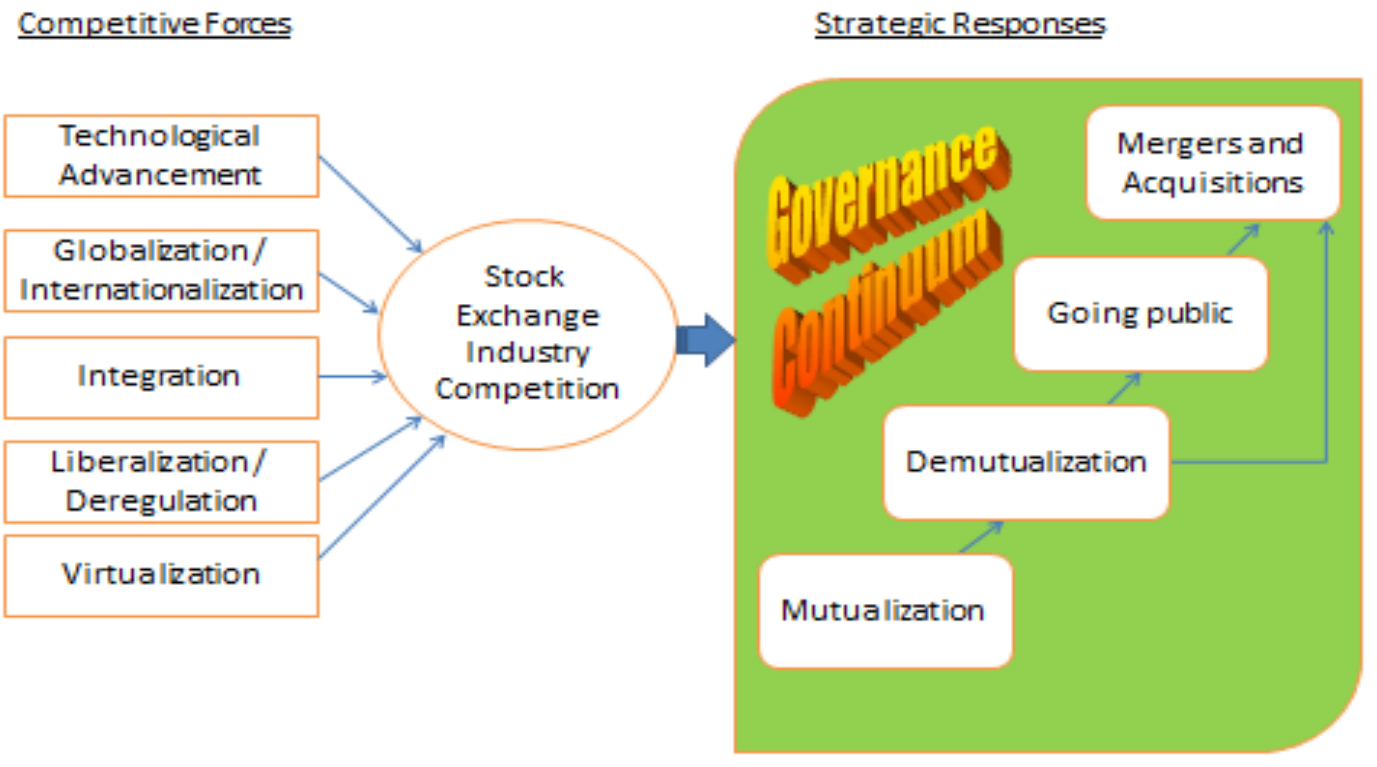

As illustrated in Figure 1.3, a compendium of competitive forces including technological advancements and internationalization has increased the level of competition in the industry and stock exchanges are responding to the increased competition by moving along the governance continuum because of the perception that the mutual form of organization is restrictive. Some responses to the stifling mutual structure have included demutualization, self-listing (IPO) and mergers and acquisitions. Some authors (e.g. Aggarwal, 2002; Oldford and Otchere, 2011) see these responses as a progression (continuum) involving demutualization, then self-listing/going public and then mergers and acquisitions. The thought is that once an exchange demutualizes, the next logical progression is to self-list/go public to raise more capital for operations. And once an 
exchange is publicly-listed, it is easy to become a candidate for mergers/acquisitions in the market for corporate control. ${ }^{3}$ Another cluster of responses to the new competitive challenges coalesce around strategic alliances, what Schmiedel (2001) calls 'coompetition' (i.e. the trend towards increasing cooperation and competition among exchanges). However, several authors (e.g. Lee, 2002) have questioned the effectiveness of alliances in dealing with the constantly increasing competition, including competition from low cost alternative trading platforms such as ECNs. One main reason why alliances are argued to be ineffective in the face of the increasing competition is the difficulty of creating credible contractual commitments between cooperating partners - since the constantly changing environment may negatively impact the benefits alliance parties are expecting over time - and hence their commitments to such alliances may weaken over time (Lee, 2002).

From the above overview, it is evident that the level of competition has heightened in the industry (with competition emanating from ECNs and other financial exchanges) and the arguments advanced so far highlight the need for stock exchanges to act or possibly face organizational stagnation or even entropy.

\footnotetext{
${ }^{3}$ This logical progression is not the norm in every situation, however. For instance, the New York Stock Exchange circumvented the self-listing step when it became a publicly traded company through the backdoor by merging with Archipelago (i.e. reverse takeover/merger).
} 


\section{References}

Aggarwal, R. (2002). Demutualization and Corporate Governance of Stock Exchanges, Journal of Applied Corporate Finance, 15(1), pp. 105-113.

Arnold, T., Hersch, P., Mulherin, J.H. and Netter, J. (1999). Merging Markets, Journal of Finance, 54(3), pp. 1083-1107.

Bhattacharyya, S. and Nain, A. (2011). Horizontal Acquisitions and Buying Power: A Product Market Analysis, Journal of Financial Economics, 99, pp. 97-115.

Chemmanur, T. J. and Fulghieri, P. (2006). Competition and Cooperation among Exchanges: A Theory of Cross-Listings and Endogenous Listing Standards, Journal of Financial Economics, 82, pp. 455-489.

Di Noia, C. (1999). The Stock-Exchange Industry: Network Effects, Implicit Mergers and Corporate Governance, Quaderni de Finanza, No. 33, pp. 1-78.

Di Noia, C. (2001). Competition and Integration among Stock Exchanges in Europe: Network Effects, Implicit Mergers and Remote Access, European Financial Management, 7(1), pp. 39-72.

Euromoney (2011). Inside investment: Regulation drives stock exchange mergers, http://www.euromoney.com/Article/2862964/Inside-investment-Regulation-drives-stockexchange-mergers.html (Last accessed 2014/06/27).

Faulconbridge, J., Engelen, W., Hoyler, M. and Beaverstock, J. (2007). Analysing the Changing Landscape of European Financial Centres: The Role of Financial Products and the Case of Amsterdam, Growth and Change, 38(2), pp. 279-303.

Foucault, T. and Parlour, C. (2004). Competition for Listings, RAND Journal of Economics 35, pp. 329-355.

Hart, O. and Moore, J. (1996). The Governance of Exchanges: Members' Cooperative versus Outside Ownership, Oxford Review of Economic Policy, 12(4), pp. 53-69.

Hasan, I., Malkamäki, M. and Schmiedel, H. (2003). Technology, Automation, and Productivity of Stock Exchanges: International Evidence, Journal of Banking and Finance, 27, pp. 1743-1773.

Hasan, I., Schmiedel, H. and Song, L. (2012). Growth Strategies and Value Creation: What Works Best for Stock Exchanges? Financial Review, 47, pp. 469-499.

Jain, P. (2003). Institutional Design and Liquidity on Stock Exchanges, Working paper.

Jain, P.K. (2005). Financial Market Design and the Equity Premium: Electronic versus Floor Trading, Journal of Finance, 60(6), pp. 2955-2985. 
Kokkoris, I. and Olivares-Caminal, R. (2008) "Lessons from the Recent Stock Exchange Merger Activity, Journal of Competition Law and Economics, 4(3), pp. 837-869.

Krishnamurti, C., Sequeira, J.M. and Fangjian, F. (2003). Stock Exchange Governance and Market Quality, Journal of Banking and Finance, 27, pp. 1859-1878.

Lee, R. (2002). The Future of Securities Exchanges, Brookings-Wharton Papers on Financial Services, pp. 1-33.

Malkamäki, M. (1999). Are there Economies of Scale in Stock Exchange Activities? Bank of Finland Discussion Paper, No. 4, pp. 1-28.

Martynova, M. and Renneboog, L. (2008). A Century of Corporate Takeovers: What Have We Learned and Where Do We Stand? Journal of Banking and Finance, 32, pp. 2148-2177.

Mendiola, A. and O'Hara, M. (2003). Taking Stock in Stock Markets: The Changing Governance of Exchanges, Working Paper, Cornell University.

Michie, R. (2001). The London Stock Exchange: A History, Oxford University Press, Oxford, UK.

Nielsson, U. (2009). Stock Exchange Merger and Liquidity: The Case of Euronext, Journal of Financial Markets, 12, pp. 229-267.

Oldford, E and Otchere, I. (2011). Can Commercialization Improve the Performance of Stock Exchanges Even without Corporatization? The Financial Review, 46, pp. 67-87.

Otchere, I. (2006). Stock Exchange Self-Listing and Value Effects, Journal of Corporate Finance, 12, pp. 926-953.

Otchere, I. and Abou-Zied, K. (2008). Stock Exchange Demutualization, Self-listing and Performance: The Case of the Australian Stock Exchange, Journal of Banking and Finance, 32, pp. 512-525.

Pagano, M. (1989). Trading Volume and Asset Liquidity, Quarterly Journal of Economics, 104, pp. 255-274.

Pagano, M. and Padilla, A.J. (2005). Efficiency Gains from the Integration of Stock Exchanges: Lessons from the Euronext 'Natural Experiment', A report for Euronext, Non-confidential version.

Pagano, M., Röell, A.A. and Zechner, J. (2002). The Geography of Equity Listing: Why Do Companies List Abroad? Journal of Finance, 57(6), pp. 2651-2694. 
Pirrong, C. (1999). The Organization of Financial Exchange Markets: Theory and Evidence, Journal of Financial Markets 2, pp. 329-357.

Ramos, S.B. and von Thadden, E-L. (2008). Stock Exchange Competition in a Simple Model of Capital Market Equilibrium, Journal of Financial Markets, 11, pp. 284-307.

Santos, T. and Scheinkman, J.A. (2001). Competition among Exchanges, Quarterly Journal of Economics, pp. 1027-1061.

Schmiedel, H. (2001) Technological Development and Concentration of Stock Exchanges in Europe, Bank of Finland Discussion Paper, No. 21, pp. 1-37. 


\title{
2 Essay One: Stock and Product Markets Effects of Stock Exchange Mergers
}

\begin{abstract}
The increased competition in the stock exchange industry, exacerbated by globalization and technological advancements, has motivated a number of stock exchanges to engage in mergers and acquisitions as one key strategic choice for stemming the competitive tide. In this paper, we examine the stock market and product market effects of six stock exchange mergers and find that shareholders of targets and shareholders of the combined exchanges realize significant abnormal returns. Additionally, we find that shareholders of competitors from countries in the same geographical region and competitors at the same stage of development also realize significant abnormal returns. We also find that on the product market, the merging exchanges increase their market share and experience reductions in bid-ask spreads while competitors/rivals experience decreased market share and increased bid-ask spreads. These findings support the contention that the stock exchange mergers have resulted in significant wealth creation on the stock market and significant value creation on the product market for the merging entities.
\end{abstract}

\subsection{Introduction}

Having operated in a relatively stable business environment (in the past) in which many of them enjoyed monopoly power, stock exchanges are now faced with increased competition (both from within and without). The increasing competition continues to be 
accelerated by a number of forces including technological advancements, internationalization, virtualization, integration and liberalization.

An important way that some stock exchanges are responding to the increased competition has been the pervasive use of mergers (especially cross-border mergers) to increase their presence and reach beyond their own national boundaries. The popularity of exchange mergers is predicated on the expectation that these mergers will create economies of scale and reduce cost, which in turn will increase order flow and benefit all stakeholders including shareholders, listed firms, investors and traders. Two examples highlighting the merger trends in the stock exchange industry include the New York Stock Exchange (NYSE) and Euronext merger in 2007 and the NASDAQ and OMX Group merger in 2008.

By helping allocate resources in market economies through the transfer of risk capital from sellers to buyers, stock exchanges play important roles in national as well as international financial market development. Indeed, stock exchanges are special firms ${ }^{4}$ because as marketplaces for the transfer of risk capital, their actions have broader effects and impact not just the exchanges but listed firms, traders, the investment community and the stock market as a whole. Therefore, when stock exchanges merge, the mergers are important not only to the exchanges but to national economies. And while there is over a century of evidence on mergers and acquisitions (Martynova and Renneboog, 2008), the literature on stock exchange mergers is scant, in part, because it is a relatively new

\footnotetext{
${ }^{4}$ Pirrong (1999) for instance notes that the exchange provides a trading infrastructure, enforces trading rules and adjudicates disputes between traders.
} 
phenomenon and has not as yet been widely studied like mergers and acquisitions in general or in other industries (e.g. Kim and Singal, 1993 and Singal, 1996, etc. in the airlines industry). ${ }^{5}$

Given the importance of stock exchange mergers on the one hand and the relatively few studies on stock exchange mergers ${ }^{6}$ on the other, we set out to study six of the recent financial exchange mergers, namely, the NYSE-Euronext merger, the NASDAQ-OMX merger, the London Stock Exchange (LSE) and Borsa Italiana (BI) merger, the Deutsche Boerse-International Securities Exchange Holdings, Inc. (ISE) merger, the NYSEArchipelago merger and the Chicago Mercantile Exchange's (CME) merger with Chicago Board of Trade (CBOT). We selected these mergers because we are motivated to examine mergers that have had transformational effects on the industry. In our view, transformational mergers are mergers involving a player with 2005 (i.e. year before the start of our sample period) average monthly value of share trading of at least US\$100 billion. We believe that exchanges with average monthly value of share trading below US\$100 billion are not big enough to likely have effects on competitors in the industry. Since our examination of the mergers is intended to be a detailed examination (including examination of the long term effects of the mergers over three years before and four years

\footnotetext{
${ }^{5}$ It should be noted, however, that despite the limited number of studies on stock exchange mergers, there is a proliferating literature on the stock exchange industry addressing a number of key aspects of the industry including stock exchange governance, organization and structure such as mutualized, demutualized and self-listed (e.g. Hart and Moore, 1996; Pirrong, 1999; Aggarwal, 2002; Otchere 2006; Otchere and Abou-Zied, 2008; Oldford and Otchere, 2011); regulation, competition and integration among exchanges (e.g. Di Noia, 1999; 2001; Santos and Scheinkman, 2001; Pagano and Padilla, 2005;

Faulconbridge e al., 2007); trading mechanisms and design (e.g. Jain, 2003; 2005); and, economies of scale in the stock exchange industry (e.g. Malkamäki, 1999).

${ }^{6}$ To the best of our knowledge, only three key empirical studies have been conducted on stock exchange mergers; one study by Arnold et al. (1999) examined the impact of mergers of regional stock exchanges in the US and another study, authored by Nielsson (2009) looked at the Euronext stock exchange merger. Hasan el al. (2012) conducted the third study looking at mergers and acquisitions as well as alliances (joint ventures and non-equity alliances) in the stock exchange industry.
} 
after the completion of the mergers), we decided to examine transformational mergers completed between 2006 and 2008 - in large part because the data to be collected from the WFE (world federation of exchanges) website for the long term analysis is comparable starting from 2003. After these considerations were accounted for, the six stock exchange mergers met the criteria for inclusion in our analysis. Our motivation for examining stock and product market effects of stock exchange mergers is multipronged.

First, finance theory identifies shareholder wealth maximization as the overriding goal of the firm. The expectation is therefore that the stock exchange mergers will improve the competitive position of the merging exchanges through the realization of financial, operational and managerial synergies and will, as a result, lead to the maximization of shareholder value. However, while synergies are easy to promise, they can be difficult to deliver, especially as diseconomies of large scale can easily set in due to managerial limitations, "unexpected corporate culture clashes and difficulties in melding two managerial and production systems" (White, 1987, pp. 18). Given the intense competition in the stock exchange industry, any improvement in the competitive position of players involved in mergers may put rivals at a competitive disadvantage since the merging firms may be better placed to draw some business from the rivals - which will hurt the rivals. If the mergers, however, increase the market power of the merging firms whereby they are able to charge higher prices for services that they provide, then rivals may also benefit from the mergers. Clearly, while stock exchange mergers could be beneficial to the merging entities (and/or competitors), they could also hurt the merging exchanges (and/or rivals). Determining who benefits from these mergers (i.e. shareholders of acquirers, 
targets, rivals/competitors, etc.) is therefore a key empirical question that merits addressing. To explore this question, we employ the seemingly unrelated regression (SUR) technique to look at the short-run abnormal returns (around the merger announcements) to shareholders of the merging and non-merging stock exchanges. Our results show that the six stock exchange mergers have resulted in significant wealth creation for shareholders of targets and shareholders of the combined firms. Targets and the combined firms realized significantly positive abnormal returns (ranging from $0.6 \%$ to $3.0 \%$ ) over several event windows. These findings are consistent with the general mergers and acquisitions literature. With respect to competitors, though we document excess returns of $1.5 \%$ and $0.8 \%$ over days $[0,2]$ and day $[-1,1]$ respectively, the reaction of the competitors is, however, varied. In particular, shareholders of competitors from Europe and North America as well as shareholders of competitors from developed countries realized significantly positive abnormal returns over the day $[0,+2]$ window. In addition, the shareholders of European rivals earned significantly positive abnormal returns on day zero while the shareholders of North American competitors and competitors from developed countries realized significantly positive abnormal returns over the 5-day window from day -2 to day +2 . These results suggest that despite the arguments about the "death of distance", geographical nearness is still a key consideration in the stock exchange industry. We also find that abnormal returns are concentrated around day zero and as the event window widens (e.g. day $[-5,+5]$ and day $[10,+10])$, the abnormal returns become insignificant. This provides support for market efficiency and absence of information leakage - as the markets impounded the information about the mergers quickly into stock prices. 
In view of the fact that one of the important reasons advanced for stock exchange mergers is to deliver significant shareholder value through synergies, our second motivation is to determine the synergy implications of stock exchange mergers. Exchange mergers and consolidations are argued to lead to network externalities (Pagano, 1989) because the combined exchange's larger pool of traders and listed firms (resulting from the consolidation of traders of the separate exchanges) is expected to attract other traders and listed firms - mainly because in addition to the fact that the economies of scale will lead to reductions in trading and listing fees, the larger pool of traders increase the chances of finding other parties for successful trade executions. Also, as a result of the combination of resources and managerial capabilities of the separate exchanges, the combined exchange may have the financial, technological and managerial heft to compete and attract more traders and listed companies. But if the merging firms are able to gain more order flow, to what extent does this affect order flow to rival stock exchanges? It is therefore important, when stock exchanges merge, to establish the empirical effects of such mergers - on not just the merging exchanges but also on rivals. To help throw more light on the synergy implications of stock exchange mergers, we studied the market share of the merging as well as non-merging firms over the long term to determine if there are statistically significant changes to market share following the mergers. Our results demonstrate that the merging exchanges achieved significant increases in market share of about $0.9 \%$ in the post-merger completion period. However, this increased market share came at the expense of rivals who lost, on average, a significant $0.1 \%$ in market share in the post-merger completion period. The results 
suggest that improvement in order flow/market share is somewhat a zero sum game where the merging firms gained overall while the rivals lost.

Finally, another frequently cited objective of stock exchange mergers has been the desire to lower the cost of transacting. When stock exchange mergers lead to increased order flow, the increased trading volume improves liquidity which usually leads to decreases in the bid-ask spread (Arnold et al., 1999; Otchere, 2006); and decreases in bid-ask spreads reduce the cost of transacting on stock exchanges. Also, increasing order flow and liquidity will in turn attract more order flow and liquidity to the exchange because as Jain (2005) noted, liquidity begets liquidity - and this further improvements in liquidity will help reduce bid-ask spreads and transaction costs. Finally, economies of scale typically expected from stock exchange mergers (Malkamäki, 1999) will also lead to reductions in the cost of transacting. Reductions in the cost of transacting benefits listed firms and investors in general. The expectation that stock exchange mergers will benefit the larger investment community makes them very unique because no merger of any ordinary firms can have such far reaching effects. This positive externality makes understanding stock exchange mergers even more compelling. As a result, comprehending the implications of stock exchange mergers on transaction costs is one central motivation of this study.

To therefore examine the effects of the stock exchange mergers on the cost of transacting, we analyzed the short-term and long-term changes in bid-ask spreads for a large number of firms listed on the sample exchanges. While Arnold et al. (1999) and Nielsson (2009) have examined the short-term effects of stock exchange mergers on bid-ask spreads, no 
study, to the best of our knowledge, has examined the long-term effects of stock exchange mergers on cost of transacting. Our study is the first study to provide evidence on the long-term effects of stock exchange mergers on transaction costs. Our results show that the bid-ask spreads of firms listed on the merging exchanges significantly reduced in both the short-term (by about $4.2 \%$ ) and long-term (by about $8.3 \%$ ) relative to those listed on rival (non-merging) exchanges. In fact, firms listed on the rival exchanges experienced significant increases in bid-ask spreads in both the short-term and long-term. We surmise that the increased market share achieved by the merging firms has led to increased order flow, increased liquidity and consequently reductions in bid-ask spreads, while the decreased market share and order flow for rivals have led to decreased liquidity and therefore increases in bid-ask spreads. In our multivariate regression analysis, we find evidence to support this conjecture, as the market share variable, our proxy for increased liquidity/order flow, is generally significantly negative in the rivals' regressions.

While most of our findings are unique to this study, we would like to note that three other papers, namely Arnold et al. (1999), Nielsson (2009) and Hasan et al. (2012) have investigated stock exchange mergers along similar lines of inquiry (as this essay). The similarity in themes notwithstanding, our study is different from all three papers on a number of fronts. Our study differs from earlier studies of stock exchange mergers because, to the best of our knowledge, it is the only study that has examined the longterm effects of stock exchange mergers on market quality (as proxied by bid-ask spreads). Unlike Arnold et al. (1999) who examined US domestic regional mergers, we examine 
cross-country financial exchange mergers. Additionally, we examine cross-border mergers, merger involving an ECN (electronic communications network) and merger between options markets. By examining financial exchange mergers covering the key stock exchange industry competitive pillars (exchanges, ECNs and options markets) in a multi-country context, our study provides further insights into this relatively recent phenomenon of financial exchange mergers and the results of our study are far more reaching. Our study also differs from Nielsson (2009) because while he studied only the Euronext merger, we study multiple mergers in multiple countries; thus our results are more generalizable. Our paper also differs from Hasan et al. (2012) because they primarily investigated the stock market performance of mergers, joint ventures and nonequity alliances in the stock exchange industry but we examine not just the stock price reactions of the merging entities, but more importantly the stock price reactions of rivals to the mergers. Thus we extend the exchange merger literature by providing evidence to show whether the market expected these mega mergers to put non-merging rival exchanges at a competitive disadvantage or whether the market believed that rivals would also benefit through increased market power and further consolidation in the industry.

\subsubsection{Benefits of Study}

This essay makes important contributions to the existing literature and has important corporate/investment policy implications. 


\subsubsection{Contributions of Essay to the Academic Community}

The essay brings additional empirical perspectives that enrich and extend the present body of literature on stock exchange mergers. Not only do we provide evidence on the stock market performance of the mergers, but we also provide unique insights on the market quality and market share implications of the mergers.

\subsubsection{Importance of Study to Investors}

The evidence that we provide on the stock market wealth creation implications of stock exchange mergers can be used by investors to inform their decisions on whether or not to include merging stock exchanges (especially potential future targets) in their portfolios. Investors can also use the results of the cost of transacting analyses to inform their decisions on which investment strategies will provide the best returns and/or which types of stock exchanges will provide the least cost of transacting.

\subsubsection{Corporate Policy Implications of Study}

This study has important corporate policy implications for managers. The management of stock exchanges can leverage the insights in this essay to inform future merger and acquisition decisions. Given that we find evidence demonstrating that the mergers created shareholder wealth for the targets and combined firms and also led to reductions in transaction costs, management of stock exchanges can invoke our results to support undertaking efficiency enhancing mergers in the future. 
Managers of firms interested in raising capital can also use the results of the market quality analyses to determine the types of stock exchanges on which the cost of raising capital may be lower.

\subsubsection{Organization of Study}

The rest of this essay is organized as follows. Section two is devoted to a review of the relevant literature. Section three highlights the research questions to be addressed and section four outlines the data and methodology. Section five presents the results while section six concludes the paper.

\subsection{Literature Review}

As already noted, most stock exchanges are resorting to mergers as a way to deal with the increased competition in the industry in recent times. The increasing use of mergers and acquisitions as a key strategic solution to the current competitive forces in the industry could partly explain why stock exchange mergers are becoming so pervasive that the business press and some authors are beginning to refer to stock exchange mergers as a binge (Fortune 2006) and a mania (Fortune 2007). Kokkoris and Olivares-Caminal (2008) for instance observed that stock exchanges across the globe have been the subject of merger discussions following pressure to cut costs and become more competitive.

While some of the stock exchange bids have been successful, others have not been. Some successful stock exchange mergers include the NYSE-Euronext merger, NASDAQ-OMX 
merger, LSE's merger with Borsa Italiana, NYSE-Archipelago merger and the OMX merger between the Nordic and Baltic stock exchanges. On the other hand, several unsuccessful bids have been made for the London stock exchange (LSE) including bids by OM Group in 2000, Euronext and Deutsche Boerse in 2005, NASDAQ in 2006 (Faulconbridge et al. 2007) and Macquarie Bank in 2005 (Gordon, 2011). Also, a proposed merger between Deutsche Boerse and NYSE Euronext announced in February 2011 was blocked in February 2012 by the European Commission on the grounds that the merger would hurt competition by creating a quasi-monopoly (with a combined market share of over 90\%) in the area of European financial derivatives traded globally on exchanges (European Commission, 2012; Bloomberg, 2012; Economist, 2012).

Our literature review looks at mergers in the stock exchange industry, summary of the general mergers and acquisition literature and some key concerns raised about mergers and acquisitions as it relates to the stock exchange industry.

\subsubsection{Literature on Stock Exchange Mergers}

Given the increasing reliance on mergers as one solution to the increased competition in the stock exchange industry, the logical starting point is to determine the reasons behind these mergers. Although there is no specific study dedicated to the motives behind stock exchange mergers, the general mergers and acquisitions (M\&As) literature is replete with studies on the motives of mergers and acquisitions. From that literature, several motives have been identified for M\&As. Some of these motives include (i) synergy motive (Berkovitch and Narayanan, 1993); (ii) agency (free cash flow) motive (Jensen and 
Ruback, 1983); (iii) undervaluation/bargain motive (Manne, 1965); and, (iv) non-value added mergers resulting mainly from managerial egos, commonly referred to as the hubris motive (Roll, 1986). The various motives of M\&As can be collectively classed into economic motives (e.g. the synergy and agency motives) and noneconomic motives (e.g. the hubris motive). It is generally argued that when firms merge, the realization of synergies ${ }^{7}$ (sometimes referred to as the " $2+2=5$ " effect) will lead to improved efficiencies and will enhance the competitive standing of the combined entity - which will lead to the value of the combined firm being more than the sum of the values of the individual firms involved in the mergers. Trautwein (1990) identifies three types of synergies that can come from mergers and acquisitions and these include financial synergies (e.g. the increased company's size may give it access to cheaper capital), operating synergies (e.g. gains from the transfer of knowledge and/or technology or gains from market power) and managerial synergies (e.g. leveraging superior managerial talent from the participating parties). The success of mergers in improving the operational performance of firms remains an open question, though. In their comprehensive review of the literature, Martynova and Renneboog (2008), for example, find that 14 out of 26 studies report a post-merger decline in operating performance. One potential issue that may make the realization of synergies illusive is potential challenges in integrating the merging firms (White, 1987). However, Singh and Montgomery (1987) find that related acquisitions (e.g. shared technological resources or participation in similar product markets) lead to substantially higher gains than unrelated acquisitions and Hoberg and Phillips (2010) report that stock returns, ex post cash flows and growth in product descriptions all increase for merger transactions having similar product market language.

\footnotetext{
${ }^{7}$ See for example Devos et al. (2009) and Hoberg and Phillips (2010).
} 
Since the stock exchange mergers we examined are within the same industry, it is our contention that there are higher chances that these mergers will improve the competitive position of the players involved in the mergers.

With respect to stock exchange mergers, Pagano (1989) argues that the consolidation of order flow leads to positively beneficial network externalities for traders. A network externality, which offers advantage to users because others are already using the same network, "arises in the provision of an order execution facility, because the likelihood of a trader receiving an execution of his order on a trading system is higher if other traders already send their orders to the trading system" (Lee, 2002, pp. 9). Pagano and Padilla (2005) argue that the integration of stock exchanges produces a number of significant efficiency gains, some of which are passed on by the exchanges to their users (e.g. intermediaries, investors and issuers) in the form of lower fees. It has also been argued that exchange mergers can potentially result in economies of scale and lower cost of operations. Theoretical support for the contention that exchanges that merge can enjoy economies of scale and lower costs is provided by Pirrong (1999) who predicted that exchange mergers will occur in order to exploit increases in scope economies in the provision of trading infrastructure and the enforcement of property rights and rules.

On the empirical front, there are only a few studies on stock exchange mergers because "there are only a handful of realized mergers to be analyzed" (Nielsson, 2009, pp. 231). In their study of regional stock exchange mergers in the US for example, Arnold et al. (1999) found that merging stock exchanges had an increased ability to compete for order 
flow, increased their market share (mostly at the expense of non-merging exchanges) and experienced narrower bid-ask spreads. Based on the evidence, Arnold et al. (1999) concluded that, at least in their study, the mergers improved performance and increased competition to the benefit of investors. Nielsson (2009) studied the liquidity implications of the Euronext merger and found that liquidity gains were unevenly distributed in favour of big firms and firms with foreign exposure, with no significant increase in liquidity for small or medium sized firms, nor for firms that only operate domestically. The author also found that the Euronext's market share rose after the merger, albeit, the increase was achieved at the expense of the London Stock Exchange. Khan and Vieito (2012) study the impact of stock exchange mergers on the informational market efficiency of Euronext Lisbon and note that while their results indicate that the Portuguese Equity Market is inefficient in the weak form during the premerger period, there was mixed evidence of improvement in market efficiency during the post-merger period. Hasan et al. (2012) examine the effect of three growth strategies (namely mergers and acquisitions, joint ventures and non-equity alliances) on stock exchange shareholders' wealth and find significantly positive stock market reaction to these M\&A and alliance activities. Hasan et al. (2012) further report that M\&As create more value (with a statistically significant 3-day CAR of 1.4\%) than alliances, and of the two alliances they studied, joint ventures generate more value (significant 3-day CAR of $1.1 \%$ ) than non-equity alliances (significant 3-day CAR of 0.94\%).

These empirical findings lend some credence to economic explanations (e.g. synergy and agency/inefficiency motives) as underpinning stock exchange mergers - while offering 
no support for noneconomic motives (e.g. the hubris motive) - at least from the few studies of the first few realized stock exchange mergers. Buttressing this contention of economic gains (as informing stock exchange mergers) are several statements by executives of the merging stock exchanges. Jan Michiel Hessels, chairman of the supervisory board of Euronext, for instance asserted that the NYSE-Euronext merger "will deliver significant shareholder value from substantial, quantified and deliverable synergies" (NYSE Group Newsletter 2006). It should, however, be noted that managerial statements are assertions, and usually given their incentive to see mergers succeed, the possibility of biases in managerial statements cannot be completely ruled out.

\subsubsection{Summary of the Literature on Mergers and Acquisitions}

While the few early studies of stock exchange mergers are limited in their coverage, the general mergers and acquisitions literature is extensive and covers several important strands including the motives of mergers and acquisitions, the wealth and operating performance impacts of mergers and the variables/reasons deemed to explain the impacts of mergers and acquisitions - among others.

To summarize, mergers and acquisitions are driven by economic and/or noneconomic motives such as the synergy motive, the agency motive and/or the hubris motive (Roll, 1986; Berkovitch and Narayanan, 1993; Devos et al., 2009). Mergers and acquisitions have implications for shareholder returns (short term as well as long term) and also have impacts on firms' operating performance. With respect to short term shareholder wealth implications, Martynova and Renneboog (2008) review over 35 studies that provided 
evidence on returns to target shareholders and report significant positive abnormal returns in almost every study. Thus, the empirical evidence overwhelmingly suggests that target shareholders reap significantly positive cumulative abnormal returns (CAR) around the announcement date. While bidders earn zero abnormal returns on average in the short term, there is significant variation in CAR from study to study (Fuller et al., 2002; Moeller et al., 2005; Martynova and Renneboog, 2008; Dutta and Jog, 2009). The evidence also shows that rivals benefit from mergers and acquisitions (Song and Walkling, 2000).

The long term stock market performance of combined firms is largely zero if the matched sample methodology is used (Dutta and Jog, 2009) and results regarding improvements in operating performance as a result of mergers are generally mixed (Martynova and Renneboog, 2008). The impacts of mergers and acquisitions can be explained by a number of factors including deal-related factors like hostile- or friendly-nature of deal (Schwert, 2000; Devos et al., 2009), firm-specific factors like firm size (Schwert, 2000; and Bargeron et al., 2008) and governance variables like CEO overconfidence (Malmendier and Tate, 2008; Dutta and Jog, 2009). Figure 2.1 provides a synopsis of some of the burgeoning literature on mergers and acquisitions. 
Figure 2.1 - Overview of the General M\&A Literature

Figure 2.1 summarizes the motives behind mergers, the effects (e.g. shareholder wealth and operating performance effects) of mergers and the factors identified to explain the effects of mergers. The figure is based on our review of the general mergers and acquisition literature.

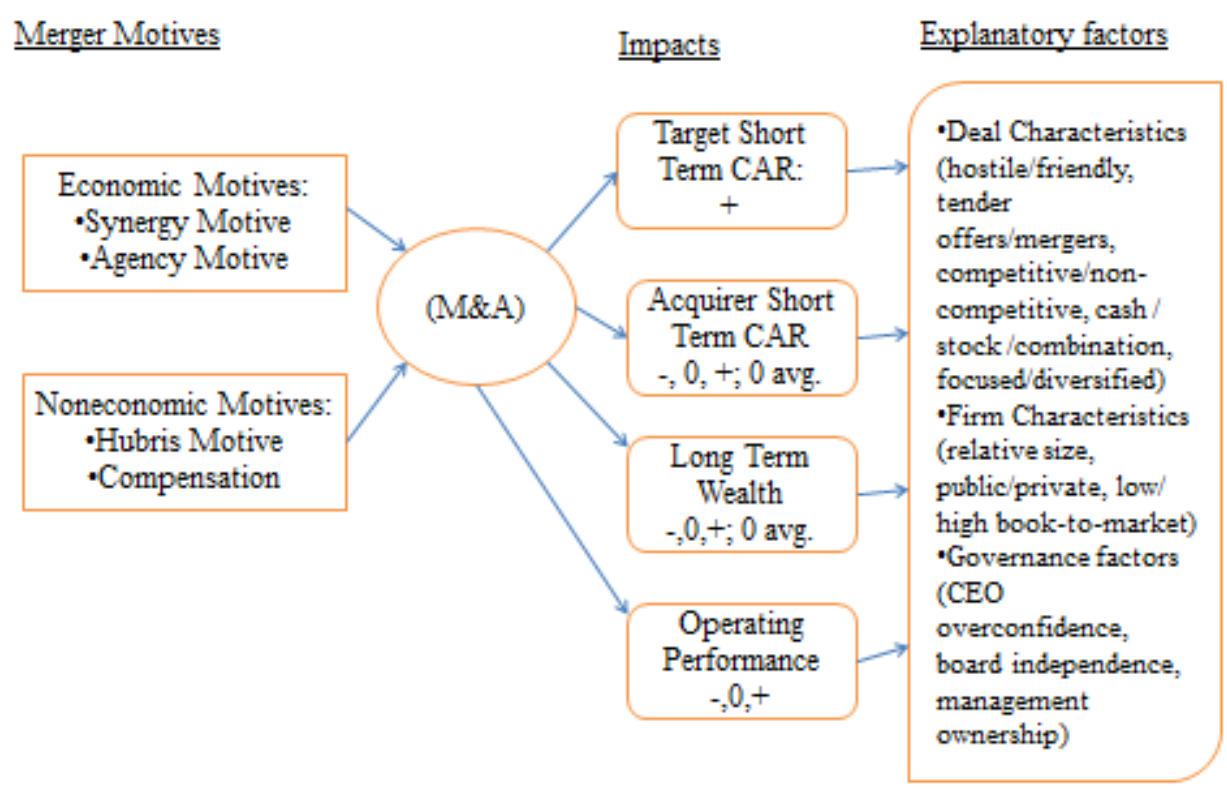

For a detailed review of the general literature on mergers and acquisitions, see appendix $1 \mathrm{~A}$.

\subsubsection{Concerns raised about Stock Exchange Mergers}

Thus, it needs no gainsaying that in the quest to remain profitable and competitive, stock exchanges around the globe are demutualizing, self-listing and/or merging. While these forms of organization could help stock exchanges succeed in the current competitive environment, stock exchange mergers are also likely heir to, potentially, a number of concerns. 
The fact that mergers can potentially lead to increased market power (with its adverse consequences on consumer welfare) has been variously noted in the literature. Kim and Singal (1993) and Singal (1996) analyzed airline mergers and came to the conclusion that while airline mergers lead to more efficient operations, the impact of the efficiency gains are more than offset by the exercise of increased market power. It has therefore been noted that stock exchange mergers could reduce competition (Hasan et al, 2012) and lead to the exercise of market power in the industry. The question of whether or not stock exchange mergers are leading to the exercise of market power will be explored in essay three of this thesis.

Stock exchange mergers could also be limiting investors' ability to diversify into international markets since there is the possibility that the stock exchange mergers (especially cross-border mergers) may increase international stock return co-movement. Evidence for this possibility is provided by Hellström et al. (2013) who study the extent to which the integration of the Nordic stock exchanges (the OMX Nordic merger) have affected the underlying interdependency structure between returns on these markets and find that the long-run trends in conditional market return correlations between the Nordic stock exchanges have increased due to the creation of a common trading platform.

The mega-mergers can also affect the competitive position of the non-merging rivals because the rival exchanges will be competing with merged exchanges that can leverage their increased size to their advantage at the expense of the rival exchanges. 


\subsection{Research Questions and Hypotheses}

Based on the above discussion, essay one addresses three key research questions. First, finance theory postulates that shareholder wealth maximization is the principal goal of the firm. Consequently, it is imperative to establish if the stock exchange mergers are wealth and value creating. Do shareholders of merged and non-merged stock exchanges realize short run abnormal returns following merger announcements? Although a merger can face integration challenges which can hinder its success, we argue that stock exchange mergers will offer a competitive advantage to the merging firms. Since these mergers are within the same industry, we believe that the merging firms will reap synergistic benefits by streamlining operations, eliminating duplication and leveraging better technology and managerial talents. As a result, the merging entities will realize efficiencies and improve their competitive position. Although unlikely, the merging exchanges may also be able to exercise market power by being able to charge a little higher for some services (e.g. listing) or being able to use their increased size (and consolidated purchasing power) to get discounts from suppliers (e.g. lower prices for new technology acquisitions). We therefore expect the stock prices of the merging exchanges to react positively to the merger announcements. And because targets and bidders are expected to achieve synergies as a result of the mergers, we expect the stock prices of targets, acquirers and the combined entities to react positively to the merger announcements. Notwithstanding our expectation of synergies and positive stock price reactions for the merging firms (including bidders), there is ample empirical evidence suggesting that bidders' stock prices react negatively to merger announcements. In their extensive review of the literature, Martynova and Renneboog (2008), for example, report 
that findings of 17 studies of takeovers in the 1990s are almost evenly split between positive and negative returns for bidders. One reason why this can happen is if the markets believe that the merger might not be successful. Another reason for this is the markets' perception that bidders are overvaluing targets and therefore overpaying target shareholders (Varaiya and Ferris, 1987; Han et al. 1998). If these perceptions dominate, then the bidders' stock prices will react negatively to the merger announcements. In summary, while we expect the stock prices of targets and the combined firms to react positively, the stock prices of bidders may react positively (if synergy dominates) or negatively (if, for example, the markets believe that bidders are overpaying for the targets).

With regards to rivals, we argue that the mergers will put them at a competitive disadvantage because they will be competing with combined exchanges that may be relatively bigger and can leverage their increased size to their advantage. In an era of financial liberalization and technological advancements, the combined firms may be able to use their improved competitive position to siphon some business from rivals. As a result, we expect rivals' stock prices to react negatively. However, the interplay of other factors may lead to the stock prices of rivals reacting positively. There is the possibility, as a result of their increased size, that the combined entities may be able to exercise some market power by charging higher fees for services such as listing. In that case, rivals will also benefit from the mergers and their stock prices will react positively as well. Also, the mergers might signal to the market that further consolidations involving rivals will happen or that there are good growth prospects in the industry. The potential for this 
positive informational effect may lead to positive stock price reactions for rivals. Whether the positive and negative reactions to rivals' stock prices will cancel each other out or one of them might dominate the other is not certain. We argue that the negative effects of the competitive disadvantage that rivals will face will significantly outweigh the positive benefits associated with the exercise of market power and/or the positive informational effects of the mergers. We thus expect the stock prices of rivals to react negatively to the merger announcements. We therefore hypothesize that:

HIa: The stock price reaction to a merger announcement for shareholders of the target firm will be positive.

HIb: The stock price reaction to a merger announcement for shareholders of the bidding firm may be positive, zero or negative.

H1c: The stock price reaction to a merger announcement for shareholders of the combined entity will be positive.

H1d: The stock price reaction to a merger announcement for shareholders of rivals will be negative.

Second, synergy has become one of the focal reasons advanced for mergers and acquisitions and stock exchange mergers are no exception. In a NYSE Group Newsletter (2006), it was noted that the merger between NYSE and Euronext will deliver significant shareholder value from substantial, quantified and deliverable synergies. Determining the extent to which the merging entities achieve the desired synergies is one of the key research questions of this essay. One way of determining the synergistic effects of the stock exchange mergers is to gauge whether or not the merging firms have achieved 
additional market share/order flow. Do stock exchange mergers lead to increased order flow for the merged entities? If so, are the increased order flows achieved at the expense of rivals? We argue that the pooling of resources and improved competitive position of the merging exchanges will give the combined exchanges an edge in attracting more order flow. Economies of scale resulting from the consolidation of exchanges will also strengthen the competitive position of the merging stock exchanges, thus, better positioning them to attract more order flow. Furthermore, in view of the fact that investors are going global in their quest for better returns and/or portfolio diversification, we contend that the (mostly cross-border) mergers will make trading on the combined stock exchanges more attractive and will, as a result, lead to increased order flow for the players involved in the mergers.

However, if there are difficulties in integrating the activities of the merger partners or if diseconomies of scale set in, then the realization of synergy will become illusive and the merging firms may lose market share. Given that these mergers are within the same industry, this is unlikely. Since the competition for order flow is mostly a zero sum game whereby some win and others lose, we also argue that the competitive disadvantage that rivals face by competing with bigger and better resourced merging exchanges will lead them to experience decreasing order flow and market share. We are thus hypothesizing that:

H2a: The market share of trading of stock exchanges involved in mergers will increase in the post-merger completion period 
H2b: The market share of trading of rival stock exchanges will decrease in the postmerger completion period.

Third, reducing the cost of transacting is one of the unique and potentially one most important objective for stock exchange mergers because lower transaction costs benefit the wider investment community since investors will experience cost reductions. Reducing the cost of transacting also benefits the stock exchanges because lower transaction costs will attract more investors - which will increase order flow to the exchanges. Therefore, the final research question we address in this study is whether or not the stock exchange mergers lead to significant reductions in the cost of transacting. The bid-ask spread around the merger completion is frequently used to gauge the extent to which stock exchange mergers have resulted in reductions in the cost of transacting. Thus, do stock exchange mergers reduce transaction costs (of firms listed on these merging stock exchanges) as measured by the bid-ask spread? For the exchanges involved in mergers, we argue that increases in order flow will lead to increased liquidity. As liquidity increases, firms listed on the merging exchanges will experience decreases in bid-ask spreads. Also, the elimination of duplication of exchanges' fixed costs and scale economies associated with mergers will, ceteris paribus, lead to decreasing costs and reductions in the cost of transacting as exchanges pass on the cost savings. For these reasons, we conjecture that the stock exchange mergers will lead to narrower bid-ask spreads for firms listed on the merging exchanges. On the other hand, reductions in order flow as a result of the competitive disadvantages that rivals may face in competing with better resourced combined entities will make the rivals less liquid as order flow migrates 
to the merging entities. As order flow decreases and liquidity deteriorates, bid-ask spreads of firms listed on rival exchanges will increase and the cost of transacting on the rival stock exchanges could increase. We therefore hypothesize that:

H3a: Bid-ask spreads of firms listed on stock exchanges involved in mergers will decrease in the post-merger completion period.

H3b: Bid-ask spreads of firms listed on merged stock exchanges will be lower in the postmerger completion period than bid-ask spreads of firms listed on rival stock exchanges not engaging in mergers.

\subsection{Data and Methodology}

\subsubsection{Data}

This essay explores the effects of six of the stock exchange mergers that have taken place recently on the main players involved in the mergers and more importantly on rival stock exchanges. Summary information about these six mergers is provided in Table 2.1.

Table 2.1 - Summary Information about the Sample Mergers

This table provides summary information about the six mergers examined in this study. The information is mostly gathered from the SDC Platinum database as well as from websites and the business press that reported on the mergers.

\begin{tabular}{|l|l|l|l|l|l|}
\hline $\begin{array}{l}\text { Merged } \\
\text { Entities }\end{array}$ & $\begin{array}{l}\text { Date } \\
\text { Announced }\end{array}$ & $\begin{array}{l}\text { Date } \\
\text { Completed }\end{array}$ & Deal Size & $\begin{array}{l}\text { Combined } \\
\text { Market } \\
\text { Capitalization }\end{array}$ & Aim of Merger \\
\hline $\begin{array}{l}\text { NYSE - } \\
\text { Euronext }\end{array}$ & $\begin{array}{l}\text { 22-May-06 (as } \\
\text { first reported in } \\
\text { Business Wire - } \\
\text { although 1-Jun- } \\
06 \text { has been } \\
\text { reported too) }\end{array}$ & 4 -Apr-07 & $\begin{array}{l}\text { \$10.2 } \\
\text { billion }\end{array}$ & \$20 billion & $\begin{array}{l}\text { Create world's largest and most liquid } \\
\text { exchange group that offers the most } \\
\text { diverse array of financial products and } \\
\text { services. }\end{array}$ \\
\hline $\begin{array}{l}\text { NASDAQ - } \\
\text { OMX }\end{array}$ & 25-May-07 & 27-Feb-08 & \$4.1 billion & \$7.1 billion & $\begin{array}{l}\text { Create "the largest global network of } \\
\text { exchanges and exchange customers } \\
\text { linked by technology". }\end{array}$ \\
\hline
\end{tabular}




\begin{tabular}{|c|c|c|c|c|c|}
\hline $\begin{array}{l}\text { Merged } \\
\text { Entities }\end{array}$ & $\begin{array}{l}\text { Date } \\
\text { Announced }\end{array}$ & $\begin{array}{l}\text { Date } \\
\text { Completed }\end{array}$ & Deal Size & $\begin{array}{l}\text { Combined } \\
\text { Market } \\
\text { Capitalization }\end{array}$ & Aim of Merger \\
\hline $\begin{array}{l}\text { London Stock } \\
\text { Exchange - } \\
\text { Borsa Italiana } \\
\text { (LSE-BI) }\end{array}$ & 20-Jun-07 & 1-Oct-07 & $\begin{array}{l}\text { £1.1 billion } \\
\text { ( } \$ 2.2 \\
\text { billion) }\end{array}$ & $£ 3.9$ billion & $\begin{array}{l}\text { Create the most advanced trading } \\
\text { platform of any exchange and most } \\
\text { efficient post-trade services in Europe. }\end{array}$ \\
\hline $\begin{array}{l}\text { Deutsche } \\
\text { Boerse - } \\
\text { International } \\
\text { Securities } \\
\text { Exchange (DB- } \\
\text { ISE) }\end{array}$ & $30-A p r-07$ & 20-Dec-07 & $\$ 2.8$ billion & Not available & $\begin{array}{l}\text { Create the largest transatlantic } \\
\text { derivatives marketplace with } \\
\text { significant USD and Euro product } \\
\text { coverage, and with significant } \\
\text { operations and revenues in both the } \\
\text { U.S. and Europe. }\end{array}$ \\
\hline $\begin{array}{l}\text { NYSE - } \\
\text { Archipelago }\end{array}$ & 20-Apr-05 & 7-Mar-06 & $\begin{array}{l}\$ 844 \\
\text { million }\end{array}$ & $\$ 3$ billion & $\begin{array}{l}\text { Combination will be the leading } \\
\text { securities market in the United States } \\
\text { and in the world. }\end{array}$ \\
\hline CME - CBOT & 17-Oct-06 & 12-Jul-07 & $\begin{array}{c}\$ 11.1 \\
\text { billion }\end{array}$ & $\begin{array}{l}\text { Combined } \\
\text { company is } \\
\text { valued at } \$ 25 \\
\text { billion }\end{array}$ & $\begin{array}{l}\text { Create the most extensive and diverse } \\
\text { global derivatives exchange. The } \\
\text { combined company will provide } \\
\text { customers with efficient, global access } \\
\text { to a wide array of benchmark } \\
\text { exchange-traded derivatives based on } \\
\text { U.S. interest rate yield curve, equity } \\
\text { indexes, foreign exchange, agricultural } \\
\text { and industrial commodities, energy and } \\
\text { alternative investment products such as } \\
\text { weather and real estate. }\end{array}$ \\
\hline
\end{tabular}

Stock market and product market data for all exchanges for which we could get data is used in this study. Given the naturally small number of realized stock exchange mergers, we believe that using all data for all stock exchanges in our analysis will improve the robustness of the study.

The data for the study was collected from a number of sources. The stock market data (i.e. stock prices, market capital, market return, etc.) and financial statement data were collected from DataStream, Bloomberg and Capital IQ databases. In all, we got stock market data for 23 publicly listed stock exchanges. We then downloaded daily data for the 23 stock exchanges and used a symmetric 250 -day (i.e. day $-250,+250$ ) window in our regression analyses. This resulted in overall firm-day observations of 20,678 for the polled sample, which starts 250 days before the earliest merger announcement date and 
ends 250 days after the last merger announcement date. The market share data was obtained from the World Federation of Exchanges website. We obtained monthly value of share trading (in USD) and calculated market share of the exchanges. ${ }^{8}$ The final data consisted of monthly data for 53 stock exchanges for a total of 24,162 firm-monthly observations for the event-time market share analysis and 5,062 exchange-months data for the calendar-time analysis. For the short-term bid-ask spreads analysis, we obtained daily bid-ask spreads information from Bloomberg for $15 \%$ of firms listed on 50 stock exchanges over the 44 days surrounding each merger completion date. This resulted in a total of over 2.3 million firm-days, which are then averaged to get the daily bid-ask spread for each exchange. The exchanges' bid-ask spreads are then used to form the various portfolios. ${ }^{9}$ For the long-term bid-ask spreads analysis, we downloaded data for some 6,500 firms traded on 52 stock exchanges from 250 trading days (one year) before the mergers' completion dates to 750 trading days (three years) after the mergers' completion dates. In total, we had over 20 million rows of firm-day data points and over 6 million rows of unique firm-day data points (since the control firms were used for more than one stock exchange merger). Given the naturally small number of stock exchange mergers, using such large volumes of data for the sample exchanges (test and control

\footnotetext{
${ }^{8}$ To obtain the market share for each month for each exchange, we take the exchange's value of share trading (in USD) and divide it by the sum of all the exchanges' value of share trading (in USD). The market shares for the exchanges involved in the mergers were calculated by summing their individual data to get the data for each combined exchange. To get the market share for each portfolio, we averaged the market shares of all the exchanges that make up the portfolio.

${ }^{9}$ The portfolios analyzed include merging exchanges and rival exchanges. The merging exchanges are in some cases broken down into targets and bidders. The competitors are broken down into stage of development (using the OECD definition of developed vs. developing countries). Despite talks about the "death of distance", it has been demonstrated that location is an important consideration when it comes to security trading (Coval and Moskowitz, 1999). Consequently, we break down the competitors into regions along the lines of the World Federation of Exchanges' (WFE) classification. We split WFE's Americas region into North America region and Latin America region and WFE's Europe - Africa - Middle East region into Europe region and Africa - Middle East region. We further interacted the stage of development with region.
} 
samples) in our analysis will improve the robustness of the study. The breakdown of the sample is presented in Table 2.2.

\section{Table 2.2 - Sample Distribution}

This table presents a breakdown of the sample into various portfolios. Panel A breaks down the total sample into merging firms and competitors and Panel B breaks down the sample of merging firms into targets and bidders. Panel C shows the distribution of the sample according to the stage of development, while Panel D breaks down the competitors by geography. Panel E interacts stage of development with geography and reports the sample distribution by the interaction of stage of development and geography. The exchange column presents information on the number of stock exchanges while the exchange-days or exchange-months columns report the sample size by exchange-days/months. The Exchange-months event time and calendar time columns show the sample size for the event time and calendar time analysis. The listed firms' columns report the number of companies listed on the exchanges that were sampled for the bid-ask spread analysis. The firm-days columns present the firm-day observations used for the bid-ask analyses. The sample window for the stock price analyses is a symmetric 250 days before and after each merger announcement date. For the market share analyses, the event time sample is based on monthly data spanning 36 months or 3 years before merger completion and 48 months or 4 years after merger completion while the calendar time analysis is based on monthly data from 2003 to 2012 (conforming to 36 months before the first merger completion and 48 months after the last merger completion). The short-term bid-ask spreads analyses use daily data for 44 days or 2 months before and 44 days or 2 months after each merger's completion to estimate the regression. The long-term bid-ask spreads analyses use daily data for 250 days ( 1 year) before the mergers' completion and 750 days (3 years) after the mergers' completion.

\begin{tabular}{|c|c|c|c|c|c|c|c|c|c|c|c|}
\hline \multirow[b]{2}{*}{ Portfolio } & \multicolumn{2}{|c|}{$\begin{array}{l}\text { Stock Price } \\
\text { Sample }\end{array}$} & \multicolumn{3}{|c|}{ Market Share Sample } & \multicolumn{3}{|c|}{ Short Term Bid-Ask Sample } & \multicolumn{3}{|c|}{ Long Term Bid-Ask Sample } \\
\hline & $\begin{array}{l}\text { Excha } \\
\text { nges }\end{array}$ & $\begin{array}{l}\text { Exchang } \\
\text { e-Days }\end{array}$ & $\begin{array}{l}\text { Exch } \\
\text { anges }\end{array}$ & $\begin{array}{l}\text { Exchange- } \\
\text { Months } \\
\text { Event Time }\end{array}$ & $\begin{array}{c}\text { Exchange- } \\
\text { Months } \\
\text { Calendar } \\
\text { Time } \\
\end{array}$ & $\begin{array}{l}\text { Excha } \\
\text { nges }\end{array}$ & $\begin{array}{l}\text { Listed } \\
\text { Firms }\end{array}$ & $\begin{array}{c}\text { Listed } \\
\text { Firm-Days }\end{array}$ & $\begin{array}{l}\text { Exc } \\
\text { han } \\
\text { ges }\end{array}$ & $\begin{array}{l}\text { Listed } \\
\text { Firms }\end{array}$ & $\begin{array}{l}\text { Listed Firm- } \\
\text { Days }\end{array}$ \\
\hline \multicolumn{12}{|c|}{ Panel A - All Exchanges } \\
\hline All Merging Firms & 9 & 8,544 & 4 & 2,040 & 432 & 9 & 1,899 & 884,812 & 9 & 2,113 & $2,280,121$ \\
\hline All Competitors & 14 & 12,134 & 49 & 22,122 & 4,630 & 41 & 3,759 & $1,487,812$ & 43 & 4,464 & $17,875,026$ \\
\hline All Exchanges & 23 & 20,678 & 53 & 24,162 & 5,062 & 50 & 5,658 & $2,372,624$ & 52 & 6,577 & $20,155,147$ \\
\hline \multicolumn{12}{|c|}{ Panel B - Breakdown of Merging Exchanges } \\
\hline Targets & 5 & 3,694 & - & - & - & 5 & 455 & 208,240 & 5 & 487 & 603,849 \\
\hline Bidders & 4 & 4,850 & - & - & - & 4 & 1,444 & 676,572 & 4 & 1,626 & $1,676,272$ \\
\hline Total & 9 & 8,544 & - & - & - & 9 & 1,899 & 884,812 & 9 & 2,113 & $2,280,121$ \\
\hline \multicolumn{12}{|c|}{ Panel C - Breakdown of Competitors by Stage of Development } \\
\hline $\begin{array}{l}\text { Competitors } \\
\text { Emerging Markets }\end{array}$ & 10 & 9,574 & 17 & 7,894 & 1,652 & 15 & 1,626 & 676,636 & 15 & 1,904 & $8,089,047$ \\
\hline Competitors & 4 & 2,560 & 32 & 14,228 & 2,978 & 26 & 2,133 & 811,176 & 28 & 2,560 & $9,785,979$ \\
\hline Total & 14 & 12,134 & 49 & 22,122 & 4,630 & 41 & 3,759 & $1,487,812$ & 43 & 4,464 & $17,875,026$ \\
\hline \multicolumn{12}{|c|}{ Panel D - Breakdown of Competitors by Region } \\
\hline $\begin{array}{l}\text { East Competitors } \\
\text { Asia - Pacific }\end{array}$ & 1 & $522 *$ & 7 & 2,309 & 466 & 4 & 161 & 55,409 & 5 & 214 & 726,645 \\
\hline Competitors & 7 & 7,235 & 19 & 8,747 & 1,846 & 17 & 2,535 & $1,015,130$ & 17 & 2,844 & $11,974,392$ \\
\hline $\begin{array}{l}\text { Europe Competitors } \\
\text { Latin America }\end{array}$ & 2 & 1,559 & 14 & 6,700 & 1,406 & 12 & 525 & 177,118 & 12 & 726 & $2,338,172$ \\
\hline $\begin{array}{l}\text { Competitors } \\
\text { North America }\end{array}$ & 1 & $133 *$ & 6 & 3020 & 626 & 5 & 186 & 76,758 & 6 & 256 & 902,680 \\
\hline Competitors & 3 & 2,685 & 3 & 1,346 & 286 & 3 & 352 & 163,397 & 3 & 424 & $1,933,137$ \\
\hline Total & 14 & 12,134 & 49 & 22,122 & 4,630 & 41 & 3,759 & $1,487,812$ & 43 & 4,464 & $17,875,026$ \\
\hline $\begin{array}{l}\text { Panel E - Breakdow } \\
\text { Developed - Asia - }\end{array}$ & foml & itors by & gion a & Stage of De & lopment & & & & & & \\
\hline $\begin{array}{l}\text { Pacific } \\
\text { Emerging - Asia - }\end{array}$ & 5 & 5,330 & 7 & 3,088 & 644 & 6 & 1,012 & 440,531 & 6 & 1,106 & $5,111,675$ \\
\hline Pacific & 2 & 1,905 & 12 & 5,659 & 1,202 & 11 & 1,523 & 574,599 & 11 & 1,738 & $6,862,717$ \\
\hline
\end{tabular}




\begin{tabular}{|c|c|c|c|c|c|c|c|c|c|c|c|}
\hline \multirow[b]{2}{*}{ Portfolio } & \multicolumn{2}{|c|}{$\begin{array}{l}\text { Stock Price } \\
\text { Sample }\end{array}$} & \multicolumn{3}{|c|}{ Market Share Sample } & \multicolumn{3}{|c|}{ Short Term Bid-Ask Sample } & \multicolumn{3}{|c|}{ Long Term Bid-Ask Sample } \\
\hline & $\begin{array}{l}\text { Excha } \\
\text { nges }\end{array}$ & $\begin{array}{l}\text { Exchang } \\
\text { e-Days }\end{array}$ & $\begin{array}{l}\text { Exch } \\
\text { anges }\end{array}$ & $\begin{array}{l}\text { Exchange- } \\
\text { Months } \\
\text { Event Time }\end{array}$ & $\begin{array}{l}\text { Exchange- } \\
\text { Months } \\
\text { Calendar } \\
\text { Time } \\
\end{array}$ & $\begin{array}{l}\text { Excha } \\
\text { nges }\end{array}$ & $\begin{array}{l}\text { Listed } \\
\text { Firms }\end{array}$ & $\begin{array}{c}\text { Listed } \\
\text { Firm-Days }\end{array}$ & $\begin{array}{l}\text { Exc } \\
\text { han } \\
\text { ges }\end{array}$ & $\begin{array}{l}\text { Listed } \\
\text { Firms }\end{array}$ & $\begin{array}{l}\text { Listed Firm- } \\
\text { Days }\end{array}$ \\
\hline Developed - Europe & 2 & 1,559 & 8 & 3,970 & 830 & 7 & 290 & 79,395 & 7 & 430 & $1,132,463$ \\
\hline Emerging - Europe* & - & - & 6 & 2,730 & 576 & 5 & 235 & 97,723 & 5 & 296 & $1,205,709$ \\
\hline $\begin{array}{l}\text { Developed - North } \\
\text { America } \\
\text { Emerging- North }\end{array}$ & 3 & 2,685 & 2 & 836 & 178 & 2 & 324 & 156,710 & 2 & 368 & $1,844,909$ \\
\hline $\begin{array}{l}\text { America } \\
\text { Emerging Africa - } \\
\text { Middle East }\end{array}$ & - & - & 1 & 510 & 108 & 1 & 28 & 6,687 & 1 & 56 & 88,228 \\
\hline $\begin{array}{l}\text { Competitors } \\
\text { Emerging Latin } \\
\text { America }\end{array}$ & 1 & $522 *$ & 7 & 2,309 & 466 & 4 & 161 & 55,409 & 5 & 214 & 726,645 \\
\hline Competitors & 1 & $133^{*}$ & 6 & 3,020 & 626 & 5 & 186 & 76,758 & 6 & 256 & 902,680 \\
\hline Total & 14 & 12,134 & 49 & 22,122 & 4,630 & 41 & 3,759 & $1,487,812$ & 43 & 4,464 & $17,875,026$ \\
\hline
\end{tabular}

\subsubsection{Methodology}

The event study methodology is the dominant technique for examining the behavior of firms' stock prices around corporate events such as mergers and acquisitions (Kothari and Warner, 2007). Several event studies models have been proposed, including among others the standard two-step procedure involving first the estimation of benchmark parameters over a period unrelated to the event and then second the cumulating of abnormal returns over the event window as well as the dummy variables model, alternatively called the multivariate regression model (Binder, 1985; Acharya 1993).

In this essay, we use the event study multivariate regression (or dummy variables) approach of Binder (1985) and Acharya (1993) which parametizes the abnormal returns in the individual return equations using dummy variables to estimate the behavior of stock prices around the merger announcements. We chose this method for a number of reasons. First, the approach allows us to use stock return data over both the event and nonevent windows. Second, the dummy variables approach is a preferable methodology 
when firms experience the same event more than once. As Acharya (1993) noted, one can use the dummy variable approach for "an individual firm experiencing the same type of event more than once in a sample period" (pp. 367). Since in our sample we have the NYSE being involved in two mergers (i.e. first with Archipelago and then with Euronext), we believe that the dummy variables approach is a better approach for this study. The multivariate regression model in its general form is given as:

$\widetilde{\mathrm{R}}_{\mathrm{it}}=\alpha_{i}+\beta_{i} \tilde{R}_{m t}+\sum_{a=1}^{A} \gamma_{\mathrm{ia}} \mathrm{D}_{\mathrm{at}}+\tilde{\mathrm{u}}_{\mathrm{it}}$

where $\widetilde{\mathrm{R}}_{\mathrm{it}}$ is the rate of return for firm i in time $t, \widetilde{\mathrm{R}}_{\mathrm{mt}}$ is the market rate of return and $\mathrm{D}_{\mathrm{at}}$ are dummies for events. The coefficients of the dummy variables represent the abnormal return.

The ordinary least squares technique is typically used in the estimation of the multivariate regression models. However, Andrade and Stafford (2004) noted that mergers and acquisitions activities in an industry usually occur in clusters. If mergers cluster in an industry, then the assumption of 'independence' among individual events that is required for the use of ordinary least squares regressions will, in all likelihood, be violated. Since the exchange mergers appear to be happening in waves (e.g. the Deutsche Boerse-ISE merger and NASDAQ-OMX merger were both announced in 2007 while four of the six mergers were completed in 2007), this study uses Zellner's (1962) seemingly unrelated regression (SUR) model to estimate the equations because of the possibility of contemporaneous correlations in the residuals. The SUR model is a superior technique 
for estimating asymptotically more efficient regression coefficients when the random disturbance terms are correlated with each other.

To analyze the short-term stock market reactions to the mergers, we estimate the following SUR regressions:

$$
\begin{aligned}
& \mathrm{R}_{1 \mathrm{t}}=\alpha_{1}+\beta_{1} R_{m t}+\sum_{a=1}^{6} \delta_{1 \mathrm{a}} \mathrm{D}_{\mathrm{at}}+\gamma_{1 \mathrm{t}} \text { Growth }_{\mathrm{i}}+\rho_{1 \mathrm{t}} \text { RelSize }_{\mathrm{i}}+\theta_{1 \mathrm{t}} \mathrm{GDP} / \mathrm{Cap}_{\mathrm{i}}+\mathrm{e}_{1 \mathrm{t}} \\
& \mathrm{R}_{2 \mathrm{t}}=\alpha_{2}+\beta_{2} R_{m t}+\sum_{a=1}^{6} \delta_{2 \mathrm{a}} \mathrm{D}_{\mathrm{at}}+\gamma_{2 \mathrm{t}} \text { Growth }_{\mathrm{i}}+\rho_{2 \mathrm{t}} \text { RelSize }_{\mathrm{i}}+\theta_{2 \mathrm{t}} \mathrm{GDP} / \mathrm{Cap}_{\mathrm{i}}+\mathrm{e}_{2 \mathrm{t}} \\
& \begin{array}{llllllllll}
\vdots & \vdots & \vdots & \vdots & \vdots & \vdots & \vdots & \vdots & \vdots & \vdots
\end{array} \\
& \mathrm{R}_{\mathrm{it}}=\alpha_{i}+\beta_{i} R_{m t}+\sum_{a=1}^{6} \delta_{\mathrm{ia}} \mathrm{D}_{\mathrm{at}}+\gamma_{\mathrm{it}} \text { Growth }_{\mathrm{i}}+\rho_{\mathrm{it}} \text { RelSize }_{\mathrm{i}}+\theta_{\mathrm{it}} \mathrm{GDP} / \text { Cap }_{\mathrm{i}}+\mathrm{e}_{\mathrm{it}}
\end{aligned}
$$

where $\sum_{\mathrm{a}=1}^{6} \delta_{\mathrm{ia}} \mathrm{D}_{\mathrm{at}}$ represent dummies for the six event windows that we examine (i.e. day 0 ; day $[-1,+1]$; day $[0,+2]$; day $[-2,+2]$; day $[-5,+5]$; and day $[-10,+10]) . \mathrm{R}_{\mathrm{it}}$ is firm/portfolio return, $\mathrm{R}_{\mathrm{mt}}$ is market return, growth rate is approximated by book-tomarket, RelSize is the relative size of the targets, bidders or rivals to that of the combined firms and GDP/Cap is GDP per capita of the country of origin of the stock exchange. We include growth and relative size as additional control variables because prior studies show that these variables affect merger returns (see Schwert, 2000; Fuller et al., 2002; Moeller et al., 2005; Devos et al., 2009). If relative size of the target is high, this will have serious consequences for the rivals because the combined firm will be a super exchange (the likes of NYSE Euronext) and competitors may suffer if such a merger is consummated. On the other hand, if the target is very small, the competitive effects will be small. The relative size of rivals also matters because a higher relative size will imply that the competitor(s) are big and may be able to effectively compete with the merged entities. But if rival's relative size is small, then it may not be well resourced to 
effectively compete with the combined firms. Growth is also important because it gives an indication of the prospects of the industry, which affects both merging stock exchanges and the rivals. We also include GDP per capita to control for growth differences in the countries of origin of the stock exchanges. We do not include other standard control variables such as whether or not the merger bid is friendly and the mode of payment either because they cannot be determined for rival exchanges (since they are not involved in mergers) or the variable is the same for all the mergers (e.g. all the mergers were friendly). To avoid look-ahead bias, we lag, by one year, financial and macroeconomic variables that are reported with a lag (e.g. book value).

For the market share analysis, we regress market share on a merger completion dummy variable (which takes the value of one in the post-merger completion period and zero in the pre-merger completion period), a linear time trend variable (following Arnold et al., 1999) and a number of other control variables. The following market share SUR regression equations (subscripts dropped for the sake of brevity) were estimated:

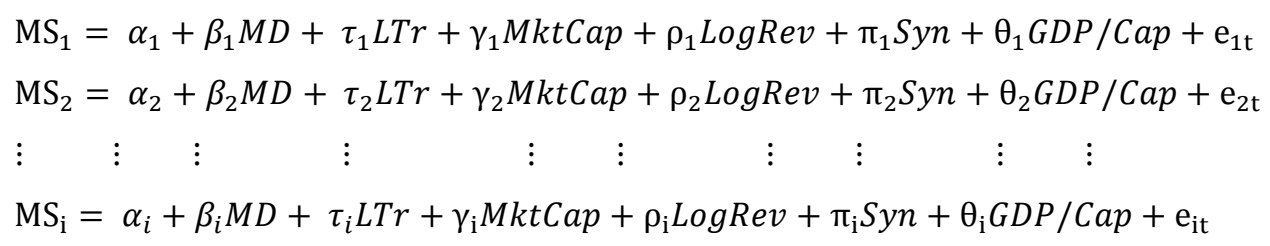

where MS represents market share, MD is merger dummy, $\mathrm{LTr}$ represents linear time trend, MktCap is domestic market capitalization, $\operatorname{LogRev}$ is $\log$ of revenue, Syn, which represents synergy is defined as the percent difference between the transaction value and target market capitalization one month before the merger announcement date, while 
GDP/Cap is GDP per capita of the country of origin of the stock exchange. Since most variables tend to trend upwards over time, we follow Arnold et al. (1999) and include a linear time trend variable as a control variable in our market share SUR regressions, which span several years. Domestic market capitalization proxies for the size of the exchange, while log of revenues controls for firm growth prospects. Since mergers are partly justified on the basis of the value to be created through synergy, we also included our proxy for synergy as a control variable in our market share regressions.

The bid-ask SUR regressions also involve regressing the bid-ask spreads on the merger completion dummy and a number of other control variables. Bid-ask spreads, which represent the markup market participants pay for predictable immediacy of exchange in organized markets (Demsetz, 1968) are key measures of trade execution costs. Although there are several measures of bid-ask spreads, quoted spreads and effective spreads are by far the most frequently used measures of transaction costs (Otchere and Abou-Zied, 2008). Quoted spreads are regarded as the simplest and most appropriate measures of trade execution costs if trades are executed at the quotes (Bessembinder and Kaufman, 1997). We use quoted spreads in this study because of their simplicity and widespread use. Quoted spreads are defined as follows:

Quoted Spread $=\frac{\mathrm{P}_{\mathrm{A}}-\mathrm{P}_{\mathrm{B}}}{\left(\left(\mathrm{P}_{\mathrm{A}}+\mathrm{P}_{\mathrm{B}}\right) / 2\right)}$

where $\mathrm{P}_{\mathrm{A}}$ is the ask and $\mathrm{P}_{\mathrm{B}}$ is the bid. We use the estimated quoted spreads in the following SUR regressions for the bid-ask analysis: 


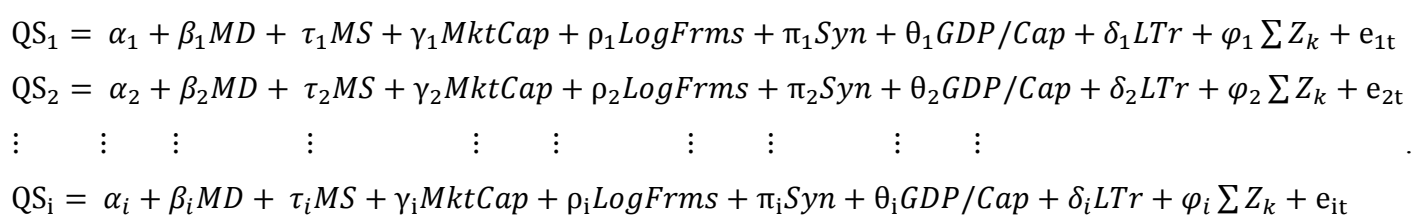

where QS represents quoted spread, $M D$ is merger dummy, $M S$ is market share, MktCap is domestic market capitalization, LogFrms represents log of listed firms, Syn represents synergy, GDP/Cap is GDP per capita of the country of origin of the stock exchange, $L T r$ represents linear time trend and $Z_{k}$ is a vector of firm specific control variables. We conjecture that because the stock exchange mergers are expected to lead to increased market share for the merging firms, we expect the increased market share to lead to increased liquidity and consequently reduction in bid-ask spreads. To test this conjecture, we include market share as a control variable in our bid-ask regressions. Pagano (1989) argues that the consolidation of order flow through stock exchange mergers should lead to positively beneficial network externalities. To examine the effect of network externalities, we include the log of listed firms as a proxy variable in our bid-ask regressions. For the long-term analysis of bid-ask spreads where we expect more variation in other variables, we include additional control variables including a linear time trend (following Arnold et al., 1999) and a number of firm level control variables $\left(Z_{k}\right)$ - including average firm market capitalization, turnover, volume, price inverse and standard deviation of 3-month stock returns (following Madhaven, 2000). 


\subsection{Results}

We present the results of our study along the three main objectives (i.e. stock market impacts, product market performance and bid-ask analysis) in the ensuing discussion.

\subsubsection{Stock Market Impacts of Mergers}

We first analyze the pooled results before presenting the stock market performance of the individual mergers.

\subsubsection{Pooled Results of All Mergers}

We pooled the six mergers together and analyzed stock price reactions to all the mergers together. The results, based on several event windows, are presented in Table 2.3. Consistent with extant literature, the results in Table 2.3 demonstrate that the mergers were significantly beneficial to targets. The day zero abnormal return (of 3.0\%) and day $[-1,+1]$ abnormal return (of $1.8 \%$ ) were significantly different from zero at the $5 \%$ level. The day $[0,+2]$ window's abnormal return was also significantly different from zero at the $10 \%$ level. For bidders, however, the day $[-1,+1]$ and day $[-2,+2]$ abnormal returns were negative and significantly different from zero (at the 10\% level) while the abnormal return for the other four event windows were statistically indistinguishable from zero. The mergers also generated significant abnormal returns for shareholders of the combined firms $(1.3 \%$ on day zero, $0.7 \%$ over the day $[-1,+1]$ window and $0.6 \%$ over the day $[0,+2]$ window). The $1.3 \%$ abnormal return on day 0 is similar to the CAR of $1.4 \%$ (for stock exchange mergers and acquisitions) reported by Hasan et al. (2012) over the 


\section{day $[-1,+1]$ window. These results demonstrate that shareholders of the stock exchanges}

\section{involved in the six mergers were positively rewarded by the markets for the mergers.}

\section{Table 2.3 - Pooled Stock Market Results}

Using the pooled data of all the mergers, this table presents the stock price performance of the various portfolios based on 6 event windows. The results are derived from seemingly unrelated regressions using data that starts 250 days before the earliest merger announcement date (on April 20,2005) and ends 250 days after the last merger announcement date (on June 20, 2007). Stock returns are regressed on market returns, relative size, book-to-market, GDP per capita and merger day dummies (which take the value of 1 on the day(s) of interest and zero otherwise). The day zero dummy, for example, takes the value of 1 on the day of the merger announcement (day 0 ) and zero otherwise. The coefficients reported are those associated with the merger day dummies. Coefficients for the other variables are excluded from the table for brevity. (z-statistics are in parentheses.)

\begin{tabular}{|c|c|c|c|c|c|c|}
\hline & Day 0 & Day $[-1,+1]$ & Day $[0,2]$ & Day $[-2,+2]$ & Day $[-5,+5]$ & $\begin{array}{c}\text { Day [- } \\
10,+10]\end{array}$ \\
\hline \multirow[t]{2}{*}{ Combined Firms } & 0.0127 & 0.0065 & 0.0061 & 0.0024 & -0.0002 & -0.0003 \\
\hline & $(2.41)^{* *}$ & $(2.11)^{* *}$ & $(1.98)^{* *}$ & $(1.01)$ & $(-0.14)$ & $(-0.22)$ \\
\hline \multirow[t]{2}{*}{ Targets } & 0.0304 & 0.0177 & 0.0152 & 0.0075 & 0.0000 & -0.0015 \\
\hline & $(1.99)^{* *}$ & $(1.99)^{* *}$ & $(1.70)^{*}$ & $(1.07)$ & $(-0.01)$ & $(-0.40)$ \\
\hline \multirow[t]{2}{*}{ Bidders } & -0.0044 & -0.0050 & -0.0029 & -0.0037 & -0.0024 & -0.0015 \\
\hline & $(-0.89)$ & $(-1.75)^{*}$ & $(-0.99)$ & $(-1.65)^{*}$ & $(-1.53)$ & $(-1.24)$ \\
\hline \multirow[t]{2}{*}{ All Competitors } & 0.0054 & 0.0015 & 0.0152 & 0.0084 & 0.0011 & 0.0005 \\
\hline & $(0.98)$ & $(0.48)$ & $(4.81)^{* * *}$ & $(3.41)^{* * *}$ & $(0.65)$ & $(0.35)$ \\
\hline \multirow[t]{2}{*}{ Developed Competitors } & 0.0076 & 0.0012 & 0.0197 & 0.0106 & 0.0021 & 0.0016 \\
\hline & $(1.12)$ & $(0.30)$ & $(5.08)^{* * *}$ & $(3.49)^{* * *}$ & $(1.01)$ & $(0.98)$ \\
\hline \multirow[t]{2}{*}{ Emerging Competitors } & -0.0008 & 0.0026 & 0.0026 & 0.0024 & -0.0003 & -0.0007 \\
\hline & $(-0.12)$ & $(0.67)$ & $(0.68)$ & $(0.81)$ & $(-0.16)$ & $(-0.44)$ \\
\hline \multirow[t]{2}{*}{ Asia - Pacific Competitors } & 0.0019 & 0.0027 & 0.0027 & 0.0015 & -0.0019 & -0.0004 \\
\hline & $(0.55)$ & $(1.30)$ & $(1.32)$ & $(0.92)$ & $(-1.69)^{*}$ & $(-0.41)$ \\
\hline \multirow[t]{2}{*}{ Europe Competitors } & 0.0231 & 0.0052 & 0.0076 & 0.0034 & 0.0018 & 0.0005 \\
\hline & $(3.87)^{* * *}$ & $(1.50)$ & $(2.18)^{* *}$ & $(1.24)$ & $(0.96)$ & $(0.33)$ \\
\hline \multirow[t]{2}{*}{ North America Competitors } & 0.0076 & -0.0030 & 0.0560 & 0.0291 & 0.0094 & 0.0037 \\
\hline & $(0.37)$ & $(-0.26)$ & $(4.75)^{* * *}$ & $(3.14)^{* * *}$ & $(1.46)$ & $(0.75)$ \\
\hline \multirow[t]{2}{*}{$\begin{array}{l}\text { Asia - Pacific - Developed } \\
\text { Competitors }\end{array}$} & 0.0014 & 0.0020 & 0.0022 & 0.0015 & -0.0024 & -0.0001 \\
\hline & $(0.36)$ & $(0.87)$ & $(0.95)$ & $(0.81)$ & $(-1.94 *)$ & $(-0.09)$ \\
\hline \multirow[t]{2}{*}{$\begin{array}{l}\text { Asia - Pacific - Emerging } \\
\text { Competitors }\end{array}$} & 0.0027 & 0.0039 & 0.0044 & 0.0013 & -0.0001 & -0.0003 \\
\hline & $(0.37)$ & $(0.92)$ & $(1.05)$ & $(0.40)$ & $(-0.05)$ & $(-0.17)$ \\
\hline \multirow[t]{2}{*}{ All Exchanges } & 0.0094 & 0.0046 & 0.0125 & 0.0069 & 0.0015 & 0.0012 \\
\hline & $(2.35)^{* *}$ & $(1.96)^{* *}$ & $(5.44)^{* * *}$ & $(3.83)^{* * *}$ & $(1.21)$ & $(1.23)$ \\
\hline
\end{tabular}


For all the rival exchanges as a group, the mergers together were beneficial. The day $[0,+2]$ abnormal return of $1.5 \%$ and the day $[-2,+2]$ abnormal return of $0.8 \%$ were significantly positive at the $1 \%$ level of significance. This finding of significantly positive abnormal returns for rivals is consistent with other mergers and acquisitions studies which have documented significant positive abnormal returns for rivals of merging firms (see for example Eckbo, 1983; Song and Walkling, 2000, etc.). Further analysis of the data shows that the abnormal returns resulting from the six stock exchange mergers were (i) significantly positive for European competitors $(2.3 \%$ and $0.8 \%$ over the day 0 and day $[0,+2]$ windows respectively); and, (ii) significantly positive for North American rivals (abnormal returns of respectively $5.6 \%$ and $2.9 \%$ over the day $[0,+2]$ and day [$2,+2]$ windows). The mergers also resulted in significantly positive stock price reactions for competitors from developed countries, with the abnormal returns being a significant $2 \%$ over the day $[0,+2]$ window and a significant $1.1 \%$ over the day $[-2,+2]$ window. Since the six mergers mostly involved European and North American exchanges and can be regarded as mergers among exchanges from developed countries, the positive reaction by shareholders of rivals from developed markets and rivals from North America and Europe signify that geographical nearness and similarities in the stage of development play important roles in the markets' perception of benefits to be derived from stock exchange mergers. We conclude from this that the level of development and geographical proximity play important roles in the stock exchange industry.

Except for the weakly significant (10\% level) negative abnormal returns over the day [$5,+5]$ window, the combined effect of all the mergers on Asia Pacific rivals were 
indistinguishable, statistically, from zero. Further breakdown of Asia Pacific competitors into rivals from emerging countries and rivals from developed countries showed that this weakly significant negative abnormal returns for Asia Pacific rivals is largely driven by a weakly significant ( $10 \%$ level of significance) negative abnormal returns of $0.2 \%$ over the day $[-5,+5]$ window for Asia Pacific competitors from developed countries. Our interpretation of this negative stock price reaction of Asia Pacific competitors from developed countries is that the markets probably didn't perceive these competitors as positioning themselves for future merger activities, or alternatively, investors believe that these exchanges will lose market share or order flow to the merged exchanges. Finally, the markets viewed all the six mergers in a positive light and the stock prices of the portfolio of all stock exchanges in our sample reacted positively over the day 0 , day [$1,+1]$, day $[0,+2]$ and day $[-2,+2]$ windows. The abnormal returns over these windows ranged from $0.5 \%$ (day $[-1,+1])$ to $1.3 \%$ (day $[0,+2])$, with the significance of these abnormal returns ranging from the $1 \%$ level $($ day $[0,+2]$ and day $[-2,+2])$ to the $5 \%$ level (day 0 and day $[-1,+1])$.

Overall, the results of our stock market analyses show that the six stock exchange mergers have led to significant wealth creation for shareholders of targets and shareholders of the combined firms. These findings support the various hypotheses we advanced on the stock market performance of the mergers. The results are also consistent with the general mergers and acquisitions literature where it has been consistently documented that target shareholders gain and shareholders of bidders realize returns that range from losses to gains. With respect to competitors, our results demonstrate that the 
stock price reaction of rivals of the merging firms is not uniform. In particular, shareholders of competitors from Europe and North America as well as shareholders of competitors from developed countries realized significantly positive abnormal returns suggesting that despite the several arguments about the "death of distance", geographical nearness is a key consideration in the stock exchange industry. It should also be noted that while we had argued that shareholders of rivals will earn negative abnormal returns because the competitive disadvantages that the rivals will face by competing with better resourced combined firms will dominate any positive informational effects that the mergers will signal to the markets, the markets appear to have thought otherwise and rewarded the shareholders of (some) rivals with significantly positive abnormal returns around the merger announcements - probably inferring that the mergers signal better future industry growth prospects and/or more future merger activities in the industry.

Also, our results show that the abnormal returns center around day zero (i.e. announcement dates) and are realized over shorter periods surrounding the announcement dates. Thus, the longer the event window, the weaker the abnormal returns. This swift response to the mergers and the immediacy with which the new information about the mergers are impounded into stock prices lend support to market efficiency. In addition, the absence of significant abnormal returns leading up to and following the merger announcements (day $[-5,+5]$; day $[-10,+10])$ demonstrate that there was no information leakage about the mergers prior to the various announcements. 


\subsubsection{Individual Merger Analysis}

\subsection{Stock Market Performance of Merging Companies}

Among the stylized facts that have emerged from the extant mergers and acquisitions

literature include evidence that shareholders of targets realize significantly positive

abnormal returns while the wealth effects for shareholders of bidders is mixed

(Martynova and Renneboog, 2008). As Table 2.4 also demonstrates, the stock market

results of the six stock exchange mergers appear to be in conformity, in general, to the

existing evidence on mergers and acquisitions.

\section{Table 2.4 - Stock Market Performance of Merging Companies}

\begin{tabular}{|c|c|c|c|c|c|c|c|}
\hline & All Mergers & $\begin{array}{c}\text { NYSE- } \\
\text { Archipelago }\end{array}$ & $\begin{array}{c}\text { NYSE- } \\
\text { Euronext }\end{array}$ & $\begin{array}{l}\text { CME- } \\
\text { CBOT }\end{array}$ & DB-ISE & $\begin{array}{l}\text { NASDAQ- } \\
\text { OMX }\end{array}$ & LSE-BI \\
\hline \multicolumn{8}{|l|}{ Panel A: Day 0} \\
\hline \multirow[t]{2}{*}{ Combined Firm(s) } & 0.0127 & 0.1335 & -0.0385 & 0.0832 & 0.2362 & 0.0356 & -0.0151 \\
\hline & $(2.41)^{* *}$ & $(3.41)^{* * *}$ & $(-2.13)^{* *}$ & $(2.96)^{* * *}$ & $(10.86)^{* * *}$ & $(2.16)^{* *}$ & $(-1.00)$ \\
\hline \multirow[t]{2}{*}{ Target(s) } & 0.0304 & 0.1335 & -0.0672 & 0.1412 & 0.4658 & 0.1030 & - \\
\hline & $(1.99)^{* *}$ & $(3.41)^{* * *}$ & $(-4.08)^{* * *}$ & $(2.64)^{* * *}$ & $(11.71)^{* * *}$ & $(5.67)^{* * *}$ & - \\
\hline \multirow[t]{2}{*}{ Bidder(s) } & -0.0044 & - & -0.0196 & 0.0295 & 0.0046 & -0.0414 & -0.0151 \\
\hline & $(-0.89)$ & - & $(-0.71)$ & $(1.92)^{*}$ & -0.29 & $(-1.87)^{*}$ & $(-1.00)$ \\
\hline \multicolumn{8}{|l|}{ Panel B: Day $[-2,+2]$} \\
\hline \multirow[t]{2}{*}{ Combined Firm(s) } & 0.0024 & 0.1383 & -0.0131 & 0.0137 & 0.0349 & 0.0177 & -0.0023 \\
\hline & $(1.01)$ & $(8.34)^{* * *}$ & $(-1.63)$ & -1.07 & $(3.23)^{* * *}$ & $(2.39)^{* *}$ & $(-0.34)$ \\
\hline \multirow[t]{2}{*}{ Target(s) } & 0.0075 & 0.1383 & 0.0026 & 0.0304 & 0.0837 & 0.0363 & - \\
\hline & $(1.07)$ & $(8.34)^{* * *}$ & $(0.35)$ & $(1.26)$ & $(4.15)^{* * *}$ & $(4.39)^{* * *}$ & - \\
\hline \multirow[t]{2}{*}{ Bidder(s) } & -0.0037 & - & -0.0294 & -0.0019 & -0.0135 & -0.0053 & -0.0023 \\
\hline & $(-1.65)^{*}$ & - & $(-2.36)^{* *}$ & $(-0.28)$ & $(-1.86)^{*}$ & $(-0.53)$ & $(-0.34)$ \\
\hline
\end{tabular}

$* * *, * *$ and $*$ indicate statistical significance at the $1 \%, 5 \%$ and $10 \%$ levels, respectively 
Except for the NYSE-Euronext merger, the day zero abnormal returns (Panel A) for targets are significantly positive at conventional levels of significance ( $1 \%$ level). The positive day zero abnormal returns range from a significant $10.3 \%$ (for the NASDAQOMX merger) to a significant $46.6 \%$ (for the Deutsche Boerse-ISE merger).

Bucking the trend, however, is the NYSE-Euronext merger which resulted in a significantly negative abnormal return of $6.7 \%$ for the target (Euronext in this case). Given that this negative reaction to the target by the market is inconsistent with our expectations and the impact of the other mergers, we conjecture that the market was perhaps doubtful that the NYSE Euronext merger will succeed - probably leaning toward the possibility that regulators were likely going to gut a merger that will create a behemoth in the stock exchange industry. As Kokkoris and Olivares-Caminal (2008) noted, if a merger breaches competition laws, the whole merger might not take place. This uncertainty was aggravated by the fact that there was negative press and opposition from European politicians and financiers. For example, when the merger announcement was made, the then French president Jacques Chirac and German chancellor Angela Merkel both noted that they preferred that Euronext links up with Deutsche Boerse instead of the New York Stock Exchange. The impact of media coverage on stock prices has been empirically documented by a number of authors including Tetlock (2007), Solomon (2012), Solomon et al. (2014) and Ahern and Sosyura (2014) - who demonstrate that media coverage (negative or positive) impacts stock prices (in a negative or positive way). Tetlock (2007) for example shows that high media pessimism is associated with downward pressure on market prices while Solomon (2012) shows that 
investor relations firms spin their clients' news by creating more positive media coverage of a company's good news relative to its bad news - and this leads to a temporary increase in stock returns. Solomon et al. (2014) also report that media coverage significantly affects mutual funds investors' capital allocation and Ahern and Sosyura (2014) establish that firms actively manage their media coverage during M\&A negotiations by reducing the number of negative news - and that this is correlated with significant run-up in stock prices (and subsequent reversal in the post-negotiation period). Therefore, the negative media coverage emanating from the opposition by European politicians and financiers, together with the markets' doubts about the merger's approval and the markets' possible perception of potential challenges in integrating and managing such a large exchange (even if the merger is approved) - potentially heightened the uncertainty surrounding the successful consummation of the NYSE-Euronext merger. We argue that this increased uncertainty probably got factored into the markets' reaction, especially since there does not appear to be any confounding news around the NYSEEuronext merger announcement date.

Also, results of the five-day window around the merger announcement from day -2 to day +2 reported in Panel B of Table 2.4 are generally similar to the day zero results. Targets in the NYSE-Archipelago merger, NASDAQ-OMX merger and the Deutsche Boerse-ISE merger earned positive abnormal returns that are statistically (and economically) significant at the $1 \%$ level. Targets in the NYSE-Euronext merger and CME-CBOT merger realized positive but insignificant abnormal returns. 
The results in Table 2.4 for bidders are mixed, however. The day zero results in panel A show that the stock price of the bidder (CME) in the CME-CBOT merger reacted positively (at the $10 \%$ level of significance) but the stock price of the bidder (NASDAQ) in the NASDAQ-OMX merger reacted negatively (at the 10\% level of significance) on the announcement day. The stock price reactions of bidders in the NYSE-Euronext merger, LSE-BI merger and the Deutsche Boerse-ISE merger were statistically indistinguishable from zero. Over the 5-day period surrounding the merger, the stock price reactions (as demonstrated in panel B of Table 2.4) were negative for bidders in the NYSE-Euronext merger (at the 5\% level of significance) and the Deutsche Boerse-ISE merger (at the $10 \%$ level of significance). While our results for bidders are similar to findings in other studies, a number of authors have cautioned against a deep read into the typical zero or negative stock price reactions of bidders. Fuller et al. (2002) note that (i) targets may be small relative to bidders and so even good acquisitions may have little impacts on the bidder; and, (ii) stock price reaction can only represent the surprise component and if the bidder is engaged in an acquisition strategy, there may be no reaction.

In view of the potential challenges in looking at bidder results in isolation when gauging the success of a merger, we also report (in Table 2.4) the stock price reactions of the combined firms. If the markets' perception of a merger is positive, we would expect that the stock price reactions of the combined firm will be positive and if the markets' perception of a merger is negative, then we would expect the stock price of the combined firm to react negatively. Panel A of Table 2.4 shows that the stock prices of the combined 
firms generally reacted positively to the mergers on day zero. The CME-CBOT and Deutsche Boerse-ISE mergers elicited statistically significant positive abnormal returns (at the $1 \%$ level) while the NASDAQ-OMX merger resulted in a significantly positive stock price reaction at the 5\% level of significance. The NYSE-Euronext merger, however, produced a statistically significant negative abnormal return (at the $5 \%$ level) on the announcement date. Over the day -2 to day +2 period, the Deutsche Boerse-ISE merger and NASDAQ-OMX merger resulted in significantly positive abnormal returns to shareholders of the combined firms (at the 1\% level and 5\% level respectively).

All in all, the six stock exchange mergers that we studied generated significant abnormal returns for shareholders of targets and for shareholders of the combined firms. There has been a lot of discussion on the impact of mergers on rivals in the M\&A literature. We next review the stock market performance of competitors.

\subsection{Stock Market Reaction of Competitors to the Merger Announcements}

It has been variously documented that rivals of target firms realize abnormal returns on the announcement of mergers (e.g. Song and Walkling, 2000). We examined the effect of each of the six mergers on rivals and our results are presented in Table 2.5. 


\section{Table 2.5 - Stock Market Performance of Competitors/Rivals}

This table presents the stock price performance of the rival firms on day 0 (Panel A) and day $[-2,+2]$ (Panel B) for all the mergers combined and the six mergers individually. The results are derived from seemingly unrelated regressions of stock returns on market returns, relative size, book-to-market, GDP per capita and merger day dummies (which take the value of 1 on the day(s) of interest and zero otherwise) - using data from day -250 to day +250 . The day zero dummy, for example, takes the value of 1 on the day of the merger announcement (day 0 ) and zero otherwise. The coefficients reported are those associated with the merger day dummies. Coefficients for the other variables are excluded from the table for brevity. (z-statistics are in parentheses.)

\begin{tabular}{|c|c|c|c|c|c|c|c|}
\hline & $\begin{array}{c}\text { All } \\
\text { Mergers } \\
\end{array}$ & $\begin{array}{c}\text { NYSE- } \\
\text { Archipelago }\end{array}$ & $\begin{array}{c}\text { NYSE- } \\
\text { Euronext }\end{array}$ & $\begin{array}{l}\text { CME- } \\
\text { CBOT } \\
\end{array}$ & DB-ISE & $\begin{array}{l}\text { NASDAQ- } \\
\text { OMX }\end{array}$ & LSE-BI \\
\hline \multicolumn{8}{|l|}{ Panel A: Day 0} \\
\hline \multirow[t]{2}{*}{ All Competitors } & 0.0054 & 0.0038 & -0.0186 & 0.0107 & 0.0028 & 0.0143 & 0.0092 \\
\hline & $(0.98)$ & $(0.51)$ & $(-1.45)$ & $(0.84)$ & $(0.23)$ & $(1.18)$ & $(0.73)$ \\
\hline \multirow[t]{2}{*}{ Developed Competitors } & 0.0076 & 0.0060 & -0.0185 & 0.0112 & 0.0028 & 0.0173 & 0.0043 \\
\hline & $(1.12)$ & $(0.73)$ & $(-1.29)$ & $(0.76)$ & $(0.20)$ & $(1.23)$ & $(0.30)$ \\
\hline \multirow[t]{2}{*}{ Emerging Competitors } & -0.0008 & -0.0006 & -0.0310 & 0.0016 & 0.0011 & -0.0042 & 0.0373 \\
\hline & $(-0.12)$ & $(-0.03)$ & $(-1.91)^{*}$ & $(0.11)$ & $(0.08)$ & -0.31 & $(2.71)^{* * *}$ \\
\hline \multirow[t]{2}{*}{ Asia - Pacific Competitors } & 0.0019 & -0.0004 & -0.0191 & 0.0013 & 0.0029 & 0.0072 & 0.0200 \\
\hline & $(0.55)$ & $(-0.06)$ & $(-2.17)^{* *}$ & $(0.14)$ & $(0.31)$ & 0.79 & $(2.24)^{* *}$ \\
\hline \multirow[t]{2}{*}{ Europe Competitors } & 0.0231 & 0.0201 & -0.0171 & 0.0057 & 0.0007 & 0.0228 & -0.0090 \\
\hline & $(3.87)^{* * *}$ & $(2.39)^{* *}$ & $(-1.63)$ & $(0.54)$ & $(0.07)$ & $2.41 * *$ & $(-1.02)$ \\
\hline \multirow[t]{2}{*}{ North America Competitors } & 0.0076 & -0.0048 & -0.0298 & 0.0214 & 0.0054 & 0.0156 & 0.0123 \\
\hline & $(0.37)$ & $(-0.21)$ & $(-0.97)$ & $(0.57)$ & $(0.17)$ & 0.49 & $(0.40)$ \\
\hline \multirow[t]{2}{*}{$\begin{array}{l}\text { Asia - Pacific - Developed } \\
\text { Competitors }\end{array}$} & 0.0014 & 0.0012 & -0.0161 & -0.0007 & 0.0019 & 0.0150 & 0.0036 \\
\hline & $(0.36)$ & $(0.15)$ & $(-1.59)$ & $(-0.06)$ & $(0.18)$ & 1.50 & $(0.37)$ \\
\hline \multirow[t]{2}{*}{$\begin{array}{l}\text { Asia - Pacific - Emerging } \\
\text { Competitors }\end{array}$} & 0.0027 & -0.0005 & -0.0311 & 0.0017 & 0.0029 & -0.0134 & 0.0624 \\
\hline & $(0.37)$ & $(-0.03)$ & $(-1.91)^{*}$ & $(0.10)$ & $(0.16)$ & -0.76 & $(3.45)^{* * *}$ \\
\hline \multirow[t]{2}{*}{ All Exchanges } & 0.0094 & 0.0095 & -0.0200 & 0.0169 & 0.0232 & 0.0150 & 0.0073 \\
\hline & $(2.35)^{* *}$ & (1.33) & $(-1.67)^{*}$ & (1.39) & $(2.02)^{* *}$ & $(1.31)$ & $(0.64)$ \\
\hline \multicolumn{8}{|l|}{ Panel B: Day $[-2,+2]$} \\
\hline \multirow[t]{2}{*}{ All Competitors } & 0.0084 & 0.0019 & -0.0054 & 0.0304 & -0.0021 & 0.0013 & 0.0023 \\
\hline & $(3.41)^{* * *}$ & $(0.56)$ & $(-0.94)$ & $(5.38)^{* * *}$ & $(-0.38)$ & 0.24 & $(0.40)$ \\
\hline \multirow[t]{2}{*}{ Developed Competitors } & 0.0106 & 0.0025 & -0.0064 & 0.0347 & -0.0020 & 0.0004 & 0.0000 \\
\hline & $(3.49)^{* * *}$ & $(0.67)$ & $(-1.00)$ & $(5.37)^{* * *}$ & $(-0.31)$ & 0.07 & $(0.01)$ \\
\hline \multirow[t]{2}{*}{ Emerging Competitors } & 0.0024 & 0.0022 & -0.0064 & 0.0017 & -0.0028 & 0.0056 & 0.0160 \\
\hline & $(0.81)$ & $(0.30)$ & $(-0.86)$ & $(0.25)$ & $(-0.45)$ & 0.92 & $(2.58)^{* * *}$ \\
\hline \multirow[t]{2}{*}{ Asia - Pacific Competitors } & 0.0015 & -0.0006 & -0.0005 & 0.0023 & -0.0035 & -0.0007 & 0.0098 \\
\hline & $(0.92)$ & $(-0.18)$ & $(-0.13)$ & $(0.53)$ & $(-0.83)$ & -0.17 & $(2.42)^{* *}$ \\
\hline \multirow[t]{2}{*}{ Europe Competitors } & 0.0034 & 0.0019 & -0.0048 & -0.0026 & 0.0010 & 0.0051 & -0.0028 \\
\hline & $(1.24)$ & $(0.50)$ & $(-1.03)$ & $(-0.55)$ & $(0.23)$ & 1.18 & $(-0.70)$ \\
\hline \multirow[t]{2}{*}{ North America Competitors } & 0.0291 & 0.0065 & -0.0135 & 0.0965 & -0.0053 & -0.0030 & -0.0016 \\
\hline & $(3.14)^{* * *}$ & $(0.63)$ & $(-0.97)$ & $(5.84)^{* * *}$ & $(-0.37)$ & -0.21 & $(-0.12)$ \\
\hline
\end{tabular}




\begin{tabular}{|c|c|c|c|c|c|c|c|}
\hline & $\begin{array}{c}\text { All } \\
\text { Mergers }\end{array}$ & $\begin{array}{c}\text { NYSE- } \\
\text { Archipelago }\end{array}$ & $\begin{array}{l}\text { NYSE- } \\
\text { Euronext }\end{array}$ & $\begin{array}{l}\text { CME- } \\
\text { CBOT }\end{array}$ & DB-ISE & $\begin{array}{l}\text { NASDAQ- } \\
\text { OMX }\end{array}$ & LSE-BI \\
\hline \multirow[t]{2}{*}{$\begin{array}{l}\text { Asia - Pacific - Developed } \\
\text { Competitors }\end{array}$} & 0.0015 & -0.0013 & -0.0004 & 0.0030 & -0.0010 & -0.0004 & 0.0039 \\
\hline & $(0.81)$ & $(-0.38)$ & $(-0.10)$ & $(0.63)$ & $(-0.22)$ & -0.08 & $(0.89)$ \\
\hline $\begin{array}{l}\text { Asia - Pacific - Emerging } \\
\text { Competitors }\end{array}$ & 0.0013 & 0.0023 & -0.0066 & 0.0007 & -0.0100 & -0.0016 & 0.0239 \\
\hline \multirow[t]{2}{*}{ All Exchanges } & 0.0069 & 0.0083 & -0.0058 & 0.0287 & 0.0004 & 0.0016 & 0.0012 \\
\hline & $(3.83)^{* * *}$ & $(2.60)^{* * *}$ & $(-1.08)$ & $(5.35)^{* * *}$ & (0.09) & 0.31 & $(0.24)$ \\
\hline
\end{tabular}

Given the small sample size, we decided to maximize the data used by including all rivals for which we could get stock price data. We then formed various portfolios including a portfolio of the merging firms versus all rival exchanges. We further formed portfolios of competitors based on their geography (North America, Europe, Africa - Middle East, Asia Pacific and Latin America), development stage of their country of origin (developed and emerging) and an intersection of development stage and geography - subject to data availability (e.g. Asia Pacific Developed Competitors).

The results in Table 2.5 demonstrate that the stock price reaction of the rival exchanges is mixed. While there was positive stock price reaction for some of the competitors, others experienced negative stock price reactions and yet others did not experience any stock price reaction significantly different from zero. For day zero (panel A), the stock prices of European competitors reacted positively to the NYSE-Archipelago and NASDAQ-OMX mergers ( $5 \%$ level of significance). The LSE-BI merger also led to stock prices of Asia Pacific rivals reacting positively (at the 5\% level). A further analysis shows that this was largely attributed to the positive stock price reaction of emerging exchanges in the Asia Pacific region. All emerging markets rivals also reacted positively to the LSE-BI merger (at the conventional 5\% level of significance). On the other hand, emerging markets 
rivals' and Asia Pacific competitors' (specifically emerging markets rivals within Asia Pacific) stock price reactions to the NYSE-Euronext merger were mostly negative (respectively 5\% and 10\% levels of significance). For all exchanges (merging as well as non-merging exchanges), the day zero stock price reaction to the Deutsche Boerse-ISE merger was positive (at the 5\% level) but negative for the NYSE-Euronext merger (at the $10 \%$ level).

Results of rivals' stock price reactions over the 5-day period from day -2 to day +2 are presented in panel B of Table 2.5. Stock price reactions over this window are either significantly positive or indistinguishable from zero. For the CME-CBOT merger, stock price reactions were significantly positive (at the $1 \%$ level) for all competitors, North American competitors, competitors in developed countries as well as all exchanges. The LSE-BI merger also resulted in significantly positive stock price reaction for competitors in Asia Pacific (5\% level) and competitors in all developing countries as well as developing countries in Asia Pacific (1\% level of significance). The NYSE-Archipelago merger also led to positive stock price reaction for all exchanges (at the $1 \%$ level). Despite the range of the markets' reactions to competitors, the results generally lean towards zero to positive reactions for rivals.

\subsubsection{Effects of Control Variables}

While we have not reported the significance of control variables in Table 2.3 to Table 2.5 for brevity, it should be noted that the control variables we included in our regression models were also mostly statistically significant and in line with expectations. To 
illustrate this fact, we present, in Table 2.6, the day $[-2,+2]$ results (for all the mergers combined) for all variables in the regression models (including the control variables).

\section{Table 2.6 - Combined Mergers Regression Results with Control Variables}

Using the pooled data of all the mergers, this table reports the results of all the variables in our regression models based on the day [$2,+2]$ event window. The results are derived from seemingly unrelated regressions using data that starts 250 days before the earliest merger announcement date (on April 20, 2005) and ends 250 days after the last merger announcement date (on June 20, 2007). Stock returns are regressed on market returns, relative size, book-to-market, GDP per capita and merger day dummies (which take the value of 1 on the day(s) of interest and zero otherwise). The day $[-2,+2]$ dummy takes the value of 1 on the five-day window surrounding the merger announcements dates and zero otherwise. (z-statistics are in parentheses.)

\begin{tabular}{|c|c|c|c|c|c|c|c|c|}
\hline & Market Return & $\begin{array}{l}\text { Relative } \\
\text { Size }\end{array}$ & $\begin{array}{l}\text { Growth (Book- } \\
\text { to-Market) }\end{array}$ & $\begin{array}{l}\text { GDP per } \\
\text { Capita }\end{array}$ & $\begin{array}{l}\text { Day }[-2,+2] \\
\text { Dummy }\end{array}$ & Constant & $\mathrm{N}$ & $\mathrm{R}^{2}$ \\
\hline \multirow[t]{2}{*}{ Combined Firms } & 1.0745 & 0.0000 & -0.0287 & 0.0000 & 0.0024 & 0.0292 & \multirow{2}{*}{1,066} & \multirow[t]{2}{*}{0.3224} \\
\hline & $(20.46)^{* * *}$ & $(0.19)$ & $(-8.45)^{* * *}$ & $(-4.30) * * *$ & $(1.01)$ & $(5.58)^{* * *}$ & & \\
\hline \multirow[t]{2}{*}{ Targets } & 0.6261 & 0.0014 & -0.0449 & 0.0000 & 0.0075 & -0.0117 & \multirow{2}{*}{1,056} & \multirow[t]{2}{*}{0.0372} \\
\hline & $(4.67)^{* * *}$ & $(3.17)^{* * *}$ & $(-7.77)^{* * *}$ & $(2.83)^{* * *}$ & $(1.07)$ & $(-1.46)$ & & \\
\hline \multirow[t]{2}{*}{ Bidders } & 1.2643 & 0.0000 & -0.0108 & 0.0000 & -0.0037 & 0.0048 & \multirow{2}{*}{1,056} & \multirow[t]{2}{*}{0.0121} \\
\hline & $(25.13 * * *)$ & $(1.75)^{*}$ & $(-2.64)^{* * *}$ & $(-0.18)$ & $(-1.65)^{*}$ & $(0.91)$ & & \\
\hline \multirow[t]{2}{*}{ All Competitors } & 1.3121 & -0.0001 & -0.0009 & 0.0000 & 0.0084 & -0.0036 & \multirow[t]{2}{*}{1,066} & \multirow[t]{2}{*}{0.2772} \\
\hline & $(19.71)^{* * *}$ & $(-0.95)$ & $(-1.61)$ & $(0.75)$ & $(3.41)^{* * *}$ & $(-0.55)$ & & \\
\hline \multirow[t]{2}{*}{ Developed Competitors } & 1.3026 & 0.0008 & -0.0036 & 0.0000 & 0.0106 & 0.0020 & \multirow{2}{*}{1,066} & \multirow[t]{2}{*}{0.2102} \\
\hline & $(16.19)^{* * *}$ & $(2.03)^{* *}$ & $(-1.40)$ & $(-0.32)$ & $(3.49)^{* * *}$ & $(0.33)$ & & \\
\hline \multirow[t]{2}{*}{ Emerging Competitors } & 0.8287 & -0.0001 & -0.0003 & 0.0000 & 0.0024 & 0.0004 & \multirow{2}{*}{1,066} & \multirow[t]{2}{*}{0.1818} \\
\hline & $(15.09)^{* * *}$ & $(-2.17)^{* *}$ & $(-1.50)$ & $(1.03)$ & $(0.81)$ & $(0.30)$ & & \\
\hline \multirow[t]{2}{*}{ Asia - Pacific Competitors } & 1.2923 & 0.0004 & -0.0035 & 0.0000 & 0.0015 & 0.0110 & \multirow{2}{*}{1,066} & \multirow[t]{2}{*}{0.5747} \\
\hline & $(37.32)^{* * *}$ & $(1.75)^{*}$ & $(-3.08) * * *$ & $(-2.41)^{* *}$ & $(0.92)$ & $(2.62)^{* * *}$ & & \\
\hline \multirow[t]{2}{*}{ Europe Competitors } & 1.0335 & 0.0015 & -0.0055 & 0.0000 & 0.0034 & 0.0080 & \multirow{2}{*}{1,066} & \multirow[t]{2}{*}{0.3585} \\
\hline & $(23.92)^{* * *}$ & $(2.10)^{* *}$ & $(-2.51)^{* *}$ & $(-1.91)^{*}$ & $(1.24)$ & $(1.83)^{*}$ & & \\
\hline \multirow[t]{2}{*}{$\begin{array}{l}\text { North America } \\
\text { Competitors }\end{array}$} & 0.9878 & 0.0024 & -0.1715 & 0.0000 & 0.0291 & 0.0118 & \multirow[t]{2}{*}{1,066} & \multirow[t]{2}{*}{0.0371} \\
\hline & $(4.91)^{* * *}$ & (1.47) & $(-2.18)^{* *}$ & $(0.30)$ & $(3.14)^{* * *}$ & $(0.68)$ & & \\
\hline \multirow[t]{2}{*}{ All Exchanges } & 1.2230 & 0.0001 & -0.0012 & 0.0000 & 0.0069 & 0.0031 & \multirow{2}{*}{1,066} & \multirow[t]{2}{*}{0.3822} \\
\hline & $(25.03)^{* * *}$ & $(3.65)^{* * *}$ & $(-1.95)^{*}$ & $(-0.51)$ & $(3.83) * * *$ & $(0.63)$ & & \\
\hline
\end{tabular}

As evident from Table 2.6, the market return variable is significantly positive for every portfolio (as expected). The relative size variable is also significantly positive in most cases, indicating that the markets believe that rivals which are relatively big are better positioned to effectively compete with the merging entities. As a result, the stock prices of relatively big exchanges reacted positively. The only exception is the negative 
coefficient for the relative size variable for exchanges from developing countries. We conjecture that this negative coefficient is due to the markets' expectations that big exchanges in emerging markets will suffer from the mergers (since they may not be able to engage in merger activities). The coefficients of the book-to-market variable (our proxy for growth) are mostly negatively significant as expected. This shows that the markets expect exchanges with high growth prospects to thrive; and as a result, rewarded them. The significance of the event window dummies, in addition to the significance of the control variables, show that our regression models are robust and capture the effects of these mergers.

\subsubsection{Product Market Effects of Mergers}

The synergy effect is an often cited reason for mergers and acquisitions. If the six stock exchange mergers resulted in significant synergies, then our expectation is that it will reflect in the product market performance of the merging exchanges. To test this hypothesis, we analyzed the market share of stock exchanges using event time analysis. The event time analysis of market share involved analyzing the six mergers in event time by regressing market share over a linear time trend (following Arnold et al. 1999), a merger completion dummy variable (which takes the value of 1 in the 48 months after the merger completion and zero in the 36 months prior to the completion of the merger) and a number of other control variables. Table 2.7 presents the results of the event time market share analysis. 


\section{Table 2.7 - Event Time Market Share Results}

This table presents seemingly unrelated regression analysis of the six mergers (individually and combined) where the market share is regressed on the merger dummy, a linear time trend, log revenues, domestic market capitalization, synergy and GDP per capita. The merger dummy takes the value of one after the merger completion and zero otherwise. The data is seven years of monthly data starting 3 years before each merger completion and ending four years after each merger completion. Value of share trading (in USD) is downloaded from the World Federation of Exchanges website and used to calculate the market share of each stock exchange, which are then averaged into the relevant portfolios we analyze in this study. The coefficients reported for the individual mergers are those associated with the merger dummy. For all the mergers combined, we report the merger dummy coefficient and the synergy coefficient. The other coefficients are excluded from the table for brevity. (z-statistics are in parentheses.)

\begin{tabular}{|c|c|c|c|c|c|c|c|c|}
\hline \multicolumn{9}{|c|}{ All Mergers } \\
\hline Portfolio & $\begin{array}{l}\text { Merger } \\
\text { Dummy }\end{array}$ & Synergy & $\begin{array}{c}\text { NYSE- } \\
\text { Archipelago }\end{array}$ & $\begin{array}{c}\text { NYSE- } \\
\text { Euronext }\end{array}$ & $\begin{array}{l}\text { CME- } \\
\text { CBOT } \\
\end{array}$ & DB-ISE & $\begin{array}{l}\text { NASDAQ- } \\
\text { OMX }\end{array}$ & LSE-BI \\
\hline $\begin{array}{l}\text { All Merging } \\
\text { Firms }\end{array}$ & 0.0085 & 0.0064 & 0.0103 & 0.0048 & 0.0098 & 0.0075 & 0.0040 & 0.0083 \\
\hline & $(5.40)^{* * *}$ & $(1.56)$ & $(3.37)^{* * *}$ & $(1.17)$ & $(1.93)^{*}$ & $(1.52)$ & $(0.85)$ & $(1.92)^{*}$ \\
\hline All Competitors & $\begin{array}{c}-0.0011 \\
(-7.01)^{* * *}\end{array}$ & $\begin{array}{c}-0.0011 \\
(-2.71)^{* * *}\end{array}$ & $\begin{array}{c}-0.0013 \\
(-5.11)^{* * *}\end{array}$ & $\begin{array}{l}-0.0007 \\
(-1.69)^{*}\end{array}$ & $\begin{array}{c}-0.0013 \\
(-2.73)^{* * *}\end{array}$ & $\begin{array}{l}-0.0011 \\
(-1.83)^{*}\end{array}$ & $\begin{array}{l}-0.0005 \\
(-1.08)\end{array}$ & $\begin{array}{c}-0.0012 \\
(-2.99)^{* * *}\end{array}$ \\
\hline $\begin{array}{l}\text { Developed } \\
\text { Markets }\end{array}$ & & & & & & & & \\
\hline Competitors & $\begin{array}{c}-0.0010 \\
(-5.90)^{* * *}\end{array}$ & $\begin{array}{c}-0.0001 \\
(-0.12)\end{array}$ & $\begin{array}{c}-0.0017 \\
(-5.06)^{* * *}\end{array}$ & $\begin{array}{c}-0.0014 \\
(-3.90)^{* * *}\end{array}$ & $\begin{array}{c}-0.0017 \\
(-3.76)^{* * *}\end{array}$ & $\begin{array}{c}0.0011 \\
(2.04)^{* *}\end{array}$ & $\begin{array}{c}0.0009 \\
(2.02)^{* *}\end{array}$ & $\begin{array}{c}-0.0004 \\
(-0.92)\end{array}$ \\
\hline $\begin{array}{l}\text { Emerging } \\
\text { Markets }\end{array}$ & & & & & & & & \\
\hline Competitors & $\begin{array}{l}0.0000 \\
(0.06)\end{array}$ & $\begin{array}{c}-0.0021 \\
(-4.06)^{* * *}\end{array}$ & $\begin{array}{l}-0.0006 \\
(-1.29)\end{array}$ & $\begin{array}{c}0.0008 \\
(1.98)^{* *}\end{array}$ & $\begin{array}{l}0.0003 \\
(0.64)\end{array}$ & $\begin{array}{l}0.0003 \\
(0.72)\end{array}$ & $\begin{array}{l}0.0000 \\
(-0.10)\end{array}$ & $\begin{array}{l}-0.0001 \\
(-0.22)\end{array}$ \\
\hline $\begin{array}{l}\text { Africa - Middle } \\
\text { East }\end{array}$ & & & & & & & & \\
\hline Competitors & $\begin{array}{l}-0.0001 \\
(-1.44)\end{array}$ & $\begin{array}{l}-0.0001 \\
(-0.40)\end{array}$ & $\begin{array}{c}-0.0009 \\
(-8.43)^{* * *}\end{array}$ & $\begin{array}{r}-0.0001 \\
(-0.51)\end{array}$ & $\begin{array}{l}0.0002 \\
(1.14)\end{array}$ & $\begin{array}{c}0.0006 \\
(3.53)^{* * *}\end{array}$ & $\begin{array}{l}0.0003 \\
(1.65)^{*}\end{array}$ & $\begin{array}{c}0.0004 \\
(2.88)^{* * *}\end{array}$ \\
\hline $\begin{array}{l}\text { Asia - Pacific } \\
\text { Competitors }\end{array}$ & $\begin{array}{c}-0.0025 \\
(-5.36)^{* * *}\end{array}$ & $\begin{array}{c}-0.0031 \\
(-2.54)^{* *}\end{array}$ & $\begin{array}{c}-0.0041 \\
(-4.59) * * *\end{array}$ & $\begin{array}{l}0.0001 \\
(0.08)\end{array}$ & $\begin{array}{c}-0.0017 \\
(-1.28)\end{array}$ & $\begin{array}{c}0.0011 \\
(0.73)\end{array}$ & $\begin{array}{l}0.0007 \\
(0.57)\end{array}$ & $\begin{array}{c}-0.0025 \\
(-2.11)^{* *}\end{array}$ \\
\hline $\begin{array}{l}\text { Europe } \\
\text { Competitors }\end{array}$ & $\begin{array}{c}-0.0001 \\
(-1.40)\end{array}$ & $\begin{array}{c}-0.0001 \\
(-0.63)\end{array}$ & $\begin{array}{l}-0.0003 \\
(-1.82)^{*}\end{array}$ & $\begin{array}{l}-0.0003 \\
(-1.81)^{*}\end{array}$ & $\begin{array}{r}-0.0003 \\
(-1.51)\end{array}$ & $\begin{array}{l}0.0000 \\
(0.01)\end{array}$ & $\begin{array}{l}-0.0003 \\
(-1.55)\end{array}$ & $\begin{array}{l}0.0000 \\
(0.22)\end{array}$ \\
\hline $\begin{array}{l}\text { Latin America } \\
\text { Competitors }\end{array}$ & $\begin{array}{c}-0.0002 \\
(-4.20)^{* * *}\end{array}$ & $\begin{array}{c}-0.0002 \\
(-1.57)\end{array}$ & $\begin{array}{c}-0.0004 \\
(-3.49)^{* * *}\end{array}$ & $\begin{array}{c}-0.0005 \\
(-3.67)^{* * *}\end{array}$ & $\begin{array}{c}-0.0004 \\
(-2.78)^{* * *}\end{array}$ & $\begin{array}{c}-0.0001 \\
(-0.56)\end{array}$ & $\begin{array}{c}-0.0001 \\
(-0.58)\end{array}$ & $\begin{array}{c}-0.0001 \\
(-0.79)\end{array}$ \\
\hline $\begin{array}{l}\text { North America } \\
\text { Competitors }\end{array}$ & $\begin{array}{c}-0.0010 \\
(-4.39)^{* * *}\end{array}$ & $\begin{array}{c}-0.0008 \\
(-1.38)\end{array}$ & $\begin{array}{c}-0.0008 \\
(-1.98)^{* *}\end{array}$ & $\begin{array}{c}-0.0020 \\
(-4.44)^{* * *}\end{array}$ & $\begin{array}{c}-0.0017 \\
(-2.86)^{* * *}\end{array}$ & $\begin{array}{c}0.0020 \\
(2.41)^{* *}\end{array}$ & $\begin{array}{c}0.0013 \\
(1.97)^{* *}\end{array}$ & $\begin{array}{c}-0.0002 \\
(-0.45)\end{array}$ \\
\hline $\begin{array}{l}\text { Developed - } \\
\text { Asia - Pacific }\end{array}$ & $\begin{array}{c}-0.0016 \\
(-4.06)^{* * *}\end{array}$ & $\begin{array}{l}0.0001 \\
(0.11)\end{array}$ & $\begin{array}{c}-0.0034 \\
(-2.95)^{* * *}\end{array}$ & $\begin{array}{c}-0.0023 \\
(-2.55)^{* *}\end{array}$ & $\begin{array}{c}-0.0034 \\
(-3.07)^{* * *}\end{array}$ & $\begin{array}{l}0.0007 \\
(0.54)\end{array}$ & $\begin{array}{l}0.0018 \\
(1.67)^{*}\end{array}$ & $\begin{array}{l}-0.0018 \\
(-1.81)^{*}\end{array}$ \\
\hline $\begin{array}{l}\text { Emerging - Asia } \\
\text { - Pacific }\end{array}$ & $\begin{array}{l}-0.0008 \\
(-1.47)\end{array}$ & $\begin{array}{c}-0.0066 \\
(-4.30)^{* * *}\end{array}$ & $\begin{array}{c}-0.0027 \\
(-2.55)^{* *}\end{array}$ & $\begin{array}{l}0.0024 \\
(1.79)^{*}\end{array}$ & $\begin{array}{l}0.0012 \\
(0.71)\end{array}$ & $\begin{array}{c}0.0064 \\
(3.56)^{* * *}\end{array}$ & $\begin{array}{c}0.0035 \\
(2.23)^{* *}\end{array}$ & $\begin{array}{c}-0.0005 \\
(-0.31)\end{array}$ \\
\hline $\begin{array}{l}\text { Developed - } \\
\text { Europe }\end{array}$ & $\begin{array}{l}-0.0001 \\
(-1.24)\end{array}$ & $\begin{array}{c}-0.0002 \\
(-0.60)\end{array}$ & $\begin{array}{l}0.0001 \\
(0.27)\end{array}$ & $\begin{array}{l}-0.0004 \\
(-1.33)\end{array}$ & $\begin{array}{l}-0.0005 \\
(-1.46)\end{array}$ & $\begin{array}{l}-0.0005 \\
(-1.47)\end{array}$ & $\begin{array}{c}-0.0008 \\
(-2.51)^{* *}\end{array}$ & $\begin{array}{l}0.0000 \\
(-0.10)\end{array}$ \\
\hline $\begin{array}{l}\text { Emerging - } \\
\text { Europe }\end{array}$ & $\begin{array}{l}0.0000 \\
(-0.40)\end{array}$ & $\begin{array}{l}-0.0001 \\
(-0.31)\end{array}$ & $\begin{array}{c}-0.0008 \\
(-5.39)^{* * *}\end{array}$ & $\begin{array}{l}-0.0003 \\
(-1.61)\end{array}$ & $\begin{array}{l}0.0001 \\
(0.25)\end{array}$ & $\begin{array}{c}0.0014 \\
(7.57)^{* * *}\end{array}$ & $\begin{array}{c}0.0008 \\
(4.88)^{* * *}\end{array}$ & $\begin{array}{c}0.0004 \\
(2.08)^{* *}\end{array}$ \\
\hline $\begin{array}{l}\text { Developed - } \\
\text { North America }\end{array}$ & $\begin{array}{c}-0.0014 \\
(-3.15)^{* * *}\end{array}$ & $\begin{array}{l}-0.0016 \\
(-1.34)\end{array}$ & $\begin{array}{c}-0.0025 \\
(-3.23)^{* * *}\end{array}$ & $\begin{array}{c}-0.0036 \\
(-3.91)^{* * *}\end{array}$ & $\begin{array}{l}-0.0025 \\
(-2.02)^{* *}\end{array}$ & $\begin{array}{c}0.0044 \\
(3.01)^{* * *}\end{array}$ & $\begin{array}{c}0.0033 \\
(2.47)^{* *}\end{array}$ & $\begin{array}{l}0.0005 \\
(0.44)\end{array}$ \\
\hline Emerging- North & & & & & & & & \\
\hline America & $\begin{array}{c}-0.0002 \\
(-5.51)^{* * *}\end{array}$ & $\begin{array}{c}0.0001 \\
(0.83)\end{array}$ & $\begin{array}{c}0.0002 \\
(2.00)^{* *}\end{array}$ & $\begin{array}{c}-0.0005 \\
(-6.22)^{* * *}\end{array}$ & $\begin{array}{c}-0.0006 \\
(-6.12)^{* * *}\end{array}$ & $\begin{array}{c}0.0008 \\
(5.52)^{* * *}\end{array}$ & $\begin{array}{c}-0.0002 \\
(-1.64)\end{array}$ & $\begin{array}{c}-0.0003 \\
(-3.37)^{* * *}\end{array}$ \\
\hline All Exchanges & $\begin{array}{l}0.0000 \\
(0.01)\end{array}$ & $\begin{array}{l}0.0000 \\
(-0.14)\end{array}$ & $\begin{array}{c}-0.0011 \\
(-8.44)^{* * *}\end{array}$ & $\begin{array}{l}0.0005 \\
(1.80)^{*}\end{array}$ & $\begin{array}{c}0.0008 \\
(2.48)^{* *}\end{array}$ & $\begin{array}{c}0.0003 \\
(0.85)\end{array}$ & $\begin{array}{c}0.0002 \\
(0.66)\end{array}$ & $\begin{array}{l}0.0004 \\
(1.74)^{*}\end{array}$ \\
\hline
\end{tabular}


The results from Table 2.7 point to significant increase in market share for the merging firms - with all the mergers generating a $0.9 \%$ increase in market share - significant at the $1 \%$ level for the merged firms (column B). An interesting finding, as the results in Table 2.7 depict, is that it appears that the success of the merging firms in attracting order flow was mainly achieved at the expense of rivals - making the gains in market share a somewhat zero sum game. For all the mergers combined, the competitors (as a whole) lost, on average, a significant $0.1 \%$ in market share following the various merger completions. Further breakdown of the competitors into those from developed countries and those from emerging countries indicate that the market share was taken primarily from rivals from developed countries. Regionally, the combination of all the mergers led to significant decreases in market share for competitors in Asia Pacific, Latin America and North America. An interaction of the regions with the countries' levels of development showed that the significant decrease in market share cut across competitors from developed markets in Asia Pacific as well as rivals from both emerging and developed countries in North America.

Looking at the mergers individually, the NYSE-Archipelago, CME-CBOT and LSE-BI mergers - all led to significant increases in market share for the merging firms as a whole (with the increase in market share being $0.8 \%$ for the LSE-BI merger at the $10 \%$ level, $1 \%$ for the CME-CBOT merger at the $10 \%$ level and $1 \%$ for the NYSE-Archipelago merger at the $1 \%$ level of significance). However, the effects of the NYSE-Euronext, Deutsche Boerse-ISE and NASDAQ-OMX mergers were positive but insignificant for the merging exchanges. Since the NYSE-Euronext merger, the second largest of the six 
mergers by deal size, was expected to create a super exchange, the statistically insignificant growth in market share seems to be contrary to expectations. However, upon delving into the reasons for this, it appears to be an open secret that there were significant challenges integrating the operations of NYSE and Euronext following the merger. The Financial Times (2013) quotes an industry insider as saying that NYSE Euronext is a big conglomerate of stuff that has never been integrated. Given the wide range of underperforming NYSE Euronext assets, it is not surprising that a couple of merger bids have since been made by rivals Deutsche Boerse (unsuccessful) and Intercontinental Exchange (successful) - who probably believed that they could unlock the value in the non-performing NYSE Euronext assets. Following the successful completion of the merger between Intercontinental Exchange (ICE) and NYSE Euronext on November 13, 2013, ICE moved in 2014 to spinoff Euronext in a 1.2 billion IPO (Bloomberg, 2014). And as already noted, integration issues can torpedo the achievement of synergies in mergers (even if the merger partners participate in the same product market). There are also indications that NASDAQ OMX has struggled to create a strong foothold in Europe (Financial News, 2012) - which may be indicative of integration challenges following the NASDAQ-OMX merger. So while the insignificant increases in market share following the NYSE-Euronext and NASDAQ-OMX mergers appear counter-intuitive at first glance, the integration challenges that these mergers faced may explain the insignificance.

The losses in market share for rivals were widespread across most of the mergers separately. Rivals' losses of market share were $0.1 \%$ for the NYSE-Archipelago, CME- 
CBOT and LSE-BI mergers (at the 1\% level) and $0.1 \%$ for the Deutsche Boerse-ISE (DB-ISE) and NYSE-Euronext mergers but at the $10 \%$ level of significance. Although most of our market share analyses show that gains in market share is a zero-sum game where the merging exchanges gain at the expense of rivals, the NYSE-Euronext and DBISE mergers did not result in significant gains for the merging exchanges although the rivals still lost market share. We conjecture that this may be due to the fact that Dark Pools captured the market share lost by rivals in the NYSE-Euronext and DB-ISE mergers. Dark Pools, which are alternative equity trading systems that do not publicly display orders (Zhu, 2014), have been capturing market share from traditional exchanges in recent years. According to Preece (2012), dark pool liquidity is estimated to have grown by about 48\% between January 2009 and March 2012, and account for some 31\% of consolidated volume. Therefore, we argue that the order flow lost by rivals (in the case of the NYSE-Euronext and DB-ISE mergers) is likely lost to dark pools - since the merging exchanges did not capture that market share.

The effects of the individual mergers were, however, different for rivals from different regions. With the exception of emerging markets' rivals, emerging North American rivals and competitors from developed markets in Europe, the NYSE-Archipelago merger led to a significant decrease in market share for all other categories of competitors. Only emerging North American rivals saw an increase in market share as a result of the NYSEArchipelago merger. The market share implications of the NYSE-Euronext merger was marginally significantly negative for European competitors (at the $10 \%$ level) and significantly negative (at the $1 \%$ or $5 \%$ significance levels) for competitors from 
developed countries, those from Latin America, North America (including those from both developed and emerging North American countries) and competitors from developed Asia Pacific regions. However, it was significantly positive at the 5\% level for emerging markets' rivals and marginally positive at the $10 \%$ level for emerging Asia Pacific rivals. The CME-CBOT merger led to a significant decrease in market share for competitors from developed countries as well as rivals from developed Asia Pacific, Latin America and North America (competitors from both developed and emerging North America countries). The Deutsche Boerse-ISE merger led to significant increases in market share for a number of competitors including rivals from developed countries, Africa - Middle East, emerging Europe, emerging Asia Pacific and North America (developed and emerging North America as well). The NASDAQ-OMX merger led to significant increases in market share for rivals from developed countries, North American countries, developed North American countries, emerging Asia Pacific countries and emerging European countries. The merger also led to a marginal increase in market share (at the 10\% level) for Africa - Middle East rivals and developed Asia Pacific rivals. However, the merger led to a significant decrease in market share for rivals from developed European countries. The market share implications of the LSE-BI merger were also mixed. Africa and Middle East rivals as well as emerging European rivals experienced increases in market share while Asia Pacific competitors and emerging North American competitors experienced significant reductions in market share. But although developed Asia Pacific rivals also saw reductions in market share, those reductions were only marginally significant at the $10 \%$ level of significance. The CMECBOT merger led to a significant increase in market share for all stock exchanges while 
the increases in market share for all stock exchanges were marginal (at the $10 \%$ level) for both the NYSE-Euronext merger and LSE-BI merger. But the NYSE-Archipelago merger led to a significant decrease in market share for all stock exchanges at the $1 \%$ level of significance. The results for some of the mergers suggest that weaker regional competitors lost whereas comparable competitors gained - perhaps reflecting the fact that investors expected comparable competitors to also engage in similar value enhancing acquisitions.

While the realization of synergy can be inferred from our results, we directly tested for synergy by including the percent premium paid by bidders (based on market capitalization one month before the merger announcement) as a proxy for synergy. As demonstrated by the results in Table 2.7 (column C), synergy has a positive but insignificant effect on the combined entity. For the merging exchanges, we argue that the significance of the synergy variable is subsumed by the significance of the merger dummy - making synergy insignificant for the merging entities. For rivals, however, the synergy variable is significantly negative at the $1 \%$ level. This supports our contention that the synergistic benefits of the mergers will put rivals at a competitive disadvantage, thus, leading to loss of market share.

All in all, the product market results support our hypothesis of increased market share or order flow for the merged exchanges. The findings therefore support some of the merging entities senior managements' proffered reasons for the mergers - to achieve synergistic advantages through the efficient utilization of resources as a result of the merger. The 
results also show that the gain in market share for the merging firms has largely been a zero sum game whereby the increase is achieved at the expense of rival exchanges. Our results further show that for the most part, the merging exchanges drew order flow or market share from competitors within the same region or from countries at the same level of development or from both. It should be noted that the loss of market share by rivals may appear to be counter-intuitive, especially given that the markets reacted positively to rival exchanges - as the shareholders of rivals also realized abnormal returns on announcements of the mergers. We argue that the positive announcement effects for rivals were based on the expectation that the rivals will also pursue merger activities to strengthen their market positions (and not because rivals will not lose market share as a result of the mergers). This conjecture is in line with Song and Walkling's (2000) acquisition probability hypothesis.

\subsubsection{Effects of the Mergers on Bid-Ask Spreads}

One of the central themes that emerged from the professed objectives of the stock exchange mergers is the need to create the most liquid stock exchanges. It is expected that improvements in liquidity will, ceteris paribus, lead to improved market quality and reductions in the cost of transacting on the exchange. To examine the short-term effects of the mergers on the cost of transacting, we analyze bid-ask spreads two months (44 days) before and two months (44 days) after the completion of each merger. To ascertain the long-term effects of the mergers on transaction costs, we analyze bid-ask spreads one year (250 trading days) before the merger completion dates and three years ( 750 trading days) after the merger completion dates. 
While there are several dimensions of market quality (e.g. liquidity, informational efficiency and volatility) and several measures of market quality (e.g. bid-ask spreads, volatility, etc.), we focus on quoted bid-ask spreads because they are one of the most effective measures of the cost dimension of liquidity (one of the dimensions of market quality). Since one of the arguments advanced for the mergers has been that they are expected to lead to increased order flow, increased liquidity and decreased transaction costs, we consider the quoted bid-ask spreads measure as one of the best metrics to help us answer our research question on the market quality implications of the stock exchange mergers. The second reason for our choice of quoted spreads relate to the practical limits imposed by the size of the data. Domowitz and Steil (2001) assert that the data requirements for studies of market quality are too large for any single research project, and consequently, any study of market quality would have to be narrowed. Consequently, we narrowed our choice and use quoted spreads.

The practical limitations imposed by the voluminous data requirements of studies of market quality probably factored into why the two earlier stock exchange merger studies by Arnold et al. (1999) and Nielsson (2009) that investigated the cost dimension of market quality (using quoted spreads) both focused on the short-term market quality effects of the mergers they examined. However, given the importance of the long-term effects of transaction costs to investors and managers of exchanges, we also investigate the long-term effects of the mergers on transaction costs. To elaborate on the data requirements, we obtained daily bid-ask information from Bloomberg for an average of 
$15 \%$ of firms listed on each stock exchange over the 44 days surrounding each merger (for our short-term analysis of the mergers' effects on transaction costs). This resulted in over 2.3 million firm-day records, which were then averaged for the exchanges and the various portfolios we analyzed. For the long-term analysis, we downloaded data for some 6,500 firms traded on 52 stock exchanges from 250 trading days (one year) before the mergers' completion dates to 750 trading days (three years) after the mergers' completion dates. In total, we had over 20 million rows of firm-day data points and over 6 million rows of unique firm-day data points (since the control firms were used for more than one stock exchange merger). In the following sections, we discuss the short-term and longterm analyses of bid-ask spreads.

\subsubsection{Short-Term Analysis of Bid-Ask Spreads}

\subsection{Univariate Tests of Means and Medians}

Table 2.8 presents the univariate tests of means (using the t-test) and medians (using the Wilcoxon signed-rank test) of the bid-ask spreads for the 44 days before and 44 days after the completion of each of the mergers. Over the four-month window surrounding the merger completion dates, the mean (median) bid-ask spreads of firms listed on the merging firms significantly decreased by about $4.2 \%$ (1.1\%). However, a further breakdown shows that the decrease in bid-ask spreads was mainly attributable to firms listed on bidders' exchanges whose mean and median bid-ask spreads decreased significantly by $12.9 \%$ and $7.6 \%$ respectively over the 44 days following the merger completions compared to the 44 days before the merger completions. On the other hand, the mean and median bid-ask spreads for firms listed on rival exchanges increased 
significantly by $2.7 \%$ and $4.1 \%$ respectively in the 44 days following the merger

completion.

\section{Table 2.8 - Tests of Mean and Median Bid-Ask Spreads for All Mergers}

In this table, we present the results of the test of mean and median bid-ask spreads 44 days before and 44 days after the completion of each of the mergers. The results are broken down by the various portfolios. (Test statistics are in parentheses.)

\begin{tabular}{|c|c|c|c|c|c|c|c|c|}
\hline & & & Mean & & & & Median & \\
\hline Portfolio & Before & After & $\begin{array}{c}\% \\
\text { Difference }\end{array}$ & $\begin{array}{l}\text { Paired T- } \\
\text { Test of } \\
\text { Difference }\end{array}$ & Before & After & $\begin{array}{c}\% \\
\text { Difference }\end{array}$ & $\begin{array}{l}\text { Wilcoxon } \\
\text { signed-rank test }\end{array}$ \\
\hline Merging Companies & 0.0272 & 0.0261 & $-4.20 \%$ & $(-2.78)^{* * *}$ & 0.0265 & 0.0262 & $-1.05 \%$ & $(-2.54)^{* *}$ \\
\hline Targets & 0.0211 & 0.0227 & $7.15 \%$ & $(3.60)^{* * *}$ & 0.0209 & 0.0231 & $10.49 \%$ & $(2.55)^{* *}$ \\
\hline Bidders & 0.0347 & 0.0302 & $-12.85 \%$ & $(-4.76)^{* * *}$ & 0.0325 & 0.0300 & $-7.61 \%$ & $(-3.58)^{* * *}$ \\
\hline All Competitors & 0.0392 & 0.0403 & $2.69 \%$ & $(3.96)^{* * *}$ & 0.0386 & 0.0402 & $4.08 \%$ & $(4.14)^{* * *}$ \\
\hline Developed Competitors & 0.0343 & 0.0359 & $4.50 \%$ & $(2.86)^{* * *}$ & 0.0335 & 0.0361 & $7.50 \%$ & $(4.48)^{* * *}$ \\
\hline Emerging Competitors & 0.0417 & 0.0425 & $1.81 \%$ & $(2.58)^{* *}$ & 0.0417 & 0.0424 & $1.84 \%$ & $(2.45)^{* *}$ \\
\hline $\begin{array}{l}\text { Africa - Middle East } \\
\text { Competitors } \\
\text { Asia - Pacific }\end{array}$ & 0.0345 & 0.0341 & $-0.98 \%$ & $(-0.47)$ & 0.0341 & 0.0341 & $0.13 \%$ & $(-0.36)$ \\
\hline Competitors & 0.0363 & 0.0385 & $6.03 \%$ & $(6.37)^{* * *}$ & 0.0365 & 0.0389 & $6.57 \%$ & $(4.61)^{* * *}$ \\
\hline Europe Competitors & 0.0308 & 0.0337 & $9.41 \%$ & $(9.74)^{* * *}$ & 0.0306 & 0.0333 & $8.78 \%$ & $(5.48)^{* * *}$ \\
\hline $\begin{array}{l}\text { Latin America } \\
\text { Competitors } \\
\text { North America }\end{array}$ & 0.0694 & 0.0689 & $-0.66 \%$ & $(-0.42)$ & 0.0722 & 0.0682 & $-5.59 \%$ & $(-0.58)$ \\
\hline $\begin{array}{l}\text { Competitors } \\
\text { Asia - Pacific - }\end{array}$ & 0.0344 & 0.0281 & $-18.20 \%$ & $(-3.12)^{* * *}$ & 0.0318 & 0.0275 & $-13.34 \%$ & $(-4.87)^{* * *}$ \\
\hline $\begin{array}{l}\text { Developed Competitors } \\
\text { Asia - Pacific - Emerging }\end{array}$ & 0.0393 & 0.0422 & $7.55 \%$ & $(8.63)^{* * *}$ & 0.0392 & 0.0424 & $8.15 \%$ & $(5.49)^{* * *}$ \\
\hline $\begin{array}{l}\text { Competitors } \\
\text { Europe - Developed }\end{array}$ & 0.0345 & 0.0363 & $5.07 \%$ & $(4.35)^{* * *}$ & 0.0345 & 0.0363 & $5.11 \%$ & $(3.50)^{* * *}$ \\
\hline $\begin{array}{l}\text { Competitors } \\
\text { Europe - Emerging }\end{array}$ & 0.0285 & 0.0311 & $9.01 \%$ & $(6.80)^{* * *}$ & 0.0285 & 0.0315 & $10.41 \%$ & $(4.83)^{* * *}$ \\
\hline $\begin{array}{l}\text { Competitors } \\
\text { North America - }\end{array}$ & 0.0328 & 0.0359 & $9.38 \%$ & $(6.13)^{* * *}$ & 0.0329 & 0.0360 & $9.41 \%$ & $(4.58)^{* * *}$ \\
\hline $\begin{array}{l}\text { Developed Competitors } \\
\text { North America - }\end{array}$ & 0.0316 & 0.0268 & $-15.31 \%$ & $(-1.57)$ & 0.0264 & 0.0259 & $-1.62 \%$ & $(-2.77)^{* * *}$ \\
\hline Emerging Competitors & 0.0399 & 0.0309 & $-22.51 \%$ & $(-5.71)^{* * *}$ & 0.0384 & 0.0318 & $-17.19 \%$ & $(-4.98)^{* * *}$ \\
\hline All Exchanges & 0.0368 & 0.0374 & $1.70 \%$ & $(2.63)^{* *}$ & 0.0362 & 0.0375 & $3.56 \%$ & $(3.02)^{* * *}$ \\
\hline
\end{tabular}

Further breakdown of the bid-ask spreads of the rivals shows that the competitors were asymmetrically impacted. While most rivals experienced increases in bid-ask spreads, a few saw reductions in bid-ask spreads. Among competitors experiencing falling bid-ask spreads were North American competitors - largely attributable to falling bid-ask spreads 
for competitors from emerging North American markets. Almost all other rivals, including competitors from developed markets, emerging markets and those from both emerging and developed European and Asia Pacific countries experienced increased bidask spreads.

These results suggest that the merged firms were able to attract more order flow (i.e. market share) at the expense of competitors, and the increased liquidity for the merging firms led to lower bid-ask spreads for firms listed on those exchanges. For competitors, however, the decreased order flow following the mergers impacted liquidity and as a result, the firms listed on the exchanges experienced increases in bid-ask spreads in the two months following the completion of each merger.

\subsection{Bid-Ask Spreads SUR Regression Equations}

In this section, we present the seemingly unrelated regression (SUR) equations' results that regress bid-ask spreads on the merger completion indicator and other control variables in Table 2.9. The overall message with respect to the SUR bid-ask spreads equations is largely consistent with the results of the univariate tests. Based on the pooled data for all exchanges, we observe that the merging exchanges experienced reductions in bid-ask spreads - with a post-merger dummy coefficient that is significant at the $5 \%$ level. The reductions in bid-ask spreads for the merging entities are largely attributed to significant reductions in bid-ask spreads for bidders since targets saw insignificant increases in bid-ask spreads. Consistent with the univariate results, we also find that firms listed on rival exchanges experienced significant increase in bid-ask spreads. Other 
portfolios of rivals including emerging markets' rivals, Asia Pacific rivals (developed as well as emerging), European rivals, Latin American rivals and emerging European competitors all experienced significant increases in bid-ask spreads following the mergers. However, North American rivals (developed as well as emerging North American rivals) achieved significant reductions in bid-ask spreads. Also, competitors from Africa - Middle East experienced weak reductions in bid-ask spreads (at the 10\%).

\section{Table 2.9 - Bid-Ask Spreads SUR Regression Equations}

In this table, we present the results of the seemingly unrelated regression equations that regress the bid-ask spread on the merger completion dummies (which take the value of 1 in the 44 days after each merger completion and zero in the 44 days before each merger completion) and other control variables. The other independent/control variables are market share, domestic market capitalization, log of total listed firms, synergy and GDP per capita. The results are broken down by the various portfolios we analyze. For all the mergers combined, we report coefficients for the merger dummy, market share, synergy and listed firms - but report only the coefficient of the merger dummy for the individual mergers - in the interest of brevity. (z statistics are in parentheses.)

\begin{tabular}{|c|c|c|c|c|c|c|c|c|c|c|}
\hline & & All & gers & & & & & & & \\
\hline Portfolio & $\begin{array}{l}\text { Merger } \\
\text { Dummy }\end{array}$ & $\begin{array}{l}\text { Market } \\
\text { Share } \\
\text { Growth }\end{array}$ & Synergy & $\begin{array}{l}\text { Listed } \\
\text { Firms }\end{array}$ & $\begin{array}{r}\text { NYSE- } \\
\text { Archipelag } \\
0\end{array}$ & $\begin{array}{l}\text { NYSE- } \\
\text { Euronext }\end{array}$ & $\begin{array}{l}\text { CME- } \\
\text { CBOT }\end{array}$ & DB-ISE & $\begin{array}{l}\text { NASDAQ } \\
\text {-OMX }\end{array}$ & LSE-BI \\
\hline $\begin{array}{l}\text { Merging } \\
\text { Firms }\end{array}$ & $\begin{array}{c}-0.0013 \\
(-2.19)^{* *}\end{array}$ & $\begin{array}{c}-0.1822 \\
(-4.72)^{* * *}\end{array}$ & $\begin{array}{l}0.0013 \\
(0.84)\end{array}$ & $\begin{array}{c}0.0430 \\
(4.43)^{* * *}\end{array}$ & $\begin{array}{c}-0.0091 \\
(-2.20)^{* *}\end{array}$ & $\begin{array}{l}0.0056 \\
(0.19)\end{array}$ & $\begin{array}{l}0.0008 \\
(1.06)\end{array}$ & $\begin{array}{l}0.0040 \\
(0.92)\end{array}$ & $\begin{array}{c}-0.0037 \\
(-2.21)^{* *}\end{array}$ & $\begin{array}{c}0.0032 \\
(7.97)^{* * *}\end{array}$ \\
\hline Targets & $\begin{array}{l}0.0005 \\
(1.57)\end{array}$ & $\begin{array}{c}0.0388 \\
(2.74)^{* * *}\end{array}$ & $\begin{array}{c}0.0035 \\
(4.16)^{* * *}\end{array}$ & $\begin{array}{c}0.0201 \\
(8.06)^{* * *}\end{array}$ & $\begin{array}{c}-0.0010 \\
(-3.02)^{* * *}\end{array}$ & $\begin{array}{l}-0.0048 \\
(-1.36)\end{array}$ & $\begin{array}{c}-0.0004 \\
(-0.42)\end{array}$ & $\begin{array}{l}0.0010 \\
(0.65)\end{array}$ & $\begin{array}{c}-0.0047 \\
(-2.13)^{* *}\end{array}$ & $\begin{array}{c}0.0010 \\
(2.84)^{* * *}\end{array}$ \\
\hline Bidders & $\begin{array}{c}-0.0036 \\
(-3.02)^{* * *}\end{array}$ & $\begin{array}{c}-0.2908 \\
(-2.56)^{* *}\end{array}$ & $\begin{array}{l}0.0028 \\
(0.85)\end{array}$ & $\begin{array}{c}-0.0335 \\
(-1.30)\end{array}$ & $\begin{array}{l}-0.0193 \\
(-1.84)^{*}\end{array}$ & $\begin{array}{l}0.0269 \\
(0.46)\end{array}$ & $\begin{array}{l}0.0020 \\
(1.03)\end{array}$ & $\begin{array}{l}0.0037 \\
(0.86)\end{array}$ & $\begin{array}{l}-0.0005 \\
(-0.52)\end{array}$ & $\begin{array}{c}0.0055 \\
(5.68)^{* * *}\end{array}$ \\
\hline $\begin{array}{l}\text { All } \\
\text { Competitors }\end{array}$ & $\begin{array}{c}0.0009 \\
(2.45)^{* *}\end{array}$ & $\begin{array}{l}-0.5436 \\
(-1.92)^{*}\end{array}$ & $\begin{array}{c}0.0054 \\
(5.35)^{* * *}\end{array}$ & $\begin{array}{c}0.0073 \\
(2.78)^{* * *}\end{array}$ & $\begin{array}{l}0.0007 \\
(1.11)\end{array}$ & $\begin{array}{c}-0.0006 \\
(-0.36)\end{array}$ & $\begin{array}{c}0.0045 \\
(2.15)^{* *}\end{array}$ & $\begin{array}{l}0.0014 \\
(0.81)\end{array}$ & $\begin{array}{l}-0.0022 \\
(-1.41)\end{array}$ & $\begin{array}{c}0.0044 \\
(4.37)^{* * *}\end{array}$ \\
\hline $\begin{array}{l}\text { Developed } \\
\text { Markets } \\
\text { Competitors }\end{array}$ & $\begin{array}{l}0.0002 \\
(0.37)\end{array}$ & $\begin{array}{l}-0.7458 \\
(-1.88)^{*}\end{array}$ & $\begin{array}{c}0.0083 \\
(4.79)^{* * *}\end{array}$ & $\begin{array}{c}0.0179 \\
(4.27)^{* * *}\end{array}$ & $\begin{array}{c}-0.0014 \\
(-3.00)^{* * *}\end{array}$ & $\begin{array}{c}-0.0033 \\
(-2.39)^{* *}\end{array}$ & $\begin{array}{l}0.0057 \\
(1.04)\end{array}$ & $\begin{array}{l}0.0016 \\
(0.89)\end{array}$ & $\begin{array}{l}0.0014 \\
(0.62)\end{array}$ & $\begin{array}{c}0.0064 \\
(6.22)^{* * *}\end{array}$ \\
\hline $\begin{array}{l}\text { Emerging } \\
\text { Markets } \\
\text { Competitors }\end{array}$ & $\begin{array}{c}0.0009 \\
(2.28)^{* *}\end{array}$ & $\begin{array}{c}-0.4886 \\
(-2.22)^{* *}\end{array}$ & $\begin{array}{c}0.0057 \\
(5.36)^{* * *}\end{array}$ & $\begin{array}{c}0.0040 \\
(3.71)^{* * *}\end{array}$ & $\begin{array}{c}-0.0004 \\
(-0.39)\end{array}$ & $\begin{array}{l}0.0014 \\
(0.49)\end{array}$ & $\begin{array}{l}0.0031 \\
(1.88)^{*}\end{array}$ & $\begin{array}{c}0.0032 \\
(2.09)^{* *}\end{array}$ & $\begin{array}{l}0.0001 \\
(0.05)\end{array}$ & $\begin{array}{c}-0.0032 \\
(-2.52)^{* *}\end{array}$ \\
\hline $\begin{array}{l}\text { Africa - } \\
\text { Middle East } \\
\text { Competitors }\end{array}$ & $\begin{array}{l}-0.0019 \\
(-1.66)^{*}\end{array}$ & $\begin{array}{c}3.1270 \\
(1.99)^{* *}\end{array}$ & $\begin{array}{l}0.0018 \\
(0.58)\end{array}$ & $\begin{array}{c}-0.0010 \\
(-0.16)\end{array}$ & $\begin{array}{c}-0.0133 \\
(-3.03)^{* * *}\end{array}$ & $\begin{array}{l}-0.0121 \\
(-1.79)^{*}\end{array}$ & $\begin{array}{c}0.0085 \\
(2.46)^{* *}\end{array}$ & $\begin{array}{c}0.0207 \\
(6.83)^{* * *}\end{array}$ & $\begin{array}{l}-0.0054 \\
(-1.28)\end{array}$ & $\begin{array}{c}-0.0060 \\
(-3.06)^{* * *}\end{array}$ \\
\hline $\begin{array}{l}\text { Asia - } \\
\text { Pacific } \\
\text { Competitors }\end{array}$ & $\begin{array}{c}0.0015 \\
(3.48)^{* * *}\end{array}$ & $\begin{array}{c}0.5035 \\
(3.16)^{* * *}\end{array}$ & $\begin{array}{c}0.0092 \\
(8.14)^{* * *}\end{array}$ & $\begin{array}{c}0.0054 \\
(2.51)^{* *}\end{array}$ & $\begin{array}{c}-0.0003 \\
(-0.37)\end{array}$ & $\begin{array}{l}0.0026 \\
(1.05)\end{array}$ & $\begin{array}{c}0.0047 \\
(3.56)^{* * *}\end{array}$ & $\begin{array}{l}0.0011 \\
(0.59)\end{array}$ & $\begin{array}{l}0.0012 \\
(0.64)\end{array}$ & $\begin{array}{c}-0.0006 \\
(-0.57)\end{array}$ \\
\hline $\begin{array}{l}\text { Europe } \\
\text { Competitors }\end{array}$ & $\begin{array}{c}0.0028 \\
(5.90)^{* * *}\end{array}$ & $\begin{array}{c}-0.3203 \\
(-0.93)\end{array}$ & $\begin{array}{c}-0.0007 \\
(-0.56)\end{array}$ & $\begin{array}{c}0.0079 \\
(8.22)^{* * *}\end{array}$ & $\begin{array}{c}0.0039 \\
(4.91)^{* * *}\end{array}$ & $\begin{array}{l}-0.0038 \\
(-1.65)^{*}\end{array}$ & $\begin{array}{c}-0.0013 \\
(-0.92)\end{array}$ & $\begin{array}{c}-0.0021 \\
(-1.29)\end{array}$ & $\begin{array}{c}0.0087 \\
(4.81)^{* * *}\end{array}$ & $\begin{array}{c}0.0034 \\
(2.40)^{* *}\end{array}$ \\
\hline
\end{tabular}




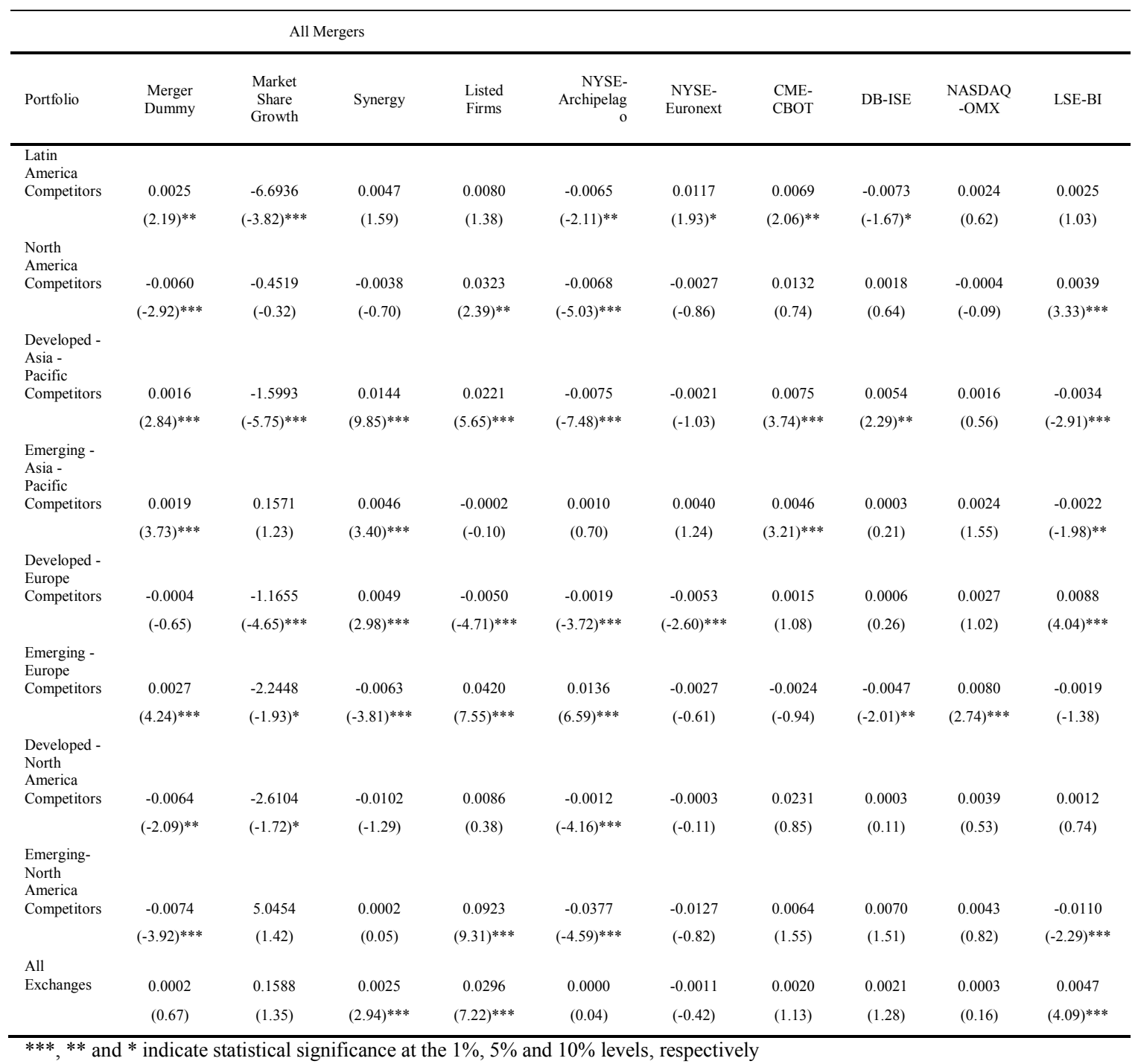

For the individual mergers, the merging firms achieved significant reductions in bid-ask spread for the NYSE-Archipelago merger and NASDAQ-OMX merger (5\% levels) but significant increases in bid-ask spreads for the LSE-BI merger. The insignificance of the NYSE-Euronext merger bid-ask regressions for the merging firms is congruent with the market share results. The integration challenges that the NYSE-Euronext merger faced probably contributed to the insignificance of its market share and bid-ask regressions (for the merging exchanges). Targets experienced significant reductions in bid-ask spreads for the NYSE-Archipelago and NASDAQ-OMX mergers but significant increases in bid-ask 
spreads for the LSE-BI merger. Bidders experienced marginal decreases in bid-ask spreads (at the 10\% level) for the NYSE-Archipelago merger but significant increases in bid-ask spreads for the LSE-BI merger.

For all the competitors combined, the CME-CBOT merger as well as the LSE-BI merger both resulted in significant increases in bid-ask spreads on rival stock exchanges. Our results also show that for rival exchanges from developed countries, the NYSEArchipelago and NYSE-Euronext mergers led to statistically significant decreases in bidask spreads while the LSE-BI merger resulted in a significant increase in bid-ask spreads. For rivals from emerging markets, the DB-ISE and CME-CBOT mergers led to significant increases in bid-ask spreads at respective significance levels of $5 \%$ and $10 \%$. But the LSE-BI merger led to a significant decrease in bid-ask spreads for rivals from emerging markets. Our results also highlight regional differences. Africa and Middle East rivals saw significant increases in bid-ask spreads for the DB-ISE and CME-CBOT mergers but significant decreases in bid-ask spreads for the NYSE-Archipelago merger (1\% level), LSE-BI merger ( $1 \%$ level) and NYSE-Euronext merger ( $10 \%$ level). Only the CME-CBOT merger resulted in a significant increase in bid-ask spreads for Asia Pacific rivals. European rivals recorded significant increases in bid-ask spreads for the NYSEArchipelago, NASDAQ-OMX and LSE-BI mergers and a marginally significant decrease in bid-ask spreads for the NYSE-Euronext merger (10\% level). Rivals from Latin America saw a significant increase in bid-ask spreads following the CME-CBOT merger, a marginally significant increase in bid-ask spreads for the NYSE-Euronext merger $(10 \%$ level), a significant decrease for the NYSE-Archipelago merger and a weakly significant 
decrease $(10 \%$ level) for the DB-ISE merger. North American rivals saw a decrease in bid-ask spreads as a result of the NYSE-Archipelago merger but the LSE-BI merger led to a significant increase in bid-ask spreads for North American rivals. The interaction between stage of development and region also produces some (mixed) interesting bid-ask spreads results. Competitors from developed Asia Pacific countries experienced significant increases in bid-ask spreads for the CME-CBOT and DB-ISE mergers but significant decreases in bid-ask spreads for the NYSE-Archipelago and LSE-BI mergers. Emerging Asia Pacific rivals saw an increase in bid-ask spreads as a result of the CMECBOT merger but a decrease in bid-ask spreads as a result of the LSE-BI merger. Developed European competitors saw a significant increase in bid-ask spreads for the LSE-BI merger but significant decreases in bid-ask spreads for the two NYSE mergers. Emerging European rivals saw significant increases in bid-ask spreads for the NYSEArchipelago and NASDAQ-OMX mergers but significant decreases in bid-ask spreads following the DB-ISE merger. The NYSE-Archipelago merger was associated with a significant decrease in bid-ask spreads for both developed and emerging North American rivals but only emerging North American rivals additionally registered a significant decrease in bid-ask spreads following the LSE-BI merger.

In sum, the bid-ask spreads analyses show that the bid-ask spreads of the firms listed on the merged exchanges significantly reduced in the period following the mergers. Given that the merging firms were able to increase their market share after the mergers, these exchanges were able to draw more order flow which increases liquidity and the market quality of the merging exchanges. The increased liquidity may have contributed to the 
reductions in bid-ask spreads in the short term. The results for the competitors (collectively) show significant increases in bid-ask spreads. Our bid-ask spreads results also highlight the fact that both geographical nearness to the merging firms and the stage of development of competitors affect bid-ask spreads for competitors (as North American and European competitors saw significant bid-ask effects following the mergers).

Therefore, the results are congruent with our expectations and hypotheses.

\subsubsection{Long-Term Analysis of Bid-Ask Spreads}

\subsection{Long-Term Trends in Bid-Ask Spreads}

We first analyze the trends in bid-ask spreads in the long-term and present the findings in Figure 2.2. The results of our long-term analysis of bid-ask spreads demonstrate that the reductions in bid ask spreads for firms involved in the mergers is not confined to only the short-term. As demonstrated in Figure 2.2a, the merging firms had higher bid-ask spreads one year before the merger consummation relative to those of non-merging rival exchanges. However, for the three years after the merger completion dates, the merging exchanges experienced decreasing bid-ask spreads. Figure $2.2 \mathrm{~b}$ (which documents the industry-adjusted bid-ask spreads, computed as bid-ask spreads of merging exchanges minus bid-ask spreads of non-merging exchanges) further illuminates the reduction in transaction costs in the post-merger periods for the exchanges involved in the mergers. 
Figure 2.2 - Long-Term Trends in Bid-Ask Spreads

Figure 2.2 presents the long-term trends in bid-ask spreads. Figure 2.2a documents the bid-ask spreads for merging and non-merging exchanges, Figure $2.2 \mathrm{~b}$ documents the industry adjusted bid-ask spreads trends, Figure $2.2 \mathrm{c}$ documents the bid-ask spreads trends for bidders and Figure 2.2d documents the bid-ask spreads trends for targets and non-merging exchanges.
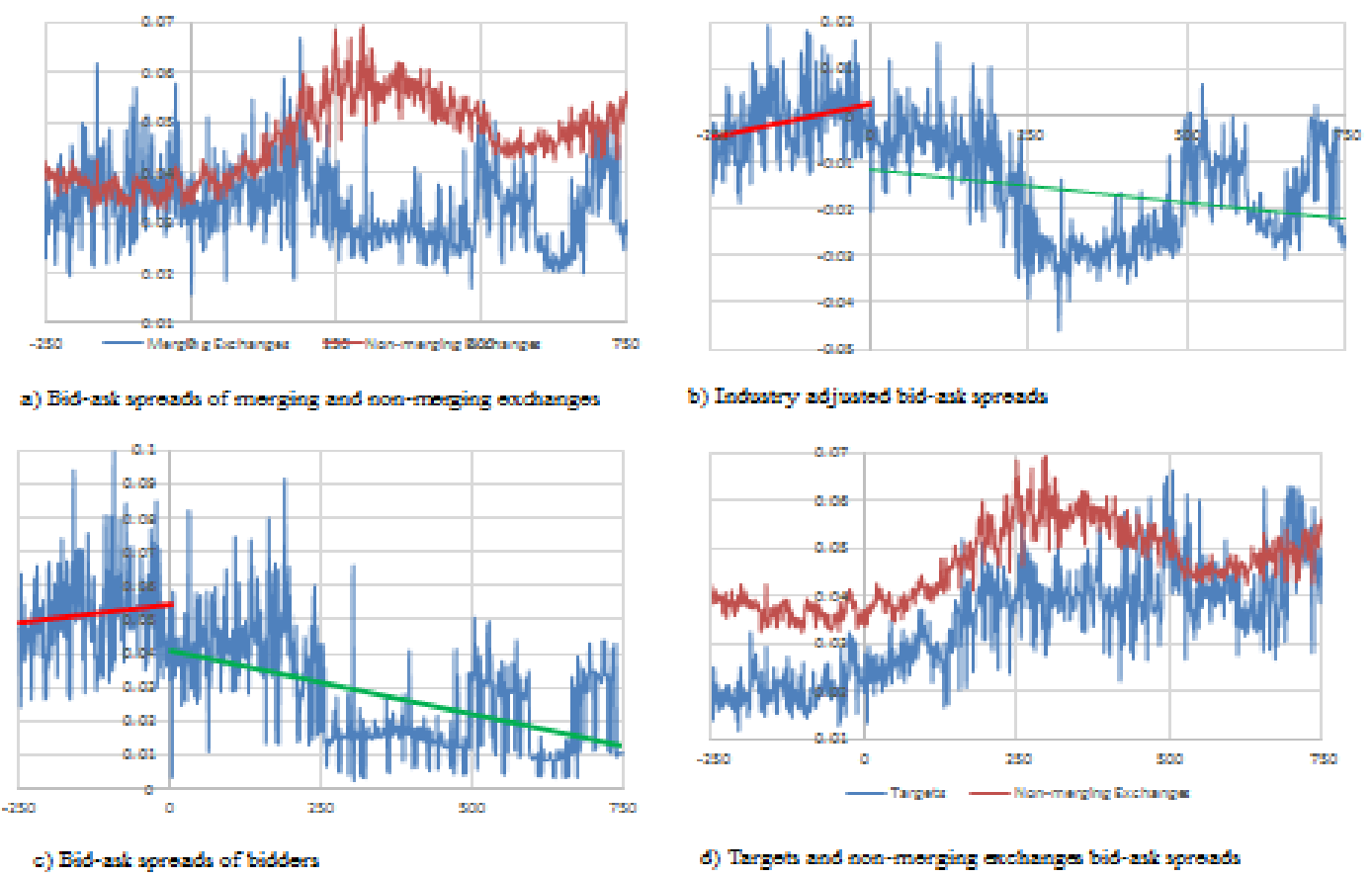

c) Bid-ack spereade of bidders

d) Tergots and non-morging exchunge bid-alk uprouds

While firms listed on the merging exchanges experienced higher bid-ask spreads relative to firms listed on non-merging exchanges in the pre-merger completion period, the trend reversed in the post-merger period - with the bid-ask spreads on merging exchanges decreasing in comparison to spreads on non-merging exchanges. Although the bid-ask spreads have been declining in the post-merger period for the exchanges involved in the mergers, we find that bidders experienced the decreases in spreads whilst targets and rivals experienced increases in spreads. Thus, the benefits of decreasing spreads are asymmetrically distributed in favor of bidding exchanges but against target exchanges and non-merging exchanges. 


\subsection{Univariate Tests of Means and Medians}

We report the long-term univariate test of means and medians in the pre-merger period and pairwise average of the three years ${ }^{10}$ in the post-merger period in Table 2.10 .

\section{Table 2.10 -Tests of Long-Term Mean and Median Bid-Ask Spreads}

In this table, we present the results of the tests of mean and median bid-ask spreads one year before and the pairwise average of three years after the completion of each of the mergers. The results are for all the mergers combined and broken down by the various portfolios. (Test statistics are in parentheses.)

\begin{tabular}{|c|c|c|c|c|c|c|c|c|}
\hline & & & Mean & & & & Median & \\
\hline Portfolio & Before & After & $\begin{array}{c}\% \\
\text { Difference }\end{array}$ & $\begin{array}{l}\text { Paired T- } \\
\text { Test of } \\
\text { Difference }\end{array}$ & Before & After & $\begin{array}{c}\% \\
\text { Difference }\end{array}$ & $\begin{array}{l}\text { Wilcoxon } \\
\text { signed-rank } \\
\text { test }\end{array}$ \\
\hline \multicolumn{9}{|l|}{ Panel A: Bid-Ask Spreads } \\
\hline Merging Companies & 0.0361 & 0.0331 & $-8.33 \%$ & $(-5.90)^{* * *}$ & 0.0355 & 0.0329 & $-7.43 \%$ & $(-2.51)^{* *}$ \\
\hline Bidders & 0.0516 & 0.0280 & $-45.85 \%$ & $(-26.44)^{* * *}$ & 0.0514 & 0.0273 & $-46.93 \%$ & $(-13.47)^{* * *}$ \\
\hline Targets & 0.0205 & 0.0382 & $86.18 \%$ & $(47.19)^{* * *}$ & 0.0200 & 0.0373 & $86.59 \%$ & $(13.54)^{* * *}$ \\
\hline All Competitors & 0.0372 & 0.0495 & $33.11 \%$ & $(71.13)^{* * *}$ & 0.0373 & 0.0493 & $32.39 \%$ & $(18.99)^{* * *}$ \\
\hline Developed Competitors & 0.0323 & 0.0524 & $62.40 \%$ & $(80.29)^{* * *}$ & 0.0322 & 0.0526 & $63.32 \%$ & $(13.54)^{* * *}$ \\
\hline Emerging Competitors & 0.0421 & 0.0465 & $10.63 \%$ & $(22.90) * * *$ & 0.0422 & 0.0464 & $9.92 \%$ & $(13.13)^{* * *}$ \\
\hline $\begin{array}{l}\text { Africa - Middle East } \\
\text { Competitors }\end{array}$ & 0.0363 & 0.0472 & $30.01 \%$ & $(22.19)^{* * *}$ & 0.0350 & 0.0471 & $34.57 \%$ & $(12.76)^{* * *}$ \\
\hline Asia - Pacific Competitors & 0.0368 & 0.0510 & $38.79 \%$ & $(71.51)^{* * *}$ & 0.0367 & 0.0511 & $39.15 \%$ & $(13.54)^{* * *}$ \\
\hline Europe Competitors & 0.0299 & 0.0449 & $50.32 \%$ & $(67.76)^{* * *}$ & 0.0299 & 0.0448 & $50.13 \%$ & $(13.54)^{* * *}$ \\
\hline Latin America Competitors & 0.0679 & 0.0621 & $-8.50 \%$ & $(-11.47)^{* * *}$ & 0.0689 & 0.0620 & $-10.05 \%$ & $(-9.37)^{* * *}$ \\
\hline North America Competitors & 0.0351 & 0.0395 & $12.46 \%$ & $(7.77)^{* * *}$ & 0.0337 & 0.0390 & $15.63 \%$ & $(7.48)^{* * *}$ \\
\hline Developed - Asia - Pacific & 0.0382 & 0.0531 & $39.15 \%$ & $(60.84)^{* * *}$ & 0.0380 & 0.0529 & $39.11 \%$ & $(13.54)^{* * *}$ \\
\hline Emerging - Asia - Pacific & 0.0387 & 0.0441 & $14.02 \%$ & $(23.14)^{* * *}$ & 0.0387 & 0.0441 & $13.99 \%$ & $(13.03)^{* * *}$ \\
\hline Developed - Europe & 0.0266 & 0.0457 & $71.56 \%$ & $(60.16)^{* * *}$ & 0.0263 & 0.0452 & $72.10 \%$ & $(13.54)^{* * *}$ \\
\hline Emerging - Europe & 0.0333 & 0.0397 & $19.04 \%$ & $(25.66)^{* * *}$ & 0.0333 & 0.0398 & $19.55 \%$ & $(13.18)^{* * *}$ \\
\hline Developed - North America & 0.0273 & 0.0365 & $33.46 \%$ & $(25.66)^{* * *}$ & 0.0244 & 0.0361 & $47.71 \%$ & $(13.16)^{* * *}$ \\
\hline Emerging- North America & 0.0429 & 0.0427 & $-0.42 \%$ & $(-0.17)$ & 0.0419 & 0.0420 & $0.38 \%$ & $(0.58)$ \\
\hline All Exchanges & 0.0366 & 0.0413 & $12.70 \%$ & $16.61 * * *$ & 0.0363 & 0.0409 & $12.87 \%$ & $9.24 * * *$ \\
\hline
\end{tabular}

The long-term univariate results are consistent with the short-term results. The merging exchanges experienced significant reductions in bid-ask spreads in the long-term $(8.3 \%$

\footnotetext{
${ }^{10}$ The pairwise averaging involves averaging specific days over the 3 -year post-merger period and comparing this average to the corresponding day in the pre-merger period (e.g. averaging 3 day $1 \mathrm{~s}$ in the post-merger period and comparing this average to the day 1 in the pre-demutualization period).
} 
reduction in mean and $7.4 \%$ reduction in median bid-ask spreads). The reductions in bidask spreads are largely due to reductions in bid-ask spreads on bidder exchanges - since target exchanges and non-merging exchanges (including developed and emerging rivals) experienced increases in bid-ask spreads. Geographically, except for competitors in Latin American countries who achieved significant reductions in bid-ask spreads and developed North American rivals who saw insignificant increases in bid-ask spreads in the long term, all other rivals experienced significant increases in bid-ask spreads in the long term.

\subsection{Bid-Ask Spreads SUR Regression Equations}

The long-term SUR regressions are reported in Table 2.11. As evident from the results, the mergers have resulted in significant decreases in bid-ask spreads for the merging exchanges as a whole and bidders specifically. Consistent with the long term univariate analyses of means and medians, target exchanges and non-merging exchanges (including developed and emerging market rivals) continue to see significant increases in bid-ask spreads in the post-merger period.

\section{Table 2.11 - Long Term Bid-Ask Spreads SUR Regression Equations}

In this table, we present the results of the seemingly unrelated regression equations that regress the bid-ask spreads on the merger completion dummies (which take the value of 1 in the post- merger period and zero in the pre-merger period) and other control variables. The other independent/control variables are firm market capitalization, price inverse, volume, return standard deviation, exchange market share, domestic market capitalization, listed firms, synergy, GDP per capita and a linear time trend. The results are for all the mergers combined. (z statistics are in parentheses.)

\begin{tabular}{lccccccc}
\hline Variable & $\begin{array}{l}\text { Merging } \\
\text { Firms }\end{array}$ & \multirow{2}{*}{ Bidders } & Targets & $\begin{array}{l}\text { All } \\
\text { Competitors }\end{array}$ & $\begin{array}{l}\text { Developed } \\
\text { Competitors }\end{array}$ & $\begin{array}{l}\text { Emerging } \\
\text { Competitors }\end{array}$ & $\begin{array}{l}\text { All } \\
\text { Exchanges }\end{array}$ \\
\hline $\begin{array}{l}\text { Merger } \\
\text { Dummy }\end{array}$ & -0.0046 & -0.0127 & 0.0040 & 0.0017 & 0.0050 & 0.0021 & 0.0012 \\
& $(-4.91)^{* * *}$ & $(-7.16)^{* * *}$ & $(3.72)^{* * *}$ & $(3.67)^{* * *}$ & $(5.60)^{* * *}$ & $(2.47)^{* *}$ & $(2.55)^{* *}$ \\
\multirow{2}{*}{ Mkt Cap Firm } & 0.0030 & 0.0248 & -0.0040 & -0.0015 & -0.0091 & -0.0026 & -0.0061 \\
& $(1.67)^{*}$ & $(7.24)^{* * *}$ & $(-3.16)^{* * *}$ & $(-1.22)$ & $(-3.45)^{* * *}$ & $(-1.89)^{*}$ & $(-5.62)^{* * *}$
\end{tabular}




\begin{tabular}{|c|c|c|c|c|c|c|c|}
\hline Variable & $\begin{array}{l}\text { Merging } \\
\text { Firms }\end{array}$ & Bidders & Targets & $\begin{array}{l}\text { All } \\
\text { Competitors }\end{array}$ & $\begin{array}{l}\text { Developed } \\
\text { Competitors }\end{array}$ & $\begin{array}{l}\text { Emerging } \\
\text { Competitors }\end{array}$ & $\begin{array}{l}\text { All } \\
\text { Exchanges }\end{array}$ \\
\hline \multirow[t]{2}{*}{ Inv Price } & 0.0012 & 0.0080 & -0.0041 & 0.0111 & 0.0053 & 0.0109 & 0.0076 \\
\hline & $(1.00)$ & $(7.38)^{* * *}$ & $(-0.77)$ & $(5.62)^{* * *}$ & $(3.52)^{* * *}$ & $(2.37)^{* *}$ & $(6.27)^{* * *}$ \\
\hline \multirow[t]{2}{*}{ Std Dev } & 0.9280 & 0.1693 & 0.8569 & 0.2946 & 0.0199 & 0.3566 & 0.1929 \\
\hline & $(9.04)^{* * *}$ & (1.10) & $(11.96)^{* * *}$ & $(3.26)^{* * *}$ & $(0.20)$ & $(3.20)^{* * *}$ & $(2.33)^{* *}$ \\
\hline \multirow[t]{2}{*}{ Volume } & 0.0053 & 0.0028 & 0.0009 & -0.0057 & -0.0044 & -0.0036 & -0.0043 \\
\hline & $(4.22)^{* * *}$ & $(1.36)$ & (1.15) & $(-7.41)^{* * *}$ & $(-4.14)^{* * *}$ & $(-4.39)^{* * *}$ & $(-5.32)^{* * *}$ \\
\hline \multirow[t]{2}{*}{ Mkt Share } & 0.0288 & 0.0947 & 0.0055 & -0.6135 & -1.9901 & -0.1930 & 0.2293 \\
\hline & $(1.47)$ & $(1.86)^{*}$ & $(0.43)$ & $(-3.13)^{* * *}$ & $(-3.68)^{* * *}$ & $(-1.19)$ & $(5.16)^{* * *}$ \\
\hline \multirow[t]{2}{*}{$\begin{array}{l}\text { Mkt Cap } \\
\text { Exch }\end{array}$} & 0.0112 & 0.0193 & -0.0073 & -0.0153 & -0.0107 & -0.0158 & -0.0110 \\
\hline & $(4.50)^{* * *}$ & $(5.30)^{* * *}$ & $(-2.31)^{* *}$ & $(-9.66)^{* * *}$ & $(-3.26)^{* * *}$ & $(-11.78)^{* * *}$ & $(-8.93)^{* * *}$ \\
\hline \multirow[t]{2}{*}{ Lstd Firms } & -0.0526 & -0.0515 & -0.0572 & 0.0078 & -0.0058 & 0.0066 & 0.0056 \\
\hline & $(-10.25)^{* * *}$ & $(-8.26)^{* * *}$ & $(-4.98)^{* * *}$ & $(1.55)$ & $(-1.09)$ & (1.11) & $(2.48)^{* *}$ \\
\hline \multirow[t]{2}{*}{ Synergy } & 0.0017 & -0.0075 & 0.0036 & -0.0014 & 0.0019 & -0.0051 & -0.0012 \\
\hline & $(0.80)$ & $(-1.51)$ & $(2.64)^{* * *}$ & $(-0.82)$ & $(0.79)$ & $(-2.55)^{* *}$ & $(-0.73)$ \\
\hline \multirow[t]{2}{*}{ Linear Trend } & 0.0000 & 0.0000 & 0.0000 & 0.0000 & 0.0000 & 0.0000 & 0.0000 \\
\hline & $(-0.37)$ & $(0.39)$ & $(0.43)$ & $(5.93)^{* * *}$ & $(7.89)^{* * *}$ & $(4.54)^{* * *}$ & $(4.48)^{* * *}$ \\
\hline \multirow[t]{2}{*}{$\begin{array}{l}\text { Lag GDP per } \\
\text { Cap }\end{array}$} & 0.0000 & 0.0000 & 0.0000 & 0.0000 & 0.0000 & 0.0000 & 0.0000 \\
\hline & $(2.09)^{* *}$ & $(1.96)^{* *}$ & $(-0.29)$ & $(3.92)^{* * *}$ & $(1.28)$ & $(-0.29)$ & $(3.37)^{* * *}$ \\
\hline \multirow[t]{2}{*}{ Constant } & 0.1281 & -0.1556 & 0.5938 & 0.2370 & 0.3109 & 0.2411 & 0.2212 \\
\hline & $(2.01)^{* *}$ & $(-2.37)^{* *}$ & $(4.32)^{* * *}$ & $(9.10)^{* * *}$ & $(7.53)^{* * *}$ & $(6.29)^{* * *}$ & $(18.64)^{* * *}$ \\
\hline $\mathrm{N}$ & 500 & 500 & 500 & 500 & 500 & 500 & 500 \\
\hline $\mathrm{R}^{2}$ & 0.6382 & 0.6095 & 0.8971 & 0.9446 & 0.9688 & 0.8016 & 0.9204 \\
\hline
\end{tabular}

All in all, since the merging firms (specifically the bidders) experienced long-term and short-term declines in bid-ask spreads following the mergers, we contend that the mergers appear to be motivated by (and did lead to) liquidity and efficiency gains. One plausible explanation for the increase in bid-ask spreads on target stock exchanges may be that market participants realized that the targets now have improved reputations as a result of mergers with well-known exchanges, and that they exploited this increased reputational capital by exacting economic rents through increased bid-ask spreads. Also, since the bid-ask spreads were lower on target exchanges prior to the mergers, another plausible explanation might be that the desire for consistency and some 
equilibrium/similarity in spreads on the combined exchanges likely led to the increase in spreads on target exchanges and decrease in spreads on bidding exchanges. However, given that bid-ask spreads also increased over the long-term on non-merging exchanges, a more likely explanation is that the mergers led to liquidity and efficiency gains, which then translated into short- and long-term decreases in bid-ask spreads at times that spreads were generally increasing.

\subsubsection{Influence of Other Factors on Bid-Ask Spreads}

We also examined the impact of other factors on short-term bid-ask spreads including market share, synergy and number of listed firms. We argued that bid-ask spreads on the merging exchanges will fall in the post-merger period because we expect the merging firms to increase their market share, and the attendant increase in order flow to lead to increased liquidity and reductions in bid-ask spreads. If this is the case, then we expect the coefficient of the market share variable to be negative. As indicated in Table 2.9 (column C), the market share variable is significantly negative for the merging firms and is largely driven by bidders who are perhaps passing on savings to investors (as a result of the increased market share). The significantly positive coefficient for the targets is symptomatic of market participants on targets using the increased market share to extract more economic rents (in the form of increased bid-ask spreads) - a result more akin to targets exercising some market power to achieve additional economic rents. The coefficients of market share for all rivals and most of the various portfolios of rivals are also significantly negative - lending support to our contention that increased market share leads to increased order flow, increased liquidity and reductions in cost of transacting (as 
measured by bid-ask spreads). The long-term results also largely support this contention. Although the merger dummy variable subsumes the market share variable for the merging exchanges, the market share coefficient is largely negative for rivals.

We also included synergy in our bid-ask SUR regressions and find that the results mimic the impact that synergy has in our market share regressions. We find that although synergy does not incrementally impact the merging firms ${ }^{11}$, it does burden rivals with a competitive disadvantage in the form of increased bid-ask spreads in the short-term.

From column D in Table 2.9, the significantly positive coefficient of synergy for all rivals as well as those from developed and emerging countries - implies that all of these rivals experienced significant increases in bid-ask spreads as a result of merger synergies. In the long-term, however, synergy does not appear to have any noticeable effect on bid-ask spreads, as the synergy coefficient is largely insignificant.

Pagano (1989) argues that the consolidation of order flow through stock exchange mergers would lead to positively beneficial network externalities. To evaluate the impact of network externalities on short-term bid-ask spreads, we included the number of firms listed as a proxy for network externalities because it captures the increases in users (e.g. firms, shareholders) resulting from the mergers. As shown in column E of Table 2.9, the coefficient of listed firms is significantly positive in several instances in the short term. Since our expectation was for a negative coefficient, the significantly positive coefficients indicate that exchanges experiencing increasing number of listed firms used this as an opportunity to extract economic rents from investors (in the short term) instead

\footnotetext{
${ }^{11}$ Targets seem to be exploiting the synergy to exact more economic rents.
} 
of passing on the savings to investors in the form of lower bid-ask spreads. In the longterm, the effects of network externalities become manifest. From Table 2.11, the coefficient of listed firms is significantly negative for the merging exchanges - as hypothesized by the network externality hypothesis.

Therefore, we find support for the argument that increased market share as a result of the mergers will increase liquidity and lead to decreased bid-ask spreads and market quality. We also find evidence to support the role of synergy in exchange mergers and find limited evidence to support the network externality argument in stock exchange mergers.

\subsubsection{Robustness Tests}

To gauge the sensitivity of our results to alternative assumptions and measures, we conducted a number of robustness tests.

\subsubsection{Volatility as Measure of Market Quality}

Market quality, as already noted, is a multidimensional concept having several measures. Domowitz and Steil (2001) for example view market quality as a three-dimensional concept hinging on liquidity, informational efficiency and volatility. Although we used bid-ask spreads as our main measure of market quality, we also evaluated changes in price volatility to determine the pervasiveness of market quality improvements as a result of the mergers. 
Figure 2.3 - Long-Term Trends in Price Volatility

Figure 2.3 presents the long-term trends in price volatility. Figure 2.3a shows price volatility for merging and non-merging exchanges, Figure $2.3 \mathrm{~b}$ exhibits the industry adjusted price volatility and Figure $2.3 \mathrm{c}$ displays price volatility trends for bidders, targets and nonmerging exchanges.
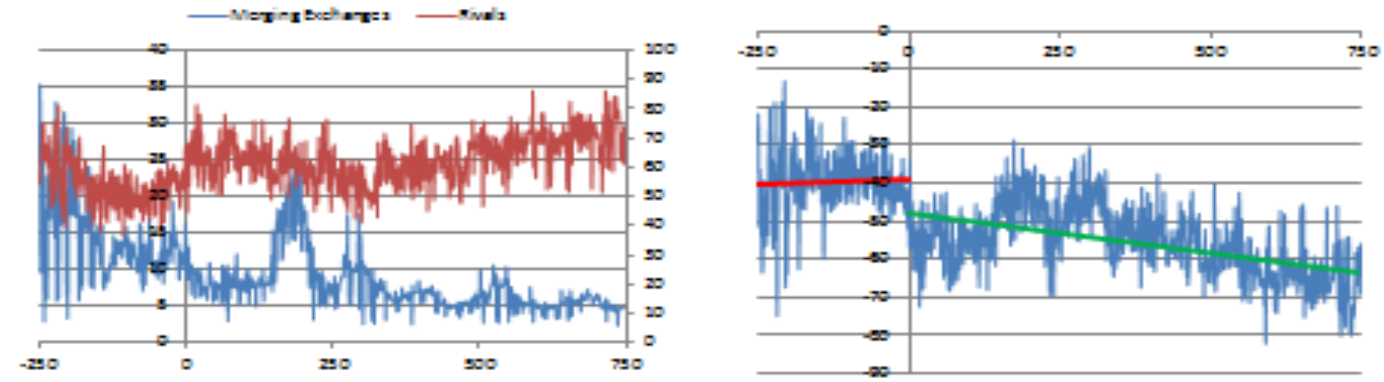

a) 3-month prico standard deviztion for meging exchenges and aivals

b) Indeatry adjusad prios volatility

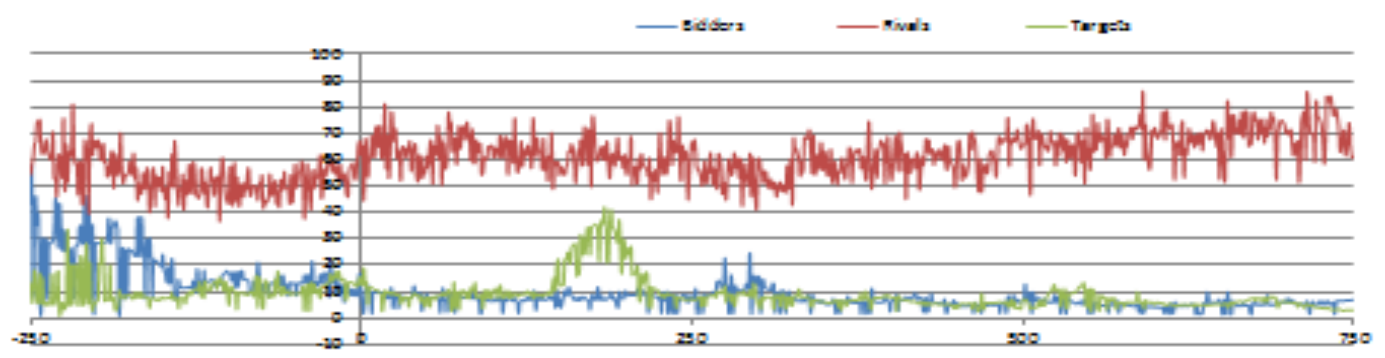

c) 3-month price standerd deviztion for targota, bidders and rivals

As shown in Figure 2.3a, the standard deviation of 3-month price (our proxy for price volatility) was high for the merging exchanges relative to that of non-merging exchanges in the pre-merger period. In the post-merger period, however, price volatility has been decreasing for the merging exchanges but increasing for the rivals. A similar pattern emerges from Figure $2.3 \mathrm{~b}$ which shows the 'industry adjusted' price volatility (i.e. difference between price volatility of merging exchanges and rival exchanges). While price volatility for the merging exchanges were increasing relative to that of rivals in the pre-merger period, this trend has reversed in the post-merger period, with price volatility for the merging exchanges decreasing relative to that on rival exchanges in the postmerger period. A breakdown of the merging firms into targets and bidders (Figure 2.3c) 
shows that the improvements in price volatility in the post-merger period have benefited bidders as well as targets.

Our price volatility results show that the stock exchange mergers have had a positive effect on not just transaction costs but also on the price discovery process.

\subsubsection{Calendar Time Market Share Analysis}

We also examined the impacts of the stock exchange mergers on market share using the calendar time approach. The results generally corroborate the event time results. The general finding that the merging firms as a group were able to increase their market share at the expense of rivals is also confirmed with the calendar time analysis (Table 2.12).

\section{Table 2.12 - Calendar Time Market Share Results}

\begin{tabular}{|c|c|c|c|c|c|c|}
\hline Portfolio & $\begin{array}{l}\text { NYSE- } \\
\text { Archipelago } \\
\text { Dummy }\end{array}$ & $\begin{array}{l}\text { NYSE- } \\
\text { Euronext } \\
\text { Dummy }\end{array}$ & $\begin{array}{l}\text { CME- } \\
\text { CBOT } \\
\text { Dummy }\end{array}$ & $\begin{array}{l}\text { DB-ISE } \\
\text { Dummy }\end{array}$ & $\begin{array}{l}\text { NASDAQ- } \\
\text { OMX } \\
\text { Dummy }\end{array}$ & $\begin{array}{l}\text { LSE-BI } \\
\text { Dummy }\end{array}$ \\
\hline \multicolumn{7}{|c|}{ Panel A - 3 Years Pre and 4 Years Post } \\
\hline \multirow[t]{2}{*}{ All Merging Firms } & 0.0115 & -0.0036 & 0.0041 & 0.0096 & -0.0007 & 0.0039 \\
\hline & $(3.59)^{* * *}$ & $(-0.69)$ & $(0.68)$ & $(1.37)$ & $(-0.13)$ & $(0.64)$ \\
\hline \multirow[t]{2}{*}{ All Competitors } & -0.0018 & 0.0008 & -0.0007 & -0.0012 & 0.0001 & -0.0007 \\
\hline & $(-6.65)^{* * *}$ & $(1.77)^{*}$ & $(-1.33)$ & $(-1.85)^{*}$ & $(0.22)$ & $(-1.27)$ \\
\hline \multirow{2}{*}{$\begin{array}{l}\text { Developed Markets } \\
\text { Competitors }\end{array}$} & -0.0014 & -0.0008 & -0.0002 & 0.0002 & 0.0000 & 0.0000 \\
\hline & $(-3.61)^{* * *}$ & $(-1.79)^{*}$ & $(-0.44)$ & $(0.29)$ & $(0.07)$ & $(0.06)$ \\
\hline \multirow[t]{2}{*}{ Emerging Markets Competitors } & -0.0008 & 0.0025 & -0.0011 & 0.0010 & 0.0006 & -0.0012 \\
\hline & $(-1.99)^{* *}$ & $(3.83)^{* * *}$ & $(-1.37)$ & $(1.03)$ & $(0.72)$ & $(-1.51)$ \\
\hline \multirow[t]{2}{*}{ All Exchanges } & -0.0013 & 0.0004 & 0.0000 & 0.0000 & 0.0001 & 0.0000 \\
\hline & $(-10.37)^{* * *}$ & $(2.05)^{* *}$ & $(-0.06)$ & $(-0.08)$ & $(0.37)$ & $(-0.12)$ \\
\hline
\end{tabular}




\begin{tabular}{|c|c|c|c|c|c|c|}
\hline Portfolio & $\begin{array}{l}\text { NYSE- } \\
\text { Archipelago } \\
\text { Dummy }\end{array}$ & $\begin{array}{l}\text { NYSE- } \\
\text { Euronext } \\
\text { Dummy }\end{array}$ & $\begin{array}{l}\text { CME- } \\
\text { CBOT } \\
\text { Dummy }\end{array}$ & $\begin{array}{l}\text { DB-ISE } \\
\text { Dummy }\end{array}$ & $\begin{array}{l}\text { NASDAQ- } \\
\text { OMX } \\
\text { Dummy }\end{array}$ & $\begin{array}{l}\text { LSE-BI } \\
\text { Dummy }\end{array}$ \\
\hline \multicolumn{7}{|l|}{ Panel B - Symmetric 3 years } \\
\hline \multirow[t]{2}{*}{ All Merging Firms } & 0.0138 & -0.0060 & 0.0051 & 0.0069 & 0.0014 & 0.0048 \\
\hline & $(4.38)^{* * *}$ & $(-1.21)$ & $(0.88)$ & $(1.03)$ & $(0.25)$ & $(0.83)$ \\
\hline \multirow[t]{2}{*}{ All Competitors } & -0.0019 & 0.0009 & -0.0007 & -0.0006 & 0.0000 & -0.0007 \\
\hline & $(-6.89)^{* * *}$ & $(2.14)^{* *}$ & $(-1.48)$ & $(-0.96)$ & $(-0.08)$ & $(-1.41)$ \\
\hline \multicolumn{7}{|l|}{ Developed Markets } \\
\hline \multirow[t]{2}{*}{ Competitors } & -0.0015 & -0.0009 & -0.0003 & 0.0002 & -0.0004 & 0.0000 \\
\hline & $(-4.08)^{* *}$ & $(-1.99)^{* *}$ & $(-0.55)$ & $(0.33)$ & $(-0.79)$ & $(0.02)$ \\
\hline \multirow[t]{2}{*}{ Emerging Markets Competitors } & -0.0006 & 0.0026 & -0.0011 & 0.0012 & 0.0003 & -0.0012 \\
\hline & $(-1.42)$ & $(4.24)^{* * *}$ & $(-1.43)$ & $(1.35)$ & $(0.44)$ & $(-1.58)$ \\
\hline \multirow[t]{2}{*}{ All Exchanges } & -0.0013 & 0.0005 & 0.0000 & 0.0001 & 0.0002 & 0.0000 \\
\hline & $(-10.11)$ & $(2.30)^{* *}$ & $(-0.08)$ & $(0.25)$ & $(0.63)$ & $(-0.16)$ \\
\hline
\end{tabular}

Using Panel A (i.e. data starting three years before the first merger and ending four years after the last merger), the NYSE-Archipelago dummy (which represents the completion of the earliest of the six mergers) is significantly positive for the portfolio of merging firms (at the $1 \%$ level) and significantly negative for the portfolio of rivals (at the $1 \%$ level). While the merging firms collectively gained $1.1 \%$ in the period following the completion of the NYSE-Archipelago merger, the rivals collectively lost $0.2 \%$ over the same period as a result of the NYSE-Archipelago merger. The rivals also lost $0.1 \%$ as a result of the Deutsche Boerse-ISE merger (10\% significance) but gained $0.1 \%$ market share as a result of the NYSE-Euronext merger (10\% level of significance). The other dummies for the remaining mergers are however subsumed by (mostly) the NYSEArchipelago dummy - and are not significantly different from zero. Conclusions are qualitatively similar when we use the results of Panel B (which uses a symmetric three years of data starting three years before the first merger and ending three years after the last merger). 
The calendar time results are therefore qualitatively similar to the event time results.

\subsubsection{Other Robustness Tests}

A number of other robustness tests were performed including estimating the event time market share SUR regression equations over a symmetrical 3-year period from 36 months before the merger completion dates to 36 months after the merger completions as well as estimating the abnormal returns over the forty one days surrounding the merger announcement dates (i.e. day $[-20,+20])$. The results of the various robustness tests are qualitatively similar to the main results reported earlier.

\section{Table 2.13 - Other Robustness Tests}

Panel A presents seemingly unrelated regression analysis of the six mergers combined where market share (three years before and after the merger completions) is regressed on the merger dummy, a linear time trend, log revenues, domestic market capitalization, synergy and GDP per capita. The merger dummy takes the value of one after the merger completion and zero otherwise. Panel B presents stock price performance SUR regressions for the day $[-20,+20]$ window using the pooled data that starts 250 days before the earliest merger announcement date and ends 250 days after the last merger announcement date. Stock returns are regressed on market returns, relative size, book-to-market, GDP per capita and merger day dummies (which take the value of one on the day(s) of interest and zero otherwise). The coefficients reported are those associated with the merger dummies. (z-statistics are in parentheses.)

\begin{tabular}{|c|c|c|c|c|c|}
\hline & $\begin{array}{l}\text { All } \\
\text { Merging } \\
\text { Firms } \\
\end{array}$ & $\begin{array}{l}\text { All } \\
\text { Competitors }\end{array}$ & $\begin{array}{l}\text { Developed } \\
\text { Markets } \\
\text { Competitors }\end{array}$ & $\begin{array}{l}\text { Emerging } \\
\text { Markets } \\
\text { Competitors }\end{array}$ & $\begin{array}{l}\text { All } \\
\text { Exchanges }\end{array}$ \\
\hline \multicolumn{6}{|c|}{ Panel A - Event time Symmetric Three Years } \\
\hline \multirow[t]{2}{*}{ All Mergers } & 0.0069 & -0.0008 & -0.0009 & 0.0000 & 0.0001 \\
\hline & $(4.21)^{* * *}$ & $(-5.09)^{* * *}$ & $(-4.95)^{* * *}$ & $(0.21)$ & '(1.05) \\
\hline \multicolumn{6}{|c|}{ Panel B - Day $[-20,+20]$ Abnormal Returns } \\
\hline \multirow[t]{2}{*}{ All Mergers } & -0.0003 & 0.0005 & 0.0016 & -0.0007 & 0.0012 \\
\hline & $(-0.22)$ & $(0.35)$ & $(0.98)$ & $(-0.44)$ & $(1.23)$ \\
\hline
\end{tabular}

From panel A of Table 2.13, the event time results using a symmetric three years before and three years after the merger completion dates are similar to the main event time results. Specifically, the merging entities gained market share at the expense of rivals. 
From panel B of Table 2.13, the abnormal returns are insignificant as the event window is widened - confirming our earlier findings that there was absence of information leakage and that the markets quickly and efficiently impounded new information about the mergers into stock prices.

\subsection{Conclusion}

Stock exchange mergers are becoming an increasingly popular strategic choice in the face of the increased competition in the stock exchange industry, which has emanated predominantly from significant advances in technology and globalization. Despite their popularity, and the special role stock exchanges play in the development of the economy, less is known about the effects of stock exchange mergers on order flow and market liquidity. We examined the stock market and product market (market share as well as bid-ask spreads) impacts of stock exchange mergers.

First, with respect to the stock market effects of the mergers, our results (which are largely consistent with the general mergers and acquisitions literature) show that the stock exchange mergers have led to significant wealth creation for shareholders of targets as well as for shareholders of the combined firms. Shareholders of targets and the combined firms realized significantly positive abnormal returns of between $0.6 \%$ and $3.0 \%$ over several event windows. Our results also indicate that shareholders of rival exchanges from countries that are geographically proximate and/or at the same level of development realized significant abnormal returns, thus highlighting the primacy of 
geographical nearness and level of development in the stock exchange industry. Second, our market share analyses show that the merging exchanges achieved significant increase in market share of about $0.9 \%$ in the post-merger completion period, and this increased market share was mainly achieved at the expense of rival exchanges that, on average, lost a significant $0.1 \%$ in market share in the post-merger completion period.

Finally, our bid-ask spreads results show that the merging exchanges were able to significantly reduce their bid-ask spreads in the short-term and long-term following the merger completions. While the bid-ask spreads on the merging exchanges narrowed, rival stock exchanges saw increases in bid-ask spreads. We conjecture that the increased market share realized by the merging firms led to increased order flow as well as increased liquidity and the reduction in bid-ask spreads in the short- and long-term, while the decrease in market share for rivals led to decreased liquidity and consequently increases in bid-ask spreads for firms listed on the competitor exchanges.

Our results show that stock exchange mergers as a strategic choice in the currently competitive business environment lead to wealth creation on the stock market and value creation on the product market for the exchanges involved. However, we would like to flag a caveat regarding the study. Since there are only a few stock exchange mergers, our sample size is naturally small, albeit it covers the major financial exchanges. Therefore, caution should be exercised when generalizing the results. 


\section{References}

Acharya, S. (1993). Value of Latent Information: Alternative Event Study Methods, Journal of Finance, 48(1), pp. 363-385.

Aggarwal, R. (2002). Demutualization and Corporate Governance of Stock Exchanges, Journal of Applied Corporate Finance, 15(1), pp. 105-113.

Ahern, K.R. and Sosyura, D. (2014). Who Writes the News? Corporate Press Releases during Merger Negotiations, Journal of Finance, 69(1), pp. 241-291.

Andrade, G. and Stafford, E. (2003). Investigating the Economic Role of Mergers, Journal of Corporate Finance, 10, pp. 1-36.

Arnold, T., Hersch, P., Mulherin, J.H. and Netter, J. (1999). Merging Markets, Journal of Finance, 54 (3), pp. 1083-1107.

Barber, B.M. and Lyon, J.D. (1997). Detecting Long-Run Abnormal Stock Returns: The Empirical Power and Specification of Test Statistics, Journal of Financial Economics, 43, pp. 341-372.

Barclay, M.J., Christie, W.G., Harris, J.H., Kandel, E. and Schultz, P.H. (1999). Effects of Market Reform on the Trading Costs and Depths of Nasdaq Stocks, Journal of Finance, 54 (1), pp. 1-34.

Bargeron, L.L., Schlingemann, F.P., Stulz, R.M. and Zutter, C.J. (2008). Why do Private Acquirers pay so Little Compared to Public Acquirers? Journal of Financial Economics, 89, pp.375-390.

Berkovitch, E. and Narayanan, M.P. (1993). Motives for Takeovers: An Empirical Investigation, Journal of Financial and Quantitative Analysis, 28(3), pp. 347-362.

Bessembinder, H. (2003). Trade Execution Costs and Market Quality after Decimalization, Journal of Financial and Quantitative Analysis, 38(4), 747-777.

Bessembinder, H. and Kaufman, H. (1997). A Cross-Exchange Comparison of Execution Costs and Information Flow for NYSE-listed Stocks, Journal of Financial Economics 46, pp. 293-319.

Binder, J.J. (1985). On the use of Multivariate Regression Model in Event Studies, Journal of Accounting Research, 23, pp. 370-383.

Bloomberg (2012). Deutsche Boerse-NYSE Takeover Vetoed by European Commission, http://www.bloomberg.com/news/2012-02-01/european-commission-blocks-proposeddeutsche-boerse-nyse-euronext-merger.html. (Last accessed 2014/06/27). 
Bloomberg (2014). Euronext Detaches From ICE Through \$1.2 Billion IPO, http://www.bloomberg.com/news/2014-06-19/ice-may-price-euronext-near-lower-end-in1-1-billion-ipo.html. (Last accessed 2014/06/28).

Chemmanur, T. J. and Fulghieri, P. (2006). Competition and Cooperation among Exchanges: A Theory of Cross-Listings and Endogenous Listing Standards, Journal of Financial Economics, 82, pp. 455-489.

Coval, J.D and Moskowitz, T.J (1999). Home Bias at Home: Local Equity Preference in Domestic Portfolios, Journal of Finance, 54(6), pp. 2045-2073.

Demsetz, H. (1968). The Cost of Transacting, Quarterly Journal of Economics, 82(1), pp. 33-53.

Devos, E., Kadapakkam, P-R. and Krishnamurthy, S. (2009). How Do Mergers Create Value? A Comparison of Taxes, Market Power, and Efficiency Improvements as Explanations for Synergies, Review of Financial Studies, 22(3), pp. 1179-1211.

Di Noia, C. (1999). The Stock-Exchange Industry: Network Effects, Implicit Mergers and Corporate Governance, Quaderni de Finanza. No. 33.

Di Noia, C. (2001). Competition and Integration among Stock Exchanges in Europe: Network Effects, Implicit Mergers and Remote Access, European Financial Management, 7(1), pp. 39-72.

Domowitz, I. and Steil, B. (2001). Automation, Trading Costs, and the Structure of the Securities Trading industry, in Davis, E. and Steil, B. (Eds) Institutional Investors, MIT Press, London, pp. 347-397.

Dutta, S. and Jog, V. (2009). The Long-Term Performance of Acquiring Firms: A ReExamination of an Anomaly, Journal of Banking and Finance, 33, pp. 1400-1412.

Eckbo, E. (1983). Horizontal Mergers, Collusion, and Stockholder Wealth, Journal of Financial Economics, 11, pp. 241-273.

Economist (2012). Deutsche Börse and NYSE Euronext: Why the marriage failed, http://www.economist.com/blogs/freeexchange/2012/02/deutsche-b\%C3\%B6rse-andnyse-euronext. (Last accessed 2014/06/27).

Euromoney (2011). Inside investment: Regulation drives stock exchange mergers, http://www.euromoney.com/Article/2862964/Inside-investment-Regulation-drives-stockexchange-mergers.html (Last accessed 2014/06/27).

European Commission (2012). Mergers: Commission blocks proposed merger between Deutsche Börse and NYSE Euronext, Presss Release, http://europa.eu/rapid/pressrelease_IP-12-94 en.htm?locale=en. (Last accessed 2014/06/27). 
Faulconbridge, J., Engelen, W., Hoyler, M. and Beaverstock, J. (2007). Analysing the Changing Landscape of European Financial Centres: The Role of Financial Products and the Case of Amsterdam, Growth and Change, 38(2), pp. 279-303.

Financial News (2013). Ten questions raised by Ice-NYSE merger, http://www.efinancialnews.com/story/2012-12-20/ten-questions-raised-by-ice-nysemerger-talks. (Last accessed 2014/06/28).

Financial Times (2013). NYSE Euronext takeover poses tough challenges for ICE boss, http://www.ft.com/cms/s/0/1b2c1e94-4b12-11e3-ac3d00144feabdc0.html\#axzz35xcvk5hv. (Last accessed 2014/06/28).

Fortune International Europe Edition (2006). What's Driving the Stock Exchange Merger Binge? June 12, 2006, Vol. 153, Issue 10.

Fortune International Europe Edition (2007). Exchange Merger Mania, Round Two, July 9, 2007, Vol. 156, Issue 1.

Fuller, K., Netter, J. and Stegemoller, M. (2002). What Do Returns to Acquiring Firms Tell Us? Evidence from Firms That Make Many Acquisitions, Journal of Finance, 57(4), pp. 1763-1793.

Gordon, C. (2011). Competing in Global Niche Markets: The Case of Macquarie Bank, International Journal of Bank Marketing, 29(4), pp. 293-307.

Haleblian, J., Devers, C.E., McNamara, G., Carpenter, M.A. (2009). Taking Stock of What We Know About Mergers and Acquisitions: A Review and Research Agenda, Journal of Management, 35(3), pp. 469-502.

Han, K.C., Suk, D.Y. and Sung, H.M. (1998). The Evidence of Bidders' Overpayment in Takeovers: The Valuation Ratios Approach, Financial Review, 33, pp. 55-68.

Hart, O. and Moore, J. (1996). The Governance of Exchanges: Members' Cooperative versus Outside Ownership, Oxford Review of Economic Policy, 12(4), pp. 53-69.

Hasan, I., Schmiedel, H. and Song, L. (2012). Growth Strategies and Value Creation: What Works Best for Stock Exchanges? Financial Review, 47, pp. 469-499.

Hellström, J., Liu, Y. and Sjögren, T. (2013). Stock Exchange Mergers and Return CoMovement : A Flexible Dynamic Component Correlations Model, Economics Letters, 121, pp. 511-515.

Hietala, P., Kaplan, S.N. and Robinson, D.T. (2003). What is the Price of Hubris: Using Takeover Battles to Infer Overpayments and Synergy, Financial Management, 32(3), pp. 5-31. 
Hoberg, G. and Phillips, G. (2010). Product Market Synergies and Competition in Mergers and Acquisitions: A Text-Based Analysis, Review of Financial Studies, 23(10), pp. 3773-3811.

Jain, P. (2003). Institutional Design and Liquidity on Stock Exchanges, Working Paper.

Jain, P.K. (2005). Financial Market Design and the Equity Premium: Electronic versus Floor Trading, Journal of Finance, 60(6), pp. 2955-2985.

Jensen, M.C. and Ruback, R.S. (1983). The Market for Corporate Control: The Scientific Evidence, Journal of Financial Economics, 11, pp. 5-50.

Khan, W. and Vieito, J.P. (2012). Stock Exchange Mergers and Weak Form of Market Efficiency: The Case of Euronext Lisbon, International Review of Economics and Finance, 22, pp. 173-189.

Kim, E.H. and Singal, V. (1993). Mergers and Market Power: Evidence from the Airline Industry, American Economic Review, 83(3), pp. 549-569.

King, G., Keohane, R. and Verba, S. (1994). Designing Social Inquiry: Scientific Inference in Qualitative Research, Princeton, NJ: Princeton University Press. Chapter 1: The Science in Social Science, pp. 3-33.

Kokkoris, I. and Olivares-Caminal, R. (2008). Lessons from the Recent Stock Exchange Merger Activity, Journal of Competition Law and Economics, 4(3), pp. 837-869.

Kothari, S.P, and Warner, J.B. (2007). Econometrics of Event Studies in Eckbo, B.E. (Eds), Handbook of Corporate Finance: Empirical Corporate Finance: 1, North Holland, pp. 3-36.

Lee, R. (2002). The Future of Securities Exchanges, Brookings-Wharton Papers on Financial Services, pp. 1-33.

Macey, J.R. and O'Hara, M. (2002). The Economics of Stock Exchange Listing Fees and Listing Requirements, Journal of Financial Intermediation, 11, pp. 297-319.

Madhavan, A. (2000). Market Microstructure: A Survey, Journal of Financial Markets, 3, pp. 205-258.

Malkamäki, M. (1999). Are there Economies of Scale in Stock Exchange Activities? Bank of Finland Discussion Paper, \# 4.

Malmendier, U. and Tate, G. (2008).Who makes Acquisitions? CEO Overconfidence and the Market's Reaction, Journal of Financial Economics, 89, pp. 20-43. 
Manne, H.G. (1965). Mergers and the Market for Corporate Control, Journal of Political Economy, 73(2), pp. 110-120.

Martynova, M. and Renneboog, L. (2008). A Century of Corporate Takeovers: What Have We Learned and Where Do We Stand? Journal of Banking and Finance, 32, pp. $2148-2177$.

Michie, R. (2001). The London Stock Exchange: A History, Oxford University Press, Oxford, UK.

Moeller, S.B., Schlingemann, F.P. and Stilz, R.M. (2005). Wealth Destruction on a Massive Scale? A Study of Acquiring-Firm Returns in the Recent Merger Wave, Journal of Finance, 60(2), pp. 757-782.

Nielsson, U. (2009). Stock Exchange Merger and Liquidity: The Case of Euronext, Journal of Financial Markets, 12, pp. 229-267.

NYSE Group Newsletter (June 2006), http://www.nyse.com/about/publication/1145959806931.html (Last accessed 2014/06/27).

Oldford, E and Otchere, I. (2011). Can Commercialization Improve the Performance of Stock Exchanges Even without Corporatization? Financial Review, 46, pp. 67-87.

Otchere, I. (2006). Intra-industry Effects of Bank Privatization: A Clinical Analysis of the Commonwealth Bank of Australia, Journal of Banking and Finance, 27, pp. 949-975.

Otchere, I. (2006). Stock Exchange Self-Listing and Value Effects, Journal of Corporate Finance, 12, pp. 926-953.

Otchere, I. and Abou-Zied, K. (2008). Stock Exchange Demutualization, Self-listing and Performance: The Case of the Australian Stock Exchange, Journal of Banking and Finance, 32, pp. 512-525.

Pagano, M. (1989). Trading Volume and Asset Liquidity, Quarterly Journal of Economics, 104, pp. 255-274.

Pagano, M. and Padilla, A.J. (2005). Efficiency Gains from the Integration of Stock Exchanges: Lessons from the Euronext 'Natural Experiment', A report for Euronext, Non-confidential version.

Pirrong, C. (1999). The Organization of Financial Exchange Markets: Theory and Evidence, Journal of Financial Markets 2, pp. 329-357.

Preece, R. (2012). Dark Pools Internalization and Equity Market Quality, CFA Institute Paper, pp. 1-76. 
Roll, R. (1986). The Hubris Hypothesis of Corporate Takeovers, Journal of Business, 59(2), pp. 197-216.

Santos, T. and Scheinkman, J.A. (2001). Competition among Exchanges, Quarterly Journal of Economics, pp. 1027-1061.

Schmiedel, H. (2001). Technological Development and Concentration of Stock Exchanges in Europe, Bank of Finland Discussion Paper, 21, pp. 1-37.

Singal, V. (1996). Airline Mergers and Competition: An Integration of Stock and Product Price Effects, Journal of Business, 69(2), pp. 233-268.

Singh, H. and Montgomery, C.A. (1987). Corporate Acquisition Strategies and Economic Performance, Strategic Management Journal, 8(4), pp. 377-386.

Solomon, D.H. (2012). Selective Publicity and Stock Prices, Journal of Finance, 67(2), pp. 599-638.

Solomon, D.H., Soltes, E. and Sosyura, D. (2014). Winners in the Spotlight: Media Coverage of Fund Holdings as a Driver of Flows, Journal of Financial Economics, 113, pp. 53-72.

Song, M.H. and Walkling, R.A. (2000). Abnormal Returns to Rivals of Acquisition Targets: A Test of the 'Acquisition Probability Hypothesis', Journal of Financial Economics, 55, pp. 143-171.

Schwert, G.W. (2000). Hostility in Takeovers: In the Eyes of the Beholder, Journal of Finance, 55(6), pp. 2599-2640.

Tetlock, P.C. (2007). Giving Content to Investor Sentiment: The Role of Media in the Stock Market, Journal of Finance, 62(3), pp. 1139-1168.

Trautwein, F. (1990). Merger Motives and Merger Prescription, Strategic Management Journal, 11(4), pp. 283-295.

Varaiya, N.P. and Ferris, K.R. (1987). Overpaying in Corporate Takeovers: The Winner's Curse, Financial Analysts Journal, 43(3), pp. 64-70.

White, L.J. (1987). Antitrust and Merger Policy: A Review and Critique, Economic Perspectives, 1(2), pp. 13-22.

World Federation of Exchanges, http://www.world-exchanges.org/statistics/monthlyreports, (Last Accessed 2014/06/28). 
Zellner, A. (1962) An Efficient Method of Estimating Seemingly Unrelated Regressions and Tests of Aggregation Bias, Journal of American Statistical Association, 57, pp. 348368.

Zhu, H. (2014). Do Dark Pools Harm Price Discovery? Review of Financial Studies, 27(3), pp. 747-789. 


\section{Appendix 1A: General Literature on Mergers and Acquisitions}

Mergers and acquisitions (M\&As) are ubiquitous and continue to draw "considerable interest from practitioners and academics" (Dutta and Jog, 2009, pp. 1400). Over the last two decades, for example, U.S. firms spent over 3.4 trillion consummating more than 12,000 mergers (Melmendier and Tate, 2008). Not only are mergers and acquisitions very popular, they have been reported to come in waves. Martynova and Renneboog (2008) have documented five waves from the beginning of the 1900s to the 1990s.

The general literature on mergers and acquisitions cover several strands including the motives behind mergers, the shareholder wealth and operating performance impacts of mergers and the factors hypothesized to explain the shareholder wealth and operating performance effects of the mergers. The ensuing paragraphs briefly discuss a few of this vast body of literature along the few (of the several) strands highlighted.

\section{Motives for Mergers and Acquisitions}

Different authors have offered different motives for M\&As, which can be broadly classified as economic motives and noneconomic motives. Berkovitch and Narayanan (1993) note that three motives advanced in the literature are the synergy motive, the agency motive and the hubris motive. The synergy and agency motives can be described as economic motives while the hubris motive can be classified as noneconomic.

The synergy motive, usually referred to as the " $2+2=5$ " effect, postulates that by combining their resources, the value of the merged firm will be greater than the sum of the separate values of the acquirer and target. A pivotal prediction of the synergy motive 
is that the combined merger gains to the target and acquirer must be positive. Some authors have decomposed synergy into a number of components including Devos et al. (2009) who discuss three sources of synergy as coming from (i) mergers generating productive efficiencies resulting in higher operating profits and/or reduced capital spending (i.e. operating synergy), (ii) interest tax shields resulting from mergers (i.e. financial synergy), and (iii) potentially anticompetitive mergers occurring in the same industry that could enable the combined firm to enjoy market power. Clearly, the second and third sources of synergy can lead to winners and losers, because with respect to tax shields, shareholders gain at the expense of the government and synergy emanating from market power makes shareholders winners and consumers/suppliers losers. However, regulators in many countries usually review proposed M\&As to ensure that noncompetitive mergers are not approved. The agency motive is aimed at eliminating inefficient (target) management. The hubris motive occurs when managerial egos dominate rational thought in M\&A, leading to Roll's (1986) prediction that the total combined takeover gain to target and bidding firm shareholders is non-positive in the presence of hubris. On the empirical front, Devos et al. (2009) used Value Line forecasts to pinpoint the exact sources of merger gains. The authors find total synergy of about $10 \%$, which primarily comes from operating synergies (8.4\%). Financial synergy emanating from interest tax shields is only $1.6 \%$. The authors also find that the operating synergies to the merging firms mainly came from "significant economies in their capital expenditures and investments in working capital" (pp. 1181). Devos et al. (2009) did not, however, find significant gains from increased market power. 


\section{Impacts of Mergers and Acquisitions}

The impacts of mergers and acquisitions can be broadly classified into effects on shareholder wealth (which can be segmented into short term wealth effects and long term wealth effects) as well as the impact of M\&As on operating performance.

\section{Short Term Wealth Effects of M\&As}

If mergers and acquisitions are undertaken for economic reasons, then one would expect that shareholders will react positively to merger announcements. This should, all things being equal, lead to positive short term abnormal returns. The short term wealth effects of mergers and acquisitions can be separated into effects on target shareholders, acquirer shareholders and shareholders of competitors.

With respect to the short term effects on target shareholders, the overwhelming conclusion is that shareholders of target firms reap statistically significant abnormal returns. In their comprehensive review of the five merger waves from the early 1900 s to the 1990s, Martynova and Renneboog (2008) concluded that target firms accumulate significant positive cumulative average abnormal returns. In a review of over 35 studies that provided evidence on returns to target shareholders, the authors documented significant positive abnormal returns in almost every study. The evidence shows targets enjoy positive abnormal returns during the run-up to the announcement, around the announcement date and the post announcement period. 
While the empirical findings show that targets enjoy positive abnormal returns, there is no unanimity when it comes to acquirers' short term abnormal returns. Our review shows a mixed bag, with variations of positive/zero/negative CAR but which, on average, generally lean towards abnormal returns to acquirers that are not different from zero. Martynova and Renneboog (2008), for example, observed that findings of 17 studies of takeovers in the 1990s are "split almost evenly between positive and negative returns" (pp. 2159). Moeller et al. (2005) measure the dollar loss of acquiring-firm shareholders over the 3 days surrounding economically significant acquisition announcements and report that acquiring firm shareholders lost an aggregate of \$216 billion from 1991 to 2001 and $\$ 4$ billion from 1980 to 1990 . On the other hand, Fuller et al. (2002), in their study of firms making multiple acquisitions from 1990 to 2000, report that the five-day cumulative abnormal return (CAR) is a statistically significant positive return of $1.77 \%$. However, when they partition their sample into public targets and nonpublic targets, they observed a statistically significant positive CAR of $2.08 \%$ for nonpublic targets but a statistically significant negative CAR of $-1 \%$ for public targets. Dutta and Jog (2009), in an extensive study of Canadian mergers over the 1993-2002 period, also find statistically significant positive CAR for acquirers over three event windows $[-1,+1],[-2,+2]$ and $[0,+2]$. However, because the CAR for the $[0,+15]$ window is a small negative return which is statistically indistinguishable from zero, the authors conclude that the "initial overreaction in the Canadian market is followed rather quickly by negative correction (i.e. negative abnormal returns)" (pp. 1408). 
For rivals of firms involved in acquisitions (especially rivals of targets), the evidence shows that they also benefit from mergers and acquisitions (see for example Song and Walkling, 2000).

\section{Long Term Wealth Effects of $M \& A$}

From the literature, long term performance (typically measured over three or five years) is largely contingent on the methodology used. In general, studies that employ the market model for long term analyses report significant negative long term performance, those using other estimation techniques report inconclusive results and studies using the matched sample approach mostly report insignificant results (Martynova and Renneboog, 2008).

\section{Impact of M\&As on Operating Performance}

An often cited reason for M\&As is to achieve synergy. A number of studies have tried to infer the realization of synergy by looking at post-acquisition operating performance. Our review of the literature indicates that the evidence is mixed. Based on the 26 studies reported by Martynova and Renneboog (in table 4), about 54\% of the papers find declining post-acquisition operating profits, $27 \%$ of the papers report insignificant changes in operating profits and about 19\% document significantly positive increases in operating profit. These studies have used a number of metrics to gauge operating performance including ROE, ROA, ROS, ROC, sales growth - among others. See Schwert (2000) and Martynova and Renneboog (2008) for a comprehensive listing of the various metrics used in measuring operating performance. 


\section{Factors explaining merger performance}

A plethora of factors have been proposed in the literature to explain the documented impacts of mergers and acquisitions, and these factors can be grouped into deal characteristics, firm characteristics and governance factors.

\section{Deal Characteristics}

Several deal characteristics have been identified as impacting abnormal returns of M\&As. The attitude towards a bid (whether it is hostile or friendly) has been identified as a key factor in explaining merger returns. Hostile bids are perceived as threatening to target management who may employ extensive defensive mechanisms; acquirer management may have to revise the bid upwards leading to positive abnormal returns to target shareholders. Martynova and Renneboog (2008) observe that when a hostile bid is made, the target's share price immediately incorporates the expectation that opposition to the bid may lead to upward revisions of the offer price. Schwert (2000) provides evidence suggesting that depending on the hostility measure used, bidders experience negative abnormal returns. Devos et al. (2009) find insignificant synergies for hostile mergers $(0.95 \%)$ but significant synergies for friendly takeovers $(10.9 \%)$.

Another deal characteristic that is related to hostility is the M\&A type - tender offers are seen as hostile while mergers are regarded as friendly. According to Jensen and Ruback (1983), mergers are generally negotiated with target managers and approved by the target's board of directors before shareholders vote to approve it while tender offers are 
offers to buy shares made to target shareholders directly who then individually decide whether or not to tender their shares. Schwert (2000) and Bargeron et al. (2008) report that tender offers lead to higher than average abnormal returns to target firms (based on short term analysis). However, Dutta and Jog (2009) find that there are no significant long-term abnormal returns for tender offers or mergers.

The level of competition has also been identified as an explanatory variable. This variable is somehow related to the hostility variable. The idea is that a hostile bid may encourage target management to seek a "white knight" (friendly competitive bid) which usually leads to competition/auction and consequently higher premium/abnormal returns for target firms (Schwert, 2000).

The method of payment (cash vs. stock vs. combination) is also deemed to be a factor that differentiates abnormal returns in M\&As. It has been demonstrated that firms that are overvalued use stock as the method of payment. Target firms therefore extract higher abnormal returns in such instances. Dutta and Jog (2009) report that stock financed deals underperform in the long-run (-10\% over three years).

Another important deal characteristic is the extent of relatedness of the merger - with focused mergers being more synergistic than diversifying mergers. Devos et al (2009) confirm this view when they find that the return-synergy relation is insignificant for diversifying mergers but highly significant for focused mergers. 


\section{Firm Characteristics}

Firm characteristics that could account for differences in abnormal returns include target type (public vs. private vs. subsidiary), acquirer type (public vs. private), growth or value acquirers, target size, bidder size, etc. Schwert (2000) finds evidence suggesting that target shareholders' abnormal returns are negatively related to target firm size and Fuller et al. (2002) report that the larger the target relative to the bidder, the more negative the acquirer's CAR. Dutta and Jog (2009) also find that relatively large acquisitions underperform in the long-run (-49\% over three years).

Bargeron et al. (2008) find that target shareholders receive higher premiums when the acquirer is a public company rather than a private equity/operating firm. When the authors control for target and deal characteristics, it does not reduce the differences in premiums between private and public acquisitions. Fuller et al. (2002) find significantly negative CAR of $-1 \%$ for public targets, significantly positive CAR of $2 \%$ for private targets and significantly positive $(2.75 \%)$ CAR for subsidiaries.

Other firm characteristics found to be important in explaining abnormal returns are: firms with high Tobin's Q and low book-to-market (glamour acquirers) experience large acquirer losses (Moeller et al., 2005) and firms with high book-to-market (value acquirers) experience superior performance - high synergies of about 12\% (Devos et al., 2009). 


\section{Governance Factors}

In a business environment characterized by the separation of ownership and control, issues related to corporate governance could feature prominently in explaining abnormal returns in M\&As. Corporate governance factors are particularly relevant to the agency motive and hubris motive of M\&As. Arguing that overconfident managers overestimate their ability to create value, Malmendier and Tate (2008) find that overconfident CEOs are unambiguously more likely to make lower-quality acquisitions that destroy shareholder value, especially when their firms have abundant internal resources.

Board independence, director ownership and CEO ownership have also been hypothesized to impact merger gains. Dutta and Jog (2009) report that their valueweighted match-sample buy-and-hold abnormal returns is significantly positive (at the $1 \%$ level) for non-independent boards (signifying that boards with a majority of related directors tend to have better insight about acquisition targets) and that the value-weighted long-term abnormal returns for “directors' ownership greater than $25 \%$ ” are significantly positive (implying that in the long-run, acquiring firms with more inside directors perform better than firms with more outside directors). 


\title{
3 Essay Two: Stock Exchange Demutualization and Market Quality
}

\begin{abstract}
Faced with an intensely competitive business environment, stock exchanges are reforming their organizational structures through demutualization in order to become flexible so that they can effectively respond to the increasing competitive threats they face in the industry. We investigated the market quality implications of stock exchange demutualization and find that exchanges undertaking demutualization achieve significant improvements in market quality in the five years following the completion of the demutualization. These exchanges achieve significant reductions in transaction costs and volatility - two important dimensions of market quality. While the demutualized exchanges see improvements in market quality, our controlled group of mutualized rival stock exchanges which have not undertaken demutualization have suffered in the postdemutualization period. These exchanges have experienced increases in spreads and volatility, and have, as a result, seen deterioration in market quality. We also find that the benefits of demutualization are unevenly distributed. Developed demutualized stock exchanges and large-cap stocks realize most of the benefits of demutualization while emerging demutualized stock exchanges and small-cap firms do not seem to benefit a lot from demutualization as far as liquidity is concerned. We additionally find that although subsequently undertaking IPO (initial public offering) after demutualization does not result in incremental improvements in market quality for publicly traded exchanges, if the IPO is undertaken by a developed demutualized stock exchange, then there are significant incremental improvements in market quality beyond what was achieved at the
\end{abstract}


demutualization stage. Our results are robust across different measures, different designs and different model specifications.

\subsection{Introduction}

The current business environment in which stock exchanges operate is characterized by unprecedented levels of competition. Among other things, technological advancements and globalization are contributing to the intensification of competition in the stock exchange industry. The competition includes competition from within (or competition among the exchanges themselves) and competition between exchanges and electronic communications networks (ECNs). In the face of the competitive turbulence in the industry, many stock exchanges are turning to demutualization as one important strategy for surviving and prospering in the increasingly competitive business environment.

Since the Stockholm stock exchange became the first stock exchange in the world to demutualize in 1993, stock exchange demutualization has become so widespread that by 2002, 63\% of the members of the World Federation of Exchanges (WFE) had changed their mutual structure (Otchere, 2006) and by 2007 , only about $20 \%$ of the members of the WFE remain as mutuals (Oldford and Otchere, 2011). The prevalence of stock exchange demutualization is largely hinged on the anticipated benefits that demutualization will bring to stock exchanges - including the ability to tap into new sources of financing for expansion and technology investment, ability to pursue business opportunities without being constrained by members' self-interest, ability to better 
control costs as well as increased flexibility, efficiency and competitiveness (Scullion, 2001; Steil, 2002; Serifsoy, 2008).

Given that stock exchanges are in the business of matching buyers and sellers of securities and providing a mechanism for price discovery (Hasan et al., 2003), market quality is fundamentally important to every stock exchange. Improving market quality is so important that stock exchanges are constantly looking for ways to improve market quality including introducing measures such as decimalization and new rules and regulations (when warranted) to help improve market quality. Since market quality is central to everything that the stock exchange does, we argue that improving market quality is most likely one variable factored into the decision (of most exchanges) to change their governance structures through demutualization. We therefore contend that stock exchange demutualization will lead to improvements in market quality. This contention is predicated on a number of reasons.

First, the profit motive is the most important driver of organizational performance. Indeed, the central goal of profit/shareholder wealth maximization is what drives forprofit organizations (the economic engines of market economies) to strive for performance excellence. By converting to a for-profit organization, we argue that the profit motive will drive demutualized stock exchanges to improve organizational performance and market quality. The quest to maximize profits will motivate demutualized stock exchanges to adopt measures that will increase order flow and trading volume since that will help grow their businesses and improve their bottom-lines. As 
order flow and trading volume increase, liquidity improves and this will lead to decreases in bid-ask spreads and volatility - both of which will improve market quality. Otchere and Abou-Zied (2008) also made this contention when they argued that because of the for-profit motive, demutualized stock exchanges will embark on strategies that increase order flow to the exchange, and as a consequence, the "increase in trading volume could lead to a fall in bid-ask spread and improve the quality of the market" (pp. 514). There is an array of tactics that demutualized stock exchanges can and have leveraged to increase order flow. They are for instance providing incentives and subsidies to market makers to use their trading systems (Lee, 2002). Malinova and Park (2015) also noted that North American exchanges have introduced an incentive scheme for traders to post attractively priced limit orders (maker-taker pricing) as a strategy for competing for trading volume. When warranted, demutualized stock exchanges also have the leeway to employ the services of professional managers whose mandate is to maximize firm value (Krishnamurti et al., 2003). In contrast, mutualized stock exchanges may not be equally motivated since the self-interest of their members is their primary goal (and not profit maximization). Citing the vested financial interest incentive of members of mutualized stock exchanges because they derive profits from intermediating nonmember transactions, Domowitz and Steil (2001) argue that "the incentive structure under which a mutualized exchange operates is different from that under which a demutualized one does" and that this could in turn lead to members of mutualized stock exchanges resisting "innovations that reduce demand for their intermediation services, even if such innovations would increase the value of the exchange" (pp. 366). Indeed, the primacy of the profit motive in driving performance in the stock exchange industry has been 
buttressed by a number of studies. Oldford and Otchere (2011) find that demutualized but member-owned exchanges and publicly traded exchanges exhibit higher levels of operating efficiency than mutually owned exchanges. For demutualized exchanges that subsequently became publicly traded, however, the authors did not find any evidence of significant incremental gains in efficiency and profitability beyond what these publicly listed exchanges achieved at the demutualization stage. This suggests that the profit mandate of demutualized stock exchanges is often a sufficient driver in improving performance. Other authors (e.g. Aggarwal, 2002; Mendiola and O'Hara, 2003; Otchere, 2006; Azzam 2010) have also shown that the operating performance of demutualized stock exchanges improve after demutualization.

Second, one central reason for demutualizing is to improve the governance of the exchange and consequently improve performance - since the mutual form of governance is perceived as being ineffective in an intensely competitive environment. A number of authors (including Mendiola and O'Hara, 2003 and Oldford and Otchere, 2011) attest to the notion that a demutualized governance structure is more effective than a mutual structure in a highly competitive environment. For instance, contending that the mutual form of organizing is anachronistic in an era of increased competition, Mendiola and O'Hara (2003) note that replacing the cooperative structure with a corporate structure provides a better governance framework suited for the current competitive environment. Effective governance structures have several benefits including improved transparency and accountability. In fact, the corporate governance literature is replete with studies showing that effective governance structures foster transparency and that transparent organizations attain better performance. Chung et al. (2010), for example, 
cite theoretical arguments that suggest that effective governance improves financial and operational transparency. Therefore, by decoupling "ownership and trading rights" (Oldford and Otchere, 2011, pp. 71), demutualization signals to market participants that the exchange is a transparent organization. This signal of transparency will bolster the confidence of issuers and investors in demutualized stock exchanges - which can be instrumental in attracting order flow and in the process, helping improve market quality by increasing trading volume and liquidity.

Third, demutualized stock exchanges typically invest in technology and automation (Domowitz and Steil, 2001; Lee, 2002; Krishnamurti et al., 2003) - investment that a mutual exchange may not be able to implement easily. Domowitz and Steil (2001) note, for instance, that demutualization usually begins with a conversion from traditional floor trading technology to automated trade execution while Krishnamurti et al. (2003) assert that the organizational structure of a demutualized stock exchange can allow "it to pursue trading automation unhindered by potential conflicts of interest with its broker-members" (pp. 1866). Investments in technology and automation improve transparency of an exchange since the dissemination of high quality information to all market participants can be done cheaply, quickly and easily. As Jain (2005) notes, computerized trading systems can increase the amount of publicly available information about the demand and supply for a stock "by transparently displaying and efficiently archiving quotes, depths, orders, and transactions" (pp. 2956). The increased transparency makes an exchange an attractive location for investors to trade because transparency reduces information asymmetry. This will increase order flow to the exchange and the increased trading 
volume will increase liquidity. As liquidity increases, bid-ask spreads and volatility will decrease and market quality will improve as a result. Investments in technology and automation also directly improve market quality by reducing the speed of transaction execution and lowering trading costs (Riordan and Storkenmaier, 2012). With technology, orders can be executed faster and cheaper. On the contrary, mutualized stock exchanges may resist automation because automation will allow the exchange to grant trading access directly to investors which will not be in the best interest of the members since that creates direct competition for members who derive revenues from intermediating nonmember trades. As Lee (2002) noted, a "nonprofit or cooperative exchange whose members are financial intermediaries will be loath to grant access to its trading system directly to investors" (pp. 19) since that would disintermediate, and thereby jeopardize the livelihood of the members whose welfare the exchange exists to serve.

The discussion above has established a link between demutualization and improvements in market quality. However, whether or not this is indeed the case in reality is an empirical question worthy of exploration. While there is some limited evidence indicating that market quality improves after demutualization, there are still gaps in the literature. To the best of our knowledge, only Krishnamurti et al. (2003) and Otchere and AbouZied (2008) demonstrate that the market quality of demutualized stock exchanges in India and in Australia (respectively) improve as a result of demutualization. While these studies have given us some insights into the market quality implications of stock exchange demutualization, they have limited generalizability because they have each 
looked at one demutualized stock exchange in one country. Therefore, whether or not demutualization leads to improvements in market quality in other countries remains unresolved. These studies have also each examined one measure of market quality which leaves unresolved the question of whether or not other measures of market quality improve as a result of demutualization. The need to address these unresolved issues and fill the gaps in the literature is a key motivating factor for this essay.

An even more important and compelling reason for us to examine the link between demutualization and market quality is the fact that improvements in market quality have implications for the wider investment community because it substantially benefits investors and issuers. When the quality of the market improves, the bid-ask spread decreases and investors benefit from reductions in the cost of transacting. Increased liquidity associated with improved market quality may also decrease the cost of capital for issuers. Since the cost of capital is positively related to risk, when improved market quality leads to increased liquidity and decreased volatility, risk reduces and the cost of capital should, ceteris paribus, reduce as well. Several studies (including Amihud and Mendelson, 1986; 2000) have demonstrated that the greater the liquidity of a security, the lower the cost of capital or the required rate of return. Thus, reducing the cost of capital is so important to not only stock exchanges but to issuers as well. The NYSE (2005) states this point more cogently when, in touting its global leadership position as a robust liquid market, it noted that reducing volatility (a key measure of market quality) for publicly traded companies is paramount because it "lowers their cost of capital, thereby enhancing their ability to raise capital to fund expansion and growth" (pp. 2). We are therefore 
additionally motivated to explore the extent to which stock exchange demutualization improves market quality because by demonstrating how demutualization improves market quality, we will also be demonstrating how the wider investment community is benefiting from stock exchange demutualization.

Driven by these motivations, we, in this study, use over 34 million firm-day records from over 4,500 unique firms listed on some 41 stock exchanges to examine 30 stock exchange demutualizations completed between 1993 and 2013. We analyzed the cost dimension of market quality (using quoted bid-ask spreads and effective bid-ask spreads) and trends in volatility (using standard deviation of stock returns as well as high-minus-low) - over a six-year period starting one year (i.e. 250 trading days) before the date of demutualization and up to five years (i.e. 1,250 trading days) after the date of demutualization. Our results show that the demutualized stock exchanges outperformed the mutualized stock exchanges in the post-demutualization period on all the measures of market quality that we examined. We find that quoted (and effective) spreads decreased by between $5.5 \%$ (and 3.7\%) on demutualized stock exchanges while mutualized stock exchanges experienced increases of $1.8 \%$ (and 3.3\%) in quoted (and effective spreads). We also find that the improvements in the cost dimension of market quality are asymmetrically distributed. Specifically, we find that the improvements in spreads are exclusive to developed demutualized stock exchanges - as emerging demutualized stock exchanges experienced insignificant increases in quoted spreads and insignificant decreases in effective spreads. 
On the measures of volatility, we also find that demutualized stock exchanges experience significant reductions in volatility - with standard deviation decreasing by about $7.1 \%$ and high-minus-low decreasing by about $5.7 \%$ in the post-demutualization period. In contrast, mutualized stock exchanges experienced increases in both measures of volatility. While developed demutualized exchanges experienced reductions in both measures of volatility following demutualization, emerging demutualized stock exchanges also achieved some reductions in volatility - with standard deviation significantly decreasing by about $3 \%$ on emerging demutualized exchanges in the postdemutualization period. We further find that the benefits of demutualization are asymmetrically distributed in favor of big firms. But although small firms do not seem to benefit much over the whole sample period, we find that there is delayed gratification for small firms in trend analyses. Specifically, we discovered that spreads, which were trending upwards in the first two years, began to trend downwards from year 3 to year 5 for small firms listed on demutualized stock exchanges. We additionally find that once demutualized, the decision to subsequently become a publicly traded firm (through IPO) does not result in incremental reduction in spreads - unless the exchange involved in the IPO is operating in a developed economy. Our findings, which demonstrate the beneficial effects of demutualization in improving market quality, have been confirmed in a number of robustness tests as well.

On the totality of our results, we contend that the profit motive of demutualized stock exchanges, strengthened for developed demutualized stock exchanges because of the 
multiple competitive threats they face ${ }^{12}$, provides an unparalleled motivation for demutualized stock exchanges (especially developed demutualized stock exchanges) to undertake value-enhancing actions such as increasing order flow in order to maximize profits. The increasing order flow increases liquidity, which reduces spreads and volatility and subsequently leads to substantial improvements in market quality. In addition to the stronger commitment to the profit motive that propels developed demutualized stock exchanges to better performance, corporate governance may be another reason for their superior performance. Since developed stock exchanges are better governed, they are able to undertake the actions necessary to increase order flow following demutualization. The increased order flow increases liquidity, decreases spreads and improves market quality. On the contrary, because of possible weak corporate governance, emerging demutualized stock exchanges may not be able to pursue all the actions necessary to increase order flow, increase liquidity, reduce spreads and improve market quality - as much as their developed counterparts. As a result, their market quality performance lags the performance of their developed counterparts.

Although our research is similar to Krishnamurti et al. (2003) and Otchere and AbouZied (2008) in the sense that it provides empirical evidence on the role of exchange demutualization in improving market quality, it differs from the two studies in a number of important ways. First, while Krishnamurti et al. (2003) and Otchere and Abou-Zied (2008) focus on demutualization of one stock exchange in one country, this essay is a robust, comprehensive, multi-exchange and cross-country study of demutualization and

\footnotetext{
${ }^{12}$ In most developed countries, for example, there are multiple stock exchanges but most developing countries have one main stock exchange.
} 
market quality using a sample of 30 demutualized stock exchanges and a control sample of 11 mutualized stock exchanges. Our results are therefore more generalizable. Second, this essay differs from Krishnamurti et al. (2003) and Otchere and Abou-Zied (2008) because it examines the performance of demutualized stock exchanges on a multidimensional basis using multiple measures of market quality. Given that the demutualized stock exchanges performed better than mutualized stock exchanges on these multiple dimensions of performance, we argue that the validity of our results is enhanced and we can reasonably rule out chance as a potential explanation for our results.

\subsubsection{Benefits of Study}

This essay makes important contributions to the academic literature and also helps practitioners.

\subsubsection{Contributions of Study to Academia}

This essay provides the only comprehensive empirical evidence on the impact of stock exchange demutualization on market quality in a multi-exchange and multi-country environment. As a result, the study enriches the literature on both demutualization and market quality/market microstructure.

\subsubsection{Importance of Study to Investors}

Investors can use the empirical evidence on the cost of transacting on demutualized vs. mutualized stock exchanges to inform their decisions on which investment strategies will 
provide the best returns and/or which trading locations will provide the least cost of transacting.

\subsubsection{Policy Implications of Essay}

This essay also has several policy implications. Managers of stock exchanges considering demutualization can use the evidence provided in this essay to help in the demutualization justification process. Managers of privately held demutualized stock exchanges considering undertaking initial public offering (IPO) can use the results of this study in the IPO justification process. Managers of firms interested in raising capital can use the results of this essay to determine the types of stock exchanges that may provide the lowest cost of raising capital.

\subsubsection{Organization of Study}

The remainder of this essay will proceed as follows. Section two is devoted to a review of the relevant literature. Section three highlights the research questions we addressed and section four outlines the data and methodology. The results are reported in section five and our conclusion is in section six.

\subsection{Literature Review}

Since this essay straddles stock exchange demutualization and market microstructure/market quality - two areas that have largely remained as separate strands 
of research, we review only literature from the market quality/market microstructure field that has direct relevance to stock exchange demutualization.

\subsubsection{Literature on Stock Exchange Demutualization}

Typically, demutualization is defined as "the process of converting a non-profit, mutually owned organization to a for-profit, investor-owned corporation” (Aggarwal, 2002, pp. 106). Demutualization has also been defined by Domowitz and Steil (2001) as separating ownership of an exchange from membership. While demutualization in the stock exchange industry is a recent phenomenon starting only in the 1990s, a number of other industries that were traditionally dominated by mutuals have undergone considerable demutualization over the years (e.g. the thrift industry). Demutualization is generally undertaken to improve governance and organizational performance and as the ensuing literature review demonstrates, there is theoretical and empirical support for the important contribution that organizational form (in general) and demutualization (in particular) play in firm performance.

The link between organizational form and performance has long been established in the literature. Jensen and Meckling (1976) for example argue that "the probability distribution of future cash flows is not independent of the capital or ownership structure" (pp. 333) while Chaddad and Cook (2004) reiterate the diverse set of alternative hypotheses regarding the economic impetus for organization structure changes posited by economists - including efficiency and expropriation motives. The efficiency hypothesis, according to Mayers and Smith (1986), is usually associated with a positive change in the 
value of the firm while the expropriation motive implies that ownership structure change is motivated by opportunities to transfer wealth and usually has a non-positive impact on firm value. Hart and Moore (1996) provide theoretical justification for the increased level of demutualization in the stock exchange industry in recent times when they note that outside ownership is more efficient than members' cooperative as the stock exchange faces more competition or as the variation across the membership becomes more skewed or heterogeneous.

Empirically, only a few authors have studied the effect of the recent stock exchange demutualization on market quality. Krishnamurti et al. (2003) examine the impact of stock exchange demutualization on market quality using companies simultaneously listed and traded on both the BSE (Bombay Stock Exchange) and NSE (National Stock Exchange). Employing both univariate and multivariate tests, Krishnamurti et al. (2003) find that the transaction costs on NSE (a demutualized stock exchange) are lower than on BSE (a mutual stock exchange) - with the mean standard deviation of the Hasbrouck (1993) pricing error respectively being $0.27 \%$ and $0.64 \%$ of stock prices on NSE and BSE. Otchere and Abou-Zied (2008) empirically assess the effects of demutualization on market quality using the Australian Stock Exchange (ASX) as a case study and find that bid-ask spreads have narrowed in the post-conversion period (especially for small-cap firms).

A number of other authors have looked at the effect of demutualization on other aspects of performance including stock market performance, accounting-based performance 
and/or product market performance. Mendiola and O'Hara (2003) examine stock exchanges that demutualize and subsequently self-list themselves and find that while stock exchange IPOs exhibit first day underpricing (like other IPOs), the exchange IPOs continue to do well in the months and years after the offering (unlike other IPOs). The authors conclude that shifting exchange governance from cooperative to corporate is a value-enhancing strategy for stock exchanges. Otchere (2006) also examines stock exchanges that demutualize and subsequently self-list themselves and finds that the selflisted exchanges have become more profitable and have diversified their income base to derive significant revenues from non-traditional sources. The author also finds that the self-listed exchanges have significantly outperformed the stock market indexes as well as non-exchange firms that also went public in the same year. Otchere and Abou-Zied (2008) empirically assess the effects of demutualization on the Australian Stock Exchange's (ASX) performance and find that the ASX's stock significantly outperformed the stock market index and a control group and also find that the ASX experienced increased trading activity by foreign investors after their demutualization and self-listing.

Serifsoy (2008) investigated a sample of 28 stock exchanges (17 demutualized and 11 mutuals) over the 1999 to 2003 period and finds that while demutualized exchanges exhibit higher technical efficiency than mutuals, they perform relatively poor on productivity growth. Azzam (2010) examined 11 demutualized stock exchanges during the period 1996 to 2008 and finds that demutualization increases an exchange's financial performance, size, and liquidity and lowers its debt. Oldford and Otchere (2011) examine the performance of mutual, demutualized (commercialized) and publicly listed 
(corporatized) exchanges and find evidence of improved performance along the stock exchange governance continuum - with publicly traded exchanges exhibiting better operating performance than demutualized exchanges. However, after demonstrating that the listed exchanges do not exhibit evidence of incremental gains in efficiency and profitability beyond what they achieved at the demutualization phase, the authors conclude that commercialization provides sufficient freedom to exploit monopoly rents while corporatization brings about proper valuation of the exchanges' franchise. Angulo et al. (2014) find that the London Stock Exchange demutualization led to important changes in corporate governance (e.g. more monitoring boards resulting from increased number of independent directors as well as modifying management team's compensation by increasing performance-related payments) and significant improvements in financial performance. However, Geranio and Lazzari (2014) find that contrary to literature expectations, demutualization of stock exchanges has not resulted in lower listing costs.

Demutualization almost always leads to investments in technology and automation (Domowitz and Steil, 2001; Lee, 2002; Krishnamurti et al., 2003). Technology and automation reduce the speed of transaction execution and lower trading costs, thereby improving market quality. Hendershott et al. (2011) examine the effect of algorithmic trading ${ }^{13}$ (i.e. the use of computer algorithms to automatically make certain trading decisions, submit orders, and manage those orders after submission) on market quality and find that algorithmic trading improves liquidity for large-cap stocks in that the quoted and effective spreads narrow under autoquote (i.e. algorithmic trading). Riordan and

\footnotetext{
${ }^{13}$ Hendershott et al. (2011) used the start of autoquoting on the NYSE in early 2003 as the important exogenous event that increases the amount of algorithmic trading.
} 
Storkenmaier (2012) examine the impact of technology by studying the decrease in latency ${ }^{14}$ (increased speed) from 50 milliseconds to 10 milliseconds as a result of Deutsche Boerse's upgrade of its Xetra software to version 8 and find that both quoted and effective spreads fall (especially for small- and medium-sized stocks) post upgrade and the contribution of quotes to price discovery doubles from $45 \%$ to $90 \%$ post upgrade.

Additionally, because technology and automation can increase the amount of publicly available information about the demand and supply for a stock through the transparent and efficient display and archiving of quotes, depths, orders and transactions (Jain, 2005), technological investments will lead to improvements in transparency which will reduce information asymmetry, attract order flow, increase trading volume, improve liquidity, reduce bid-ask spreads and improve market quality - among other things. The importance of transparency in improving market quality has been demonstrated theoretically by Madhavan (1996) who shows that greater transparency lowers price volatility and improves market quality. The notion that transparency improves market quality has also been empirically buttressed by Boehmer et al. (2005) who examine pre-trade transparency by looking at the introduction, in January 2002, of NYSE's OpenBook service $^{15}$ and finding smaller deviations of transaction prices from the efficient (random walk) price (i.e. prices are more efficient). The authors also find that effective spreads of trades decline - leading to the conclusion that increased transparency is a win-win situation. Chung and Chuwonganant (2009) examined the effect of pre-trade transparency

\footnotetext{
${ }^{14}$ Riordan and Storkenmaier (2012) define latency as the amount of time it takes for an investor to submit and receive feedback about an order.

${ }^{15}$ The OpenBook service provides limit-order book information (i.e. information about quotes and trading interest) and "allows traders off the NYSE floor to observe depth in the book in real time at each price level for all securities" (Boehmer et al., 2005, pp. 784)
} 
on market quality using data before and after NASDAQ's launch of the SuperMontage (a fully integrated order display and execution system for NASDAQ-listed securities) in 2002 and demonstrate that both bid-ask spreads and return volatility significantly decline after the implementation of SuperMontage. We expect that the increased transparency as a result of demutualization will increase order flow and liquidity and therefore contribute to our proposition that demutualization will lead to improvements in market quality.

However, other studies have presented mixed results on the impact of technology and automation on market quality. On the theoretical realm, Seppi (1997) demonstrates that no one system is good in every situation, arguing that a hybrid specialist/limit order market (i.e. floor-based system like the NYSE) provides better liquidity to small retail and institutional trades while a pure limit order market (i.e. automated market like the Paris Bourse) may offer better liquidity for mid-size orders. On the empirical front, Venkataraman (2001) compare the CAC40 index stocks against similar stocks on the NYSE from April 1997 to March 1998 and find execution costs to be higher in Paris (i.e. automated market) than on the floor-based NYSE market. Lai (2007) also examined the adoption (in September 1999) of electronic limit order book for FTSE Mid-250 stocks and finds that the overall quality of the market dropped after the transition. Hendershott and Moulton (2011) study the NYSE's introduction of its Hybrid Market (at the end of 2006) which increased automation and helped drive down execution time for market orders from 10 seconds to less than one second - and find that the Hybrid Market raises the cost of immediacy (the effective spread) by about $10 \%$ relative to its pre-Hybrid level but reduces the noise in prices, making prices more efficient. 


\subsubsection{Literature on Market Quality}

There is a vast body of literature on market quality which continues to proliferate. The extensive literature in this area probably explains why market quality has been variously defined in the literature. The several definitions, notwithstanding, the common theme cutting across these definitions relate to the market's ability to effectively and efficiently provide liquidity and price discovery. Domowitz and Steil (2001) for example perceive market quality as a three-dimensional concept hinging on liquidity, informational efficiency and volatility while O'Hara and Ye (2011) define market quality as the "market's ability to meet its dual goals of liquidity and price discovery" (pp. 463).

\subsubsection{The Many Factors Impacting Market Quality}

Several factors deemed to impact market quality have been identified in the market microstructure literature. Some of the factors include market consolidation/fragmentation, regulatory changes/reforms/liberalization, decimalization and tick size. However, since this literature is largely unconnected to stock exchange demutualization, we have not reviewed this bourgeoning literature on the numerous factors impacting market quality. 


\subsubsection{Measures of Market Quality}

Just as there are several factors influencing market quality, there are several measures of market quality. Figure 3.1 summarizes some of the key measures that have been used in the literature to gauge performance on the three dimensions of market quality.

As evident from Figure 3.1, there are several measures of market quality for the three main dimensions of market quality including bid-ask spreads, turnover and Amihud illiquidity as measures of the liquidity dimension of market quality, execution speed as a measure of the speed of execution dimension and pricing error as well as volatility as measures of the pricing efficiency dimension of market quality. 


\section{Figure 3.1 - Dimensions and Measures of Market Quality}

Figure 3.1 summarizes the various dimensions and measures of market quality. The figure is based on our review of the market quality/microstructure literature.

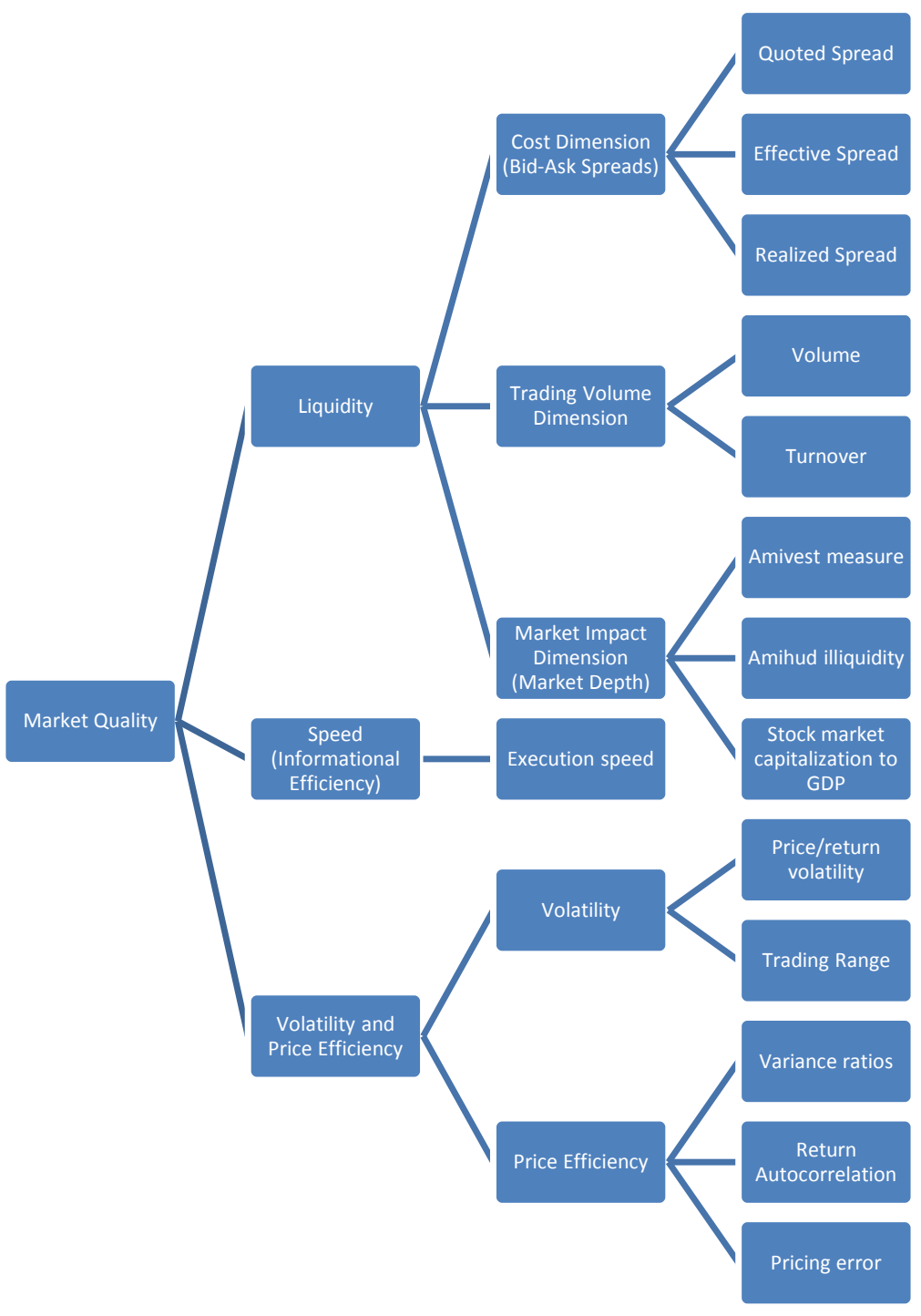

We briefly review the various dimensions and measures of market quality next.

\subsection{Measures of Liquidity}

Liquidity, a broad and sometimes vague concept, has long been regarded as a key dimension of market quality. Generally perceived as the ability to convert an asset into 
cash easily, liquidity can be looked at from the perspective of either the time required to trade an asset for cash at a reasonable price or the cost of trading an asset for cash quickly (Hasbrouck and Schwartz, 1988). Alternatively, liquidity has been denoted as the ability to trade large quantities quickly, at low cost, and without moving the price (Pástor and Stambaugh, 2003). Pástor and Stambaugh's (2003) definition of liquidity highlights the three components of liquidity, namely, cost, trading volume and price impact. Similarly, Hasbrouck and Schwartz (1988) identify the three characteristics of liquid markets as depth (i.e. the existence of orders on both sides of the book near the price at which shares are currently trading, which is impacted by the bid-ask spreads), breadth (the existence of orders in substantial volume) and resiliency (the responsiveness of new orders to price changes caused by temporary order imbalance).

\subsection{Measures of the Cost Dimension of Liquidity}

There are several measures of the cost dimension of liquidity in the literature. Bid-ask spreads, defined as the markup "paid for predictable immediacy of exchange in organized markets" (Demsetz, 1968, pp. 36), are by far the most widely used measures of the cost dimension of liquidity. Stoll (1978) identifies three components that make up the cost of immediacy (i.e. bid-ask spreads) and these include holding costs (i.e. the price of risk and opportunity cost of holding securities), order costs (i.e. the costs of arranging trades, recording and clearing a transaction), and information costs (or adverse selection costs which arise if investors trade on the basis of superior information). Several variants of bid-ask spreads have been suggested in the literature including quoted spreads, effective spreads and realized spreads. According to Bessembinder and Kaufman (1997), (i) 
quoted spreads measure trade execution costs if trades are executed at the quotes; (ii) effective spreads measure trading costs that reflect savings due to trading inside the quotes; and, (iii) realized spreads measure traders' temporary price impacts.

A number of issues with quoted spreads have been identified including the tendency for quoted spreads to overstate the true spread because trades are often executed inside the quoted spread and block trades execute outside the quoted spread (Keim and Madhavan, 1998). To mitigate some of the concerns raised about quoted spreads, a number of authors have suggested the use of effective spreads. Roll (1984) proposed a measure of effective spreads based on transactions data which, Keim and Madhavan (1998) note, has been extended by others over the years. Typically interpreted as the total price impact of a trade, effective spreads measure the non-commission out-of-pocket costs of a trader and can be decomposed into a permanent component or price impact (which approximates the information component of the trade) and a temporary component or realized spreads (Boehmer, 2005). Venkataraman (2001) notes that realized spreads measure trading costs after account is taken of the risk of adverse selection. Realized spreads, which are typically forward-looking, are measured as the difference between the trade price and the quote midpoint at a certain period after the trade (Boehmer, 2005). Realized spreads, according to Boehmer (2005), can be construed as the market's inherent execution cost since they exclude the effects of the information content of order flow. 


\subsection{Measures of the Trading Volume Dimension of Liquidity}

Measures of market quality that track the trading volume dimension of liquidity include volume traded and turnover. Turnover is defined as volume scaled by the number of shares outstanding. According to Nielsson (2009), turnover captures the amount of trading taking place among market participants.

\subsection{Measures of the Market Impact Dimension of Liquidity}

One issue with bid-ask spreads is their inability to capture the impact that a large trade may have in moving prices in the direction of the trade. Although difficult to measure, price impacts, which can be "thought of as the deviation of the transaction price from the 'unperturbed price' that would have prevailed had the trade not occurred" (Keim and Madhavan, 1998, pp. 52) - are aimed at eliminating this shortcoming of bid-ask spreads. Key measures of the market impact dimension of liquidity include the Amivest measure and Amihud's measure of illiquidity. The Amivest measure is defined as the ratio of the sum of the daily volume to the sum of the absolute return. The Amihud (2002) measure of illiquidity, interpreted as the average daily price impact of order flow, is defined as the monthly average of absolute value of daily return divided by daily dollar volume. According to Acharya and Pedersen (2005), a stock is illiquid if the stock's price moves a lot in response to little volume.

\subsection{Measures of Execution Speed}

Speed of execution is usually used in the literature to track the execution speed or informational efficiency dimension of market quality. Although lots of studies have 
analyzed the liquidity/cost dimension of market quality, there are not as many studies that have looked at the speed of execution component of market quality - probably, in part, due to the lack of high quality data to allow for rigorous analysis. However, after finding that execution costs on NASDAQ exceed those on the NYSE but that orders execute faster on NASDAQ, Boehmer (2005) highlights an apparent trade-off between cost and execution speed and cautions that inferring market quality from costs alone could be problematical.

It is therefore clear that understanding the execution speed dimension is important to getting a complete picture on market quality. Boehmer (2005) defines execution speed as "the time between order receipt and execution" (pp. 560).

\subsection{Measures of Volatility and Price Efficiency}

A number of measures used to track market quality along this dimension include price/return volatility, variance ratios and pricing error. Hasbrouck (1993) proposes a security pricing model that decomposes price into a random-walk component (i.e. the efficient price) and a residual stationary component (i.e. the pricing error, which is taken as the implicit transaction cost). According to Hasbrouck (1993), the "dispersion of the pricing error measures how closely actual transaction prices track a random walk and is therefore a natural measure of market quality" (pp. 192). The author therefore proposes that the standard deviation of the pricing error be used as a measure of market quality. According to Hendershott and Moulton (2011), the absolute value of return autocorrelation measures the extent to which quote returns diverge from a random walk 
in either direction; so a decline in the absolute value of the quote return autocorrelation would indicate an increase in price efficiency.

\subsubsection{Concerns Raised about Demutualization and Market Quality}

A number of concerns have been raised about demutualization as well as market quality. With a profit mandate, demutualized stock exchanges' desire to maximize profits and shareholder value could come at the expense of reduced regulation and supervision (Aggarwal, 2002; Otchere, 2006). With profit maximization as the primary driver, demutualized stock exchanges may not make the needed investments in supervision and monitoring since that will reduce profits. The desire to increase revenues and maximize profits may also encourage demutualized stock exchanges to lower their listing requirements in order to attract more listed companies. However, weak listing requirements may lead to low quality firms qualifying for listing.

Studies of market quality hinge on the notion that an improvement in market quality is mutually beneficial to all stakeholders and therefore desirable. However, the notion that improving market quality (especially liquidity) is always desirable has been contested in the literature. The price of liquidity - especially with respect to corporate governance has been highlighted by some authors. Bhide (1993) argues that stock liquidity discourages internal monitoring by reducing the costs of 'exit' of unhappy stockholders. Noting that more than half of publicly-listed US equities are owned by investors who do not play an active role in firm governance, Bhide (1993) asserts that the unparalleled focus on liquidity is discouraging “Jensen's (1989) 'active' investors, who provide 
valuable internal monitoring and who control the compensation and tenure of managers" (pp. 32). But Maug (1998) notes that while public markets are more liquid and efficient than ever, shareholder monitoring seems to be increasing - following his empirical exposition that a liquid market makes it less costly to hold larger stakes and easier to purchase additional shares. Maug (1998) concludes that liquid stock markets are beneficial because they make corporate governance more effective. Also, block ownership and diffused ownership can complement each other in ways that are beneficial to shareholders. As Jacoby and Zheng (2010) noted, combining the number of shareholders and block ownership to proxy for ownership dispersion ensures that higher ownership dispersion improves stock liquidity.

\subsection{Research Questions and Hypotheses}

From the preceding discussion and analysis, we submit that the profit mandate of demutualized stock exchanges will drive them to improve corporate performance. The central objective of shareholder value maximization will motivate demutualized stock exchanges to undertake actions (e.g. incentivizing market participants to trade on the exchange) that will increase order flow and revenues to the exchange. As order flow and trading volume increase, the exchange will become more liquid and the increased liquidity will reduce bid-ask spreads and price volatility - which will both lead to improvements in market quality. Also, conversion through demutualization is intended to improve stock exchange governance and effective governance signals to market participants that demutualized stock exchanges are transparent organizations. Indeed, 
studies have shown that demutualized stock exchanges are more transparent than mutualized stock exchanges. Krishnamurti et al. (2003) report that mutualized stock exchanges like the Bombay Stock Exchange are typically less transparent and more secretive than demutualized stock exchanges like the National Stock Exchange. The authors argue that the desire to protect the interest of their members usually results in lax enforcement and weak internal control systems - which is not the case with demutualized stock exchanges whose primary goal is to maximize firm value and profits. Reiffen and Robe (2011) analyze the relationship between a self-regulatory financial exchange's (SRO) ownership structure and its incentives to protect customers trading on the exchange from dishonest agents and demonstrate that a for-profit SRO carries out more investigations than does a mutual SRO. The authors contend that because the goal of a mutual exchange is to maximize member income, they are less likely to enforce trade practice rules (i.e. rules governing how end-investors' agents such as securities dealers carry out their customers' trades). But because demutualized stock exchanges are less concerned about member income, they have greater incentives to enforce trade practice rules and thus provide a more rigorous trading environment. As a result, demutualized stock exchanges provide a more transparent trading environment. Since investors and issuers may have more confidence in trading on transparent stock exchanges, this signal of transparency can be very influential in attracting order flow to demutualized stock exchanges, and in the process, helping improve market quality by increasing trading volume and liquidity and decreasing bid-ask spreads and volatility. Additionally, the desire to effectively respond to increased competition (especially competition from ECNs), coupled with enhanced sources of financing (e.g. by selling equity to others 
through private placements) - invariably make investments in technology a key priority for demutualized stock exchanges. Given that technological investments will lead to the effective and efficient dissemination of information to all market participants, we argue that demutualization will lead to reduction in information asymmetry and will also improve transparency. With improvements in transparency, issuers and investors will find demutualized exchanges as the preferred locations for trading, and order flow and trading volume will increase as a result. As order flow migrates to demutualized stock exchanges, network externalities will kick in as other market participants find it attractive to do business on demutualized stock exchanges due to the increased number of market participants. The net effects of all these influences will be that liquidity will increase, bidask spreads and price volatility will decrease and market quality will improve. Also, by reducing the level of manual work, technological investments principally made possible through demutualization ${ }^{16}$ will directly reduce the cost of transacting and improve the speed with which orders are executed - both of which are important dimensions of market quality. For all of these reasons, we contend that stock exchange demutualization will lead to improvements in market quality.

It should be noted, however, that there is also the possibility of deterioration in overall market quality as a result of demutualization. For instance, the profit maximization objective of demutualized, for-profit stock exchanges may motivate some demutualized exchanges to loosen their listing requirements so as to encourage more firms to list in order to improve their bottom-lines. If this happens, then the overall quality of the market

\footnotetext{
${ }^{16}$ While demutualized stock exchanges have many options of raising funds for technological investments, mutualized stock exchanges can mostly source additional funds from members - who may be unable to provide more funds because of their own business needs.
} 
could be impacted as a result of the lax listing requirements - since the presence of low quality firms on demutualized stock exchanges may turn investors away from these exchanges and the associated flight of order flow will decrease liquidity, increase bid-ask spreads and volatility and worsen the quality of the market. While this possibility exists, we argue that this is unlikely - especially given the high value of market integrity to stock exchanges and the intense government regulation of the industry (Otchere, 2006).

While we expect demutualized stock exchanges to experience improvements in market quality, we argue that mutualized stock exchanges could experience deteriorations in market quality. Given that increases in order flow is a zero sum game whereby some exchanges gain while others lose (Arnold et al., 1999), the migration of order flow to transparent demutualized for-profit stock exchanges could lead to mutualized stock exchanges experiencing reductions in order flow and trading volume. The decrease in trading volume will increase bid-ask spreads and price volatility/oscillations. Consequently, the liquidity of mutualized stock exchanges will deteriorate. Also, the vested interest of members which is the principal driver of mutualized stock exchanges may dissuade these exchanges from exposing innovations (e.g. technological innovations) that will improve transparency and open up the exchange to other (nonmember) market participants - since that will decrease revenues from intermediating nonmember trades. There is also the possibility that mutualized stock exchanges may not have the required financing to make the needed investments in technology - since the financing may have to come from their members who might be unwilling or unable to advance more money for technological investments. The lack of transparency and 
absence of modernized trading systems will hasten the migration of order flow, reduce trading volume and liquidity, increase bid-ask spreads and volatility and reduce market quality of mutual stock exchanges. Consequently, we hypothesize that:

H1: Measures of market quality (including quoted and effective bid-ask spreads) for demutualized stock exchanges will improve in the post-demutualization period. H2: Measures of market quality (including quoted and effective bid-ask spreads) for mutualized stock exchanges will deteriorate in the post-demutualization period.

A number of demutualized stock exchanges also list their shares on stock exchanges and become publicly traded firms. This phenomenon is referred to as self-listing (Otchere, 2006). Because self-listing/going public results in the complete decoupling of ownership and control (Oldford and Otchere, 2011), management of corporatized stock exchanges have complete control and the freedom to pursue strategies that maximize profits and firm value. As a result, we argue that publicly traded demutualized stock exchanges are in a better position to undertake strategies that increase order flow, trading volume and liquidity - compared to privately held demutualized stock exchanges (and mutuals). As trading volume and liquidity increase more, bid-ask spreads decrease more and the market quality of publicly traded demutualized stock exchanges will improve more than the improvements that their privately held counterparts will achieve. Also, undertaking the initial public offering (IPO) journey and continuing to be publicly listed require that corporatized exchanges continue to publicly disclose a significant amount of information. These disclosure requirements make publicly traded stock exchanges more transparent than privately held demutualized exchanges and mutuals. This enhanced transparency 
makes publicly traded stock exchanges even more attractive to investors and issuers (compared to privately held demutualized exchanges). This increases the likelihood that publicly listed stock exchanges will attract even more order flow, increase their trading volume, reduce bid-ask spreads and improve their market quality more than privately held demutualized stock exchanges can improve market quality as a result of demutualization. On the contrary, however, the separation of ownership and control in publicly listed stock exchanges can introduce the possibility of the agency problem (Jensen and Merkling, 1976) whereby managers maximize their own welfare at the expense of owners/shareholders. The agency problem has the potential of leading to deterioration in market quality because of the possibility that managerial opportunism could lead to expropriation (e.g. consumption of perquisites, taking cash out, etc.) or misallocation of shareholder funds instead of adopting shareholder value-enhancing strategies that increase order flow, turnover and liquidity (which will lead to decreases in bid-ask spreads and improvements in market quality). Despite this possibility, it is our view that the discipline of the market for corporate control will constrain managers of publicly traded stock exchanges from misappropriating shareholder funds. As a result, we submit that the complete separation of ownership from control and the higher transparency of publicly listed demutualized stock exchanges will help increase order flow, increase trading volume and liquidity, decrease bid-ask spreads and volatility and improve market quality more for publicly listed demutualized stock exchanges than privately held demutualized stock exchanges (and mutuals). Consequently, we hypothesize that: 
H4: Measures of market quality (including quoted and effective bid-ask spreads) for publicly traded demutualized stock exchanges will be better than measures of market quality for privately held demutualized stock exchanges (and mutualized stock exchanges).

\subsection{Data and Methodology}

\subsubsection{Data}

This essay uses daily firm-level stock market data (in US dollars), exchange-level data and country-level data to investigate the effects of 30 stock exchange demutualizations on market quality of the demutualizing exchanges as well as a control group of 11 rival mutualized exchanges. The 30 demutualizations, which occurred between 1993 and 2013, are typically analyzed over a six-year window starting one year or 250 trading days before the demutualization date and ending five years or 1,250 trading days after the demutualization date. Some of the key firm-level market data variables that we collected from Bloomberg include closing bid, ask, price, volume and market capitalization. The firm-level data is supplemented with exchange-level data (e.g. number of listed firms, domestic market capitalization, value of share trading, etc.) obtained from the World Federation of Exchanges' website. We obtained country-level data from Capital IQ. However, since there is no centralized location from which the dates of demutualization can be obtained, we employed a multipronged approach to collecting the dates of demutualization. This approach included web searches, article searches and also contacting some of the exchanges, Mondo Visione, and the World Federation of 
Exchanges. ${ }^{17}$ Appendix 2A has the list of the sampled demutualized and mutualized stock exchanges used in this study.

Given the large amount of data, it was infeasible to include all firms listed on all the sample stock exchanges in this study. As Domowitz and Steil (2001) observed, the data requirements for studies of market quality are too large for any single research project. Consequently, any study of market quality may have to be narrowed. To help narrow our research, we sampled a manageable number of representative companies from each stock exchange for inclusion in this study. The sampled firms are representative of the broad spectrum of firms listed on each exchange - including small firms, medium-sized firms and large firms. Given the large amount of data, we used a sample of about $15 \%$ of firms listed on the various stock exchanges, largely motivated by the need to get a representative sample from each stock exchange by selecting a random sample of about $5 \%$ of stocks in each size tercile (i.e. large, medium and small) on each stock exchange. Our final sample is made up of over 34 million firm-day records over the 1993 to 2013 period - derived from over 4,500 unique firms listed on 41 stock exchanges.

It should be noted that most market quality studies investigating the effects of an issue (e.g. decimalization) on stocks in one or a few stock exchanges (usually US exchanges) usually use intraday data obtained from the TAQ (trade and quotations) database. However, intraday data for firms trading on the majority of the demutualized stock

\footnotetext{
${ }^{17}$ We would like to acknowledge the invaluable help of Mr. Herbie Skeete at Mondo Visione, who took it upon himself to collect the demutualization dates for stock exchanges for which we could not find the dates. We would also like to acknowledge the help of Ms. Eleanor Penistone at the World Federation of Exchanges and several individuals from a number of stock exchanges.
} 
exchanges (used in this study) is not publicly available. Consequently, we use daily data for gauging the market quality implications of stock exchange demutualization. There is empirical justification for using daily data in studies of market quality. Goyenko et al. (2009) demonstrate, based on a sample of 400 randomly selected stocks over the period 1993 to 2005, that low-frequency measures (based on daily data) parsimoniously capture high-frequency measures of transaction costs (based on intraday data) in many cases that "the effort of using high-frequency measures is simply not worth the cost" (pp. 179).

\subsubsection{Methodology}

To achieve our central research objective of establishing the market quality implications of stock exchange demutualization, we employ a multipronged and multi-stepped methodology in this study. The first step involved the computation of the measures of market quality and other variables. Once the measures were calculated, the next step involved aggregating the data to obtain averages at the exchange level and then trending the measures of transaction costs and volatility to understand their behaviour over time. We next performed univariate analysis of the key measures used in the study. Univariate analysis employed t-tests of means and nonparametric z-tests of medians to determine if the means and/or medians of the various measures of market quality have improved in the post-demutualization period compared to the pre-demutualization period. The univariate analysis also involved segmenting the data into the portfolio of demutualizing stock exchanges versus the portfolio of stock exchanges that are still operated as mutuals. The final step involved multivariate analyses that regress bid-ask spread measures on a demutualization dummy plus a number of firm-level, exchange-level and country-level 
control variables. Quoted and effective spreads, the two measures of bid-ask spreads used in the multivariate regressions, are discussed below.

\section{Quoted and Effective Bid-Ask Spreads}

Following Bessembinder and Kaufman (1997) and Venkataraman (2001), we define quoted spreads as follows:

Quoted Spread $=\frac{A s k_{i t}-B i d_{i t}}{\operatorname{Mid}_{i t}}$

where $A s k_{i t}$ is the closing ask price for security $i$ at time $t, B i d_{i t}$ is the closing bid price for security $i$ at time $t$ and $\operatorname{Mid}_{i t}$ is the quote midpoint.

Because we are using daily data, we used a formula for estimating effective spreads that has been suggested by Blume and Goldstein (1992). The Blume and Goldstein (1992) method compares transaction prices to the midpoint of the quoted spread. A similar formulation of effective spreads is used by Porter and Weaver (1997), Bessembinder and Kaufman (1998), Peterson and Sirri (2003), Otchere and Abou-Zied (2008), Kale and Loon (2011), Kedia and Zhou (2011) - among others - and is given as:

Effective Spread $=2 * \mid$ Transaction Price $-\left(\frac{B i d+A s k}{2}\right) \mid$

Given that our sample is a multi-exchange sample (of small and big exchanges), we use relative effective spreads which we define, following Diether et al. (2009), as effective 
spreads expressed as a percent of the quote midpoint. We also, in robustness tests, express relative spreads as a percent of price (following Harris, 1994).

\section{Multivariate Regression Analysis}

Several authors have noted that a number of factors impact bid-ask spreads/transaction costs and market quality. Schwartz (1988), for example, identifies four clusters of variables, viz., activity, risk, information and competition, as determinants of bid-ask spreads while Madhavan (2000) contends that volume, risk, price and firm size appear to explain most of the variability in bid-ask spreads. In order to ensure that any reported univariate improvements in spreads/market quality following demutualization is not merely a reflection of the impacts of these other factors on market quality, we employed multivariate regression analysis to control for the effects of all these other important factors impacting market quality.

While several regression models have been used in the market quality literature, we based our multivariate regression specification on a model presented in Madhavan (2000). Although we estimated various regression equations, the equation below provides a good representation of our central regression equation:

$$
\begin{aligned}
& \text { Spreads }= \\
& \beta_{0}+\beta_{1} \text { MktCap }+\beta_{2} \text { InvPrice }+\beta_{3} \text { StdDev }+\beta_{4} \text { Volume }+\beta_{5} \text { DemutualDummy }+ \\
& \beta_{6} \text { IPO Dummy }+\beta_{7} \text { GDP per Capita }+\beta_{8} \text { Time Trend }+\gamma_{k} \sum Z_{k}+\varepsilon_{i} \ldots \ldots \ldots . .(3.3)
\end{aligned}
$$


where Spreads represent quoted spreads or effective spreads, MktCap is log of firm market capitalization, InvPrice represents price inverse (i.e. 1/price), StdDev is standard deviation, Volume represents log of volume traded, DemutualDummy represents the demutualization dummy which takes the value of one in the post-demutualization period if the stock exchange is demutualized and zero otherwise, IPO Dummy represents the stock exchange's IPO dummy which takes the value of one in the post IPO period for stock exchanges that are publicly traded and zero otherwise, GDP per Capita is lag of GDP per capita, Time Trend is a linear time trend and $Z_{k}$ is a vector of exchangespecific control variables (including log of domestic market capitalization, log of number of listed firms, capital expenditures to revenue ratio and market share growth).

The variables in the multivariate regression model are informed by theory and/or empirical evidence. Demsetz (1968) finds that the cost of exchanging a security declines as trading activity in that security increases while McInish and Wood (1992) opine that because of economies of scale in trading costs, greater trading activity may lead to lower spreads. Peterson and Fialkowski (1994) formed deciles based on stock's average daily trading volume during 1990 and find that the posted spread falls from 26 cents for the least actively traded issues to 16 cents for the most actively traded issues. The authors also find that the effective spread declines, but the magnitude of the decline is much smaller (i.e. from 10 cents to 8 cents). Stoll (2000) argues that increases in volume, number of trades, and firm size increase the probability of locating a counterparty, thereby reducing the risk of accepting inventory. Stoll (2000) notes that as "a matter of empirical regularity, quoted proportional spreads are negatively related to measures of 
trading activity, such as volume, negatively related to the stock price, and positively related to a stock's volatility" (pp. 1481). However, Keim and Madhavan (1998) study the common stock trades by 21 institutions from January 1991 to March 1993 and find trading costs to be larger for the largest trades than for the smaller trades (i.e. positive relation between trade size and costs) and also, trading costs to be monotonically decreasing with market capitalization (i.e. negative relation between market capitalization and costs). Harris (1994) predicts a negative relationship between trading volume and bid-ask spreads, noting that simple demand theory implies smaller spreads will be associated with larger volumes. Easley et al. (1996) report that the risk of informationbased trading is lower for active (high volume) stocks than it is for infrequently traded securities - supporting the notion of a negative relationship between spreads and trading volume. While some authors use price in their market quality regressions, Madhavan (2000) notes that price inverse is typically used as a variable in multiple regressions because the minimum tick induces a convexity in percentage spreads. The author also observes that the riskiness of the security is usually measured by the volatility (or standard deviation) of past returns. In general, the standard deviation of the past three months' returns is used although high-minus-low is also used in some studies (e.g. Bacidore et al., 2002).

In addition to the firm-level variables, we include a number of stock exchange control variables. We argue that because demutualization is expected to lead to increased market share for the demutualizing exchanges, we expect the increased market share to lead to increased liquidity and consequently reduction in bid-ask spreads. As a result, we include 
market share growth as a control variable in our bid-ask regressions. We argued that one benefit of demutualization is the increased likelihood of making technological investments that will improve transparency, reduce cost, increase order flow and liquidity and help reduce bid-ask spreads. In order words, we expect technological investments to be negatively related to spreads. We control for the effects of technology using the capital expenditures to revenue ratio (i.e. capital expenditures scaled by revenue/size). While the capital expenditures to revenue ratio (CAPEX to Rev) is an imperfect proxy for technology, we believe that it is a good proxy. With virtualization and the emergence of ECNs, we believe that the majority of stock exchanges' capital expenditures will be in the form of technological investments. As a result, the CAPEX to revenue ratio will be a good (albeit an imperfect) proxy to capture the effects of technology on spreads in our analysis. We also control for the number of firms listed on the exchanges as well as the domestic market capitalization of firms traded on the exchanges. We follow Arnold el al. (1999) and include a linear time trend as a control variable to capture increases in other variables over time. To control for country growth differences, we include GDP per capital as a control variable. We lag GDP per capital by a year because it is reported with delay.

From our hypothesis development, we expect the demutualization dummy to be negatively related to bid-ask spreads because of our contention that demutualization will improve market quality by lowering transaction costs. From the literature, we expect firm market capitalization and trading volume to be negatively related to spreads and standard deviation as well as price inverse to be positively related to spreads. We expect the stock 
exchange's market share and domestic market capitalization to be negatively related to spreads. Based on the network externalities argument (Pagano, 1989), we expect the number of firms listed on the exchange to be negatively related to spreads. However, the relationship could also be positive if (exploitation of) market power dominates network externalities. The linear time trend and GDP per capital variables could be either negatively or positively related to spreads.

We use the ordinary least squares technique for our multivariate analysis. Also, given the inherently small population of stock exchanges and the consequent small sample sizes of studies using stock exchanges, we use Binder's (1985) and Acharya's (1993) dummy variables approach since it allows us to use data over both the event and nonevent windows - helping increase the number of observations for our regressions.

\section{Averaging Methods}

Since we are interested in the long term effects of stock exchange demutualization, we study our sample firms and exchanges over a six year window starting 250 days before the consummation of the demutualization and ending 1,250 days after the demutualization completion. Given our research objectives (including establishing changes in market quality over time and impacts of subsequent IPO), we aggregate firmlevel daily data to get daily exchange-level (portfolio) averages. Although we used the exchange-level averages in our main analysis, we also used the firm-level data in robustness tests. Aggregating the data at the exchange-level allows us to effectively answer our research questions. Also, aggregating at the exchange-level offers additional 
benefits including minimizing potential endogeneity and clustering of residuals which can be present at the firm-level. As Shin (1987), who investigated and compared the endogeneity problems in micro and aggregate equations demonstrated, "aggregate equations are in general subject to less endogeneity due to the synchronization effect" (pp. 57).

To compare the pre-demutualization period's performance to the post-demutualization period, we adopted a number of averaging/aggregation strategies (informed by market quality studies such as Boehmer et al., 2005 and Diether et al., 2009). One approach involved chunking up the post-demutualization period into years and then comparing the pre-demutualization period to the chunked post-demutualization periods (e.g. day [-250, 1] compared to day $[+1,+250]$ or day $[+251,+500])$. The second approach is a pairwise averaging of the post-demutualization data. Here, we average the specific days over the 5-year post-demutualization period and compare this average to the corresponding day in the pre-demutualization period (e.g. averaging 5 day $1 \mathrm{~s}$ in the post-demutualization period and comparing this average to the day 1 in the pre-demutualization period). The third approach involved pooling the data in the post-demutualization period.

\subsection{Results}

The results of our study are presented in the following discussion. 


\subsubsection{Descriptive Statistics and Correlations}

We present, in Table 3.1, descriptive statistics and Pearson's correlations for the variables in our study. Panel A demonstrates that bid-ask spreads are generally lower on demutualized stock exchanges than mutualized stock exchanges. For instance, quoted spreads, which are $6.2 \%$ on demutualized stock exchanges, are about $7.4 \%$ on mutualized stock exchanges. Effective spreads and high-minus-lows are also generally lower on demutualized stock exchanges, but standard deviations are, on average, higher on demutualized exchanges than on mutualized stock exchanges. The average market capitalization of firms listed on demutualized stock exchanges is higher but the median is lower. The main inference from the descriptive statistics is that spreads are lower (by more than $15 \%$ ) on demutualized stock exchanges compared to mutualized stock exchanges. It should be noted, however, that the demutualized exchanges are usually larger, well established and are mostly in developed countries.

\section{Table 3.1 - Descriptive Statistics and Pearson Correlations}

\begin{tabular}{|c|c|c|c|c|c|c|}
\hline Panel A: Desc & ives & & & & & \\
\hline Variable & Mean & Median & Std. Dev. & Min & Max & $\begin{array}{l}\text { Firm-Day } \\
\text { Obs. }\end{array}$ \\
\hline $\begin{array}{l}\text { All } \\
\text { Exchanges }\end{array}$ & & & & & & \\
\hline Quoted & 0.0686 & 0.0614 & 0.0421 & 0.0036 & 0.2773 & $35,920,760$ \\
\hline Effective & 0.0692 & 0.0633 & 0.0443 & 0.0028 & 0.3231 & $35,519,275$ \\
\hline $\begin{array}{l}\text { Mkt Cap } \\
\text { Firm }\end{array}$ & 6.43 & 6.36 & 1.43 & 0.53 & 10.32 & $34,321,489$ \\
\hline Std Dev & 0.0316 & 0.0293 & 0.0089 & 0.0101 & 0.0797 & $35,186,428$ \\
\hline $\begin{array}{l}\text { High minus } \\
\text { Low }\end{array}$ & 0.0417 & 0.0392 & 0.0141 & 0.0041 & 0.1123 & $29,621,632$ \\
\hline
\end{tabular}




\begin{tabular}{lcccccc}
\hline Variable & Mean & Median & Std. Dev. & Min & Max & $\begin{array}{l}\text { Firm-Day } \\
\text { Obs. }\end{array}$ \\
\hline Quoted & 0.0622 & 0.0514 & 0.0461 & 0.0036 & 0.2773 & $6,168,185$ \\
Effective & 0.0578 & 0.0451 & 0.0472 & 0.0028 & 0.3231 & $6,000,783$ \\
$\begin{array}{l}\text { Mkt Cap } \\
\text { Firm }\end{array}$ & 7.03 & 7.00 & 1.58 & 0.53 & 10.32 & $5,255,437$ \\
$\begin{array}{l}\text { Std Dev } \\
\text { High minus }\end{array}$ & 0.0325 & 0.0306 & 0.0106 & 0.0131 & 0.0797 & $6,042,999$ \\
Low & 0.0399 & 0.0377 & 0.0154 & 0.0041 & 0.1115 & $4,797,981$ \\
& & & & & \\
Mutuals & & & & & & \\
Quoted & 0.0736 & 0.0641 & 0.0379 & 0.0101 & 0.2493 & $29,752,575$ \\
Effective & 0.0781 & 0.0664 & 0.0397 & 0.0098 & 0.3148 & $29,518,492$ \\
$\begin{array}{l}\text { Mkt Cap } \\
\text { Firm }\end{array}$ & 5.97 & 5.80 & 1.11 & 3.10 & 7.89 & $29,066,052$ \\
Std Dev & 0.0308 & 0.0290 & 0.0071 & 0.0101 & 0.0641 & $29,143,429$ \\
$\begin{array}{l}\text { High minus } \\
\text { Low }\end{array}$ & 0.0432 & 0.0394 & 0.0127 & 0.0059 & 0.1123 & $24,823,651$ \\
\hline
\end{tabular}

Panel B: Correlations

\begin{tabular}{|c|c|c|c|c|c|c|c|c|c|c|c|c|}
\hline & {$[1]$} & [2] & [3] & {$[4]$} & {$[5]$} & {$[6]$} & [7] & [8] & [9] & [10] & [11] & [12] \\
\hline \multicolumn{13}{|l|}{$\begin{array}{l}\text { All } \\
\text { Exchanges }\end{array}$} \\
\hline [1] Quoted & 1.0000 & & & & & & & & & & & \\
\hline [2] Effective & $\begin{array}{c}0.8922 \\
(* * *)\end{array}$ & 1.0000 & & & & & & & & & & \\
\hline $\begin{array}{l}\text { [3] Mkt Cap } \\
\text { Firm }\end{array}$ & $\begin{array}{c}-0.2096 \\
(* * *)\end{array}$ & $\begin{array}{c}-0.2644 \\
(* * *)\end{array}$ & 1.0000 & & & & & & & & & \\
\hline [4] Inv Price & $\begin{array}{c}0.4410 \\
(* * *)\end{array}$ & $\begin{array}{c}0.3566 \\
(* * *)\end{array}$ & $\begin{array}{c}-0.2097 \\
(* * *)\end{array}$ & 1.0000 & & & & & & & & \\
\hline [5] Std Dev & $\begin{array}{l}0.2050 \\
(* * *)\end{array}$ & $\begin{array}{c}0.2148 \\
(* * *)\end{array}$ & $\begin{array}{c}-0.2178 \\
(* * *)\end{array}$ & $\begin{array}{c}0.0443 \\
(* * *)\end{array}$ & 1.0000 & & & & & & & \\
\hline [6] Volume & $\begin{array}{c}-0.2972 \\
(* * *)\end{array}$ & $\begin{array}{c}-0.3185 \\
(* * *)\end{array}$ & $\begin{array}{c}0.3603 \\
(* * *)\end{array}$ & $\begin{array}{c}0.1695 \\
(* * *)\end{array}$ & $\begin{array}{c}-0.3110 \\
(* * *)\end{array}$ & 1.0000 & & & & & & \\
\hline $\begin{array}{l}\text { [7] Mkt } \\
\text { Share }\end{array}$ & $\begin{array}{c}-0.0116 \\
(* *)\end{array}$ & $\begin{array}{c}-0.0153 \\
(* * *)\end{array}$ & $\begin{array}{c}-0.0265 \\
(* * *)\end{array}$ & $\begin{array}{c}0.0161 \\
(* * *)\end{array}$ & $\begin{array}{c}-0.0110 \\
(*)\end{array}$ & $\begin{array}{c}0.0361 \\
(* * *)\end{array}$ & 1.0000 & & & & & \\
\hline $\begin{array}{l}\text { [8] Mkt Cap } \\
\text { Exch }\end{array}$ & $\begin{array}{c}-0.5394 \\
(* * *)\end{array}$ & $\begin{array}{c}-0.5267 \\
(* * *)\end{array}$ & $\begin{array}{c}0.7250 \\
(* * *)\end{array}$ & $\begin{array}{c}-0.3723 \\
(* * *)\end{array}$ & $\begin{array}{c}-0.1558 \\
(* * *)\end{array}$ & $\begin{array}{c}0.3785 \\
(* * *)\end{array}$ & $\begin{array}{c}-0.0208 \\
(* * *)\end{array}$ & 1.0000 & & & & \\
\hline $\begin{array}{l}{[9] \text { Lstd }} \\
\text { Firms }\end{array}$ & $\begin{array}{c}-0.4763 \\
(* * *)\end{array}$ & $\begin{array}{c}-0.4658 \\
(* * *)\end{array}$ & $\begin{array}{c}0.4258 \\
(* * *)\end{array}$ & $\begin{array}{c}-0.2342 \\
(* * *)\end{array}$ & $\begin{array}{c}-0.0546 \\
(* * *)\end{array}$ & $\begin{array}{c}0.1838 \\
(* * *)\end{array}$ & $\begin{array}{c}-0.0283 \\
(* * *)\end{array}$ & $\begin{array}{c}0.7734 \\
(* * *)\end{array}$ & 1.0000 & & & \\
\hline $\begin{array}{l}{[10] \mathrm{CAPEX}} \\
\text { to } \mathrm{Rev}\end{array}$ & -0.0084 & $\begin{array}{c}-0.0201 \\
(* * *)\end{array}$ & $\begin{array}{c}-0.1374 \\
(* * *)\end{array}$ & $\begin{array}{c}0.0700 \\
(* * *)\end{array}$ & $\begin{array}{c}0.2086 \\
(* * *)\end{array}$ & $\begin{array}{c}-0.0223 \\
(* * *)\end{array}$ & -0.0020 & $\begin{array}{c}0.0441 \\
(* * *)\end{array}$ & $\begin{array}{c}0.1495 \\
(* * *)\end{array}$ & 1.0000 & & \\
\hline $\begin{array}{l}{[11] \text { GDP }} \\
\text { per Cap }\end{array}$ & $\begin{array}{c}-0.0628 \\
(* * *)\end{array}$ & $\begin{array}{c}-0.0529 \\
(* * *)\end{array}$ & $\begin{array}{c}0.1810 \\
(* * *)\end{array}$ & $\begin{array}{c}-0.3027 \\
(* * *)\end{array}$ & $\begin{array}{c}0.0602 \\
(* * *)\end{array}$ & $\begin{array}{c}-0.3755 \\
(* * *)\end{array}$ & $\begin{array}{c}-0.0572 \\
(* * *)\end{array}$ & $\begin{array}{c}0.3892 \\
(* * *)\end{array}$ & $\begin{array}{c}0.3985 \\
(* * *)\end{array}$ & $\begin{array}{c}0.0246 \\
(* * *)\end{array}$ & 1.0000 & \\
\hline $\begin{array}{l}{[12] \text { High }} \\
\text { minus Low }\end{array}$ & $\begin{array}{c}0.3520 \\
(* * *)\end{array}$ & $\begin{array}{c}0.3382 \\
(* * *)\end{array}$ & $\begin{array}{c}-0.3765 \\
(* * *)\end{array}$ & $\begin{array}{c}0.2041 \\
(* * *)\end{array}$ & $\begin{array}{c}0.6705 \\
(* * *)\end{array}$ & $\begin{array}{c}-0.2440 \\
(* * *)\end{array}$ & $\begin{array}{c}0.0109 \\
(* * *)\end{array}$ & $\begin{array}{c}-0.4041 \\
(* * *)\end{array}$ & $\begin{array}{c}-0.2124 \\
(* * *)\end{array}$ & $\begin{array}{c}-0.0434 \\
(* * *)\end{array}$ & $\begin{array}{c}0.1142 \\
(* * *)\end{array}$ & 1.0000 \\
\hline
\end{tabular}

Demutualized Exchanges

[1] Quoted $\quad 1.0000$

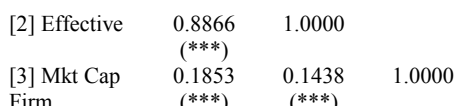

[4] Inv Price $\quad 0.4412 \quad 0.3053 \quad-0.0815 \quad 1.0000$

$(* * *) \quad(* * *) \quad(* * *)$

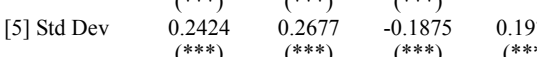

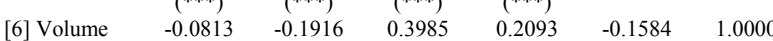

$\begin{array}{lllll}(* * *) & (* * *) & (* * *) & (* * *) & (* * *)\end{array}$

[7] Mkt $\quad-0.0152 \quad-0.0242 \quad-0.0341 \quad 0.0152 \quad-0.001$

$\begin{array}{ccc}-0.0152 & -0.0242 & -0.0341 \\ \text { Share } & (* *) & (* *)\end{array}$

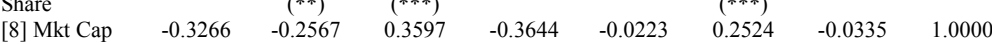

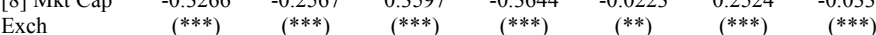

[9] Lstd $-0.3373-0.2788-0.0310=-0.1836-0.0980-0.0851-0.0286$

$\begin{array}{lccccccc}\text { Firms } & -0.337 & -0.2788 & -0.0310 & -0.1836 & 0.0980 & 0.0851 & -0.0286 \\ & (* *) & (* *) & (* * *) & (* * *) & (* * *) & (* * *) & (* * *)\end{array}$

to Rev

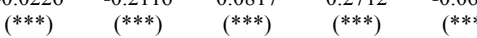




\begin{tabular}{lcccccccccccc}
\hline & {$[1]$} & {$[2]$} & {$[3]$} & {$[4]$} & {$[5]$} & {$[6]$} & {$[7]$} & {$[8]$} & {$[9]$} & {$[10]$} & {$[11]$} & {$[12]$} \\
\hline$[11]$ GDP & -0.3252 & -0.2250 & 0.1453 & -0.3100 & -0.1521 & -0.0446 & -0.0511 & 0.6456 & 0.4830 & 0.0379 & 1.0000 \\
per Cap & $(* * *)$ & $(* * *)$ & $(* * *)$ & $(* * *)$ & $(* * *)$ & $(* * *)$ & $(* * *)$ & $(* * *)$ & $(* * *)$ & $(* * *)$ & \\
{$[12]$ High } & 0.1058 & 0.0900 & -0.1587 & 0.2484 & 0.6651 & 0.0117 & 0.0217 & -0.0274 & 0.1539 & -0.2316 & 0.1656 & 1.0000 \\
minus Low & $(* * *)$ & $(* *)$ & $(* * *)$ & $(* *)$ & $(* * *)$ & & $(* *)$ & $(* * *)$ & $(* * *)$ & $(* * *)$ & $(* * *)$ &
\end{tabular}

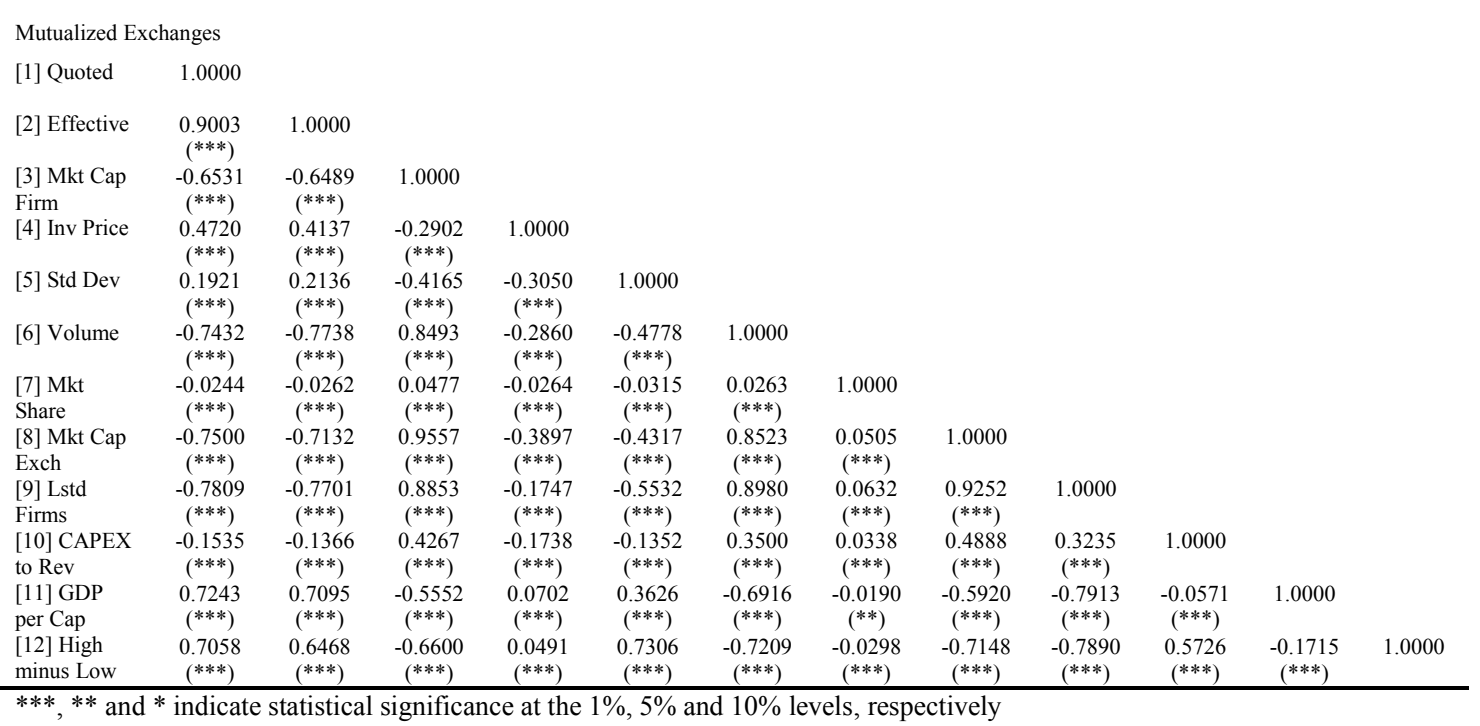

The bivariate correlations between the variables are presented in panel B of Table 3.1.

The relationships among the independent variables and the two spread measures are

mostly in line with expectations. When we examine the correlations for all the exchanges,

we find that measures of activity and size such as firm market capitalization and volume

as well as stock exchanges' market share and domestic market capitalization of firms

traded on the exchanges are all negatively related to spreads as postulated. However,

although firm market capitalization has a negative relationship for all exchanges and

mutualized exchanges, the correlation between firm market capitalization and spreads for

demutualized exchanges is positive - which could signify that there are proportionately

more small firms in the demutualized subsample. As expected also, measures of risk such

as standard deviation and high-minus-low are also positively related to spreads. Log of

number of firms listed on the exchanges also has a negative relationship with the two

spread measures - implying that the network externality argument dominates the market 
power argument. The capital expenditures to revenue ratio (CAPEX to Rev), our proxy for technology investments, is negatively related to both quoted and effective spreads for mutualized exchanges and negatively related to effective spreads for all exchanges and demutualized exchanges, indicating that investments in technology help reduce spreads and transaction costs.

The correlation between quoted spreads and effective spreads is very high - generally about $90 \%$. This high correlation between quoted and effective spreads means using any one of them to summarize our results will present a good and representative picture of our results. Except for the high correlation between domestic market capitalization and the number of firms listed on the exchanges for the mutualized subsample, the bivariate correlations among independent variables are generally low - implying that multicolinearity is not an issue.

\subsubsection{Trends in Spreads and Volatility}

While statistical tests give the significance or otherwise of variables, trend analyses provide the additional benefit of describing the behavior of variables over time - in visually insightful ways that enhance our understanding of the variables/data. To therefore provide more insights into the behavior of spreads and volatility on mutualized and demutualized stock exchanges, we present trend charts of two measures of transaction costs and two measures of volatility in Figure 3.2 to Figure 3.5. 
Figure 3.2 presents trends in quoted spreads from one year (250 days) before the date of demutualization to five years (1,250 days) after the date of demutualization. Chart a) shows that quoted spreads of all demutualized exchanges, which were slightly falling in the pre-demutualization period, started to decline (at an accelerated pace) in the postdemutualization period.

Chart b) shows that quoted spreads of mutualized stock exchanges which were also falling in the pre-demutualization period started increasing in the post-demutualization period - most likely, we conjecture, because of the competitive disadvantages mutualized stock exchanges began to face in the post-demutualization period as order flow migrated to more transparent (and less opaque) demutualized exchanges propelled to higher levels of achievement on the corporate performance ladder by the profit motive resulting from demutualization and conversion.

Figure 3.2 - Quoted Spreads of Firms listed on Demutualized and Mutualized Exchanges

This figure trends quoted spreads of demutuals, mutuals and developed demutuals starting 250 days (one year) before the dates of demutualization and ending 1,250 days ( 5 years) after the demutualization dates. Charts: a) presents quoted spreads of all demutualized exchanges; b) plots quoted spreads of mutualized stock exchanges; c) graphs the industry adjusted (demutuals minus mutuals) quoted spreads ; and, d) trends quoted spreads of developed demutualized exchanges. 

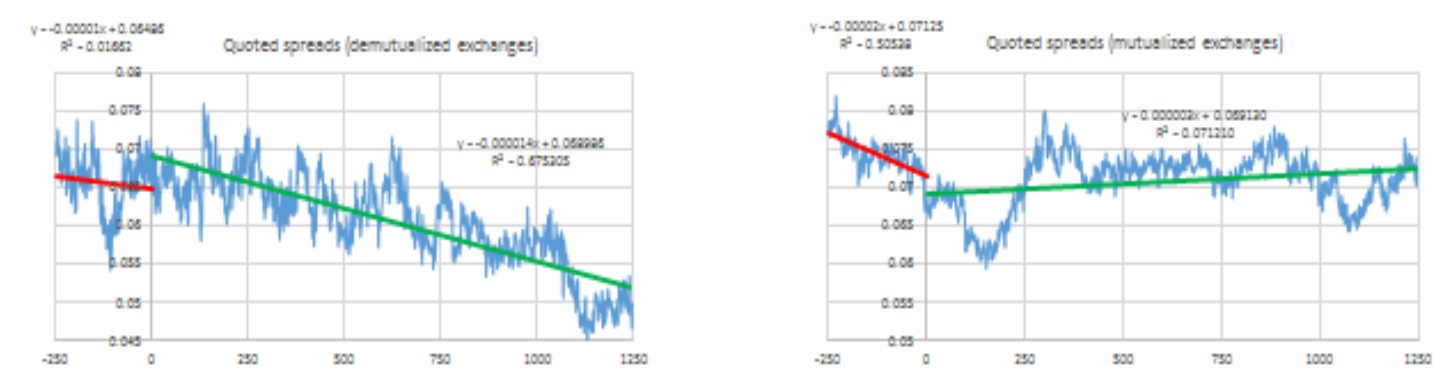

a) Quoted bid-ask spreads of demutuals

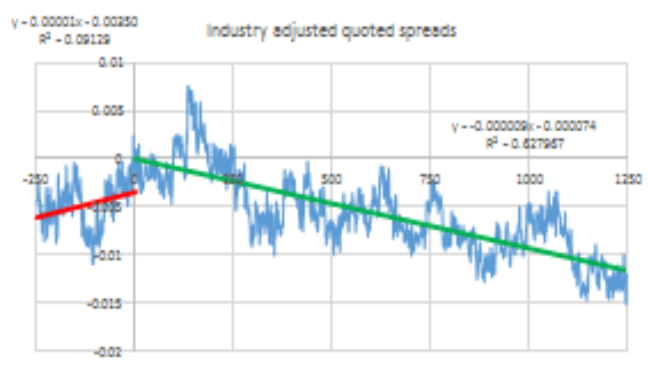

c) Industry adjusted quoted bid-ask spreads

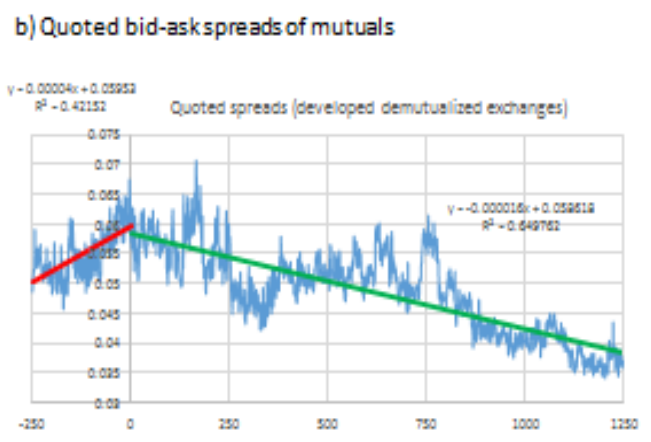

d) Quoted bid-askspreads of developed demutuals

Chart c) trends the industry adjusted quoted spreads (defined as quoted spreads of demutuals minus quoted spreads of mutuals). As the chart demonstrates, demutualized stock exchanges underperformed mutualized stock exchanges in the one year before the demutualization dates - with the difference between spreads on demutualized exchanges and mutualized exchanges trending upwards. However, the trends reversed in the postdemutualization period. Industry-adjusted spreads monotonically decline in the postdemutualization period - signifying improving market quality on demutualized exchanges compared to mutualized exchanges in the post-demutualization period. Contrarily, chart d) shows the even more pronounced decline in bid-ask spreads for developed demutualized stock exchanges in the post-demutualization period. While quoted spreads on developed demutualized exchanges were trending upwards in the one year before demutualization, they began to significantly decline in the post- 
demutualization period, falling almost $64 \%$ from $5.7 \%$ on day zero (i.e. dates of

demutualization) to $3.6 \%$ on day $+1,250$.

To determine how pervasive the superior performance of demutualized exchanges on the cost dimension of market quality in the post-demutualization period is, we also trended effective spreads, a second measure of transaction costs or the cost dimension of market quality, and present the results in Figure 3.3.

Figure 3.3 - Effective Spreads of Firms listed on Demutualized and Mutualized Exchanges

This figure trends effective spreads of demutuals, mutuals and developed demutuals starting 250 days (one year) before the dates of demutualization and ending 1,250 days (5 years) after the demutualization dates. Charts: a) presents effective spreads of all demutualized exchanges; $b$ ) plots effective spreads of mutualized stock exchanges; $c$ ) graphs the industry adjusted (demutuals minus mutuals) effective spreads; and, d) trends effective spreads of developed demutualized exchanges.

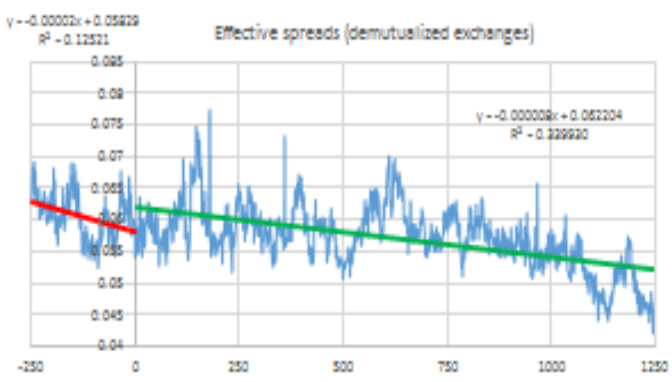

a) Effective bid-ask spreads of demutuals

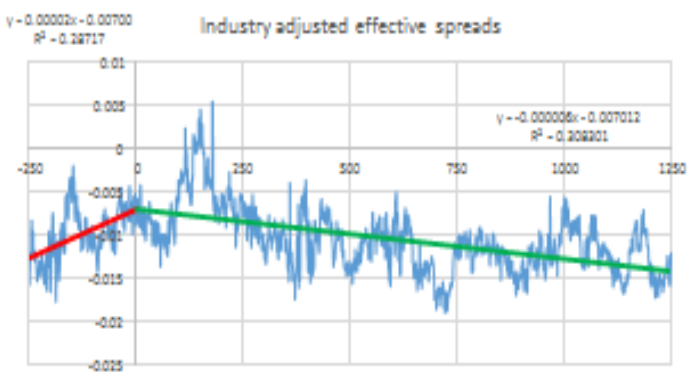

c) Industry adjusted effective bid-ask spreads

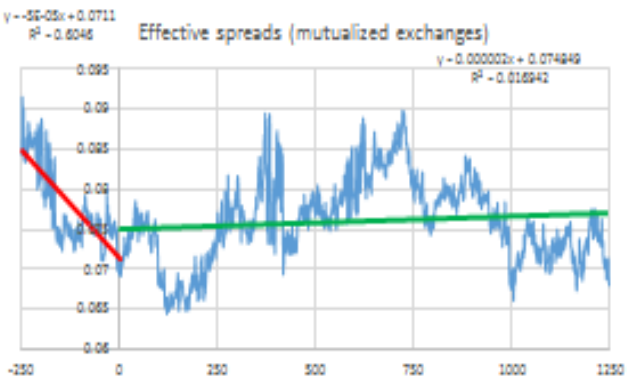

b) Effective bid-ask spreads of mutuals

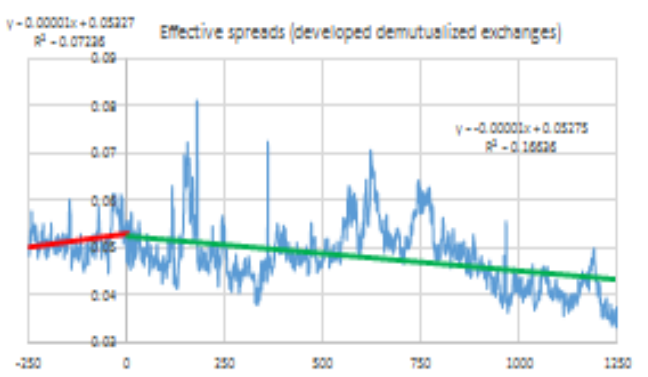

d) Effective bid-ask spreads of developed demutuals 
Just as with quoted spreads, chart a) shows that all demutualized stock exchanges experienced decreasing effective spreads in the post-demutualization period. Chart b) highlights the slight increases in effective spreads for firms listed on mutualized stock exchanges following the completion of the various demutualizations and chart c) shows that demutualized exchanges performed inferiorly (vs. mutualized exchanges) in the predemutualization period, with the difference in effective spreads increasing. However, in the post-demutualization period, difference in effective spreads began to fall, as demutualized stock exchanges outperformed mutualized stock exchanges. Chart d) shows that developed demutualized stock exchanges experienced decreasing effective spreads in the post-demutualization period.

Thus, both quoted spreads and effective spreads show that stock exchange demutualization has resulted in improvements in (the cost dimension of) market quality for demutualized stock exchanges. As demonstrated in the literature review, however, market quality is a multidimensional concept. While the spreads' trend charts have demonstrated improvements (deteriorations) in the cost dimension of market quality for demutualized (mutualized) exchanges, we also trended two measures of volatility to determine whether or not the volatility dimension has also seen improvements (deteriorations) in the post-demutualization period for demutualized (mutualized) exchanges. 
As evident from chart a) of Figure 3.4, volatility, which was on the rise in the predemutualization period on all demutualized exchanges, started (and continued) to decline in the post-demutualization period.

\section{Figure 3.4 - Standard Deviation of Firms listed on Exchanges}

This figure trends standard deviations of demutuals, mutuals and developed demutuals starting 250 days (one year) before the dates of demutualization and ending 1,250 days (5 years) after the demutualization dates. Charts: a) presents standard deviation of all demutualized exchanges; b) plots standard deviation of mutualized stock exchanges; $c$ ) graphs the industry adjusted (demutuals minus mutuals) standard deviations; and, d) trends standard deviation of developed demutualized exchanges.

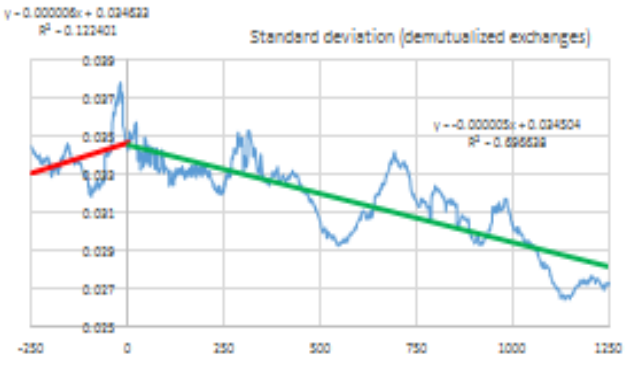

a) Standard deviation of demutuals

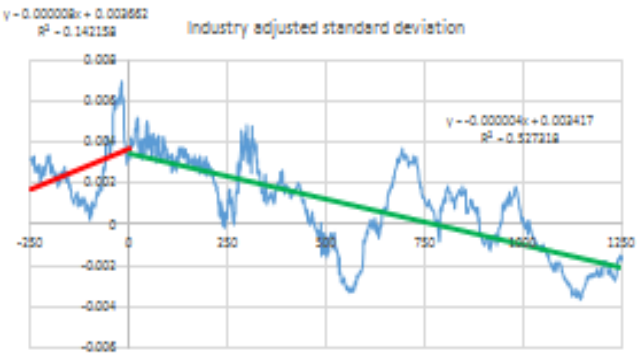

c) Industry adjusted standard deviation

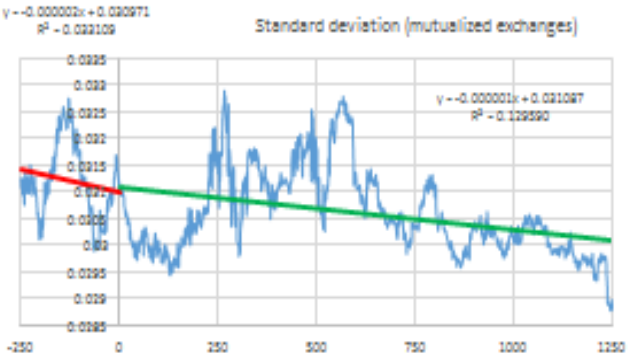

b) Standard deviation of mutuals

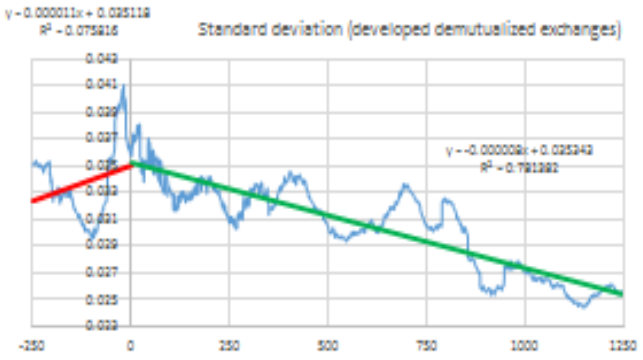

d) Standard deviation of developed demutuals

Chart b) shows that standard deviation, which was decreasing on mutualized stock exchanges in the pre-demutualization period continued to slighly decrease in the postdemutualization period and chart c) shows that industry adjusted standard deviation in the pre-demutualization period was increasing. However, following the demutualization, the differences between standard deviation of demutualized and mutualized stock exchanges have been on a downward trajectory. This clearly demonstrates that volatility on 
demutualized stock exchanges, compared to mutualized stock exchanges, has been on the decline in the post-demutualization period, implying improvements in the volatility dimension of market quality due to the demutualization. Chart d) shows that volatility, which was on the rise in the pre-demutualization period on developed demutualized exchanges, started (and continued) to decline in the post-demutualization period.

Figure 3.5 summarizes the performance of the exchanges on high-minus-low, our second measure of volatility.

Figure 3.5 - High-minus-low of Firms listed on Demutualized and Mutualized Exchanges

This figure trends high-minus-low of demutuals, mutuals and developed demutuals starting 250 days (one year) before the dates of demutualization and ending 1,250 days (5 years) after the demutualization dates. Charts: a) presents high-minus-low of all demutualized exchanges; b) plots high-minus-low of mutualized stock exchanges; c) graphs the industry adjusted (demutuals minus mutuals) high-minus-lows; and, d) trends high-minus-low of developed demutualized exchanges.

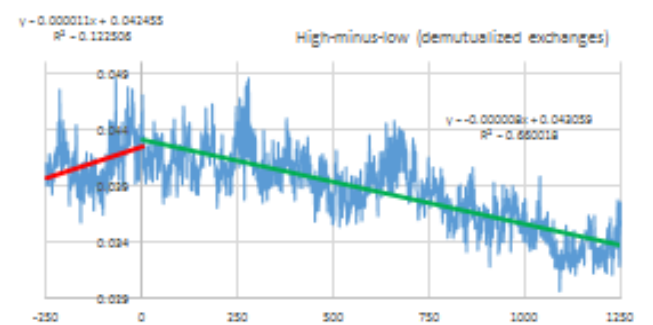

a) High-minus-low of demutuals

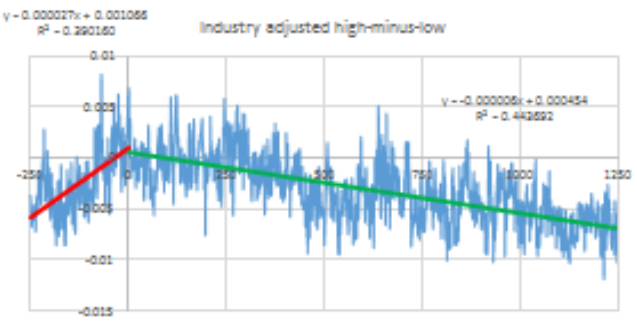

c) Industry adjusted high-minus-low

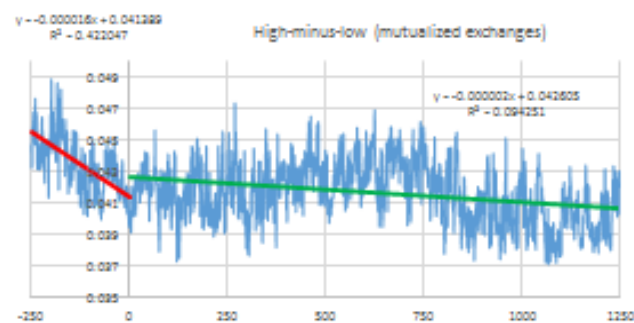

b) High-minus-low of mutuals

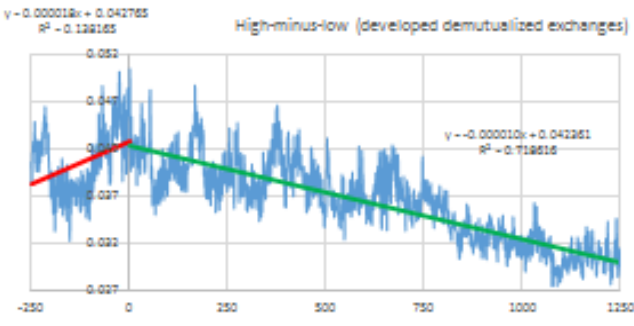

d) High-minus-low of developed demutuals

As demonstrated in chart a), high-minus-lows increased in the pre-demutualization period but decreased in the post-demutualization period on all demutualized exchanges. Chart b) shows that while high-minus-lows were rapidly declining on mutualized stock exchanges 
in the pre-demutialization period, the pace of decline significantly decreased in the postdemutualization period. Chart c) reveals that market adjusted high-minus-lows increased in the pre-demutualization period but decreased in the post-demutualization period. Chart d) also shows that high-minus-lows increased in the pre-demutualization period but decreased in the post-demutualization period on developed demutualized exchanges.

On the whole, Figure 3.2 to Figure 3.5 demonstrate that the performance of demutualized stock exchanges on measures of transaction costs and volatility significantly improved in the post-demutualization period while the performance of mutualized stock exchanges worsened or stagnated in the post-demutualization period. In general, firms listed on demutualized exchanges enjoyed reductions in bid-ask spreads and volatility in the postdemutualization period. The performance improvements are even more marked for firms listed on demutualized exchanges operating in developed markets. On the other hand, the performance of mutualized exchanges either deteriorated or stagnated in the postdemutualization period - as spreads of firms listed on these exchanges started (and continued) to increase (while volatility stagnated) in the post-demutualization period.

\subsubsection{Univariate Analysis of the Impact of Demutualization on Market Quality}

To establish the extent to which performance on the key variables statistically improved or deteriorated in the post-demutualization period compared to the pre-demutualization period, we provide univariate tests of means (using the t-test) and medians (using the 
Wilcoxon signed-rank test) in the pre-demutualization period and pairwise average ${ }^{18}$ of the five years in the post-demutualization period in Table 3.2. The univariate results presented in Table 3.2 are substantially consistent with the trend analyses results.

\section{Table 3.2 - Univariate Tests of Means and Medians}

This table presents the results of the univariate tests of means and medians 250 trading days before the dates of demutualization compared to the pairwise average of the 1250 days after the demutualization dates. The results are presented for demutuals, mutuals, developed demutuals and emerging demutuals. (Test statistics are in parentheses.)

\begin{tabular}{|c|c|c|c|c|c|c|c|c|}
\hline & \multicolumn{4}{|c|}{ Mean } & \multicolumn{4}{|c|}{ Median } \\
\hline Portfolio & Before & After & $\begin{array}{c}\% \\
\text { Difference }\end{array}$ & $\begin{array}{l}\text { Paired T- } \\
\text { Test of } \\
\text { Difference }\end{array}$ & Before & After & $\begin{array}{c}\% \\
\text { Difference }\end{array}$ & $\begin{array}{l}\text { Wilcoxon } \\
\text { signed-rank } \\
\text { test }\end{array}$ \\
\hline \multicolumn{9}{|l|}{ Panel A: Demutuals } \\
\hline Quoted Spreads & 0.0657 & 0.0621 & $-5.48 \%$ & $(-14.93)^{* * *}$ & 0.0663 & 0.0620 & $-6.43 \%$ & $(-10.99)^{* * *}$ \\
\hline Effective Spreads & 0.0606 & 0.0583 & $-3.70 \%$ & $(-8.67)^{* * * *}$ & 0.0605 & 0.0582 & $-3.72 \%$ & $(-7.40)^{* * *}$ \\
\hline Standard Deviation & 0.0339 & 0.0315 & $-7.06 \%$ & $(-31.87)^{* * *}$ & 0.0337 & 0.0315 & $-6.46 \%$ & $(-13.70)^{* * *}$ \\
\hline High minus Low & 0.0411 & 0.0388 & $-5.67 \%$ & $(-15.90)^{* * *}$ & 0.0409 & 0.0387 & $-5.27 \%$ & $(-11.71)^{* * *}$ \\
\hline \multicolumn{9}{|l|}{ Panel B: Mutuals } \\
\hline Quoted Spreads & 0.0742 & 0.0755 & $1.76 \%$ & $(10.96)^{* * *}$ & 0.0743 & 0.0751 & $1.06 \%$ & $(9.51)^{* * *}$ \\
\hline Effective Spreads & 0.0779 & 0.0805 & $3.32 \%$ & $(9.83)^{* * *}$ & 0.0759 & 0.0804 & $6.01 \%$ & $(8.58)^{* * *}$ \\
\hline Standard Deviation & 0.0312 & 0.0316 & $1.27 \%$ & $(6.82)^{* * *}$ & 0.0312 & 0.0316 & $1.50 \%$ & $(6.00)^{* * *}$ \\
\hline High minus Low & 0.0434 & 0.0449 & $3.45 \%$ & $(14.09)^{* * *}$ & 0.0434 & 0.0448 & $3.20 \%$ & $(10.75)^{* * *}$ \\
\hline \multicolumn{9}{|l|}{$\begin{array}{l}\text { Panel C: Developed } \\
\text { Demutuals }\end{array}$} \\
\hline Quoted Spreads & 0.0548 & 0.0486 & $-11.41 \%$ & $(-27.86)^{* * *}$ & 0.0541 & 0.0485 & $-10.21 \%$ & $(-13.61)^{* * *}$ \\
\hline Effective Spreads & 0.0516 & 0.0480 & $-7.07 \%$ & $(-14.48)^{* * *}$ & 0.0510 & 0.0480 & $-5.81 \%$ & $(-11.15)^{* * *}$ \\
\hline Standard Deviation & 0.0338 & 0.0304 & $-10.05 \%$ & $(-19.83)^{* * *}$ & 0.0331 & 0.0304 & $-8.06 \%$ & $(-13.27)^{* * *}$ \\
\hline High minus Low & 0.0405 & 0.0362 & $-10.71 \%$ & $(-18.98)^{* * *}$ & 0.0402 & 0.0361 & $-10.18 \%$ & $(-12.43)^{* * *}$ \\
\hline
\end{tabular}

Panel C: Emerging

Demutuals

Quoted Spreads

Effective Spreads

$0.0814 \quad 0.0818$

$0.47 \% \quad(0.67)$

0.0815

0.0817

$0.26 \%$

(0.59)

Standard Deviation

0.0734

0.0733

$-0.12 \%$

$(-0.16)$

0.0720

0.0733

$1.72 \%$

(0.39)

High minus Low

$0.0341 \quad 0.0331$

$-2.99 \%$

0.0335

0.0330

$-1.34 \%$

$(-5.84)^{* * *}$

$\begin{array}{ll}0.0420 & 0.0425\end{array}$

$1.13 \%$

$(1.92)^{*}$

0.0415

0.0425

$2.44 \%$

$(2.60)^{* * *}$

${ }^{18}$ For the pairwise average, we average the specific days over the 5-year post-demutualization period and compare this average to the corresponding day in the pre-demutualization period (e.g. averaging 5 day $1 \mathrm{~s}$ in the post-demutualization period and comparing this average to the day 1 in the pre-demutualization period) 


\begin{tabular}{|c|c|c|c|c|c|c|c|c|}
\hline & \multicolumn{4}{|c|}{ Mean } & \multicolumn{4}{|c|}{ Median } \\
\hline Portfolio & Before & After & $\begin{array}{c}\% \\
\text { Difference }\end{array}$ & $\begin{array}{l}\text { Paired T- } \\
\text { Test of } \\
\text { Difference }\end{array}$ & Before & After & $\begin{array}{c}\% \\
\text { Difference }\end{array}$ & $\begin{array}{l}\text { Wilcoxon } \\
\text { signed-rank } \\
\text { test }\end{array}$ \\
\hline
\end{tabular}

Panel D: $t$ tests of Mean and Mann-Whitney $z$ tests of Median Differences

Demutuals - Mutuals

\begin{tabular}{|c|c|c|c|c|c|c|c|c|}
\hline Quoted Spreads & $(-30.00)^{* * *}$ & $(-86.13)^{* * *}$ & $-7.24 \%$ & $(-18.24)^{* * *}$ & $(-18.62)^{* * *}$ & $(-19.34)^{* * *}$ & $-7.50 \%$ & $(-14.31)^{* * *}$ \\
\hline Effective Spreads & $(-44.00)^{* * *}$ & $(-130.00)^{* * *}$ & $-7.02 \%$ & $(-13.09)^{* * *}$ & $(-19.34)^{* * *}$ & $(-19.34)^{* * *}$ & $-9.72 \%$ & $(-11.62)^{* * *}$ \\
\hline Standard Deviation & $(28.84)^{* * *}$ & $(-3.91)^{* * *}$ & $-8.34 \%$ & $(-29.36)^{* * *}$ & $(18.73)^{* * *}$ & $(-3.39)^{* * *}$ & $-7.96 \%$ & $(-18.18)^{* * *}$ \\
\hline High minus Low & $(-12.85)^{* * *}$ & $(-72.23)^{* * *}$ & $-9.12 \%$ & $(-21.14)^{* * *}$ & $(-11.52)^{* * *}$ & $(-19.34)^{* * *}$ & $-8.47 \%$ & $(-15.87)^{* * *}$ \\
\hline \multicolumn{9}{|l|}{ eveloped - Emerging } \\
\hline Effective Spreads & $(-43.46)^{* * *}$ & $(-110.00)^{* * *}$ & $-6.95 \%$ & $(-6.00)^{* * *}$ & $(-19.31)^{* * *}$ & $(-19.34)^{* * *}$ & $-7.53 \%$ & $(-6.26)^{* * *}$ \\
\hline Standard Deviation & $(-1.49)$ & $(-56.92) * * *$ & $-7.06 \%$ & $(-11.10)^{* * *}$ & $(-2.57)^{* *}$ & $(-19.34)^{* * *}$ & $-6.72 \%$ & $(-9.93)^{* * *}$ \\
\hline High minus Low & $(-4.79)^{* * *}$ & $(-52.99) * * *$ & $-11.84 \%$ & $(-14.30)^{* * *}$ & $(-4.54)^{* * *}$ & $(-19.33)^{* * *}$ & $-12.62 \%$ & $(-12.27)^{* * *}$ \\
\hline
\end{tabular}

$* * *, * *$ and $*$ indicate statistical significance at the $1 \%, 5 \%$ and $10 \%$ levels, respectively

Panel A of Table 3.2 shows that the demutualized stock exchanges experienced statistically significant and economically important reductions in quoted bid-ask spreads in the long-term $(5.5 \%$ reduction in mean and $6.4 \%$ reduction in median quoted bid-ask spreads). Mean and median effective spreads also decreased by $3.7 \%$ on demutualized exchanges in the post-demutualization period. Performance on the measures of volatility also showed significant improvements in the post-demutualization period for demutualized stock exchanges. Mean (median) standard deviation decreased by $7.1 \%$ (6.5\%) while mean (median) high-minus-low decreased by $5.7 \%$ (5.3\%) on demutualized exchanges in the post-demutualization period.

On the other hand, panel B of Table 3.2 shows that performance of mutualized stock exchanges deteriorated in the post-demutualization period. Means and medians of both measures of spreads and volatility significantly increased in the post-demutualization period. Means (medians) of quoted spreads, effective spreads, standard deviation and 
high-minus-low all respectively increased 1.8\% (1.1\%), 3.3\% (6\%), 1.3\% (1.5\%) and $3.5 \%(3.2 \%)$

The univariate results demonstrate that demutualization has led to improvements in market quality for the demutualizing exchanges while putting the exchanges not undertaking demutualization at a competitive disadvantage -exposing them to increasing transaction costs and volatility in the post-demutualization period. These findings also confirm our hypotheses that measures of market quality will improve in the postdemutualization period on demutualized stock exchanges but deteriorate on mutualized stock exchanges.

To gain a deeper understanding of who benefits more from demutualization, we segmented the demutualizing stock exchanges (based on their level of development using the OECD classifications) into developed demutualized and emerging demutualized stock exchanges. We submit that the profit motive of demutualization/conversion will be strengthened in developed countries because, among other things, the deepened financial markets in advanced countries will lead to increasing competition for the demutualizing exchanges (including competition from low-cost ECNs). In these environments, halfhearted commitment to the profit motive may be disadvantageous because half-hearted commitment may inevitably lead to a below average edge to perform, which will not lead to profit maximization. We therefore argue that in developed markets, demutualized exchanges will have extra commitment to the profit motive - which would provide an added incentive to perform better than their counterparts in emerging markets who do not 
face similar levels of competition. However, spreads are generally lower in the developed capital markets than they are in emerging markets. Demutualization could therefore have a much bigger impact on spreads/liquidity in emerging markets than on already liquid (developed) markets.

As evident from panels $\mathrm{C}$ and $\mathrm{D}$ of Table 3.2, the reductions in spreads and volatility are primarily due to reductions in spreads and volatility on developed demutualized exchanges. For developed demutualized exchanges, mean (median) quoted spreads, effective spreads, standard deviation and high-minus-low decreased by $11.4 \%(10.2 \%)$, $7.1 \%(5.8 \%), 10.1 \%(8.1 \%)$ and $10.7 \%(10.2)$ respectively in the post-demutualization period (panel C). For emerging demutualized stock exchanges, panel D shows that apart from the significant declines in volatility $-3 \%(1.3 \%)$ decrease in mean (median) standard deviation, $1.1 \%$ decrease in mean high-minus-low (at the $10 \%$ level of significance) and $2.4 \%$ reduction in median high-minus-low (at the $1 \%$ level of significance), the two measures of transaction costs were not significantly different from zero for the emerging demutuals. Therefore, it appears that the benefits of demutualization are disproportionately higher on the developed demutualized exchanges. This is confirmed in panel $\mathrm{E}$ which shows that the tests of mean and median differencesin-differences between demutuals vs. mutuals and developed vs. emerging demutualized exchanges are generally statistically significantly negative at the $1 \%$ level of significance. 


\subsubsection{Multivariate Analysis of Stock Exchange Demutualization}

To test our contention that demutualization will lead to improvements in market quality, we used multivariate ordinary least squares regressions to determine the incremental improvements that demutualization brings after controlling for other factors that impact market quality.

\subsubsection{Separate Effects of Exchange Demutualization}

We report the separate impacts of all demutualizations as well as demutualization of developed stock exchanges on bid-ask spreads in Table 3.3. The results show that all demutualizations and developed stock exchange demutualizations have significant impacts on transaction costs and market quality (as represented by quoted and effective bid-ask spreads).

Table 3.3 - Separate Effects of Exchange and Developed Exchange Demutualization

In this table, we present the results of the ordinary least squares regression equations that regress bid-ask spreads on demutualization, developed demutualization or developed dummies and firm-level, exchange-level, country-level and other control variables. The control variables include firm market capitalization, price inverse, volume, return standard deviation, exchange market share, domestic market capitalization, listed firms, CAPEX to revenue, GDP per capita and a linear time trend. We estimated the regressions using pairwise average data as well as pooled data in the post-demutualization period. Panel A presents the pairwise average results while panel B presents the pooled sample results. ( $t$ statistics, which are in parentheses, are based on White's heteroscedastic consistent robust standard errors.)

Panel A: Pairwise Average

\begin{tabular}{lcccccc}
\hline \multicolumn{7}{c}{ Pairwise Average } \\
\hline & Quoted & Effective & Quoted & Effective & Quoted & Effective \\
\hline Demutual Dummy & -0.0153 & -0.0196 & - & - & - & - \\
& $(-21.80)^{* * *}$ & $(-28.65)^{* * *}$ & - & - & - & - \\
Developed Demutual & - & - & -0.0330 & -0.0239 & - & - \\
Dummy & - & - & $(-27.88)^{* * *}$ & $(-18.25)^{* * *}$ & - & - \\
Developed Dummy & - & - & - & - & 0.0310 & 0.0346 \\
& - & - & - & - & $(22.52)^{* * *}$ & $(21.24)^{* * *}$ \\
Mkt Cap Firm & 0.0139 & 0.0098 & 0.0139 & 0.0091 & 0.0126 & 0.0081 \\
& $(48.39)^{* * *}$ & $(32.79)^{* * *}$ & $(48.24)^{* * *}$ & $(28.22)^{* * *}$ & $(39.38)^{* * *}$ & $(24.04)^{* * *}$
\end{tabular}




\begin{tabular}{|c|c|c|c|c|c|c|}
\hline & \multicolumn{6}{|c|}{ Pairwise Average } \\
\hline & Quoted & Effective & Quoted & Effective & Quoted & Effective \\
\hline \multirow[t]{2}{*}{ Inv Price } & 0.0010 & 0.0008 & 0.0010 & 0.0007 & 0.0010 & 0.0008 \\
\hline & $(53.33)^{* * *}$ & $(38.85)^{* * *}$ & $(47.49)^{* * *}$ & $(31.41)^{* * *}$ & $(48.54)^{* * *}$ & $(33.37)^{* * *}$ \\
\hline \multirow[t]{2}{*}{ Std Dev } & 0.4130 & 0.4026 & 0.3732 & 0.3774 & 0.2220 & 0.1906 \\
\hline & $(10.75)^{* * *}$ & $(9.81)^{* * *}$ & $(9.40)^{* * *}$ & $(9.04)^{* * *}$ & $(5.48)^{* * *}$ & $(4.44)^{* * *}$ \\
\hline \multirow[t]{2}{*}{ Volume } & -0.0085 & -0.0109 & -0.0068 & -0.0090 & -0.0073 & -0.0093 \\
\hline & $(-37.99)^{* * *}$ & $(-39.11)^{* * *}$ & $(-30.20)^{* * *}$ & $(-29.68)^{* * *}$ & $(-33.19)^{* * *}$ & $(-33.36)^{* * *}$ \\
\hline \multirow[t]{2}{*}{ Mkt Share } & -0.0224 & 0.0422 & -0.0441 & 0.0255 & -0.0201 & 0.0444 \\
\hline & $(-0.40)$ & (1.07) & $(-0.85)$ & $(0.71)$ & $(-0.35)$ & $(1.34)$ \\
\hline \multirow[t]{2}{*}{ Mkt Cap Exch } & -0.0143 & -0.0104 & -0.0166 & -0.0122 & -0.0102 & -0.0059 \\
\hline & $(-44.24)^{* * *}$ & $(-28.65)^{* * *}$ & $(-47.84)^{* * *}$ & $(-28.49)^{* * *}$ & $(-24.18)^{* * *}$ & $(-12.59)^{* * *}$ \\
\hline \multirow[t]{2}{*}{ Lstd Firms } & -0.0056 & -0.0075 & -0.0029 & -0.0063 & -0.0091 & -0.0116 \\
\hline & $(-14.53)^{* * *}$ & $(-17.75)^{* * *}$ & $(-7.25)^{* * *}$ & $(-13.63)^{* * *}$ & $(-22.10)^{* * *}$ & $(-27.06)^{* * *}$ \\
\hline \multirow[t]{2}{*}{ CAPEX to Rev } & 0.0954 & 0.0364 & 0.1654 & 0.0926 & 0.0564 & -0.0054 \\
\hline & $(5.87)^{* * *}$ & $(1.73)^{*}$ & $(10.93)^{* * *}$ & $(4.41)^{* * *}$ & $(2.91)^{* * *}$ & $(-0.22)$ \\
\hline \multirow[t]{2}{*}{ Linear Trend } & 0.0000 & 0.0000 & 0.0000 & 0.0000 & 0.0000 & 0.0000 \\
\hline & $(-1.00)$ & $(4.58)^{* * *}$ & $(-0.93)$ & $(4.61)^{* * *}$ & $(-1.15)$ & $(4.40)^{* * *}$ \\
\hline \multirow[t]{2}{*}{ GDP per Cap } & 0.0000 & 0.0000 & 0.0000 & 0.0000 & 0.0000 & 0.0000 \\
\hline & $(28.84)^{* * *}$ & $(21.40)^{* * *}$ & $(32.46)^{* * *}$ & $(20.60)^{* * *}$ & $(-10.13)^{* * *}$ & $(-14.91)^{* * *}$ \\
\hline \multirow[t]{2}{*}{ Constant } & 0.2618 & 0.2958 & 0.2416 & 0.2816 & 0.2378 & 0.2691 \\
\hline & $(75.38)^{* * *}$ & $(72.80)^{* * *}$ & $(68.62)^{* * *}$ & $(63.42)^{* * *}$ & $(71.09)^{* * *}$ & $(67.99)^{* * *}$ \\
\hline $\mathrm{N}$ & 26906 & 26906 & 26906 & 26906 & 26906 & 26906 \\
\hline $\mathrm{R}^{2}$ & 0.5614 & 0.5010 & 0.5725 & 0.4914 & 0.5619 & 0.4961 \\
\hline Adjusted $\mathrm{R}^{2}$ & 0.5613 & 0.5008 & 0.5723 & 0.4912 & 0.5618 & 0.4959 \\
\hline
\end{tabular}

Panel B: Pooled

\begin{tabular}{|c|c|c|c|c|c|c|}
\hline & \multicolumn{6}{|c|}{ Pooled } \\
\hline & Quoted & Effective & Quoted & Effective & Quoted & Effective \\
\hline \multirow[t]{2}{*}{ Demutual Dummy } & -0.0147 & -0.0241 & - & - & - & - \\
\hline & $(-31.29)^{* * *}$ & $(-48.60)^{* * *}$ & - & - & - & - \\
\hline \multirow[t]{2}{*}{$\begin{array}{l}\text { Developed Demutual } \\
\text { Dummy }\end{array}$} & - & - & -0.0324 & -0.0295 & - & - \\
\hline & - & - & $(-44.92)^{* * *}$ & $(-38.08)^{* * *}$ & - & - \\
\hline \multirow[t]{2}{*}{ Developed Dummy } & - & - & - & - & 0.0300 & 0.0348 \\
\hline & - & - & - & - & $(34.56)^{* * *}$ & $(35.50)^{* * *}$ \\
\hline \multirow[t]{2}{*}{ Mkt Cap Firm } & 0.0114 & 0.0081 & 0.0104 & 0.0057 & 0.0096 & 0.0050 \\
\hline & $(59.91)^{* * *}$ & $(40.54)^{* * *}$ & $(57.06)^{* * *}$ & $(27.49)^{* * *}$ & $(50.52)^{* * *}$ & $(23.83)^{* * *}$ \\
\hline \multirow[t]{2}{*}{ Inv Price } & 0.0008 & 0.0006 & 0.0008 & 0.0005 & 0.0008 & 0.0005 \\
\hline & $(89.63)^{* * *}$ & $(66.89)^{* * *}$ & $(85.94)^{* * *}$ & $(58.16)^{* * *}$ & $(88.62)^{* * *}$ & $(60.44)^{* * *}$ \\
\hline \multirow[t]{2}{*}{ Std Dev } & 1.3046 & 1.3449 & 1.2399 & 1.2478 & 1.1180 & 1.0947 \\
\hline & $(55.71)^{* * *}$ & $(50.69)^{* * *}$ & $(53.36)^{* * *}$ & $(46.95)^{* * *}$ & $(47.39)^{* * *}$ & $(40.42)^{* * *}$ \\
\hline
\end{tabular}




\begin{tabular}{|c|c|c|c|c|c|c|}
\hline & \multicolumn{6}{|c|}{ Pooled } \\
\hline & Quoted & Effective & Quoted & Effective & Quoted & Effective \\
\hline \multirow[t]{2}{*}{ Volume } & -0.0073 & -0.0086 & -0.0047 & -0.0047 & -0.0048 & -0.0046 \\
\hline & $(-48.37)^{* * *}$ & $(-42.45)^{* * *}$ & $(-40.40) * * *$ & $(-27.08)^{* * *}$ & $(-38.43)^{* * *}$ & $(-26.41)^{* * *}$ \\
\hline \multirow[t]{2}{*}{ Mkt Share } & -0.0526 & -0.0213 & -0.0574 & -0.0252 & -0.0532 & -0.0192 \\
\hline & $(-3.97)^{* * *}$ & $(-1.62)$ & $(-4.33)^{* * *}$ & $(-1.93)^{*}$ & $(-4.07)^{* * *}$ & $(-1.45)$ \\
\hline \multirow[t]{2}{*}{ Mkt Cap Exch } & -0.0102 & -0.0067 & -0.0122 & -0.0086 & -0.0068 & -0.0028 \\
\hline & $(-48.56)^{* * *}$ & $(-26.92)^{* * *}$ & $(-56.28) * * *$ & $(-31.67)^{* * *}$ & $(-27.00)^{* * *}$ & $(-9.49)^{* * *}$ \\
\hline \multirow[t]{2}{*}{ Lstd Firms } & -0.0095 & -0.0112 & -0.0074 & -0.0106 & -0.0135 & -0.0165 \\
\hline & $(-36.06) * * *$ & $(-36.53) * * *$ & $(-28.25) * * *$ & $(-33.23) * * *$ & $(-51.20) * * *$ & $(-54.08) * * *$ \\
\hline \multirow[t]{2}{*}{ CAPEX to Rev } & -0.0524 & -0.1154 & -0.0192 & -0.0851 & -0.0739 & -0.1399 \\
\hline & $(-14.74) * * *$ & $(-27.36) * * *$ & $(-5.51)^{* * *}$ & $(-18.68) * * *$ & $(-17.62) * * *$ & $(-28.8)^{* * *}$ \\
\hline \multirow[t]{2}{*}{ Linear Trend } & 0.0000 & 0.0000 & 0.0000 & 0.0000 & 0.0000 & 0.0000 \\
\hline & $(5.74)^{* * *}$ & $(17.63)^{* * *}$ & $(7.08)^{* * *}$ & $(15.22)^{* * *}$ & $(-3.03)^{* * *}$ & $(5.64)^{* * *}$ \\
\hline \multirow[t]{2}{*}{ GDP per Cap } & 0.0000 & 0.0000 & 0.0000 & 0.0000 & 0.0000 & 0.0000 \\
\hline & $(31.50)^{* * *}$ & $(31.32)^{* * *}$ & $(44.38)^{* * *}$ & $(38.05)^{* * *}$ & $(-18.48) * * *$ & $(-22.30) * * *$ \\
\hline \multirow[t]{2}{*}{ Constant } & 0.2240 & 0.2391 & 0.2021 & 0.2149 & 0.1959 & 0.2030 \\
\hline & $(101.74)^{* * *}$ & $(91.86)^{* * *}$ & $(95.84)^{* * *}$ & $(80.21)^{* * *}$ & $(92.98)^{* * *}$ & $(79.01)^{* * *}$ \\
\hline $\mathrm{N}$ & 73432 & 73281 & 73432 & 73281 & 73432 & 73281 \\
\hline $\mathrm{R}^{2}$ & 0.5110 & 0.4078 & 0.5218 & 0.3942 & 0.5136 & 0.3951 \\
\hline Adjusted $\mathrm{R}^{2}$ & 0.5109 & 0.4077 & 0.5217 & 0.3941 & 0.5135 & 0.3950 \\
\hline
\end{tabular}

The demutualization dummy, which represents all stock exchange demutualizations, is significantly negatively related to quoted spreads as well as effective spreads at the $1 \%$ level of significance - irrespective of whether we use the pairwise average of the postdemutualization period (columns B and $\mathrm{C}$ of panel A) or the pooling of all postdemutualization data (columns B and C of panel B). The significant negative relationship implies that after controlling for factors deemed to affect bid-ask spreads, demutualization still leads to significant reductions in bid-ask spreads. These findings support our hypothesis that demutualization will lead to improvements in market quality on demutualizing stock exchanges. Our results are also consistent with Krishnamurti et al. (2003) and Otchere and Abou-Zied (2008) - who find in their single stock exchange 
studies that demutualization of stock exchanges in India and Australia (respectively) led to improvements in market quality.

Regression equations in columns $\mathrm{D}$ and $\mathrm{E}$ of panel $\mathrm{A}$ (pairwise data) as well as in columns D and E of panel B (pooled data) use the developed demutualization dummy variable (instead of the all demutualizations dummy). The coefficient of the developed demutualization dummy is also significantly negatively related to bid-ask spreads at the $1 \%$. This means that demutualization has been significantly beneficial to exchanges in developed markets.

In general, developed stock exchanges are more liquid. It is therefore likely that the significantly negative coefficient for developed stock exchanges in the postdemutualization period may be a mere reflection of the fact that these exchanges are generally more liquid. In columns F and $\mathrm{G}$ of panels A (pairwise) and B (pooled), we report results of regressions that use the developed dummy instead of the developed demutualization dummy. The coefficient of the developed dummy is significantly positive at the $1 \%$ in the effective and quoted spreads regressions in both the pairwise as well as pooled results. These findings imply that being a developed stock exchange does not necessarily mean lower spreads; only when developed stock exchanges demutualize that they achieve reductions in spreads.

We interpret these results as implying that the profit motive resulting from demutualization/conversion, strengthened in developed markets by factors such as intense 
competition, has motivated and propelled demutualizing stock exchanges to undertake profit maximizing actions that increase order flow and liquidity. The increased liquidity in the post-demutualization period leads to reductions in bid-ask spreads and transaction costs, thereby improving market quality.

\subsubsection{Combined Effects of Exchange and Developed Exchange Demutualization}

While regression models in Table 3.3 demonstrate that the demutualization and developed demutualization dummies are each separately significantly negatively related to spreads (while developed dummy is not), we report in Table 3.4, regression models that incorporate both the demutualization and developed demutualization dummy variables to ascertain whether they both have incremental significance or one of them dominates the other (especially given that a large majority of the demutualized exchanges are from developed countries). We recognize that we should also have included the developed dummy in our regression models together with the demutualization dummy and the developed demutualization dummy. However, given our particular sample where $95 \%$ of the developed exchanges have demutualized, including the developed demutualization with the developed dummy in the same regression could lead to multicolinearity issues. As a result, we do not include both the developed demutualization dummy and developed dummy in the same regression. Instead, we include either the developed demutualization and demutualization dummy or the developed dummy and demutualization dummy in the same regressions in Table 3.4. 


\section{Table 3.4 - Combined Effects of Exchange and Developed Exchange Demutualization}

We present the results of the ordinary least squares regression equations that regress bid-ask spreads on demutualization as well as developed demutualization dummies and firm-level, exchange-level, country-level and other control variables. The control variables are firm market capitalization, price inverse, volume, return standard deviation, exchange market share, domestic market capitalization, listed firms, CAPEX to revenue, country GDP per capita and linear time trend. We estimated the regressions using pairwise average data as well as pooled data in the post-demutualization period. We also report the short term (44 days before and 44 days after the demutualization dates) impacts of demutualization on transaction costs. ( $\mathrm{t}$ statistics, which are in parentheses, are based on White's heteroscedastic consistent robust standard errors.)

\begin{tabular}{|c|c|c|c|c|c|c|c|c|}
\hline & \multicolumn{4}{|c|}{ Pairwise Average } & \multicolumn{4}{|c|}{ Pooled } \\
\hline & Quoted & Effective & Quoted & Effective & Quoted & Effective & Quoted & Effective \\
\hline \multicolumn{8}{|l|}{ Demutual } & - \\
\hline Dummy & $(-8.64)^{* * *}$ & $(-21.52)^{* * *}$ & $(-18.87)^{* * *}$ & $(-25.22)^{* * *}$ & $(-10.03)^{* * *}$ & $(-30.77)^{* * *}$ & - & - \\
\hline \multicolumn{9}{|l|}{ Developed } \\
\hline \multirow[t]{2}{*}{$\begin{array}{l}\text { Demutual } \\
\text { Dummy }\end{array}$} & -0.02773 & -0.00994 & - & - & -0.0128 & -0.0046 & -0.0125 & -0.0217 \\
\hline & $(-22.01)^{* * *}$ & $(-6.76)^{* * *}$ & - & - & $(-17.70)^{* * *}$ & $(-5.50) * * *$ & $(-25.51)^{* * *}$ & $(-41.92)^{* * *}$ \\
\hline \multicolumn{9}{|l|}{ Developed } \\
\hline \multirow[t]{2}{*}{ Dummy } & - & - & 0.0282 & 0.0309 & - & - & 0.0264 & 0.0285 \\
\hline & - & - & $(20.20)^{* * *}$ & $(19.31)^{* * *}$ & - & - & $(30.83)^{* * *}$ & $(30.65)^{* * *}$ \\
\hline \multirow[t]{2}{*}{ Mkt Cap Firm } & 0.014191 & 0.009889 & 0.0138 & 0.0097 & 0.0129 & 0.0095 & 0.0112 & 0.0079 \\
\hline & $(49.25)^{* * *}$ & $(32.60)^{* * *}$ & $(44.13)^{* * *}$ & $(30.02)^{* * *}$ & $(68.91)^{* * *}$ & $(48.11)^{* * *}$ & $(55.92)^{* * *}$ & $(37.84)^{* * *}$ \\
\hline \multirow[t]{2}{*}{ Inv Price } & 0.0010 & 0.0008 & 0.0010 & 0.0008 & 0.0008 & 0.0006 & 0.0008 & 0.0006 \\
\hline & $(50.23)^{* * *}$ & $(37.25)^{* * *}$ & $(54.75)^{* * *}$ & $(40.29)^{* * *}$ & $(82.70)^{* * *}$ & $(58.15)^{* * *}$ & $(91.03)^{* * *}$ & $(68.21)^{* * *}$ \\
\hline \multirow[t]{2}{*}{ Std Dev } & 0.3780 & 0.3901 & 0.2340 & 0.2063 & 0.7063 & 0.7344 & 1.1796 & 1.2054 \\
\hline & $(9.51)^{* * *}$ & $(9.40)^{* * *}$ & $(5.84)^{* * *}$ & $(4.76)^{* * *}$ & $(52.35)^{* * *}$ & $(44.79)^{* * *}$ & $(49.27)^{* * *}$ & $(44.05)^{* * *}$ \\
\hline \multirow[t]{2}{*}{ Volume } & -0.0074 & -0.0105 & -0.0083 & -0.0106 & -0.0064 & -0.0084 & -0.0067 & -0.0080 \\
\hline & $(-30.31)^{* * *}$ & $(-33.16)^{* * *}$ & $(-36.53)^{* * *}$ & $(-38.28)^{* * *}$ & $(-43.51)^{* * *}$ & $(-39.21)^{* * *}$ & $(-43.77)^{* * *}$ & $(-39.05)^{* * *}$ \\
\hline \multirow[t]{2}{*}{ Mkt Share } & -0.0402 & 0.0358 & -0.0189 & 0.0460 & -0.0823 & -0.0497 & -0.0538 & -0.0213 \\
\hline & $(-0.75)$ & $(0.86)$ & $(-0.32)$ & $(1.06)$ & $(-6.28)^{* * *}$ & $(-3.45)^{* * *}$ & $(-4.03)^{* * *}$ & $(-1.55)$ \\
\hline \multirow[t]{2}{*}{ Mkt Cap Exch } & -0.0162 & -0.0111 & -0.0105 & -0.0062 & -0.0068 & -0.0031 & -0.0071 & -0.0034 \\
\hline & $(-47.46)^{* * *}$ & $(-26.78)^{* * *}$ & $(-25.94)^{* * *}$ & $(-13.89)^{* * *}$ & $(-31.65)^{* * *}$ & $(-11.49)^{* * *}$ & $(-28.85)^{* * *}$ & $(-11.81)^{* * *}$ \\
\hline \multirow[t]{2}{*}{ Lstd Firms } & -0.0030 & -0.0065 & -0.0077 & -0.0098 & -0.0086 & -0.0112 & -0.0118 & -0.0136 \\
\hline & $(-7.70)^{* * *}$ & $(-14.91)^{* * *}$ & $(-18.40)^{* * *}$ & $(-22.43)^{* * *}$ & $(-32.84)^{* * *}$ & $(-35.83)^{* * *}$ & $(-42.19)^{* * *}$ & $(-42.66)^{* * *}$ \\
\hline \multicolumn{9}{|l|}{ CAPEX to } \\
\hline \multirow{2}{*}{ Rev } & 0.1517 & 0.0566 & 0.0520 & -0.0113 & -0.0159 & -0.0878 & $-0.0 / 15$ & -0.1358 \\
\hline & $(9.88)^{* * *}$ & $(2.67)^{* * *}$ & $(2.85)^{* * *}$ & $(-0.48)$ & $(-3.79)^{* * *}$ & $(-17.15)^{* * *}$ & $(-18.17)^{* * *}$ & $(-29.72)^{* * *}$ \\
\hline \multirow[t]{2}{*}{ Linear Trend } & 0.0000 & 0.0000 & 0.0000 & 0.0000 & 0.0000 & 0.0000 & 0.0000 & 0.0000 \\
\hline & $(-0.96)$ & $(4.61)^{* * *}$ & $(-1.19)$ & $(4.46)^{* * *}$ & $(-3.79)^{* * *}$ & $(9.75)^{* * *}$ & $(1.88)^{*}$ & $(13.79)^{* * *}$ \\
\hline \multirow[t]{2}{*}{ GDP per Cap } & 0.0000 & 0.0000 & 0.0000 & 0.0000 & 0.0000 & 0.0000 & 0.0000 & 0.0000 \\
\hline & $(31.27)^{* * *}$ & $(17.79)^{* * *}$ & $(-5.16)^{* * *}$ & $(-9.55)^{* * *}$ & $(14.39)^{* * *}$ & $(8.45)^{* * *}$ & $(-10.72)^{* * *}$ & $(-11.15)^{* * *}$ \\
\hline \multirow[t]{2}{*}{ Constant } & 0.2446 & 0.2896 & 0.2392 & 0.2710 & 0.1663 & 0.1945 & 0.2036 & 0.2167 \\
\hline & $(69.49)^{* * *}$ & $(65.87)^{* * *}$ & $(72.65)^{* * *}$ & $(70.60)^{* * *}$ & $(88.31)^{* * *}$ & $(75.12)^{* * *}$ & $(98.30)^{* * *}$ & $(87.79)^{* * *}$ \\
\hline $\mathrm{N}$ & 26906 & 26906 & 26906 & 26906 & 71604 & 71453 & 73432 & 73281 \\
\hline $\mathrm{R}^{2}$ & 0.5741 & 0.5026 & 0.5733 & 0.5147 & 0.463 & 0.3192 & 0.5225 & 0.4203 \\
\hline Adjusted $\mathrm{R}^{2}$ & 0.5740 & 0.5023 & 0.5731 & 0.5145 & 0.4629 & 0.3191 & 0.5224 & 0.4202 \\
\hline
\end{tabular}


As illustrated in Table 3.4 column B and column C (pairwise average) and columns $\mathrm{F}$ and $\mathrm{G}$ (pooled), both the demutualization dummy and developed demutualization dummy variables are significantly negatively related to bid-ask spreads (at the $1 \%$ level) in regression models that incorporate both variables. This means that both variables do incrementally result in improvements in market quality in a multivariate context. However, in regressions that have the demutualization dummy and the developed dummy, the demutualization dummy is significantly negative at the $1 \%$ level while the developed dummy is significantly positive at the $1 \%$ level (columns D and E for pairwise average and columns $\mathrm{H}$ and I for pooled data). Based on these results, we conclude that while demutualization leads to reductions in bid-ask spreads in the post-demutualization period, being a developed stock exchange does not automatically lead to lower spreads. Only developed stock exchanges that demutualize experience reductions in bid-ask spreads following demutualization.

\subsubsection{Effects of Technology on Market Quality}

Although technological advancements have the ability to reduce the cost of trading and improve the speed of execution, the effect of technological investments on market quality remains a contested issue. For instance, Riordan and Storkenmaier (2012) find that technology investments improve market quality by reducing the speed of transaction execution and lowering trading costs but Hendershott and Moulton (2011) find that NYSE's introduction of its hybrid market (which increased automation) drove down execution time for market orders from 10 seconds to less than one second but increased 
the cost of immediacy (i.e. effective spreads) by about $10 \%$ relative to its pre-hybrid level. We argued, however, that investments in technology will improve transparency and help reduce bid-ask spreads.

While univariate tests show that investments in technology (proxied by the CAPEX to revenue ratio) lead to reductions in bid-ask spreads, the multivariate results in Table 3.4 present a mixed picture. Though the pooled results (in columns F to I) show that technological investments are negatively related to spreads at the $1 \%$ level of significance, the pairwise average results are mostly positively significant at the $1 \%$ level or positively insignificantly different from zero. Whilst the negative coefficients of the CAPEX to revenue variable in the pooled results support our argument that technological investments increase transparency, order flow and liquidity - and leads to reduction in spreads, the positive coefficient of the technology proxy variable in the pairwise average results do not appear to support our contention. Whereas this result may be due to issues with an imperfect proxy or may be highlighting the possibility of an insignificant role of technology in reducing spreads, we argue that the positive or insignificant coefficients of the CAPEX to revenue ratio in the pairwise regression models may not be due to the absence of a technology effect in reducing spreads. If there is a delayed technology effect on spreads whereby reductions in spreads occur later, then the positive relationship in the early years may cancel out the negative relationship in the later years - making the pairwise average technology proxy coefficients insignificant or significantly positive. We find support for this possibility in our yearly regressions - where the technology effect in reducing bid-ask spreads becomes manifest in years 4 and 5. Another reason for the 
insignificance of the technology coefficient in the pairwise regressions may be due to the fact that technology has an asymmetric effect on different types of firms. We also find support for this possibility in our size segmentation analysis - where we document that technology's impact in reducing spreads is pervasive for large firms. In totality, therefore, we conclude that technological investments by stock exchanges have a significant effect in reducing spreads for all firms over time and for large-cap firms at all times.

\subsubsection{Effects of Other Variables on Market Quality}

Our regression equations also incorporate the other determinants of bid-ask spreads and market quality. As exemplified in Table 3.4, the other explanatory variables are generally significant and mostly have the expected signs. Measures of activity and competition such as trading volume are significantly negatively related to spreads (quoted and effective). As expected, trading volume is significantly negative in all regression models in Table 3.4. Thus, due to economies of scale, increases in trading volume leads to decreases in bid-ask spreads. Also, as competition increases, spreads will narrow resulting in a negative relationship between measures of competition such as trading volume and bid-ask spreads. Growth in exchange market share, another measure of competition, is insignificant in most instances. However, in models that market share is significant, it is generally negative, thereby supporting the contention that increased competition leads to the narrowing of spreads.

While we were expecting the size related variables to be also negatively related to spreads, we find that only domestic market capitalization of firms traded on the 
exchanges is significantly negative in the regression models as expected. The log of firm market capitalization is positive and significant - which could imply that we have proportionately more small firms in our sample. This is not unexpected in a multiexchange multi-country sample like ours.

Standard deviation, our proxy measure of the risk component of bid-ask spreads, is significant and positive, as expected, in all regression models in Table 3.4. This signifies that as risk increases, bid-ask spreads increase as well. Number of listed firms on exchanges also has a significantly negative relationship with bid-ask spreads (as expected). These findings support the network externality argument advanced by Pagano (1989) - since increases in the number of firms listed on the exchange leads to decreases in bid-ask spreads. As more firms are listed, the network grows and the probability of finding a counterparty for trade execution increases. As a result of this, inventory holding costs will decline and this will lead to reductions in bid-ask spreads. The other remaining variables (price inverse, GDP per capital and time trend) are also generally significant and have intuitive coefficients.

All in all, the variables hypothesized to impact bid-ask spreads in the literature are generally significantly impactful in our regression models as well - adding to the validity and robustness of our findings. 


\subsubsection{Short Term Effects of Exchange Demutualization on Market Quality}

To gauge the short term impacts of stock exchange demutualization on market quality, we report the results of regression models using data for the 44 trading days before the demutualization dates and 44 days after the demutualization dates (i.e. data for approximately 2 months before and after the demutualization dates). A two-month event window has been used in other stock exchange studies such as Nielsson (2009) to examine the short term impacts of mergers and acquisitions on market quality. The choice of two months as the short term event window is generally motivated by findings that it takes an average of about two months to negotiate key corporate events such as mergers and acquisitions. Ahern and Sosyura (2014) for example find that the median number of days from the start of merger talks to the public announcement is 44 . We therefore follow the existing literature (e.g. Nielsson, 2009) and use two months for our short term analysis. As reported in columns B and C (panel A) of Table 3.5, both the demutualization dummy and developed demutualization dummy are significantly negative at the $1 \%$ level in the short term in regression models with quoted spreads and effective spreads as response variables. The significant negative coefficient of both the demutualization and developed demutualization dummies in the short term implies that even in the short term, demutualization leads to reduction in spreads and improvement in market quality. The fact that the benefits of demutualization on market quality kick in almost immediately is significant and demonstrates that the impact of demutualization on market quality is robust and sustained. 


\subsubsection{Yearly and Long Term Effects of Exchange Demutualization}

Given that stock exchange demutualization involves a change in organizational structure (from a mutualized exchange to a demutualized exchange), the long term implications of such a significant change is important to not only the management of stock exchanges but to investors and issuers as well. While our results based on the pooled and pairwise average of the five years following demutualization have already demonstrated that demutualization leads to significant improvements in market quality, we also analyzed the data in yearly chunks to gain deeper insights into the effects of demutualization on market quality from year 1 through year 5 . We report the year-by-year analysis in Table 3.5 .

Table 3.5 - Effects of Demutualization on Market Quality over Time

Table 3.5 presents the results of the year-by-year ordinary least squares regression equations that regress bid-ask spreads on demutualization as well as developed demutualization dummies and firm-level, exchange-level, country-level and other control variables. The other independent/control variables are firm market capitalization, price inverse, volume, return standard deviation, exchange market share, domestic market capitalization, listed firms, CAPEX to revenue, GDP per capita and linear time trend. We estimated the regressions using yearly data (i.e. one year before vs. one year after, two years after, etc.). ( $\mathrm{t}$ statistics, which are in parentheses, are based on White's heteroscedastic consistent robust standard errors.)

Panel A: 2 Months Pre and Post, Years 1-2

\begin{tabular}{lcccccc}
\hline & \multicolumn{2}{c}{ Short Term } & \multicolumn{2}{c}{ Year 1 } & \multicolumn{2}{c}{ Year 2 } \\
\hline & Quoted & Effective & Quoted & Effective & Quoted & Effective \\
\hline Demutual Dummy & -0.0062 & -0.0099 & -0.0075 & -0.0138 & -0.0094 & -0.0168 \\
& $(-3.41)^{* * *}$ & $(-5.62)^{* * *}$ & $(-8.53)^{* * *}$ & $(-13.43)^{* * *}$ & $(-11.62)^{* * *}$ & $(-17.88)^{* * *}$ \\
Developed Demutual Dummy & -0.0143 & -0.0108 & -0.0101 & -0.0136 & -0.0349 & -0.0282 \\
& $(-4.16)^{* * *}$ & $(-3.75)^{* * *}$ & $(-6.86)^{* * *}$ & $(-8.43)^{* * *}$ & $(-26.85)^{* * *}$ & $(-20.89)^{* * *}$ \\
Mkt Cap Firm & 0.0188 & 0.0152 & 0.0175 & 0.0157 & 0.0154 & 0.0131 \\
& $(26.14)^{* * *}$ & $(26.78)^{* * *}$ & $(61.58)^{* * *}$ & $(55.66)^{* * *}$ & $(53.82)^{* * *}$ & $(45.76)^{* * *}$ \\
Inv Price & 0.0012 & 0.0009 & 0.0011 & 0.0007 & 0.0007 & 0.0005 \\
& $(34.69)^{* * *}$ & $(26.57)^{* * *}$ & $(58.32)^{* * *}$ & $(32.48)^{* * *}$ & $(51.24)^{* * *}$ & $(33.95)^{* * *}$ \\
Std Dev & -0.7569 & 0.0190 & 0.1838 & 0.9230 & 0.8334 & 1.1505 \\
& $(-12.42)^{* * *}$ & $(0.36)$ & $(3.86)^{* * *}$ & $(16.31)^{* * *}$ & $(20.46)^{* * *}$ & $(30.39)^{* * *}$ \\
Volume & -0.0080 & -0.0062 & -0.0079 & -0.0062 & -0.0061 & -0.0052
\end{tabular}




\begin{tabular}{lcccccc}
\hline & \multicolumn{2}{c}{ Short Term } & \multicolumn{2}{c}{ Year 1 } & \multicolumn{2}{c}{ Year 2 } \\
\hline & Quoted & Effective & Quoted & Effective & Quoted & Effective \\
\hline Mkt Share & -0.5661 & -0.1222 & 0.0274 & 0.0435 & -0.0332 & -0.0213 \\
& $(-2.55)^{* *}$ & $(-0.73)$ & $(0.51)$ & $(0.85)$ & $(-1.54)$ & $(-1.18)$ \\
Mkt Cap Exch & -0.022 & -0.0210 & -0.0175 & -0.0186 & -0.0172 & -0.0163 \\
& $(-22.79)^{* * *}$ & $(-26.63)^{* * *}$ & $(-45.55)^{* * *}$ & $(-46.68)^{* * *}$ & $(-47.00)^{* * *}$ & $(-43.21)^{* * *}$ \\
Lstd Firms & 0.0026 & 0.0012 & -0.0041 & -0.0056 & -0.0082 & -0.0099 \\
& $(2.10)^{* *}$ & $(1.08)$ & $(-8.49)^{* * *}$ & $(-10.72)^{* * *}$ & $(-18.16)^{* * *}$ & $(-19.61)^{* * *}$ \\
CAPEX to Rev & 0.6130 & 0.5770 & 0.2886 & 0.2271 & 0.2262 & 0.1959 \\
Linear Trend & $(38.62)^{* * *}$ & $(31.47)^{* * *}$ & $(25.51)^{* * *}$ & $(16.86)^{* * *}$ & $(24.37)^{* * *}$ & $(16.65)^{* * *}$ \\
& 0.0000 & 0.0001 & 0.0000 & 0.0000 & 0.0000 & 0.0000 \\
GDP per Cap & $(2.46)^{* *}$ & $(6.33)^{* * *}$ & $(12.79)^{* * *}$ & $(21.87)^{* * *}$ & $(28.21)^{* * *}$ & $(34.70)^{* * *}$ \\
& 0.0000 & 0.0000 & 0.0000 & 0.0000 & 0.0000 & 0.0000 \\
Constant & $(20.12)^{* * *}$ & $(12.20)^{* * *}$ & $(29.00)^{* * *}$ & $(25.31)^{* * *}$ & $(30.76)^{* * *}$ & $(29.39)^{* * *}$ \\
& 0.2502 & 0.2253 & 0.2403 & 0.2356 & 0.2396 & 0.2372 \\
N & $(27.70)^{* * *}$ & $(22.47)^{* * *}$ & $(57.36)^{* * *}$ & $(49.02)^{* * *}$ & $(56.90)^{* * *}$ & $(52.10)^{* * *}$ \\
$\mathrm{R}^{2}$ & 4084 & 4084 & 23426 & 23444 & 23793 & 23834 \\
\hline & 0.6681 & 0.6211 & 0.5392 & 0.4543 & 0.5702 & 0.5077 \\
& 0.6671 & 0.6200 & 0.5389 & 0.4540 & 0.5699 & 0.5075 \\
\hline
\end{tabular}

Panel B: Years 3-5

\begin{tabular}{lcccccc}
\hline & \multicolumn{2}{c}{ Year 3 } & \multicolumn{2}{c}{ Year 4 } & \multicolumn{2}{c}{ Year 5 } \\
\hline & Quoted & Effective & Quoted & Effective & Quoted & Effective \\
\hline Demutual Dummy & -0.0099 & -0.0256 & -0.0081 & -0.0234 & -0.0096 & -0.0205 \\
& $(-12.14)^{* * *}$ & $(-25.50)^{* * *}$ & $(-7.83)^{* * *}$ & $(-21.17)^{* * *}$ & $(-7.83)^{* * *}$ & $(-16.45)^{* * *}$ \\
Developed Demutual Dummy & -0.0213 & -0.0100 & -0.0367 & -0.0130 & -0.0319 & -0.0178 \\
& $(-15.89)^{* * *}$ & $(-5.56)^{* * *}$ & $(-25.01)^{* * *}$ & $(-6.65)^{* * *}$ & $(-18.49)^{* * *}$ & $(-9.51)^{* * *}$ \\
Mkt Cap Firm & 0.0140 & 0.0098 & 0.0134 & 0.0087 & 0.0112 & 0.0081 \\
& $(47.90)^{* * *}$ & $(29.15)^{* * *}$ & $(41.93)^{* * *}$ & $(25.43)^{* * *}$ & $(28.39)^{* * *}$ & $(20.58)^{* * *}$ \\
Inv Price & 0.0007 & 0.0006 & 0.0010 & 0.0009 & 0.0013 & 0.0010 \\
Std Dev & $(38.30)^{* * *}$ & $(28.48)^{* * *}$ & $(38.20)^{* * *}$ & $(33.53)^{* * *}$ & $(44.29)^{* * *}$ & $(35.14)^{* * *}$ \\
& 0.2322 & 0.7274 & 0.6204 & 0.6663 & 0.7608 & 0.8034 \\
Volume & $(5.91)^{* * *}$ & $(17.41)^{* * *}$ & $(16.21)^{* * *}$ & $(16.15)^{* * *}$ & $(16.87)^{* * *}$ & $(18.08)^{* * *}$ \\
& -0.0070 & -0.0084 & -0.0075 & -0.0106 & -0.0080 & -0.0092 \\
Mkt Share & $(-28.63)^{* * *}$ & $(-24.38)^{* * *}$ & $(-31.67)^{* * *}$ & $(-30.43)^{* * *}$ & $(-29.31)^{* * *}$ & $(-28.86)^{* * *}$ \\
& -0.1331 & -0.0715 & -0.0271 & -0.0104 & -0.0011 & 0.0010 \\
Mkt Cap Exch & $(-9.10)^{* * *}$ & $(-3.86)^{* * *}$ & $(-0.63)$ & $(-0.27)$ & $(-0.02)$ & -0.03 \\
& -0.0164 & -0.0134 & -0.0175 & -0.0119 & -0.0128 & -0.0107 \\
& $(-45.42)^{* * *}$ & $(-27.31)^{* * *}$ & $(-45.16)^{* * *}$ & $(-23.39)^{* * *}$ & $(-28.66)^{* * *}$ & $(-21.27)^{* * *}$ \\
& -0.0025 & -0.0059 & -0.0023 & -0.0070 & -0.0019 & -0.0034 \\
& $(-5.79)^{* * *}$ & $(-12.38)^{* * *}$ & $(-4.68)^{* * *}$ & $(-12.56)^{* * *}$ & $(-3.62)^{* * *}$ & $(-5.70)^{* * *}$
\end{tabular}




\begin{tabular}{lcccccc}
\hline & \multicolumn{2}{c}{ Year 3 } & \multicolumn{2}{c}{ Year 4 } & \multicolumn{2}{c}{ Year 5 } \\
\hline & Quoted & Effective & Quoted & Effective & Quoted & Effective \\
\hline CAPEX to Rev & 0.1844 & 0.0710 & -0.0336 & -0.1254 & 0.0003 & -0.0419 \\
& $(13.13)^{* * *}$ & $(3.30)^{* * *}$ & $(-5.27)^{* * *}$ & $(-13.77)^{* * *}$ & $(0.04)$ & $(-4.75)^{* * *}$ \\
Linear Trend & 0.0000 & 0.0000 & 0.0000 & 0.0000 & 0.0000 & 0.0000 \\
& $(17.75)^{* * *}$ & $(38.35)^{* * *}$ & $(21.87)^{* * *}$ & $(33.47)^{* * *}$ & $(24.19)^{* * *}$ & $(34.71)^{* * * *}$ \\
GDP per Cap & 0.0000 & 0.0000 & 0.0000 & 0.0000 & 0.0000 & 0.0000 \\
& $(27.33)^{* * *}$ & $(23.46)^{* * *}$ & $(33.11)^{* * *}$ & $(22.68)^{* * *}$ & $(23.34)^{* * *}$ & $(19.24)^{* * *}$ \\
Constant & 0.2442 & 0.2678 & 0.2646 & 0.3069 & 0.2202 & 0.2456 \\
& $(70.85)^{* * *}$ & $(61.06)^{* * *}$ & $(79.17)^{* * *}$ & $(71.09)^{* * *}$ & $(56.36)^{* * *}$ & $(54.03)^{* * *}$ \\
$\mathrm{~N}$ & 24200 & 24160 & 24537 & 24395 & 25000 & 24972 \\
$\mathrm{R}^{2}$ & 0.5249 & 0.4681 & 0.5496 & 0.4756 & 0.4865 & 0.4254 \\
Adjusted $\mathrm{R}^{2}$ & 0.5247 & 0.4679 & 0.5493 & 0.4754 & 0.4863 & 0.4251 \\
\hline$* * * * *$ and $*$ indicate statistical significance at the $1 \%, 5 \%$ and $10 \%$ levels, respectively & &
\end{tabular}

From Table 3.5, the post-demutualization reductions in quoted and effective bid-ask spreads are not only limited to the short term (columns B and C of panel A). The reductions in bid-ask spreads continue from the short term to the long term following the consummation of the demutualizations. Comparing the pre-demutualization period to year 1, year 2, year 3, year 4 and year 5, we find that the demutualization dummy and developed demutualization dummy continue to be significantly negatively related to spreads from year to year at the $1 \%$ level of significance.

The magnitude of the declines in spreads as a result of demutualization and developed exchange demutualization continue to increase from year to year - which is indicative of the growing importance of demutualization over time. For instance, the developed demutualization dummy decreased from $0.0101(0.0138)$ in year 1 in the quoted (effective) spreads regression model to $0.0319(0.0178)$ in year 5 . The demutualization dummy also experiences higher magnitude declines over time - falling from 0.0075 
(0.138) in year 1 in the quoted (effective) spreads regression model to $0.0099(0.0256)$ in year 3 - before leveling off to $0.0096(0.0205)$ in year 5 . With respect to technology, the significance of the CAPEX to revenue ratio coefficient in years 4 and 5 signify that technology has a delayed effect in reducing bid-ask spreads. This delayed effect may be behind the lack of a technology effect in reducing bid-ask spreads in the pairwise average regressions - as positive spreads in early years cancel out negative spreads in later years. Given the possibility that it takes some time to get bugs in new software fixed and for users to get comfortable with the technology, the delayed effect of technology on bid-ask spreads may be understandable. In addition, most of the other control variables continue to be significant and have the expected signs. The yearly regressions also have good fit with the data, with $\mathrm{R}^{2}$ and adjusted $\mathrm{R}^{2}$ ranging from $42.5 \%$ to $57.0 \%$.

The significant improvements in market quality as a result of demutualization from the short term (two months after demutualization) to the long term (five years after demutualization) is symptomatic of the robust and sustained improvements in market quality that stock exchange demutualization brings. We therefore conclude that demutualization leads to comprehensive improvements in market quality over time; and these improvements are not restricted to specific time windows - either short- or longterm.

\subsubsection{Exchange Demutualization and Subsequent IPO}

The current governance changes occurring in the stock exchange industry have been described by authors such as Aggarwal (2002) and Oldford and Otchere (2011) as a 
progression, involving first demutualization (the conversion from a not-for-profit organization to a for-profit organization) and then second IPO (listing of shares to become publicly traded). Given the prominence of stock exchange IPOs in recent times, it is imperative to determine the market quality effects of going beyond demutualization to self-list and become publicly traded. In particular, since undertaking IPO leads to the complete separation of ownership from control and higher transparency because of higher disclosure requirements for publicly listed demutualized stock exchanges, the expectation is that exchanges that subsequently undertake IPOs will see more improvements in liquidity and market quality (beyond the improvements at the demutualization stage). We investigated the question of whether there are incremental improvements in market quality (beyond the improvements garnered through demutualization) if stock exchanges take the next step on the governance continuum to self-list and become publicly traded. The results of our investigation into the incremental benefits of IPO are presented in Table 3.6 below.

Table 3.6 - Demutualization, IPO and Market Quality

This table reports the results of the ordinary least squares regression equations that regress bid-ask spreads on a demutualization dummy, IPO dummy, developed IPO dummy as well as firm-level, exchange-level, country-level and other control variables. The other independent/control variables are firm market capitalization, price inverse, volume, return standard deviation, exchange market share, domestic market capitalization, listed firms, CAPEX to revenue, GDP per capita and linear time trend. We estimated the regressions using the pre-demutualization data and the pairwise average of the 5-year post-demutualization data. ( $\mathrm{t}$ statistics, which are in parentheses, are based on White's heteroscedastic consistent robust standard errors.)

\begin{tabular}{lcccccc}
\hline & Quoted & Effective & Quoted & Effective & Quoted & Effective \\
\hline Demutual Dummy & -0.0223 & -0.0352 & -0.0062 & -0.0164 & -0.0236 & -0.0360 \\
& $(-29.02)^{* * *}$ & $(-44.67)^{* * *}$ & $(-8.64)^{* * *}$ & $(-21.52)^{* * *}$ & $(-31.35)^{* * *}$ & $(-46.56)^{* * *}$ \\
Mkt Cap Firm & 0.0140 & 0.0101 & 0.0142 & 0.0099 & 0.0149 & 0.0107 \\
& $(49.39)^{* * *}$ & $(35.06)^{* * *}$ & $(49.25)^{* * *}$ & $(32.6)^{* * *}$ & $(53.82)^{* * *}$ & $(36.26)^{* * *}$ \\
Inv Price & 0.0010 & 0.0007 & 0.0010 & 0.0008 & 0.0009 & 0.0007 \\
& $(49.84)^{* * *}$ & $(35.29)^{* * *}$ & $(50.23)^{* * *}$ & $(37.25)^{* * *}$ & $(42.31)^{* * *}$ & $(29.72)^{* * *}$ \\
Std Dev & 0.4020 & 0.3783 & 0.3780 & 0.3901 & 0.3226 & 0.3275
\end{tabular}




\begin{tabular}{|c|c|c|c|c|c|c|}
\hline & Quoted & Effective & Quoted & Effective & Quoted & Effective \\
\hline & $(10.5)^{* * *}$ & $(9.37)^{* * *}$ & $(9.51)^{* * *}$ & $(9.4)^{* * *}$ & $(8.05)^{* * *}$ & $(7.87)^{* * *}$ \\
\hline \multirow[t]{2}{*}{ Volume } & -0.0086 & -0.0111 & -0.0074 & -0.0105 & -0.0070 & -0.0100 \\
\hline & $(-38.34)^{* * *}$ & $(-40.15)^{* * *}$ & $(-30.31)^{* * *}$ & $(-33.16)^{* * *}$ & $(-28.73)^{* * *}$ & $(-31.25)^{* * *}$ \\
\hline \multirow[t]{2}{*}{ Mkt Share } & -0.0188 & 0.0502 & -0.0402 & 0.0358 & -0.0387 & 0.0374 \\
\hline & $(-0.34)$ & $(1.34)$ & $(-0.75)$ & $(0.86)$ & $(-0.74)$ & $(0.9)$ \\
\hline \multirow[t]{2}{*}{ Mkt Cap Exch } & -0.0146 & -0.0112 & -0.0162 & -0.0111 & -0.0184 & -0.0135 \\
\hline & $(-45.06)^{* * *}$ & $(-31.55)^{* * *}$ & $(-47.46)^{* * *}$ & $(-26.78)^{* * *}$ & $(-51.48)^{* * *}$ & $(-31.12)^{* * *}$ \\
\hline \multirow[t]{2}{*}{ Lstd Firms } & -0.0053 & -0.0069 & -0.0030 & -0.0065 & -0.0007 & -0.0040 \\
\hline & $(-14.17)^{* * *}$ & $(-17.16)^{* * *}$ & $(-7.7)^{* * *}$ & $(-14.91)^{* * *}$ & $(-1.83)^{*}$ & $(-9.23)^{* * *}$ \\
\hline \multirow[t]{2}{*}{ Linear Trend } & 0.0000 & 0.0000 & 0.0000 & 0.0000 & 0.0000 & 0.0000 \\
\hline & $(-0.99)$ & $(4.64)^{* * *}$ & $(-0.96)$ & $(4.61)^{* * *}$ & $(-0.92)$ & $(4.75)^{* * *}$ \\
\hline \multirow[t]{2}{*}{ CAPEX to Rev } & 0.0929 & 0.0307 & 0.1517 & 0.0566 & 0.1758 & 0.0837 \\
\hline & $(5.65)^{* * *}$ & -1.43 & $(9.88)^{* * *}$ & $(2.67)^{* * *}$ & $(11.44)^{* * *}$ & $(3.98)^{* * *}$ \\
\hline \multirow[t]{2}{*}{ GDP per Cap } & 0.0000 & 0.0000 & 0.0000 & 0.0000 & 0.0000 & 0.0000 \\
\hline & $(24.61)^{* * *}$ & $(15.18)^{* * *}$ & $(31.27)^{* * *}$ & $(17.79)^{* * *}$ & $(32.56)^{* * *}$ & $(19.27)^{* * *}$ \\
\hline \multirow[t]{2}{*}{ IPO dummy } & 0.0098 & 0.0217 & - & - & 0.0316 & 0.0356 \\
\hline & $(9.76)^{* * *}$ & $(20.62)^{* * *}$ & - & - & $(29.77)^{* * *}$ & $(30.81)^{* * *}$ \\
\hline \multirow[t]{2}{*}{ Developed IPO Dummy } & - & - & -0.0277 & -0.0099 & -0.0437 & -0.0279 \\
\hline & - & - & $(-22.01)^{* * *}$ & $(-6.76)^{* * *}$ & $(-29.8)^{* * *}$ & $(-16.44)^{* * * *}$ \\
\hline \multirow[t]{2}{*}{ Constant } & 0.2657 & 0.3044 & 0.2446 & 0.2896 & 0.2472 & 0.2926 \\
\hline & $(74.68)^{* * *}$ & $(73.47)^{* * *}$ & $(69.49)^{* * *}$ & $(65.87)^{* * *}$ & $(70.75)^{* * *}$ & $(67.04)^{* * *}$ \\
\hline $\mathrm{N}$ & 26906 & 26906 & 26906 & 26906 & 26906 & 26906 \\
\hline $\mathrm{R}^{2}$ & 0.563 & 0.5086 & 0.5741 & 0.5026 & 0.5866 & 0.5179 \\
\hline Adjusted $\mathrm{R}^{2}$ & 0.5628 & 0.5084 & 0.5740 & 0.5023 & 0.5864 & 0.5176 \\
\hline
\end{tabular}

From Table 3.6, we find the IPO dummy to be significantly positive (instead of being significantly negative) in regression models that include the demutualization dummy (columns B, C, F and G). While an IPO does not appear to lead to improvements in market quality (beyond what is achieved through demutualization), we further explored the question of whether developed exchange IPOs might lead to incremental improvements in market quality over and above the improvements from demutualization. In this regard, we added the developed IPO dummy to our regression models (columns D, E, F and G). As shown in Table 3.6, both the developed IPO dummy and demutualization 
dummy are significantly negative at the $1 \%$ level in the regressions. This shows that while all IPOs do not lead to further improvements in market quality, the IPOs undertaken by exchanges operating in advanced countries do result in significant reductions in bid-ask spreads. These findings confirm our contention that going public will lead to incremental improvements in market quality over and above the improvements associated with demutualization. Our findings that the stock exchange IPOs in aggregate do not lead to improvements in market quality are consistent with Oldford and Otchere's (2011) findings that listed exchanges do not exhibit evidence of incremental gains in efficiency and profitability beyond what they achieved at the demutualization phase. However, our results that show that developed IPOs attain incremental improvements in market quality beyond the improvements from demutualization are unique to our study - since Oldford and Otchere (2011) did not consider this in their study.

On the basis of our evidence, we maintain that listing (especially by developed exchanges) offers incremental improvements in market quality beyond the improvements realized at the demutualization stage.

\subsubsection{The Size Effects of Exchange Demutualization}

Firm size plays an important role in a number of important performance dimensions including the volume of trading, frequency of trading, etc. Indeed, Fama and French (1992) highlight firm size as one of the important determinants of stock returns. Given 
the importance of size in firm performance, there is the possibility that the market quality improvements emanating from demutualization may be asymmetrically beneficial to firms of different sizes. Otchere and Abou-Zied (2008) underscored the possibility of asymmetric gains in market quality from demutualization when, in their empirical assessment of the effects of demutualization on market quality using the Australian Stock Exchange (ASX) as a case study, they find that bid-ask spreads have narrowed in the post-conversion period (especially for small-cap firms). It is also possible that the differences in the results for demutualized exchanges in the developed and emerging markets is due to the differences in the sheer size of the firms listed on the exchanges in these markets.

To determine whether or not firm size plays an important role when it comes to the market quality improvements associated with exchange demutualization in a multiexchange and multi-country context, we use the market cap of the last trading day of the previous year to rank stocks on each stock exchange in the following year. We then divide the sample into portfolios of small-cap (bottom 50\%) and large-cap (top 50\%). We report the results of our size segmentation in Table 3.7. 


\section{Table 3.7 - Size Segmentation}

Reported in this table are the results of the size-based ordinary least squares regression equations that regress quoted bid-ask spreads on a demutualization dummy as well as firm-level, exchange-level, country-level and other control variables. The other control variables are firm market capitalization, price inverse, volume, return standard deviation, exchange market share, domestic market capitalization, listed firms, CAPEX to revenue, GDP per capita and linear time trend. We estimated the regressions using the predemutualization data and the pairwise average of the 5-year post-demutualization data. ( $\mathrm{t}$ statistics, which are in parentheses, are based on White's heteroscedastic consistent robust standard errors.)

\begin{tabular}{|c|c|c|c|c|c|c|c|c|}
\hline & \multicolumn{8}{|c|}{ Quoted Spreads } \\
\hline & $\begin{array}{l}\text { Big } \\
\text { Demutuals }\end{array}$ & $\begin{array}{l}\text { Small } \\
\text { Demutuals }\end{array}$ & $\begin{array}{l}\text { Big } \\
\text { Mutuals }\end{array}$ & $\begin{array}{l}\text { Small } \\
\text { Mutuals }\end{array}$ & $\begin{array}{l}\text { Big Dev } \\
\text { Demutuals }\end{array}$ & $\begin{array}{l}\text { Small Dev } \\
\text { Demutuals }\end{array}$ & $\begin{array}{l}\text { Big } \\
\text { Emerging } \\
\text { Demutuals }\end{array}$ & $\begin{array}{l}\text { Small } \\
\text { Emerging } \\
\text { Demutuals }\end{array}$ \\
\hline \multirow[t]{2}{*}{$\begin{array}{l}\text { Post Demutual } \\
\text { Dummy }\end{array}$} & -0.0047 & 0.0051 & 0.0016 & 0.0006 & -0.0052 & 0.0027 & 0.0000 & 0.0143 \\
\hline & $(-8.46) * * *$ & $(4.61)^{* * *}$ & $(9.66)^{* * *}$ & $(2.31)^{* *}$ & $(-9.23)^{* * *}$ & $(2.06)^{* *}$ & $(-0.05)$ & $(12.56)^{* * *}$ \\
\hline \multirow[t]{2}{*}{ Mkt Cap Firm } & 0.0008 & 0.0011 & -0.0197 & -0.0394 & -0.0145 & -0.0161 & -0.0003 & 0.0032 \\
\hline & $(2.74)^{* * *}$ & $(2.57)^{* * *}$ & $(-30.99)^{* * *}$ & $(-90.05)^{* * *}$ & $(-34.50)^{* * *}$ & $(-23.49)^{* * *}$ & $(-0.54)$ & $(4.50) * * *$ \\
\hline \multirow[t]{2}{*}{ Inv Price } & 0.0023 & 0.0007 & 0.0014 & 0.0012 & 0.0037 & 0.0005 & 0.0012 & 0.0003 \\
\hline & $(65.42)^{* * *}$ & $(68.92)^{* * *}$ & $(47.17)^{* * *}$ & $(39.54)^{* * *}$ & $(22.90)^{* * *}$ & $(10.64)^{* * *}$ & $(28.42)^{* * *}$ & $(26.93)^{* * *}$ \\
\hline \multirow[t]{2}{*}{ Std Dev } & -0.0813 & 1.1835 & -0.0540 & -0.3398 & -1.0389 & 0.7362 & 1.0913 & 2.3406 \\
\hline & $(-2.25)^{* *}$ & $(30.70)^{* * *}$ & $(-1.92)^{*}$ & $(-7.88) * * *$ & $(-25.68)^{* * *}$ & $(17.68)^{* * *}$ & $(24.09)^{* * *}$ & $(43.09)^{* * *}$ \\
\hline \multirow[t]{2}{*}{ Volume } & -0.0073 & -0.0065 & 0.0001 & 0.0055 & -0.0113 & -0.0061 & -0.0018 & -0.0071 \\
\hline & $(-33.53)^{* * *}$ & $(-27.42)^{* * *}$ & $(0.70)$ & $(22.27)^{* * *}$ & $(-31.21)^{* * *}$ & $(-19.72)^{* * *}$ & $(-3.52) * * *$ & $(-13.05)^{* * *}$ \\
\hline \multirow[t]{2}{*}{ Mkt Share } & -0.0157 & -0.0552 & 0.3026 & 0.0544 & -0.0042 & -0.1259 & 0.6667 & 0.8733 \\
\hline & $(-1.09)$ & $(-1.98)^{* *}$ & $(7.23)^{* * *}$ & $(0.94)$ & $(-0.35)$ & $(-5.72) * * *$ & $(4.25)^{* * *}$ & $(2.61)^{* * *}$ \\
\hline \multirow[t]{2}{*}{ Mkt Cap Exch } & 0.0025 & 0.0003 & 0.0195 & 0.0091 & 0.0211 & 0.0193 & -0.0061 & -0.0105 \\
\hline & $(6.85)^{* * *}$ & $(0.42)$ & $(46.63)^{* * *}$ & $(19.11)^{* * *}$ & $(21.61)^{* * *}$ & $(14.85)^{* * *}$ & $(-10.18)^{* * *}$ & $(-12.58) * * *$ \\
\hline \multirow[t]{2}{*}{ Lstd Firms } & -0.0030 & -0.0129 & -0.0553 & -0.0125 & 0.0001 & -0.0114 & -0.0059 & -0.0213 \\
\hline & $(-11.96)^{* * *}$ & $(-23.76)^{* * *}$ & $(-45.91)^{* * *}$ & $(-6.54)^{* * *}$ & $(0.05)$ & $(-7.82)^{* * *}$ & $(-14.64)^{* * *}$ & $(-26.85)^{* * *}$ \\
\hline \multirow[t]{2}{*}{ CAPEX to Rev } & -0.0529 & -0.0266 & -0.2524 & 1.0615 & -0.1291 & -0.1319 & -0.0181 & 0.0075 \\
\hline & $(-11.08) * * *$ & $(-1.90)^{*}$ & $(-4.21)^{* * *}$ & $(14.90)^{* * * *}$ & $(-23.95)^{* * *}$ & $(-12.45) * * *$ & $(-3.12)^{* * *}$ & $(0.47)$ \\
\hline \multirow[t]{2}{*}{ Linear Trend } & 0.0000 & 0.0000 & 0.0000 & 0.0000 & 0.0000 & 0.0000 & 0.0000 & 0.0001 \\
\hline & $(-2.55)^{* *}$ & $(4.35)^{* * *}$ & $(-7.29)^{* * *}$ & (1.19) & $(-3.3) * * *$ & $(-0.06)$ & $(-0.09)$ & $(9.13)^{* * *}$ \\
\hline \multirow[t]{2}{*}{ GDP per Cap } & 0.0000 & 0.0000 & 0.0000 & 0.0000 & 0.0000 & 0.0000 & 0.0000 & 0.0000 \\
\hline & $(7.10)^{* * *}$ & $(-17.63)^{* * *}$ & $(14.29)^{* * *}$ & $(52.81)^{* * *}$ & $(-8.82)^{* * *}$ & $(-4.38)^{* * * *}$ & $(-17.84) * * *$ & $(-38.25)^{* * *}$ \\
\hline \multirow[t]{2}{*}{ Constant } & 0.1103 & 0.1862 & 0.2702 & 0.0326 & 0.0632 & 0.0153 & 0.1465 & 0.3521 \\
\hline & $(31.68)^{* * *}$ & $(31.23)^{* * *}$ & $(57.93)^{* * *}$ & $(3.94)^{* * *}$ & $(14.78)^{* * * *}$ & $(2.54)^{* *}$ & $(20.79)^{* * *}$ & $(39.09)^{* * *}$ \\
\hline $\mathrm{N}$ & 13526 & 13710 & 16859 & 15932 & 5889 & 5520 & 7637 & 8190 \\
\hline $\mathrm{R}^{2}$ & 0.3739 & 0.4489 & 0.8017 & 0.864 & 0.5243 & 0.4847 & 0.5499 & 0.6285 \\
\hline Adjusted $\mathrm{R}^{2}$ & 0.3734 & 0.4484 & 0.8016 & 0.8639 & 0.5234 & 0.4836 & 0.5492 & 0.6280 \\
\hline
\end{tabular}

Unlike Otchere and Abou-Zied (2008) who find the benefits of demutualization to be disproportionately in favor of small-cap stocks, our results from Table 3.7 show that the 
benefits of demutualization in reducing transaction costs and improving market quality are exclusively enjoyed by large-cap stocks. Our results (which are inconsistent with Otchere and Abou-Zied, 2008) show that the demutualization dummy is only significantly negative for big firms listed on demutualized exchanges (column B) and developed demutualized exchanges (column F). Small firms on demutualized and mutualized stock exchanges (columns C, E, G and I) as well as big firms on mutualized stock exchanges (column D) all experienced significant increases in transaction costs with the demutualization dummy for these subsamples all being significantly positive at the $1 \%$ level or $5 \%$ level. Big firms listed on emerging demutualized stock exchanges (column $\mathrm{H}$ ) registered insignificant reductions in bid-ask spreads.

To gain further insights into the behavior of spreads and volatility of different-sized firms over time, we trended quoted spreads and standard deviation for small- and large-cap stocks listed on all demutualized exchanges, mutualized exchanges, developed demutualized exchanges and developed mutualized exchanges. We present the trend charts in Figure 3.6 to Figure 3.9. From an inspection of the trend plots, it becomes obvious that the behavior of spreads and volatility in the first 2 years following demutualization are different from the year 3 to year 5 behaviors. Consequently, we split the data accordingly and superimposed linear trends on the sub-periods. 
Figure 3.6 - Quoted Spreads of Small- and Large-cap Stocks listed on Demutualized and Mutualized Exchanges

This figure trends quoted spreads of small- and large-cap stocks on demutuals and mutuals starting 250 days (one year) before the dates of demutualization and ending 1,250 days (5 years) after the demutualization dates. Charts: a) trends quoted spreads of big firms on all demutualized stock exchanges; b) charts quoted spreads of big firms on all mutualized stock exchanges; c) presents quoted spreads of small firms on all demutualized stock exchanges; and, d) plots quoted spreads of small firms on all mutualized stock exchanges.

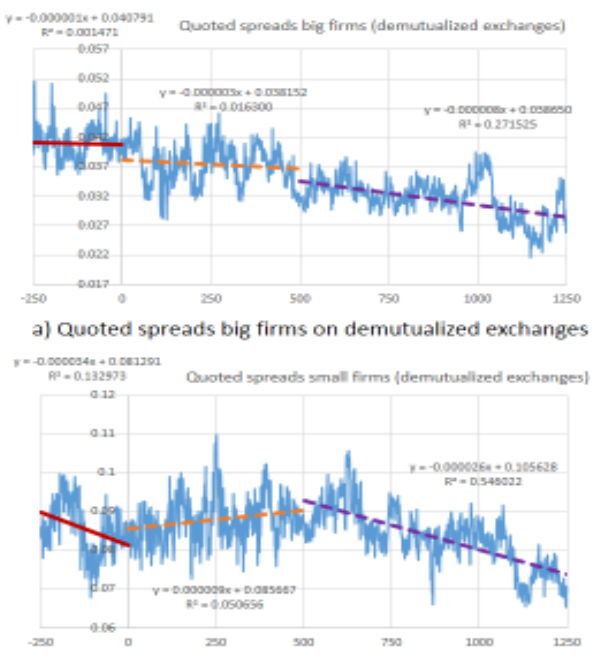

c) Quoted spreads small firms on demutualized exchanges

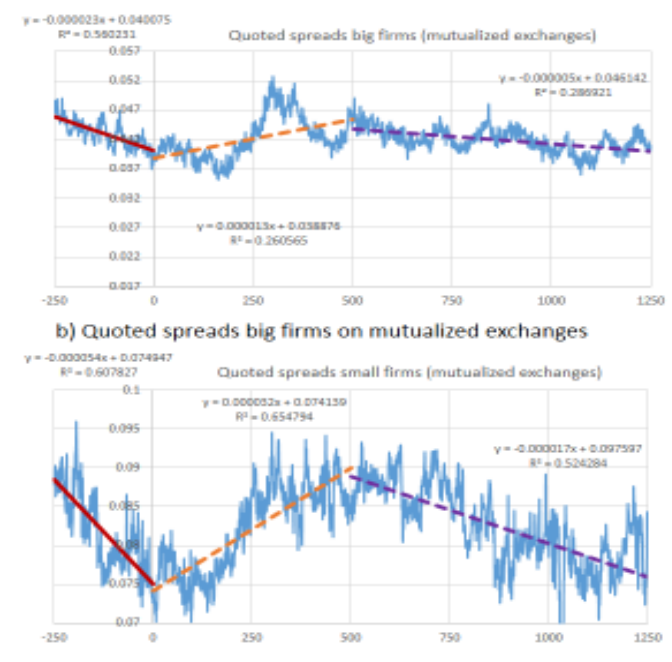

d) Quoted spreads small firms on mutualized exchanges

Figure 3.7 - Quoted Spreads of Small- and Large-cap Stocks listed on Developed Demutualized and Mutualized Exchanges

This figure trends quoted spreads of small- and large-cap stocks on developed demutuals and mutuals starting 250 days (one year) before the dates of demutualization and ending 1,250 days (5 years) after the demutualization dates. Charts: a) trends quoted spreads of big firms on developed demutualized stock exchanges; b) charts quoted spreads of big firms on developed mutualized stock exchanges; c) presents quoted spreads of small firms on developed demutualized stock exchanges; and, d) plots quoted spreads of small firms on developed mutualized stock exchanges.

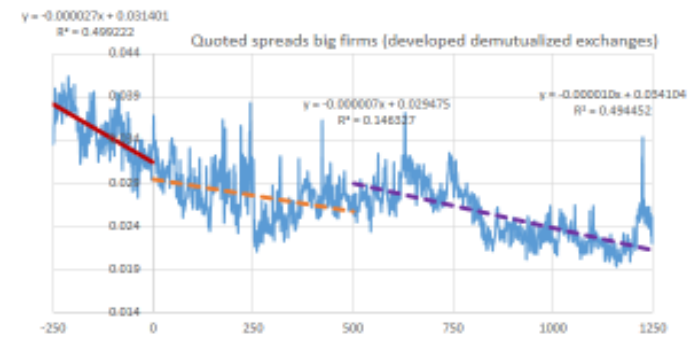

a) Quoted spreads big firms on developed demutualized exchanges

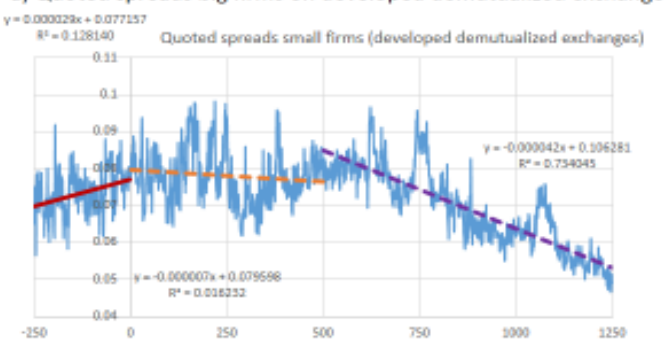

c) Quoted spreads small firms on developed demutualized exchanges

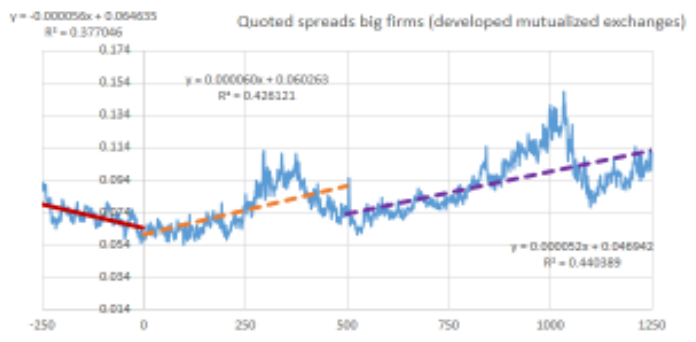

b) Quoted spreads big firms on developed mutualized exchanges

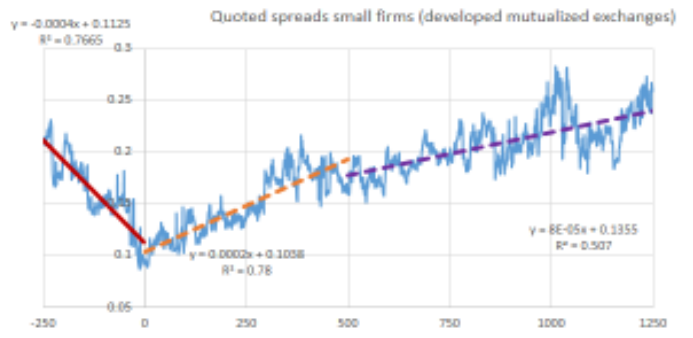

d) Quoted spreads small firms on developed mutualized exchanges 


\section{Figure 3.8 - Standard Deviation of Small- and Large-cap Stocks listed on Demutualized and Mutualized Exchanges}

This figure trends standard deviation of small- and large-cap stocks on demutuals and mutuals starting 250 days (one year) before the dates of demutualization and ending 1,250 days ( 5 years) after the demutualization dates. Charts: a) trends standard deviation of big firms on all demutualized stock exchanges; $b$ ) charts standard deviation of big firms on all mutualized stock exchanges; $c$ ) presents standard deviation of small firms on all demutualized stock exchanges; and, d) plots standard deviation of small firms on all mutualized stock exchanges.

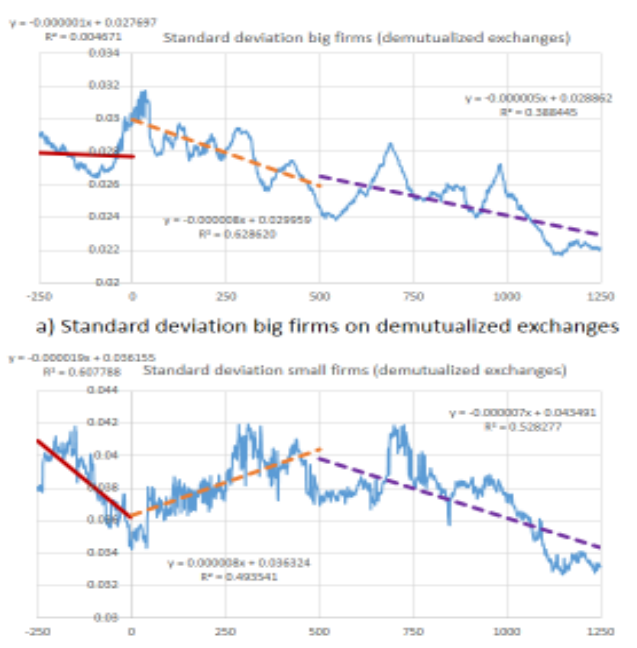

c) Standard deviation small firms on demutualized exchanges

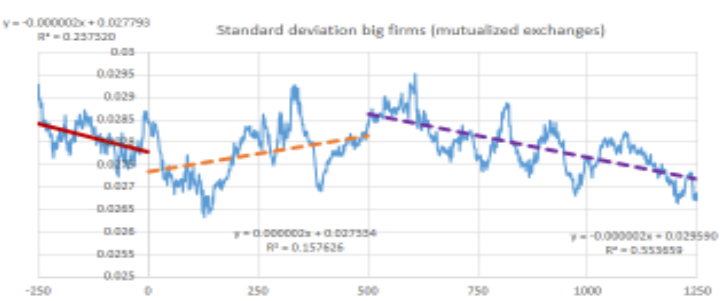

b) Standard deviation big firms on mutualized exchanges

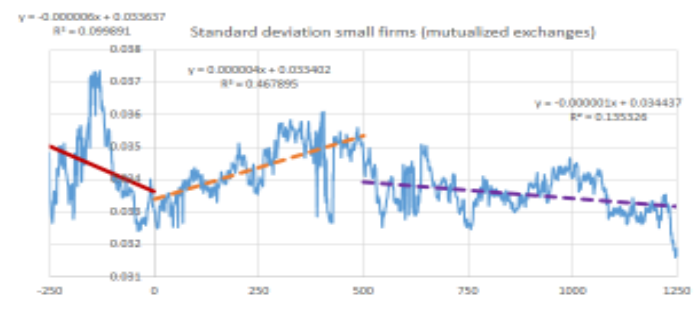

d) Standard deviation small firms on mutualized exchanges

\section{Figure 3.9 - Standard Deviation of Small- and Large-cap Stocks listed on Developed Demutualized and Mutualized Exchanges}

This figure trends standard deviation of small- and large-cap stocks on developed demutuals and mutuals starting 250 days (one year) before the dates of demutualization and ending 1,250 days ( 5 years) after the demutualization dates. Charts: a) trends standard deviation of big firms on developed demutualized stock exchanges; b) charts standard deviation of big firms on developed mutualized stock exchanges; c) presents standard deviation of small firms on developed demutualized stock exchanges; and, d) plots standard deviation of small firms on developed mutualized stock exchanges.

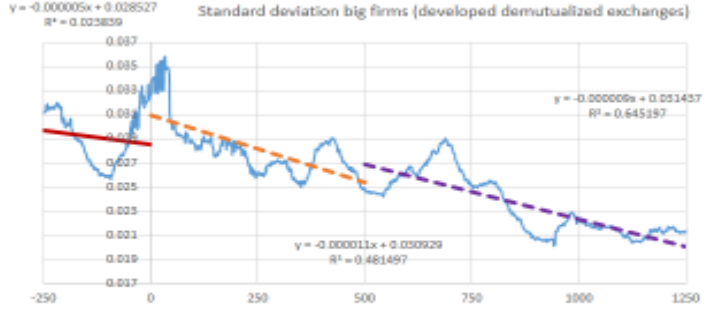

a) Standard deviation big firms on developed demutualized exchanges

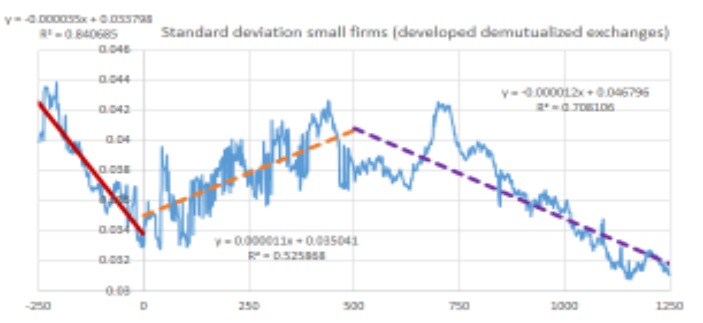

c) Standard deviation small firms on developed demutualized exchanges

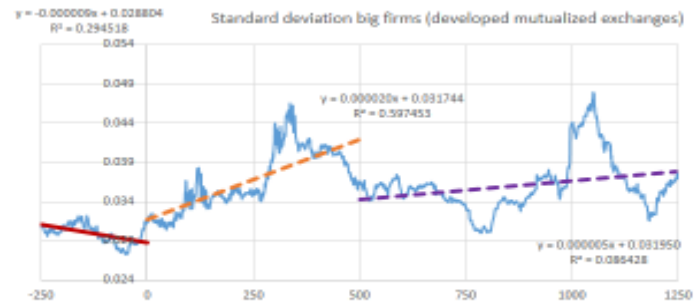

b) Standard deviation big firms on developed mutualized exchanges

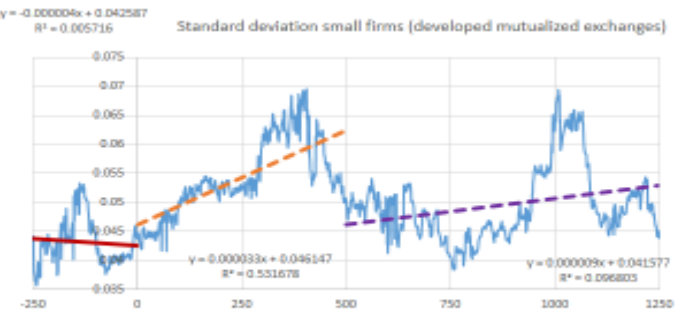

d) Standard deviation small firms on developed mutualized exchanges 
The size-based trends provide some unique insights. First, demutualization is beneficial to big firms on demutualized exchanges (charts a of Figure 3.6 and Figure 3.8) and developed demutualized exchanges (charts a of Figure 3.7 and Figure 3.9) - as big firms on demutualized exchanges and developed demutualized exchanges continue to experience decreasing spreads and volatility in the 5 years following demutualization. Second, demutualization is disadvantageous to big firms on mutualized exchanges (charts b of Figure 3.6 and Figure 3.8) and developed mutualized exchanges (charts b of Figure 3.7 and Figure 3.9) - as big firms on these exchanges generally continue to experience increasing spreads and volatility in the 5 years following demutualization. Third, while small firms on demutualized exchanges (as well as developed demutualized exchanges) appear to not benefit when one considers the whole 5-year sample period, a split into subperiods does show some delayed gratification and realization of benefits for small firms. In the first two years, small firms on demutualized stock exchanges are saddled with the faith of small firms on mutualized exchanges - increasing spreads and volatility. However, from the third to fifth year, small firms on demutualized and developed demutualized exchanges experience decreasing spreads and volatility. The benefits are even more pronounced for small firms listed on developed demutualized exchanges because spreads in the first two years for small firms on these exchanges are even decreasing (albeit at a less pronounced pace than from year 3 to year 5). Finally, although small-cap stocks on mutualized stock exchanges have seen some slight decreases in spreads and volatility in year 3 to year 5, spreads and volatility of small firms on 
developed mutualized exchanges continue to increase in both sub-periods in the postdemutualization period.

From the size-related analyses, while demutualization is clearly beneficial to large-cap stocks, we also find that small-cap stocks do somewhat reap some market quality benefits as a result of stock exchange demutualization - but the realization of benefits is delayed till year 3 through year 5 .

It is not unexpected that large-cap stocks will realize significant reductions in bid-ask spreads following demutualization. Large-cap stocks (which are already probably heavily traded and likely well-known by investors because of their size advantage) are better positioned to increase their trading volume in the post-demutualization period when more transparent demutualized exchanges are expected to attract more order flow. When trading volume increase for large-cap stocks after demutualization, economies of scale in trading volume for large-cap stocks will inevitably lead to decreases in bid-ask spreads. For the reason why small-cap stocks do not seem to benefit from demutualization, we submit that because small firms are not as well-known as big firms, they are not able to immediately tap into the increasing order flow from demutualization. As a result, they are probably still thinly traded and the absence of economies of scale in trading volume means that bid-ask spreads, at best, would be close to being constant. However, as time goes by and demutualized stock exchanges continue to attract more order flow, the profile of small firms would begin to rise - especially as investors seek to diversify. The increasing profile of small firms on demutualized exchanges will allow them to capture 
some of the increasing order flow, leading to increased trading. The increased trading in small-cap stocks over time will therefore lead to increased liquidity and decreased bidask spreads. Hence the patterns in bid-ask spreads for small-cap firms.

Finally, another interesting finding in Table 3.7 relates to the CAPEX to revenue variable, our proxy for technological investments. The coefficient of the CAPEX to revenue variable is significantly negative at the $1 \%$ level for big firms in all markets (demutualized, mutualized, developed demutualized and emerging demutualized). This pronounced effect of technology in reducing bid-ask spreads for large-cap firms in all markets, we argue, is because technology enhances the profile of firms with less information asymmetry. As a result, they are able to attract more order flow because of the enhanced information flow from technology. This increases liquidity and helps reduce bid-ask spreads for large-cap firms. These results are consistent with Hendershott et al.'s (2011) findings that algorithmic trading (i.e. technology) improves liquidity for large-cap stocks. However, the significantly negative relationship (at the $1 \%$ level) between the CAPEX to revenue variable and quoted spreads for small firms in developed demutualized exchanges may indicate that for technological investments to have an effect in reducing spreads for firms with high information asymmetry (i.e. small firms), the effect must be moderated by an exchange's reputation. We believe that because developed demutualized stock exchanges may be perceived as more reputable exchanges than emerging demutualized exchanges and mutualized exchanges, the effect of the enhanced information (from technology) on small firms listed on developed demutualized exchanges has stronger signaling effect because of the exchanges' reputation. 
Consequently, small firms on developed demutualized exchanges (with higher reputation) are able to attract more order flow and experience increased liquidity - which helps to reduce bid-ask spreads. The significantly positive coefficient of the CAPEX to revenue variable for small firms listed on mutualized stock exchanges and the insignificantly positive coefficient for the CAPEX to revenue variable for small firms listed on emerging demutualized stock exchanges provide some corroborating evidence on the moderating effect of exchange reputation on technology's impact in reducing bid-ask spreads for firms with high information asymmetry.

\subsubsection{Robustness Tests}

We conducted a number of robustness tests to test the sensitivity of our results to alternative specifications and measures. We discuss the results of these robustness tests in this section.

\subsubsection{Traditional Firm-Level Analysis}

While the research objectives we set out to achieve are best addressed by aggregating our data at the exchange level and analyzing the effects of demutualization over the six year period from one year before to five years after, we also estimated our main regression models based on the traditional firm-level analysis prevalent in the market microstructure literature. 


\section{Table 3.8 - Firm-level analysis}

In this table, we report the results of the ordinary least squares regression equations that regress quoted bid-ask spreads on a demutualization dummy and/or developed demutualization dummy as well as firm-level, exchange-level, country-level and other control variables. The other control variables are firm market capitalization, price inverse, volume, return standard deviation, exchange market share, domestic market capitalization, listed firms, CAPEX to revenue and GDP per capita. We estimated the regressions using the average of the one year pre-demutualization data and the average of the 5-year post-demutualization data. ( $\mathrm{t}$ statistics are in parentheses.)

\begin{tabular}{|c|c|c|c|}
\hline & \multicolumn{3}{|c|}{ Traditional } \\
\hline & Quoted & Quoted & Quoted \\
\hline \multirow[t]{2}{*}{ Demutual Dummy } & -0.0026 & - & 0.0000 \\
\hline & $(-2.02)^{* *}$ & - & $(0.00)$ \\
\hline \multirow[t]{2}{*}{ Developed Demutual Dummy } & - & -0.0064 & -0.0064 \\
\hline & - & $(-3.52)^{* * *}$ & $(-2.88)^{* * *}$ \\
\hline \multirow[t]{2}{*}{ Mkt Cap Firm } & -0.0059 & -0.0058 & -0.0058 \\
\hline & $(-16.91)^{* * *}$ & $(-16.73)^{* * *}$ & $(-16.72)^{* * *}$ \\
\hline \multirow[t]{2}{*}{ Inv Price } & 0.0010 & 0.0010 & 0.0010 \\
\hline & $(24.94)^{* * *}$ & $(25.11)^{* * *}$ & $(25.11)^{* * *}$ \\
\hline \multirow[t]{2}{*}{ Std Dev } & 0.5504 & 0.5477 & 0.5477 \\
\hline & $(12.58)^{* * *}$ & $(12.53)^{* * *}$ & $(12.52)^{* * *}$ \\
\hline \multirow[t]{2}{*}{ Volume } & -0.0065 & -0.0065 & -0.0065 \\
\hline & $(-27.67)^{* * *}$ & $(-27.78)^{* * *}$ & $(-27.59)^{* * *}$ \\
\hline \multirow[t]{2}{*}{ Mkt Share } & -0.8670 & -0.8320 & -0.8320 \\
\hline & $(-4.89)^{* * *}$ & $(-4.68)^{* * *}$ & $(-4.68)^{* * *}$ \\
\hline \multirow[t]{2}{*}{ Mkt Cap Exch } & 0.0006 & 0.0003 & 0.0003 \\
\hline & $(0.79)$ & $(0.40)$ & $(0.40)$ \\
\hline \multirow[t]{2}{*}{ Lstd Firms } & -0.0073 & -0.0072 & -0.0072 \\
\hline & $(-7.83)^{* * *}$ & $(-7.81)^{* * *}$ & $(-7.71)^{* * *}$ \\
\hline \multirow[t]{2}{*}{ CAPEX to Rev } & 0.0968 & 0.1122 & 0.1122 \\
\hline & $(3.01)^{* * *}$ & $(3.51)^{* * *}$ & $(3.44)^{* * *}$ \\
\hline \multirow[t]{2}{*}{ GDP per Cap } & 0.0000 & 0.0000 & 0.0000 \\
\hline & $(6.25)^{* * *}$ & $(6.88)^{* * *}$ & $(6.83)^{* * *}$ \\
\hline \multirow[t]{2}{*}{ Constant } & 0.1547 & 0.1545 & 0.1545 \\
\hline & $(24.73)^{* * *}$ & $(24.72)^{* * *}$ & $(24.71)^{* * *}$ \\
\hline $\mathrm{N}$ & 5961 & 5961 & 5961 \\
\hline $\mathrm{R}^{2}$ & 0.4125 & 0.4133 & 0.4133 \\
\hline Adjusted $\mathrm{R}^{2}$ & 0.4115 & 0.4123 & 0.4122 \\
\hline
\end{tabular}

The results of the firm-level regressions are similar to the exchange-level regressions. We find that demutualization leads to decreases in spreads for firms listed on the 
demutualized stock exchanges. The reductions in spreads are even more pronounced for demutualized exchanges from developed nations. The developed demutualization dummy is so strong that it subsumes the demutualization dummy when they are both included in the same model. As well, the other control variables (including firm market value) are significant and have the expected coefficients.

\subsubsection{High-minus-low as an Alternative Measure of Risk}

While we have used the past 3-month returns standard deviation as the measure of risk in the main market quality regression models, we also run a number of our regression equations using high-minus-low (as a percent of the midpoint) as the measure of risk. As reported in Table 3.9, the results are qualitatively similar to our main findings.

Table 3.9 - High-minus-low as a Measure of Risk

\begin{tabular}{|c|c|c|c|c|c|c|}
\hline & \multicolumn{3}{|c|}{ Pairwise Average } & \multicolumn{3}{|c|}{ Pooled } \\
\hline & Quoted & Quoted & Quoted & Quoted & Quoted & Quoted \\
\hline \multirow[t]{2}{*}{ Demutual Dummy } & -0.0141 & - & -0.0084 & -0.0071 & - & -0.0046 \\
\hline & $(-20.78)^{* * *}$ & - & $(-12.33)^{* * *}$ & $(-15.74)^{* * *}$ & - & $(-10.03)^{* * * *}$ \\
\hline \multirow[t]{2}{*}{$\begin{array}{l}\text { Developed Demutual } \\
\text { Dummy }\end{array}$} & - & -0.0248 & -0.0175 & - & -0.0153 & -0.0128 \\
\hline & - & $(-20.55)^{* * *}$ & $(-13.90)^{* * *}$ & - & $(-21.2)^{* * *}$ & $(-17.70)^{* * *}$ \\
\hline \multirow[t]{2}{*}{ Mkt Cap Firm } & 0.0164 & 0.0160 & 0.0165 & 0.0130 & 0.0124 & 0.0129 \\
\hline & $(56.46)^{* * *}$ & $(54.64)^{* * *}$ & $(56.52)^{* * *}$ & $(69.16)^{* * *}$ & $(68.04)^{* * *}$ & $(68.91)^{* * *}$ \\
\hline \multirow[t]{2}{*}{ Inv Price } & 0.0009 & 0.0009 & 0.0009 & 0.0008 & 0.0008 & 0.0008 \\
\hline & $(52.60)^{* * *}$ & $(47.54)^{* * *}$ & $(50.69)^{* * *}$ & $(83.65)^{* * *}$ & $(82.61)^{* * *}$ & $(82.70)^{* * *}$ \\
\hline \multirow[t]{2}{*}{ High minus Low } & 0.6249 & 0.5670 & 0.5832 & 0.7356 & 0.6965 & 0.7063 \\
\hline & $(30.61)^{* * *}$ & $(27.22)^{* * *}$ & $(28.15)^{* * *}$ & $(54.18)^{* * *}$ & $(51.12)^{* * *}$ & $(52.35)^{* * *}$ \\
\hline Volume & -0.0085 & -0.0071 & -0.0078 & -0.0069 & -0.0057 & -0.0064 \\
\hline
\end{tabular}




\begin{tabular}{|c|c|c|c|c|c|c|}
\hline & \multicolumn{3}{|c|}{ Pairwise Average } & \multicolumn{3}{|c|}{ Pooled } \\
\hline & Quoted & Quoted & Quoted & Quoted & Quoted & Quoted \\
\hline & $(-36.87)^{* * *}$ & $(-31.81)^{* * *}$ & $(-31.56)^{* * *}$ & $(-47.17)^{* * *}$ & $(-48.85)^{* * *}$ & $(-43.51)^{* * *}$ \\
\hline \multirow[t]{2}{*}{ Mkt Share } & -0.0342 & -0.0485 & -0.0437 & -0.0803 & -0.0820 & -0.0823 \\
\hline & $(-0.57)$ & $(-0.87)$ & $(-0.75)$ & $(-6.16)^{* * *}$ & $(-6.31)^{* * *}$ & $(-6.28)^{* * *}$ \\
\hline \multirow[t]{2}{*}{ Mkt Cap Exch } & -0.0109 & -0.0128 & -0.0122 & -0.0060 & -0.0070 & -0.0068 \\
\hline & $(-33.00)^{* * *}$ & $(-36.14)^{* * *}$ & $(-34.80)^{* * *}$ & $(-28.50)^{* * *}$ & $(-32.15)^{* * *}$ & $(-31.65)^{* * *}$ \\
\hline \multirow[t]{2}{*}{ Lstd Firms } & -0.0060 & -0.0041 & -0.0043 & -0.0098 & -0.0088 & -0.0086 \\
\hline & $(-16.68)^{* * *}$ & $(-10.74)^{* * *}$ & $(-11.55)^{* * *}$ & $(-37.76)^{* * *}$ & $(-33.96)^{* * *}$ & $(-32.84)^{* * *}$ \\
\hline \multirow[t]{2}{*}{ CAPEX to Rev } & 0.1163 & 0.1696 & 0.1511 & -0.0285 & -0.0134 & -0.0159 \\
\hline & $(6.84)^{* * *}$ & $(10.52)^{* * *}$ & $(9.22)^{* * *}$ & $(-6.79)^{* * *}$ & $(-3.17)^{* * *}$ & $(-3.79)^{* * *}$ \\
\hline \multirow[t]{2}{*}{ Linear Trend } & 0.0000 & 0.0000 & 0.0000 & 0.0000 & 0.0000 & 0.0000 \\
\hline & -1.28 & -1.31 & -1.28 & $(-5.92)^{* * *}$ & $(-5.07)^{* * *}$ & $(-3.79)^{* * *}$ \\
\hline \multirow[t]{2}{*}{ GDP per Cap } & 0.0000 & 0.0000 & 0.0000 & 0.0000 & 0.0000 & 0.0000 \\
\hline & $(13.62)^{* * *}$ & $(18.04)^{* * *}$ & $(16.53)^{* * *}$ & $(4.66)^{* * *}$ & $(14.81)^{* * *}$ & $(14.39)^{* * *}$ \\
\hline \multirow[t]{2}{*}{ Constant } & 0.1949 & 0.1848 & 0.1876 & 0.1705 & 0.1623 & 0.1663 \\
\hline & $(65.87)^{* * *}$ & $(60.12)^{* * *}$ & $(61.13)^{* * *}$ & $(88.56)^{* * *}$ & $(89.00)^{* * *}$ & $(88.31)^{* * *}$ \\
\hline $\mathrm{N}$ & 26433 & 26433 & 26433 & 71604 & 71604 & 71604 \\
\hline $\mathrm{R}^{2}$ & 0.5481 & 0.5506 & 0.5544 & 0.4589 & 0.4616 & 0.463 \\
\hline Adjusted $\mathrm{R}^{2}$ & 0.5479 & 0.5504 & 0.5542 & 0.4589 & 0.4615 & 0.4629 \\
\hline
\end{tabular}

As expected, the demutualization dummy and developed demutualization dummy are both significantly negatively related to quoted spreads in the various regression models. As expected also, the coefficient of the high-minus-low variable is significantly positively related to quoted spreads - indicating that the higher the risk, the higher the spreads. Finally, most of the other variables in the regression models maintain their significance and have the expected signs.

\subsubsection{Alternative Specifications}

We also run alternative specifications of our main regression model and present the results in Table 3.10 . 


\section{Table 3.10 - Alternatively Specified Models}

This table provides results of alternatively specified ordinary least squares regression equations that regress bid-ask spreads on a demutualization dummy as well as firm-level, exchange-level, country-level and other control variables. The other control variables are firm market capitalization, price inverse, volume, return standard deviation, exchange market share, domestic market capitalization, listed firms, CAPEX to revenue, GDP per capita and linear time trend. We estimated the regressions using the predemutualization data and the pairwise average of the 5-year post-demutualization data. The alternative specifications include (i) centering the predictor variables around their means; (ii) using median values (i.e. quantile regression) instead of mean values; (iii) using effective spreads as percent of price as the dependent variable instead of quoted spreads or effective spreads as a percent of the midpoint; and, (iv) substituting price in place of price inverse. (t statistics, which are in parentheses, are based on White's heteroscedastic consistent robust standard errors.)

\begin{tabular}{|c|c|c|c|c|}
\hline & $\begin{array}{c}\text { Centered Regression } \\
\text { Quoted }\end{array}$ & $\begin{array}{l}\text { Quantile / Median } \\
\text { Regression Quoted }\end{array}$ & $\begin{array}{c}\text { Effective as \% } \\
\text { of Price }\end{array}$ & $\begin{array}{c}\text { Alternative Model } \\
\text { Quoted }\end{array}$ \\
\hline \multirow[t]{2}{*}{ emutual Dummy } & -0.0153 & -0.0154 & -0.0182 & -0.0105 \\
\hline & $(-21.80)^{* * *}$ & $(-55.38)^{* * *}$ & $(-25.06)^{* * *}$ & $(-13.50)^{* * *}$ \\
\hline \multirow[t]{2}{*}{ Mkt Cap Firm } & 0.0139 & 0.0127 & 0.0092 & 0.0149 \\
\hline & $(48.39)^{* * *}$ & $(117.24)^{* * *}$ & $(34.31)^{* * *}$ & $(51.99)^{* * *}$ \\
\hline \multirow[t]{2}{*}{ Inv Price } & 0.0010 & 0.0010 & 0.0008 & - \\
\hline & $(53.33)^{* * *}$ & $(139.43)^{* * *}$ & $(40.65)^{* * *}$ & - \\
\hline \multirow[t]{2}{*}{ Price } & - & - & - & 0.0000 \\
\hline & - & - & - & $(-6.85)^{* * *}$ \\
\hline \multirow[t]{2}{*}{ Std Dev } & 0.4130 & 0.5407 & 0.7355 & 0.8478 \\
\hline & $(10.75)^{* * *}$ & $(37.92)^{* * *}$ & $(18.34)^{* * *}$ & $(18.95)^{* * *}$ \\
\hline \multirow[t]{2}{*}{ Volume } & -0.0085 & -0.0104 & -0.0115 & -0.0035 \\
\hline & $(-37.99)^{* * *}$ & $(-101.12)^{* * *}$ & $(-45.3)^{* * *}$ & $(-14.89)^{* * *}$ \\
\hline \multirow[t]{2}{*}{ Mkt Share } & -0.0224 & -0.0220 & 0.0625 & -0.0563 \\
\hline & $(-0.4)$ & $(-0.95)$ & $(1.57)$ & $(-0.94)$ \\
\hline \multirow[t]{2}{*}{ Mkt Cap Exch } & -0.0143 & -0.0068 & -0.0102 & -0.0220 \\
\hline & $(-44.24)^{* * *}$ & $(-47.10)^{* * *}$ & $(-32.78)^{* * *}$ & $(-65.11)^{* * *}$ \\
\hline \multirow[t]{2}{*}{ Lstd Firms } & -0.0056 & -0.0074 & -0.0087 & -0.0028 \\
\hline & $(-14.53)^{* * *}$ & $(-39.18)^{* * *}$ & $(-20.01)^{* * *}$ & $(-6.78)^{* * *}$ \\
\hline \multirow[t]{2}{*}{ CAPEX to Rev } & 0.0954 & 0.2143 & -0.0140 & 0.1350 \\
\hline & $(5.87)^{* * *}$ & $(47.72)^{* * *}$ & $(-0.61)$ & $(7.80)^{* * *}$ \\
\hline \multirow[t]{2}{*}{ Linear Trend } & 0.0000 & 0.0000 & 0.0000 & 0.0000 \\
\hline & $(-1.00)$ & $(0.32)$ & $(7.78)^{* * *}$ & $(-0.28)$ \\
\hline \multirow[t]{2}{*}{ GDP per Cap } & 0.0000 & 0.0000 & 0.0000 & 0.0000 \\
\hline & $(28.84)^{* * *}$ & $(15.59)^{* * *}$ & $(27.23)^{* * *}$ & $(30.13)^{* * *}$ \\
\hline \multirow[t]{2}{*}{ Constant } & 0.0753 & 0.2080 & 0.3004 & 0.2571 \\
\hline & $(190.47)^{* * *}$ & $(160.82)^{* * *}$ & $(75.92)^{* * *}$ & $(63.81)^{* * *}$ \\
\hline $\mathrm{N}$ & 26906 & 26906 & 26906 & 26906 \\
\hline $\mathrm{R}^{2}$ & 0.5614 & 0.2718 & 0.5258 & 0.4711 \\
\hline Adjusted $\mathrm{R}^{2}$ & 0.5613 & - & 0.5256 & 0.4708 \\
\hline
\end{tabular}


While inspection of the correlation matrix and variance inflation factors do not suggest the presence of multicolinearity, we run regressions that use values of the variables centered around their mean values. As column B of Table 3.10 shows, the results of the centered regressions are similar to our main regressions - and also demonstrate that stock exchange demutualization leads to reductions in transaction costs and improvements in market quality. We also estimate the regression models using median values instead of mean values. As reported in column $\mathrm{C}$ of Table 3.10 , the results of the quantile regression, which also show the important role of demutualization in improving market quality, are similar to our main regression results. We also estimated a regression equation that uses effective spreads as a percent of price (instead of as a percent of the midpoint). As column $\mathrm{D}$ of Table 3.10 shows, the results are similar to what we have reported so far. Finally, we estimated a regression equation that uses price in place of price inverse. As the results in column E of Table 3.10 highlight, the results are consistent with our main findings.

Given that the results of our various robustness tests are similar to our main findings, we contend that stock exchange demutualization robustly lead to statistically significant and economically important improvements in market quality for the demutualizing exchanges in the post-demutualization period. 


\subsection{Conclusion}

Demutualization has become one of the most important strategic choices that stock exchanges are employing in the face of the increased competition in the stock exchange industry. Despite its prevalence, a lot is still unknown empirically about the effects of stock exchange demutualization on market quality in a multi-exchange and multi-country environment. Motivated by the need to understand its empirical ramifications across many exchanges and many countries, we assessed the effect of stock exchange demutualization on market quality using 30 stock exchange demutualizations consummated between 1993 and 2013.

First, our results show that demutualized exchanges experience significant reductions in bid-ask spreads and volatility, and consequently, significant improvements in market quality in the subsequent five years following demutualization. For instance, quoted spreads have declined an average of over $5 \%$ and standard deviation has fallen an average of over $7 \%$ in the post-demutualization period on demutualized stock exchanges. In contrast, mutualized stock exchanges experienced increasing bid-ask spreads and volatility in the 5-year post-demutualization period.

Second, we find that the benefits of demutualization are asymmetrically distributed in favor of developed demutualized exchanges and large-cap stocks. While developed demutualized stock exchanges experience significant and important reductions in spreads and volatility, emerging demutualized exchanges do not see the same across-the-board improvements in market quality following demutualization. The second evidence of 
asymmetric distribution of demutualization's benefits is the fact that the reductions in spreads are almost exclusive to large-cap stocks. While small-cap firms experience increased bid-ask spreads and volatility over the 5 -year post-demutualization period, further slicing and trending of the data reveals that the increasing spreads and volatility of small-cap stocks are restricted to only the first two years of demutualization. Volatility and spreads for small-cap firms turnaround in the third to fifth year and begin to decrease.

Third, while there is no evidence that subsequently undertaking IPO after demutualizing does lead to further reductions in spreads for stock exchanges, there are incremental improvements in market quality if the IPO is undertaken by a developed stock exchange.

On the whole, our results show that demutualization in the stock exchange industry has resulted in robust and sustained improvements in market quality in not only over the long term but over the short term as well. Despite the unique and comprehensive findings of our study, we see a couple of important paths for future research. First, it would be important to understand why emerging demutualized stock exchanges do not seem to attain the same level of improvements in market quality that developed demutualized stock exchanges have achieved. While we conjecture that this might be due to halfhearted commitment to the profit motive of demutualization and/or weak corporate governance, it would be important to provide prima facie evidence on what is actually behind this. Second, future research can investigate why small stocks appear to be immune to the realization of reduction in spreads following demutualization. While our contention is that this may be due to the fact that small firms are not as well-known and 
are therefore not attracting enough order flow to enjoy reductions in spreads as a result of economies of scale in trading volume, it is necessary to assess the validity or otherwise of this contention in future research. 


\section{References}

Acharya, S. (1993). Value of Latent Information: Alternative Event Study Methods, Journal of Finance, 48(1), pp. 363-385.

Acharya, V.V. and Pedersen, L.H. (2005). Asset Pricing with Liquidity Risk, Journal of Financial Economics, 77, pp. 375-410.

Aggarwal, R. (2002). Demutualization and Corporate Governance of Stock Exchanges, Journal of Applied Corporate Finance, 15(1), pp. 105-113.

Ahern, K.R. and Sosyura, D. (2014). Who Writes the News? Corporate Press Releases during Merger Negotiations, Journal of Finance, 69(1), pp. 241-291.

Alexander, G.J., Ors, E., Peterson, M.A. and Seguin, P.J. (2004). Margin Regulation and Market Quality: A Microstructure Analysis, Journal of Corporate Finance, 10, pp. 549574.

Amihud, Y. (2002). Illiquidity and Stock Returns: Cross-Section and Time-Series Effects, Journal of Financial Markets, 5, pp. 31-56.

Amihud, Y. and Mendelson, H. (1986). Asset Pricing and the Bid-Ask Spread, Journal of Financial Economics, 17, pp. 223-249.

Amihud, Y. and Mendelson, H. (2000). The Liquidity Route to a Lower Cost of Capital, Journal of Applied Corporate Finance, 12(4), pp. 8-25.

Angulo, L.P., Slimane, F.B. and Alidou, D. (2014). The London Stock Exchange:

Strategic Corporate Governance Restructuring after Demutualization, Journal of Applied Business Research, 30(1), pp. 211-226.

Arnold, T., Hersch, P., Mulherin, J.H. and Netter, J. (1999). Merging Markets, Journal of Finance, 54 (3), pp. 1083-1107.

Azzam, I. (2010). Stock Exchange Demutualization and Performance, Global Finance Journal, 21, pp. 211-222.

Bacidore, J.M. (1997). The Impact of Decimalization on Market Quality: An Empirical Investigation of the Toronto Stock Exchange, Journal of Financial Intermediation, 6, pp. 92-120.

Bacidore, J.M., Battalio, R.H. and Jennings, RH. (2002). Depth Improvement and Adjusted Price Improvement on the New York Stock Exchange, Journal of Financial Markets, 5, pp.169-195. 
Barclay, M.J., Christie, W.G., Harris, J.H., Kandel, E. and Schultz, P.H. (1999). Effects of Market Reform on the Trading Costs and Depths of Nasdaq Stocks, Journal of Finance, 54(1), pp. 1-34.

Battalio, R., Greene, J. and Jennings, R. (1997). Do Competing Specialists and Preferencing Dealers Affect Market Quality? Review of Financial Studies, 10(4), pp. 969-993.

Battig, C. and Chelley-Steeley, P.L. (2010). The Impact of the Closing Call Auction: An Examination of Effects in London, Applied Financial Economics, 20, pp. 303-315.

Bennett, P. and Wei, L. (2006). Market Structure, Fragmentation, and Market Quality, Journal of Financial Markets, 9, pp. 49-78.

Bessembinder, H. (2003a). Issues in Assessing Trade Execution Costs, Journal of Financial Markets, 6, pp. 233-257.

Bessembinder, H. (2003b). Trade Execution Costs and Market Quality after

Decimalization, Journal of Financial and Quantitative Analysis, 38(4), 747-777.

Bessembinder, H. and Kaufman, H. (1997). A Cross-Exchange Comparison of Execution Costs and Information Flow for NYSE-listed Stocks, Journal of Financial Economics 46, pp. 293-319.

Bessembinder, H. and Kaufman, H. (1998). Trading Costs and Volatility for Technology Stocks, Financial Analysts Journal, September/October, pp. 64-71.

Bhide, A. (1993). The Hidden Costs of Stock Market Liquidity, Journal of Financial Economics 34, pp. 31-51.

Binder, J.J. (1985). On the use of Multivariate Regression Model in Event Studies, Journal of Accounting Research, 23, pp. 370-383.

Blume, M.E. and Goldstein, M.A. (1992). Displayed and Effective Spreads by Market, Working Paper no. 27-92, Rodney L. White Center for Financial Research, University of Pennsylvania, Philadelphia, PA.

Boehmer, B. and Boehmer, E. (2003). Trading Your Neighbor's ETFs: Competition or Fragmentation? Journal of Banking and Finance, 27, pp. 1667-1703.

Boehmer, E. (2005). Dimensions of Execution Quality: Recent Evidence for U.S. Equity Markets, Journal of Financial Economics, 78, pp. 553-582.

Boehmer, E., Saar, G. and Yu, L. (2005). Lifting the Veil: An Analysis of Pre-trade Transparency at the NYSE, Journal of Finance, 60(2), pp. 783-815. 
Chaddad, F.R. and Cook, M.L. (2004). The Economics of Organization Structure Changes: A US Perspective on Demutualization, Annals of Public and Cooperative Economics, 75(4), pp. 575-594.

Chakrabarti, R. and Roll, R. (1999). Learning from Others, Reacting, and Market Quality, Journal of Financial Markets, 2, pp. 153-178.

Chelley-Steeley, P.L. (2008). Market Quality Changes in the London Stock Market, Journal of Banking and Finance, 32, pp. 2248-2253.

Chung, K.H. and Chuwonganant, C. (2009). Transparency and Market Quality: Evidence from SuperMontage, Journal of Financial Intermediation, 18, pp. 93-111.

Chung, K.H. and Chuwonganant, C. (2012). Regulation NMS and Market Quality, Financial Management, Summer, pp. 285-317.

Chung, K.H., Chuwonganant, C. and McCormick, D.T. (2004). Order Preferencing and Market Quality on NASDAQ Before and After Decimalization, Journal of Financial Economics, 71, pp. 581-612.

Chung, K.H., Elder, J. and Kim, J-C. (2010). Corporate Governance and Liquidity, Journal of Financial and Quantitative Analysis, 45(2), pp. 265-291.

Chung, K.H., Kang, J. and Kim, J-S. (2011). Tick Size, Market Structure, and Market Quality, Review of Quantitative Finance and Accounting, 36, pp. 57-81.

Cole, R.A. and Mehran, H. (1998). The Effect of Changes in Ownership Structure on Performance: Evidence from the Thrift Industry, Journal of Financial Economics, 50, pp. 291-317.

Cooper, S.K., Groth, J.C. and Avera, W.E. (1985). Liquidity, Exchange Listing, and Common Stock Performance, Journal of Economics and Business, 37, pp. 19-33.

Cordell, L.R., Macdonald, G.D. and Wohar, M.E. (1993). Corporate Ownership and the Thrift Crisis, Journal of Law and Economics, 36, pp. 719-756.

Demsetz, H. (1968). The Cost of Transacting, Quarterly Journal of Economics, 82(1), pp. 33-53.

Diether, K.B., Lee, K-H. and Werner, I.M. (2009). It's SHO Time! Short-Sale Price Tests and Market Quality, Journal of Finance, 64(1), pp. 37-73.

Domowitz, I. and Steil, B. (2001). Automation, Trading Costs, and the Structure of the Securities Trading industry, in Davis, E. and Steil, B. (Eds) Institutional Investors, MIT Press, London, pp. 347-397. 
Easley, D., Kiefer, N.M., O’Hara, M. and Paperman, J.B. (1996). Liquidity, Information, and Infrequently Traded Stocks, Journal of Finance, 51(4), pp. 1405-1436.

Esty, B.S. (1997). Organizational Form and Risk Taking in the Savings and Loan Industry, Journal of Financial Economics, 44, pp. 25-55.

Fama, E.F. and French, K.R. (1992). The Cross-Section of Expected Stock Returns, Journal of Finance, 47(2), pp. 427-465.

Finucane, T.J. (2000). A Direct Test of Methods for Inferring Trade Direction from IntraDay Data, Journal of Financial and Quantitative Analysis, 35(4), pp. 553-576.

Frino, A., Lecce, S. and Lepone, A. (2011). Short-Sales Constraints and Market Quality: Evidence from the 2008 Short-Sales Bans, International Review of Financial Analysis, 20, pp. 225-236.

Geranio, M. and Lazzari, V. (2014). Exchanges Competition in Listing Services: Evidence for Italian Companies, Economic Notes, 43(3), pp. 283-307.

Goyenko, R.Y., Holden, C.W. and Trzcinka, C.A. (2009). Do liquidity measures measure liquidity?, Journal of Financial Economics, 92, pp. 153-181.

Ghysels, E. and Cherkaoui, M. (2003). Emerging Markets and Trading Costs: Lessons from Casablanca, Journal of Empirical Finance, 10, pp. 169-198.

Harris, L. (1994). Minimum Price Variations, Discrete Bid-Ask Spreads, and Quotation Sizes, Review of Financial Studies, 7, pp. 149-178.

Hart, O. and Moore, J. (1996). The Governance of Exchanges: Members' Cooperative versus Outside Ownership, Oxford Review of Economic Policy, 12(4), pp. 53-69.

Hasan, I., Malkamäki, M. and Schmiedel, H. (2003). Technology, Automation, and Productivity of Stock Exchanges: International Evidence, Journal of Banking and Finance, 27, pp. 1743-1773.

Hasbrouck, J. (1993). Assessing the Quality of a Security Market: A New Approach to Transaction-cost Measurement, Review of Financial Studies, 6, pp.191-212.

Hasbrouck, J. and Schwartz, R.A. (1988). Liquidity and Execution Costs in Equity Markets, Journal of Portfolio Management, 14, pp. 10-16.

Hendershott, T. and Jones, C.M. (2005). Trade-Through Prohibitions and Market Quality, Journal of Financial Markets, 8, pp. 1-23.

Hendershott, T. and Moulton, P.C. (2011). Automation, Speed, and Stock Market Quality: The NYSE's Hybrid, Journal of Financial Markets, 14, pp. 568-604. 
Jacoby, G. and Zheng, S.X. (2010). Ownership Dispersion and Market Liquidity, International Review of Financial Analysis, 19, pp. 81-88.

Jain, P.K. (2005). Financial Market Design and the Equity Premium: Electronic versus Floor Trading, Journal of Finance, 60(6), pp. 2955-2985.

Jensen, M. and Meckling, W. (1976). Theory of the Firm: Managerial Behavior, Agency Costs and Ownership Structure, Journal of Financial Economics, 4, pp. 305-360.

Jiang, C.X., Kim, J.C. and Wood, R.A. (2011). A Comparison of Volatility and Bid-Ask Spread for NASDAQ and NYSE after Decimalization, Applied Economics, 43, pp. 12271239.

Kale, J.R. and Loon, Y.C. (2011). Product Market Power and Stock Market Liquidity, Journal of Financial Markets, 14, pp. 376-410.

Kam, T-K., Panchapagesan, V. and Weaver, D.G. (2003). Competition among Markets: The Repeal of Rule 390, Journal of Banking and Finance, 27, pp. 1711-1736.

Keim, D.B. and Madhavan, A. (1998). The Cost of Institutional Equity Trades, Financial Analysts Journal, July/August, pp. 50-69.

Kedia, S. and Zhou, X. (2011). Local Market Makers, Liquidity and Market Quality, Journal of Financial Markets, 14, pp. 540-567.

Kothari, S.P. and Warner, J.B. (2007) Econometrics of Event Studies in Eckbo, B.E. (Eds) Handbook of Corporate Finance: Empirical Corporate Finance: 1, North Holland, pp. 3-36.

Krishnamurti, C., Sequeira, J.M. and Fangjian, F. (2003). Stock Exchange Governance and Market Quality, Journal of Banking and Finance, 27, pp. 1859-1878.

Kumar, R., Sarin, A. and Shastri, K. (1998). The Impact of Options Trading on the Market Quality of the Underlying Security: An Empirical Analysis, Journal of Finance, 53(2), pp. 717-732.

Lai, H-N. (2007). The Market Quality of Dealer versus Hybrid Markets: The Case of Moderately Liquid Securities, Journal of Business Finance and Accounting, 34(1) \& (2), pp. 349-373.

Larrymore, N.L. and Murphy, A.J. (2009). Internationalization and Market Quality: An Empirical Investigation, Journal of Financial Research, 32(3), Pages 337-363.

Lee, C.M.C. and Ready, M.J. (1991). Inferring Trade Direction from Intraday Data, Journal of Finance, 46(2), pp. 733-746. 
Lee, H. (2008). Implementation of Pre-Opening Session and Market Quality: An Empirical Study on the Hong Kong Stock Market, International Journal of Finance, 20(3), pp. 4884-4909.

Lee, R. (2002). The Future of Securities Exchanges, Brookings-Wharton Papers on Financial Services, pp. 1-33.

Madhavan, A. (1996). Security Prices and Market Transparency, Journal of Financial Intermediation, 5, pp. 255-283.

Madhavan, A. (2000). Market Microstructure: A Survey, Journal of Financial Markets, 3, pp. 205-258.

Malinova, K. and Park, A. (2015). Subsidizing Liquidity: The Impact of Make/Take Fees on Market Quality, Journal of Finance, 70(2), pp. 509-536.

Marsh, I.W. and Payne, R. (2012). Banning Short Sales and Market Quality: The UK's Experience, Journal of Banking and Finance, 36, pp. 1975-1986.

Masulis, R.W. (1987). Changes in Ownership Structure: Conversions of Mutual Savings and Loans to Stock Charter, Journal of Financial Economics, 18, pp. 29-59.

Maug, E. (1998). Large Shareholders as Monitors: Is There a Trade-Off between Liquidity and Control? Journal of Finance, 53(1), pp. 65-98.

Mayers, D. and Smith, C.W. (1986). Ownership Structure and Control: The Mutualization of Stock Life Insurance Companies, Journal of Financial Economics, 16, pp. 73-98.

McInish, T.H. and Wood, R.A. (1992). An Analysis of Intraday Patterns in Bid/Ask Spreads for NYSE Stocks, Journal of Finance, 47(2), pp. 753-764.

Mendelson, H. (1987). Consolidation, Fragmentation, and Market Performance, Journal of Financial and Quantitative Analysis, 22(2), pp. 189-208.

Mendiola, A. and O'Hara, M. (2003). Taking Stock in Stock Markets: The Changing Governance of Exchanges, Working Paper, Cornell University.

Nielsson, U. (2009). Stock Exchange Merger and Liquidity: The Case of Euronext, Journal of Financial Markets, 12, pp. 229-267.

NYSE (2005). NYSE Market Quality Benefits Issuers and Investors, The Exchange, 12(2), pp. 1-2, http://www.nyse.com/pdfs/02-05 newsletter_full.pdf, Accessed December 4, 2012, 
O’Hara, M. and Ye, M. (2011). Is Market Fragmentation Harming Market Quality? Journal of Financial Economics, 100, pp. 459-474.

Odders-White, E, R, (2000). On the Occurrence and Consequences of Inaccurate Trade Classification, Journal of Financial Markets, 3, pp. 259-286.

Oldford, E and Otchere, I. (2011). Can Commercialization Improve the Performance of Stock Exchanges Even without Corporatization? Financial Review, 46, pp. 67-87.

Otchere, I. (2006). Stock Exchange Self-Listing and Value Effects, Journal of Corporate Finance, 12, pp. 926-953.

Otchere, I. and Abou-Zied, K. (2008). Stock Exchange Demutualization, Self-listing and Performance: The Case of the Australian Stock Exchange, Journal of Banking and Finance, 32, pp. 512-525.

Pagano, M. (1989). Trading Volume and Asset Liquidity, Quarterly Journal of Economics, 104, pp. 255-274.

Pagano, M. S. and Schwartz, R.A. (2003). A Closing Call's Impact on Market Quality at Euronext Paris, Journal of Financial Economics, 68, pp. 439-484.

Pástor, L. and Stambaugh, R.F. (2003). Liquidity Risk and Expected Stock Returns, Journal of Political Economy, 111, pp. 642-685.

Peterson, M.A. and Fialkowski, D. (1994). Posted versus Effective Spreads: Good Prices or Bad Quotes? Journal of Financial Economics, 35, pp. 269-292.

Peterson, M.A. and Sirri, E.R. (2003). Order Preferencing and Market Quality on U.S. Equity Exchanges, Review of Financial Studies, 16(2), pp. 385-415.

Pirrong, C. (2000). A Theory of Financial Exchange Organization, Journal of Law and Economics, 43, pp. 437-471.

Porter, D.C. and Weaver, D.G. (1997). Tick Size and Market Quality, Financial Management, 26(4), pp. 5-26.

Reiffen, D. and Robe, M. (2011). Demutualization and Customer Protection at SelfRegulatory Financial Exchanges, Journal of Futures Markets, 31(2), pp. 126-164.

Riordan, R. and Storkenmaier, A. (2012). Latency, Liquidity and Price Discovery, Journal of Financial Markets, 15, pp. 416-437.

Roll, R. (1984). A Simple Implicit Measure of the Effective Bid- Ask Spread in an Efficient Market, Journal of Finance, 39(4), pp. 1127-1139. 
Sadka, R. (2006). Momentum and Post-Earnings-Announcement Drift Anomalies: The Role of Liquidity Risk, Journal of Financial Economics, 80, pp. 309-349.

Schwartz, R.A. (1988). Equity Markets, Harper and Row, New York.

Scullion, M. (2001). Demutualisation: The Challenges facing Global Exchanges, in The Compaq Handbook of World Stock, Derivative and Commodity Exchanges, Mondo Visione, $\mathrm{pp} \mathrm{xxv}-\mathrm{xxxii}$

Seppi, D.J. (1997). Liquidity Provision with Limit Orders and a Strategic Specialist, Review of Financial Studies, 10(1), pp. 103-150.

Serifsoy, B. (2008). Demutualization, Outsider Ownership, and Stock Exchange Performance: Empirical Evidence, Economics of Governance, 9, pp. 305-339.

Shin, J-S. (1987). Aggregation and the Endogeneity Problem, International Economic Journal, 1(1), pp. 57-65.

Smith, B.F., D.A. Turnbull, and White, R.W. (2006). The Impact of Pennies on the Market Quality of the Toronto Stock Exchange, Financial Review, 41, pp. 273-288.

Steil, B. (2002). Changes in the Ownership and Governance of Securities Exchanges: Causes and Consequences, Brookings-Wharton Papers on Financial Services, pp. 61-91.

Stoll, H.R. (1978). The Supply of Dealer Services in Securities Markets, Journal of Finance, 33(4), pp. 1133-1151.

Stoll, H.R. (2000). Friction, Journal of Finance, 55(4), pp. 1479-1514.

Sun, Q., Tong, W.H.S. and Yan, Y. (2009). Market Liberalization within a Country, Journal of Empirical Finance 16, pp. 18-41.

Tse, Y. and Erenburg, G. (2003). Competition for Order Flow, Market Quality, and Price Discovery in the NASDAQ 100 Index Tracking Stock, Journal of Financial Research, 26(3), pp. 301-318.

Venkataraman, K. (2001). Automated Versus Floor Trading: An Analysis of Execution Costs on the Paris and New York Exchanges, Journal of Finance, 56(4), pp. 1445-1485.

Zhao, X. and Chung, K.H. (2007). Information Disclosure and Market Quality: The Effect of SEC Rule 605 on Trading Costs, Journal of Financial and Quantitative Analysis, 42, 3, pp. 657-682. 


\section{Appendix 2A: List of Demutualized and Mutualized Stock Exchanges}

\begin{tabular}{|c|c|c|c|c|c|}
\hline Exchange & Demutualized & Demutualization Date & IPO & Listing Date & Development Stage \\
\hline American SE & Yes & $3 / 23 / 2006$ & & & Developed \\
\hline Amman SE & No & & & & Emerging \\
\hline Athens Exchange & Yes & 7/13/1999 & Yes & $7 / 28 / 2000$ & Developed \\
\hline Australian SE & Yes & $10 / 13 / 1998$ & Yes & $10 / 14 / 1998$ & Developed \\
\hline BM\&FBOVESPA & Yes & 9/19/2007 & Yes & $11 / 28 / 2007$ & Emerging \\
\hline BME Spanish Exchanges & Yes & $2 / 15 / 2002$ & Yes & $7 / 14 / 2006$ & Developed \\
\hline Bombay SE & Yes & $5 / 19 / 2005$ & & & Emerging \\
\hline Budapest SE & Yes & $7 / 1 / 2002$ & & & Emerging \\
\hline Buenos Aires SE & No & & & & Emerging \\
\hline Bursa Malaysia & Yes & $4 / 14 / 2004$ & Yes & $3 / 18 / 2005$ & Emerging \\
\hline Colombo SE & No & & & & Emerging \\
\hline Cyprus SE & No & & & & Developed \\
\hline Deutsche $B \div$ rse & Yes & $2 / 5 / 2001$ & Yes & $2 / 5 / 2001$ & Developed \\
\hline Egyptian Exchange & No & & & & Emerging \\
\hline Hong Kong Exchanges & Yes & $3 / 7 / 2000$ & Yes & $6 / 27 / 2000$ & Developed \\
\hline Indonesia SE & No & & & & Emerging \\
\hline Istanbul SE & Yes & $1 / 2 / 2013$ & & & Emerging \\
\hline Jasdaq & Yes & $2 / 2 / 2001$ & & & Developed \\
\hline Johannesburg SE & Yes & $7 / 1 / 2005$ & Yes & $7 / 1 / 2005$ & Emerging \\
\hline Korea Exchange & Yes & $1 / 19 / 2005$ & & & Emerging \\
\hline Lima SE & Yes & $1 / 4 / 2003$ & & & Emerging \\
\hline London SE & Yes & $3 / 15 / 2000$ & Yes & $7 / 20 / 2001$ & Developed \\
\hline Mexican Exchange & Yes & $6 / 13 / 2008$ & Yes & $6 / 13 / 2008$ & Emerging \\
\hline MICEX & Yes & $12 / 8 / 2011$ & Yes & $2 / 15 / 2013$ & Emerging \\
\hline NASDAQ OMX & Yes & $1 / 18 / 2001$ & Yes & $7 / 1 / 2002$ & Developed \\
\hline NASDAQ OMX Nordic Copenhagen & Yes & $1 / 2 / 1993$ & & & Developed \\
\hline New Zealand Exchange & Yes & $12 / 31 / 2002$ & Yes & $6 / 4 / 2003$ & Developed \\
\hline NYSE Euronext (Europe) & Yes & $9 / 22 / 2000$ & Yes & $7 / 10 / 2001$ & Developed \\
\hline NYSE Euronext (US) & Yes & $3 / 7 / 2006$ & Yes & $3 / 7 / 2006$ & Developed \\
\hline OMX Nordic Exchange Copenhagen & Yes & $1 / 2 / 1993$ & Yes & $1 / 1 / 1993$ & Developed \\
\hline Osaka SE & Yes & $4 / 1 / 2001$ & Yes & $4 / 2 / 2004$ & Developed \\
\hline Oslo Børs & Yes & $4 / 25 / 2001$ & Yes & $5 / 28 / 2001$ & Developed \\
\hline Philippine SE & Yes & $8 / 3 / 2001$ & Yes & $12 / 15 / 2003$ & Emerging \\
\hline Santiago SE & No & & & & Emerging \\
\hline Saudi Stock Market - Tadawul & No & & & & Emerging \\
\hline Shanghai SE & No & & & & Emerging \\
\hline Shenzhen SE & No & & & & Emerging \\
\hline The Stock Exchange of Thailand & No & & & & Emerging \\
\hline TSX Group & Yes & $4 / 4 / 2000$ & Yes & $11 / 12 / 2002$ & Developed \\
\hline
\end{tabular}




\begin{tabular}{lccccc}
\hline Exchange & Demutualized & Demutualization Date & IPO & Listing Date & Development Stage \\
\hline Warsaw SE & Yes & $11 / 10 / 2010$ & Yes & $11 / 9 / 2010$ & Emerging \\
Wiener Börse & Yes & $6 / 4 / 1999$ & & & Developed \\
\hline
\end{tabular}




\title{
4 Essay Three: Stock Exchange Mergers and Market Power
}

\author{
Abstract \\ Whereas stock exchange mergers can lead to increased efficiency, the increasing level of \\ concentration can potentially lead to the exercise of market power in the industry. We \\ investigate whether or not stock exchange mergers lead to the exercise of market power \\ and find that stock exchange mergers have not led to the exercise of market power. Not \\ only do we find that industry concentration levels have not increased (and do not \\ influence exchanges' profitability) in the post-merger period, but we also find that the \\ profitability of the merging exchanges in the post-merger period is largely influenced by \\ efficiencies in revenue generation and cost management. We further find that non- \\ merging rival exchanges suffer efficiency losses in the post-merger period. Given that our \\ results do not show that the six stock exchange mergers led to the exercise of market \\ power, we maintain that there is no immediate need for regulatory agencies to be \\ concerned about stock exchange mergers leading to the exploitation of market power to \\ the detriment of consumer welfare. On the contrary, the cost and revenue efficiency \\ benefits resulting from the mergers will, ceteris paribus, be beneficial to all stakeholders.
}

\subsection{Introduction}

Stock exchange mergers and acquisitions continue to gain prominence over the years largely because of the expected gains from these combinations. Although there are 
several sources of gains that can emanate from mergers and acquisitions ${ }^{19}$, efficiency gains and market power gains are two of the most important sources of gains that have gained currency in the extant literature over time. Leonard (1964) for example notes that while "any merger may result in greater efficiency, it tends to lessen competition" (pp. 30). Whereas efficiency gains are positively perceived because of the possibility that improvements in efficiency can lead to lower prices, gains resulting from market power are regarded in a negative light because they lessen competition and can have detrimental effects (such as price increases or output reductions) on consumer welfare. As Sullivan (1974) observed, the higher profitability linked to market power is generally "condemned because it implies higher prices, restricted output and consequently allocative inefficiency" (pp. 1407).

The conventional expectation is that mergers and acquisitions, especially horizontal mergers "among a subset of firms in the same market may reduce competition by reducing the number of firms and increasing concentration" (Levin, 1990, pp. 1238). As the number of firms is reduced and market concentration increases, the remaining firms (i.e. merged firms as well as rivals) can potentially exercise market power by either charging higher prices or restricting output (which, as the laws of demand and supply predict, will inevitably lead to price increases). Thus, if market power is exercised, then it is not only the merging exchanges that gain but rivals will also gain and will therefore

\footnotetext{
${ }^{19}$ In their comprehensive review of the literature on mergers and acquisitions from several disciplines, Haleblian et al. (2009) identified several reasons why firms acquire which they grouped into (i) value creation motives such as market power, efficiency, resource redeployment and market discipline of ineffective managers; (ii) managerial self-interest (i.e. value destruction) drivers such as compensation, hubris and target defense tactics; (iii) environmental factors such as environmental uncertainty, resource dependence, imitation, regulation and networks ties; and, (iv) firm characteristics such as acquisition experience and firm strategy and position.
} 
react positively to mergers involving competitors. This relationship between mergers, market concentration and market power has been variously labelled in the literature including being referred to as the market concentration doctrine and the market power hypothesis. According to Eckbo (1985), the market concentration doctrine - which is hinged on the notion that the level of industry concentration is a reliable indicator of the industry's market power - predicts that a horizontal merger is more likely to have collusive, anticompetitive effects the greater the merger-induced change in industry concentration.

The theoretical predictions of the market power doctrine seem to be somewhat validated empirically - based on evidence gleaned from (some) industries such as airlines and banking - that, in general, link mergers to the exercise of market power with its attendant negative welfare consequences for consumers. In the banking industry, for example, Berger et al. (1999), based on a comprehensive review of the empirical evidence, conclude that banks in more concentrated markets charge higher rates. Acknowledging the negatives of the exercise of market power in the banking industry are authors such as Karceski et al. (2005), who assert that increases in market power could result in higher prices, lower quality, and fewer financial products, and Hankir et al. (2011), who note that firms with significant market power may be able to "demand higher prices, thereby maximizing their profits by exploiting consumer surplus" (pp. 2343). Kim and Singal (1993) also find that airline mergers lead to airfare increases of about $10 \%$ and Maudos and Guevara (2007) report that welfare loss from the misallocation of resources attributable to market power represented about $0.54 \%$ of the GDP of the European Union 
in 2002. In fact, the detrimental effects of significant market power (stemming from mergers and acquisitions) are so much frowned upon that a number of countries, including the US and Canada, have antitrust laws that can be invoked to quash proposed mergers which will increase market power and significantly dampen competition in a market. Kokkoris and Olivares-Caminal (2008) attest to this when they note that any proposed stock exchange merger that is in breach of competition laws might not take place. Exemplifying this is the European Commission's vetoing, in 2012, the proposed merger between Deutsche Boerse and NYSE Euronext on the grounds that the merger would hurt competition by creating a quasi-monopoly (with a combined market share of over 90\%) in the area of European financial derivatives traded globally on exchanges (European Commission, 2012; Bloomberg, 2012; Economist, 2012).

But while the popular belief is that merging firms (in highly concentrated industries) wielding considerable market power may be apt to exploiting the consumer in the form of higher prices or reduced output, it is also possible that merging firms could positively impact consumer welfare if their bigness "produces greater efficiency, lower costs, more research and product improvement” (Leonard, 1964, pp. 28). Indeed, Stillman (1983), Eckbo (1983; 1985; 1992), Eckbo and Wier (1985), Fee and Thomas (2004) and Devos et al. (2009) - among others - demonstrate empirically that mergers and acquisitions do not necessarily lead to the exercise of market power.

The theoretical arguments and the (sometimes differing) empirical evidence presented in the numerous studies examining the market power effects of industries experiencing 
mergers and acquisitions activities demonstrate the importance of studying market power effects in industries experiencing merger activities. And with stock exchange mergers gaining momentum in recent years, studying the market power effects of these mergers is necessary and timely. Furthermore, since every merger reduces the number of players and narrows competition (Hankir et al., 2011), the possibility that the increasing popularity of stock exchange mergers are leading to significant market concentration and market power that could lessen competition in the industry with relatively few players (given that in most countries except the US there is only one main stock exchange) cannot be discounted. Hasan et al. (2012) highlight this possibility of reduced competition in the industry when they "acknowledge that the consolidation of exchanges may reduce competition" (pp. 495). Kokkoris and Olivares-Caminal (2008) further buttress this possibility when they note that the "threat of head-to-head competition for the trading of equities conducted on an incumbent stock exchange places competitive constraints on the incumbent, and any merger between a potential entrant and the incumbent will remove these competitive constraints, possibly allowing the merged entity to behave anticompetitively" (pp. 858).

These arguments point to the likelihood that with the possible increasing market concentration (as a result of stock exchange mergers), these mega exchanges could exploit their growing market power to boost their profits by, for example, increasing the prices of services such as listing and trading (two main services provided by stock exchanges) as well as prices paid by third parties (e.g. data service providers) for the right to disseminate the exchanges' trading information (e.g. price data, trading volume, etc.). 
In addition to the above discussion establishing the importance of testing the market concentration doctrine in the stock exchange industry, there are other reasons for examining the implications of stock exchange mergers on market concentration, market power and investor welfare. First, it is not certain that an increase in market concentration results in increased market power. While some industries are susceptible to increased market power as a result of increased market concentration, other industries seem to be immune to this - and irrespective of the level of concentration, there does not seem to be any significant increase in market power in these industries. For example, Coase (1972) argues that in the durable goods industry, price appears to be independent of the number of suppliers and is usually always equal to the competitive price. Because of the special role stock exchanges play in the allocation of resources in market economies, there is the chance that higher concentration could affect market efficiency and the economy as a whole. It is therefore crucial to establish whether or not the stock exchange industry is an industry that enjoys market power as a result of possible increased market concentration resulting from mergers and acquisitions. Second, even when there is increased market power as a result of mergers, it does not mean that the increased market power will be used in ways inimical to consumer welfare. As Holt (1989) notes, even though theory may suggest that mergers can lead to market power, market power may not be exercised in reality. Holt (1989) argues that empirical work is needed to establish whether or not market power is exercised as a result of mergers. Third, if there are indeed negative investor welfare consequences associated with stock exchange mergers, are these consequences severe enough to warrant intervention by regulators? 
To ascertain whether or not stock exchange mergers are leading to the exercise of market power and/or are breaching competition laws, we investigated the market power implications of six major financial exchange mergers using data on some 53 stock exchanges over the five years before each merger consummation and five years after each merger completion date (starting from year 2 to year 6). The six mergers we examine are the NYSE-Euronext merger, the NASDAQ-OMX merger, the London Stock Exchange (LSE) and Borsa Italiana (BI) merger, the Deutsche Boerse-International Securities Exchange Holdings, Inc. (ISE) merger, the NYSE-Archipelago merger and the Chicago Mercantile Exchange's (CME) merger with Chicago Board of Trade (CBOT). Our choice of these mergers involving exchanges with average monthly value of share trading of at least US\$100 billion is hinged on the fact that these mergers are likely to have significant effects on competitors in the industry, and are therefore good candidates for finding any market power effects - if indeed there is the exploitation of market power as a result of stock exchange mergers.

Our results show that the six stock exchange mergers have not led to any significant increase in industry concentration as proxied by the Herfindahl-Hirschman Index (HHI) and four-firm concentration ratio (CR4). While monthly trend analysis shows that the $\mathrm{HHI}$ increased in the first twelve months following the merger completions, it is actually significantly lower in the five years after the merger completions (starting from year 2 to year 6) compared to the five years before the merger completion dates. Also, gauging industry concentration using the four-firm concentration ratio shows that the mergers 
have not led to any significant increase in concentration in the post-merger period. Indeed, we find that the four-firm concentration ratio actually decreased $13 \%$ in the five years of the post-merger period compared to the five years of the pre-merger period. At the exchange level, using market share (our proxy for market power) does not indicate the exercise of market power either - as the market share coefficient, instead of being positively related to profits in the post-merger period, is mostly insignificantly or significantly negatively related to profits. Conversely, our results show that the mergers have led to improved cost efficiency in the stock exchange industry - with mean (median) cost efficiency, operationalized as total expenses to total assets, significantly improving by about $62 \%(33 \%)$ in the five years following the merger completion dates compared to the five years before the merger completion dates.

When we estimated separate seemingly unrelated regression (SUR) models for the merging exchanges and rivals, our results show that the profitability of the merging exchanges in the post-merger period is largely related to sales efficiency and expense efficiency but not to industry concentration or the stock exchanges' market share (our proxy for market power). These findings broadly signify that the stock exchange mergers have largely delivered efficiency gains to the exchanges involved. Our results are therefore supportive of arguments advanced by authors such as Economides (1993) and Di Noia (2001) - to the effect that financial exchange consolidations are likely hinged on grounds other than the exercise of market power. For the rivals, we do not find evidence of efficiency gains - as the expenses to assets ratio in the post-merger period is positively 
(instead of negatively) related to profits and the sales to assets ratio in the post-merger period is negatively (instead of positively) related to profitability.

Thus, although the six stock exchange mergers appear to be creating mega exchanges, we do not find any evidence to support the notion that these mega exchanges are exploiting investors through the exercise of market power. On the contrary, these mergers are creating operationally efficient stock exchanges which are cost efficient and have an enhanced motivation to generate more revenues (i.e. are revenue efficient). While the merging exchanges enjoy efficiency improvements, rivals appear to be burdened with competitive disadvantages in the post-merger period. Our results support our central position that because of the increasing competition in the stock exchange industry as a result of technological advancements, globalization/internalization and liberalization, stock exchanges have to compete on multiple dimensions (e.g. price, speed of execution, etc.) in order to survive and remain relevant in an industry with falling entry barriers. As a result, we submit that stock exchange mergers will be motivated by efficiency gains rather than market power gains. Mergers hinged on market power benefits will jeopardize the competitive position of the exchanges exploiting market power because the intense competition will almost certainly induce most rival exchanges (especially low cost rivals such as ECNs) to "stay the course" and not partake in market power exploitation in order to wrestle business (e.g. order flow and market share) from exchanges exploiting market power following the mergers. The desire to maintain and/or improve their own competitive position will therefore, we argue, motivate exchanges to merge for efficiency reasons rather than for market power exploitation. 
Given the objective of examining the market power implications of stock exchange mergers, our study has bridged this significant gap in the literature by examining the market power implications of six stock exchange mergers. While our research, to the best of our knowledge, is the first formal empirical test of stock exchange mergers and the market power hypothesis, it should be noted again that a number of studies have looked at this issue in other industries, including the banking industry (e.g. Hankir et al., 2011) and airline industry (e.g. Kim and Singal, 1993). Whereas our study is similar to the other studies in the other industries because they are all looking at the market power effects of mergers, our study differs because we examined the market power effects of mergers in the stock exchange industry, an industry which is unlike other industries - given that stock exchanges are not just firms but are also marketplaces for the transfer of risk capital from sellers to buyers. The only study on the stock exchange industry that talks about the effect of mergers on competition/market power, to our knowledge, is by Kokkoris and Olivares-Caminal (2008), and their study is a survey of the professional as well as the academic literature with no empirical testing of the market power hypothesis in the stock exchange industry. The conclusion from their review of the literature is that the effects of stock exchange mergers on competition are not likely to be significantly adverse. The empirical findings in this essay, which differ from Kokkoris and Olivares-Caminal (2008) because we empirically tested the market power hypothesis in the stock exchange industry, provides support for our hypothesis that the stock exchange mergers will not lead to the exercise of market power. 


\subsubsection{Benefits of Study}

With the central aim of helping illuminate our understanding of the market power ramifications of stock exchange mergers (on the merging as well as non-merging stock exchanges), we believe that the results of this essay make important contributions to the literature and also help practitioners.

\subsubsection{Contributions of Study to Academic Community}

The study has established, empirically, that rather than leading to the exercise of market power, the financial exchange mergers we examined have largely led to efficiency gains for the exchanges involved in these mergers while rivals appear to have suffered some competitive disadvantages. As the first study of the market power ramifications of stock exchange mergers, our results add to the developing literature on stock exchange mergers and the proliferating literature on market power.

\subsubsection{Policy Implications of Study}

The results of our study have important policy implications for regulators. Given that we do not find evidence to support the contention that stock exchanges are merging to exploit market power, the message to regulators may be that future consolidations in the stock exchange industry should be viewed positively (for the possible efficiency gains of such mergers) and not automatically be considered as anticompetitive and blocked on antitrust grounds or for fears of exchanges exploiting market power - unless the evidence regulators have about proposed future merger(s) conclusively support such a determination. 


\subsubsection{Organization of the Study}

The remainder of this essay proceeds as follows. Section two is devoted to a review of the relevant literature. The research questions we address are outlined in section three. Section four highlights the data and methodology and section five presents our results. Section six concludes the essay.

\subsection{Literature Review}

It needs no gainsaying that mergers, especially horizontal mergers, increase concentration because they reduce the number of firms in a field (Leonard, 1964, pp. 30). While companies engaged in mergers usually argue that the combinations are intended to improve efficiency, there is a mushrooming body of literature that suggests that the increasing concentration as a result of mergers usually lead to the exercise of significant market power in industries such as banking and airline. Theoretical support for the market power contention is provided by a number of authors including Eckbo and Wier (1985) who argue that in theory, horizontal mergers (i.e. mergers between competitors) can lead to accumulations of market power. The concern is that when firms amass significant market power, they typically tend to use that power in ways that can be inimical to consumer welfare. Given that this essay examines the market power implications of stock exchange mergers, the literature review is substantially concentrated on this topic. 


\subsubsection{Overview of Market Power}

Market power has been variously defined by different authors but the common theme among the various definitions revolves around being able to price products at levels higher than the competitive level. Landes and Posner (1981) for example define market power as "the ability of a firm (or a group of firms, acting jointly) to raise price above the competitive level without losing so many sales so rapidly that the price increase is unprofitable and must be rescinded" (pp. 937) or more simply, "the ability to set price above marginal cost” (pp. 939).

Since the exercise of market power involves charging prices above marginal costs or the competitive level, the general consensus seems to be that firms with significant market power tend to use it in ways that are detrimental to consumer welfare. Shaffer (2004) notes the fundamental policy concern over market power as being the elevation of prices above marginal cost, with its attendant reduction in output quantity below the competitive level. The negative consequences of market power on consumer welfare are generally frowned upon and regulators typically challenge proposed mergers that are deemed to result in significant market power increase.

Empirical studies on market power generally involve choosing a particular framework for the study and then evaluating the data empirically to determine whether or not there is indeed the exercise of market power. The two frameworks usually leveraged are the structure-conduct-performance (SCP) paradigm and the new empirical industrial organization (NEIO) models. Structure-conduct-performance tests usually measure the 
level of concentration in a market and relate it to performance (e.g. price, profits, etc.) whilst the new empirical industrial organization models use optimization models and equilibrium conditions to estimate the conduct parameter. Some measures used in SCP studies include the Herfindahl index and concentration ratios whereas the two main measures used in NEIO studies are the revenue test and markup test.

In the ensuring paragraphs of our literature review, we review the measures of market power and then summarize the large body of studies on market power (along industry lines wherever possible).

\subsubsection{Measuring Market Power}

Empirical studies of market power have generally followed two main strands of inquiry, viz., the structure-conduct-performance (SCP) tests or the new empirical industrial organization (NEIO) models (Shaffer, 2004).

\subsubsection{Structure-Conduct-Performance (SCP) Tests}

Usually used to demonstrate the effect of market concentration on competition, structureconduct-performance (SCP) tests typically measure the level of concentration in a market and relate it to performance (e.g. price, profits, etc.). The SCP paradigm, which is based on the notion that structure affects the conduct of firms, which ultimately determines their performance - predicts an increasing relationship between the level of market concentration and market power (Cetorelli, 1999), and "suggests that increasing market concentration leads to less competitive conduct in terms of higher prices and less output 
and results in higher profits" (Park, 2009, pp. 654). Barton and Sherman (1984) note that a vast body of empirical literature has demonstrated a positive statistical relationship between measures of industry structure, such as entry barriers and concentration, and average industry profit. Thus, the SCP paradigm postulates that fewer and larger firms are more likely to engage in anticompetitive conduct (Cetorelli, 1999).

The SCP framework is the most widely used methodology in studies of market power. In fact, regulatory agencies use the SCP methodology in assessing the antitrust implications of proposed mergers and acquisitions. Theoretical and empirical expositions on the SCP paradigm have been advanced by a number of authors. Bain (1951), for instance, hypothesizes that the average profit rate of firms in industries with high concentration will tend to be significantly larger than that of firms in less concentrated industries. Bain (1951) then demonstrates empirically, based on American manufacturing industries, that only the degree of seller concentration within industries is related to the size of profits or profit rates (and not other determinants like firm size, ratio of capital to total assets, ratio of overhead to total costs, ratio of net worth to sales, composition of purchasers as between producers and consumers, and durability of output).

However, the positive linear relationship between market concentration and market power espoused by the SCP paradigm has been critiqued on a number of grounds. Demsetz (1973) provides an alternative explanation that is counter to the SCP paradigm's prediction that a positive relationship between concentration and profits is symptomatic of the exercise of market power. According to Demsetz (1973), competitive superiority in 
producing and marketing products could explain the increased concentration and profitability (and not the exercise of market power). However, after analyzing a sample of 6,492 banks from 1969 to 1978 and finding that market share per se is a source of high profits - after controlling for variables such as firm size and explicit product differentiation, Rhoades (1985) questions Demsetz (1973) view that high profits of market leaders are due to efficiency rather than to some form of market power.

Despite its potential shortcomings, regulatory authorities rely on the SCP paradigm in challenging mergers deemed to be anticompetitive. According to Landes and Posner (1981), the standard method of proving market power in antitrust cases involves first defining a relevant market in which to compute the defendant's market share, then computing that market share, and then finally deciding whether it is large enough to support an inference of the required degree of market power. A number of measures have been used in studies employing the SCP tests including the Herfindahl-Hirschman index (HHI), concentration ratios, etc. These measures are briefly reviewed next.

\subsection{The Herfindahl-Hirschman Index}

The Herfindahl-Hirschman Index (HHI), which gauges an industry's concentration in a given market, is defined as the sum of squared market shares (Giroud and Mueller, 2011). The HHI gained international prominence when it was adopted as the primary market concentration guide by the U.S. Department of Justice in 1982 (White, 1987). 


\subsection{Concentration Ratios}

By showing the proportion of an industry's sales accounted for by the largest firms, concentration ratios $(\mathrm{CR})$ have also been used to determine the potential for the exercise of market power. Several variants of concentration ratios have been used including CR1, CR2, CR4, CR8, CR10, etc. By far, CR4 is the most widely used concentration ratio. White (1987) notes that the four-firm concentration ratio (CR4) represents the percentage of an industry's sales that are accounted for by the largest four sellers. White (1987) argues that when the $\mathrm{CR} 4$ exceeds the $50 \%$ to $60 \%$ range, there is the increased likelihood that an industry's behaviour might change (e.g. higher prices).

\subsection{Dynamic Measures of Market Structure}

Arguing that the HHI and CR are static measures of structure, Marlow and Wright (1987) advocate for the use of dynamic measures of structure in market power studies. The authors propose the use of changes in HHI and changes in CR as two dynamic measures of structure. However, they also propose two additional dynamic measures of structure for use in structure-conduct-performance studies, namely, mobility (defined as the number of changes in rank that occur among the three largest firms) and turnover (which represents the number of times that firms below the top three move into the top three). Marlow and Wright (1987) tested the relationship between profitability and structure (using the static $\mathrm{HHI}$ and $\mathrm{CR}$ as well as the dynamic measures of structure) and find that while the static HHI and CR and the dynamic changes in the HHI and CR were not significantly related to profitability, their two newly proposed dynamic measures of 
structure, mobility and turnover, were significantly negatively related to profitability as predicted.

\subsection{Firm Level SCP Measures of Market Power}

\subsection{Market Share}

Market share is the dominant measure used in the literature to determine the extent of market power enjoyed at the firm level. As Berger (1995) notes, firms with large market shares generally have well-differentiated products and may be able to exercise market power in the pricing of these products.

\subsection{Lerner's Index}

Lerner (1934) proposes a measure of monopoly power (now known as the Lerner index) as the divergence of price from marginal cost to price. By measuring the disparity between price and marginal costs expressed as a percentage of price, Turk-Ariss (2010) asserts that the Lerner index captures the essence of pricing power.

\subsection{Tobin's $Q$}

Lindenberg and Ross (1981) leveraged the pioneering insights of Tobin ${ }^{20}$ and argue that in the absence of barriers to entry and exit (as in competitive markets), Q will be driven down to one/unity as new firms enter (or existing firms expand if $Q$ is above 1). But in the case of a monopolist (who can successfully bar entry), monopoly rents in excess of the ordinary returns on the employed capital will be earned. Since the market will

\footnotetext{
${ }^{20}$ Tobin, who introduced the Tobin's Q or Q ratio, argues that if, at the margin, $\mathrm{Q}$ exceeds unity, firms would have an incentive to invest, since the value of their new capital investment would exceed its replacement cost.
} 
capitalize these rents, the market value of the monopolist will exceed the replacement cost of its capital stock - resulting in a $\mathrm{Q}$ ratio that will persist above one. The $\mathrm{Q}$ ratio is generally defined as the market value of reproducible real capital assets to the current replacement cost of those assets (Tobin and Brainard, 1977).

\subsubsection{New Empirical Industrial Organization (NEIO) Models}

The NEIO models are grounded in optimization techniques and equilibrium conditions. Delis and Tsionas (2009) assert that the focal point of the NEIO literature is pivoted on the "simultaneous estimation of a supply relation and a demand function so as to identify the so-called 'conjectural variation elasticity' or 'conduct parameter', which serves as a measure of market power" (pp. 1842). Gallet (1996) argues that the NEIO models are intended to mitigate one key shortcoming of SCP - the SCP's reliance on data across several industries and hence its overlooking of industry specific characteristics - by uncovering the "structure-performance relationship using time series data from a single industry" (pp. 221). Gallet (1996) notes that NEIO practitioners estimate the degree of market power from a system of demand and supply equations. The two main measures/tests of the NEIO models are markup test/model and revenue test/model.

\subsection{Markup Test}

The markup test/model "involves estimating a structural model with separate demand and supply equations, parameterizing the markup of price over estimated marginal cost as a measure of market power" (Shaffer, 2004, pp. 291). 


\subsection{Revenue Test}

The revenue test/model involves estimating "a reduced-form equation relating gross revenue to a vector of input prices and other control variables" (Shaffer, 2004, pp. 291).

\subsubsection{Market Power in the Banking Industry}

The literature on market power is replete with studies examining the effect that bank consolidations (especially in the US) have had on competition and consumer welfare. Most of the studies provide unassailable evidence that bank mergers by and large lead to the exercise of market power. In their comprehensive review of the literature on bank mergers, Berger et al. (1999) assert that most studies "usually found that banks in more concentrated markets charge higher rates on small business loans and pay lower rates on retail deposits" while other "studies found that in more concentrated markets, bank deposit rates were 'sticky' or slow to respond to changes in open-market interest rates, and that this stickiness was greater with respect to rate increases than decreases, consistent with market power" (pp. 153). Some studies corroborating the market power hypotheses in the banking industry are (i) Prager and Hannan (1998) - who find that participants in substantial horizontal mergers and their local market rivals exhibited greater reductions in deposit interest rates than banks operating only in markets where no such horizontal mergers took place; (ii) Kane (2000) - who finds that shareholders of large-bank acquirers gain value when a target is large and gain even more value when a target is headquartered in the same state (in-state competitor); and, (iii) Baltazar and Santos (2003) - who report that the market's reaction to the failed bank megamerger attempts in Canada is consistent with the Canadian market ascribing market power as the 
primary benefit of the mergers (not scale, scope or efficiency economies or access to government safety net subsidies). Fraser et al. (2011) assess the stock price response of commercial borrowers with loans outstanding at 12 large banks involved in megamergers and report that the wealth effects on these borrowers are highly negative, statistically significant, and economically important. Hankir et al. (2011) analyze the combined stock return patterns of targets, bidders and their peers upon takeover announcement and closing or withdrawal and find that there are more investors who believe in gains through the exploitation of market power ( $10.8 \%$ of all sample deals) by the post-merger entity than investors who believe in any of the other four motives of M\&A they tested (i.e. merger wave hypothesis, pre-emptive merger hypothesis, synergy hypothesis and financial distress hypothesis).

The adverse consequences of the exercise of market power stemming from increased concentration following bank mergers and acquisitions is not only restricted to unfavourable prices/interest rates but has also led to reduced output. Sapienza (2002) reports that small borrowers of target banks involved in mergers are less likely to borrow money (in the future) from the consolidated bank than small borrowers of banks that do not merge. The author observes that large banks that acquire small banks tend to cut off many more small borrowers than do other banks and concludes that as banks become larger, they reduce the supply of loans to small borrowers. Ryan et al. (2014) examine 118,000 SMEs across 20 European countries over the 2005-2008 period and find that increased market power results in increased financing constraints for SME. 
The numerous studies linking bank mergers to market power notwithstanding, there are studies that provide evidence to the contrary. Focarelli and Panetta (2003) take issue with conclusions on the adverse effects of in-market mergers on prices solely on the basis of short term analysis while ignoring effects that take a longer time to materialize. The authors investigate the long-run (i.e. nine years from 1990 to 1998) pricing effects of Italian mergers and find strong evidence that although consolidation does generate adverse price changes, these are temporary. In the short run, the authors find that inmarket mergers increase market power and lead to deposit rate changes that are unfavorable to consumers. In the long run, however, efficiency gains dominate the market power effect - as deposit rates of the banks involved in in-market mergers rise relative to the control sample - leading to more favorable prices for consumers. Shaffer (2004) studies four highly concentrated US banks and finds that the hypothesis of pure monopoly pricing is robustly rejected in favor of monopolistic competition. Weinberg (2005) studied five North Carolina markets and reports that while the behavior of banks in these markets is consistent with models in which mergers are motivated by the prospect of gains in market power, they are also consistent with the notion that mergers are one of the means by which industries evolve toward an efficient allocation of productive capacity among heterogeneous firms. Park (2009) studied the Korean banking industry which went through periods where the market concentration decreased before the Asian financial crisis in 1997 as a result of financial deregulation and then subsequently increased after the crisis as a result of bank consolidations. Despite the increase in market concentration, the author finds that the Korean banking industry was monopolistically competitive during the pre-crisis period (1992-1996) and the post-crisis 
period (2001-2004). Park (2009) therefore concluded that "bank competition has not been negatively affected by bank consolidation" (pp. 664). Coccorese (2009) studied single-branch Italian banks operating as monopolists in small local areas and find evidence strongly rejecting the hypothesis of pure monopoly pricing. Bendeck and Waller (2011) study consolidation in the banking industry and find that returns to bidders, targets and rivals are not affected by changes in concentration resulting from consolidation. Efthyvoulou and Yildirim (2014) find that while the significantly positive coefficient of the lagged Lerner Index in their regression models signify the persistence of market power over time, the estimated coefficient on their 'inefficiency' variable is significantly negative - leading the authors to conclude that their findings support the relative efficiency paradigm, which posits that firms earn superior profits because they are more efficient than other firms. Bremus (2015) theorize (and find evidence supporting the hypothesis) that both cross-border lending and bank FDI mitigate concentration.

While the evidence presented thus far tends to dichotomize the findings into market power effects and efficiency effects, Evanoff and Fortier (1988) raise the possibility that the efficiency and market power hypotheses are complementary. After finding that bank profits are positively influenced by market share (as proposed by the efficient structure thesis) and that for markets characterized by significant entry barriers, bank profits are positively influenced by market structure (as proposed by the traditional SCP paradigm), Evanoff and Fortier (1988) suggest that these competing hypotheses may actually be complementary theories. 


\subsubsection{Mergers and Market Power in the Airline Industry}

A number of studies on the effect of airline mergers on market power have also been conducted. Knapp (1990) examine the abnormal returns to rivals of nine airline mergers and finds that rival airlines experienced between $3 \%$ to $6 \%$ positive abnormal returns per merger event (with the cumulative effect of the 9 mergers being around $25 \%$ excess gain in rival value). These significant spillover benefits to rivals led the authors to conclude that "firms, if given the freedom, will combine to gain market power" (pp. 707). Kim and Singal (1993) examine the impact of airline mergers on airfares from 1985 to 1988 (a period of natural experimentation since airline mergers were not contested by the government) and find that routes affected by the airline mergers show increases in fares of about $10 \%$ relative to a control group of routes not affected by the mergers. The authors also find that the "price increases are positively correlated with changes in market concentration and do not appear to be the result of an improvement in quality or of an industry-wide contraction of air services to rectify a supply-demand imbalance" - and consequently conclude that the "price changes associated with airline mergers reveals evidence of the exercise of increased market power" (Kim and Singal, 1993, pp. 567).

Singal (1996) also examined the same airline mergers from 1985 to 1988 by integrating both product market data and stock market data and reports that both stock prices and product prices demonstrate that airline mergers enhance market power - although the mergers also lead to efficiency improvements for the companies involved in the mergers. For example, Singal (1996) estimates that rival airlines gain a significant $1.5 \%$ due to enhanced market power but also lose a significant $1.2 \%$ due to a more efficient merged 
firm. Hüschelrath and Müller (2015) find that while the 2009 merger between Delta Air Lines and Northwest Airlines led to short-term price increases of about $11 \%$ on overlapping routes and about $10 \%$ on routes that experienced a merger-induced switch of the operating carrier, they find, over the long-term, results that are consistent with the notion that merger efficiencies and the entry of competitors in the post-merger period led to a downward trend in price - leaving consumers with a small net price increase of about $3 \%$ on the affected routes.

\subsubsection{Market Power in Insurance and Thrift Industries}

The insurance industry and thrift industry are also two industries that have undergone demutualization over the years. A number of studies on market power have been conducted in the insurance industry. Bajtelsmit and Bouzouita (1998) examine the relationship between profitability and market structure in the automobile insurance industry and find that concentration has a significantly positive effect on profitability, even after controlling for regulatory and cost differences by state and over time.

Cummins et al. (1999) examine the efficiency implications of mergers and acquisitions in the US life insurance industry and find that firms engaged in acquisitions achieve greater efficiency gains than firms that have not been involved in mergers and acquisitions. Choi and Weiss (2005) test the market power and efficient structure hypotheses ${ }^{21}$ in the insurance industry from 1992 to 1998 and find that cost-efficient firms charge lower prices and earn higher profits - as predicted by the efficient structure hypothesis. But the authors did not find evidence supporting the market power hypothesis (as market share,

\footnotetext{
${ }^{21}$ The efficient structure hypothesis postulates that more efficient firms can charge lower prices than competitors - which enable them to capture larger market shares and economic rents - leading to increased concentration.
} 
their measure of market power, was negatively (rather than positively) related to price and profit). Bikker and van Leuvensteijn (2008) find that market power of insurance firms in the Netherlands is limited due to the existence of ample entry possibilities.

Most of the literature on thrifts is focused on the crises and failure of many thrift firms in the 1980 s and little attention has been paid to the market power implications of thrifts. This is probably due, in part, to the fact that demutualization in the thrift industry was largely encouraged by regulators after the insolvency of individual thrifts (Kroszner and Strahan, 1996) and not based on efficiency or economic reasons. It is therefore likely that after the thrifts demutualized, any subsequent acquisition might have been due to reasons other than market power and/or efficiencies (e.g. to salvage failing firms). Gosnell et al. (1993) discussed this view in their study examining the wealth transfer effects of federally assisted mergers - whereby bidders "identified the amount and types of federal assistance required for their involvement" (pp. 58) in the mergers. The few studies that touched on the market concentration question had different rationalizations for their results. Berger et al. (1999) report increases in concentration of the thrift industry but attributed this to the high rate of thrift failure in the late 1980s and early 1990s. However, Gan (2004) did demonstrate, using a sample of 252 thrifts, that market concentration leads to higher franchise value for thrifts and that "franchise value comes mainly from fewer competitors instead of from operating efficiency" (pp. 582) for urban thrifts. For rural thrifts, the author noted that performance was largely driven by management and operations. 


\subsubsection{Market Power Studies in Other Industries}

Studies of mergers and the exercise of market power have also been conducted in other industries. Sullivan (1974) studied 92 firms in 30 industries to determine if leverage could offer an alternative explanation to the observed higher profitability. But after finding that powerful firms in highly concentrated industries and industries with higher entry barriers used relatively less debt in their capital structures, Sullivan (1974) concludes that the "higher profitability of these firms presumably came from restricted output and noncompetitive pricing” (pp. 1411). Barton and Sherman (1984) investigated a case study of two acquisitions in the duplicating microfilm industry and find statistically significant increases in relative prices and notes that the estimated gain from raising prices was enough to recoup the cost of the acquisition in two years. Gallet (1996) examined four mergers in the steel industry and reports that while market power has been falling in recent years, two of the four mergers did boost market power.

The evidence linking mergers to the exercise of market power in the other industries, notwithstanding, there are a number of studies (largely based on the event study methodology) that do not find evidence supporting the market power hypothesis. In their review of the mergers and acquisitions literature, Jensen and Ruback (1983) assert that the evidence indicates that merger gains do not come from the acquisition of market power, but instead from some source of efficiencies that also appears to be available to rival firms in the industry. Jensen and Ruback's (1983) conclusion that gains to rivals were the result of efficiencies also available to the rivals was hinged on the fact that contrary to the market power hypothesis, there was no evidence of negative reactions to 
rivals when antitrust challenges were announced. Eckbo (1983) tests the collusion hypothesis of horizontal mergers ${ }^{22}$ using a sample of 259 mergers in the mining and manufacturing industries and finds little evidence of collusive, anticompetitive effects. Eckbo (1985) tests the market concentration doctrine and finds evidence of significant negative correlation between the industry wealth effect of merger announcements and merger-induced changes in concentration (represented by changes in the Herfindahl index).

Ghosh (2004) finds that the median market share of merging firms increases from $2.77 \%$ to $4.39 \%$ following acquisitions (reflecting a $58 \%$ increase relative to the market share in the previous year) while the median industry concentration only increases from 0.120 to 0.124 over the same period (i.e. a $3 \%$ relative increase). Also, in regressions of abnormal returns to merging firms' shareholders on changes in market share and changes in industry concentration, Ghosh (2004) finds the coefficient of changes in market share is positive and economically significant while the coefficient of changes in market concentration is negative and mostly insignificant. Fee and Thomas (2004) study the upstream and downstream product market effects of a sample of horizontal mergers from 1980 to 1997 and find little evidence of increased monopolistic collusion. Instead, the authors find evidence consistent with improved productive efficiency and buying power. Gugler and Siebert (2007) analyze empirically mergers and research joint ventures (RJVs) in the semiconductor industry and find that efficiency effects dominate market

\footnotetext{
${ }^{22}$ The collusion hypothesis predicts that horizontal mergers generate positive abnormal returns to stockholders of the bidder and target firms because they increase the probability of successful collusion among rival producers. Rival firms also benefit from the mergers since successful collusion limits output and raises product prices and/or lowers factor prices.
} 
power effects for both mergers and RJVs. Devos et al. (2009) decomposed synergy into a number of components and did not find market power to significantly contribute to synergy. Becher et al. (2012) examine the source of gains in 384 mergers in the electric and gas utility sector from 1980 to 2004 and find that while utility mergers create wealth for the combined bidder and target (results consistent with both synergy and collusion), the returns to rivals are positive in the regulated 1980-1992 period but become negative in the deregulated 1993-2004 period (results inconsistent with collusion).

All in all, despite the mixed evidence of increased market concentration on market power, the evidence seems to be leaning towards the conclusion that an increase in market concentration more frequently leads to the exercise of market power in industries such as banking and airlines. In other industries (e.g. durable goods), this relationship is either weak or non-existent.

\subsubsection{Potential Benefits of Market Power}

As the foregoing discussion demonstrates, the early conventional wisdom has been that a merger that increases market power or market concentration is always bad for society. As Weinberg (2005) notes, there is more likelihood of market prices deviating from the competitive ideal in more concentrated markets. However, this argument has become contentious over the years and many authors have cautioned against wholesale classification of every merger that increases market concentration/power as bad. In his groundbreaking work, Williamson (1968) posed the question that in cases where "efficiency and market power consequences exist, can economies be dismissed on the 
grounds that market power effects invariably dominate?” (pp. 18). Williamson (1968) answered this question using his Naïve Tradeoff Model (also referred to as the Williamson or Williamsonian tradeoff model) by demonstrating that for a merger that generates efficiencies and also enhances market power, a relatively modest cost reduction (or efficiency increase) "is usually sufficient to offset relatively large price increases" (pp. 23). Fisher et al. (1983) also show that "under less extreme assumptions, a merger that increased market power could lead to lower consumer prices with much smaller efficiencies, at a level that one could expect under more normal conditions" (pp. 1705). White (1987) however takes issue with the efficiency argument, asserting that efficiencies "are easy to promise, yet may be difficult to deliver", especially as diseconomies of large scale can easily set in due to managerial limitations, "unexpected corporate culture clashes and difficulties in melding two managerial and production systems" (pp. 18).

A number of authors have also identified specific benefits of market power. Peress (2010) hypothesizes that firms with greater market power have less volatile profits and returns and that their stock prices are less sensitive to noise shocks - which enhances their stock liquidity. The theoretical conjectures of the benefits of greater market power on liquidity have been bolstered by a number of empirical studies. Kale and Loon (2011) for example test the relationship between product market power and liquidity and find that product market power improves stock liquidity by lowering the variability of cash flows and returns. 
Peress (2010) also predicts other benefits of increased market power including less dispersed earnings forecasts. Empirical support for this prediction is provided by Datta et al. (2011) who document that firms' relative pricing power and their industry concentration are strong positive determinants of analysts' earnings forecast accuracy.

Some empirical evidence also leans toward the conclusion that market power may be good for firms in some environments. For example, Turk-Ariss (2010) examine the relationship between market power and bank stability using a sample of 821 banks in 60 developing countries and find a significant positive relationship between market power and bank profit efficiency as well as overall stability.

\subsection{Research Questions and Hypotheses}

As with mergers in other industries, market power gains and/or efficiency gains are two plausible outcomes that may be possible with stock exchange mergers. On the one hand, there is the possibility that stock exchange mergers are helping stock exchanges to become more efficient. On the other hand, there is the possibility that stock exchange mergers are helping create mega exchanges which are exercising market power to the detriment of consumers. White (1987) parsimoniously captured the dichotomy of mergers in his main and alternative hypotheses of mergers. On the one hand, the "more easily a group of sellers (who collectively might have market power) can coordinate and police their mutual actions, the more likely are they to approximate a monopoly outcome" with 
its potential effects of increases in prices and profits and yet on the other hand, it is possible that "it only takes two to make a horse race" (White, 1987, pp. 14).

From the literature review and foregoing discussion, while merger gains can come from market power in other industries, we argue, based on the nature of competition in the stock exchange industry, that gains from stock exchange mergers will not come from market power but instead from improvements in efficiencies. This contention is largely based on the nature of competition in the stock exchange industry. It has been indicated that stock exchanges compete on a number of factors including price and non-price factors such as technology, speed of order execution, depth of liquidity visible to market participants, likelihood of order execution and chances of order settlement (Kokkoris and Olivares-Caminal, 2008). We argue that this threat of competition from the multiple sources of competitive forces will constrain stock exchanges from exercising market power even if they potentially can. This argument is partly reinforced by some indirect evidence on stock exchange mergers by both Arnold et al. (1999) and Nielsson (2009) who do not find any evidence of increased trading costs as a result of the mergers they examine. If the mergers they examined had led to the exercise of market power, one would have expected increased cost of trading but since this was not the case in their studies, it can be surmised that market power was not a major issue.

If mergers reduce the number of players in the industry and the remaining players can manipulate prices and/or quantity, then rival exchanges will benefit from the mergers by their competitors. If so, one would expect a positive reaction by the rivals to the mergers 
since whatever rents the merged firms could extract from the increased concentration could also spread to the remaining players. However, because we contend that the gains to the merging entities (if any) will come from efficiencies and not from market power, we argue that rivals will suffer from the mergers because of the competitive disadvantages they will face competing with the larger merged exchanges. Accordingly, we hypothesize that:

HIa: Gains for stock exchanges involved in mergers will not come from the exercise of market power.

H1b: Gains for stock exchanges involved in mergers will come from efficiencies H2a: Rivals not involved in mergers will not experience any market power gains from stock exchange mergers.

H2b: Rivals not involved in mergers will experience efficiency losses from stock exchange mergers.

\subsection{Data and Methodology}

\subsubsection{Data}

In this study, because we examine the market power ramifications of six major financial exchange mergers - in part due to the fact that there are only a few realized stock exchange mergers, we use product market and financial statement data for all World Federation of Exchanges (WFE) member exchanges for which we could get data. This, we believe, will help increase the number of observations for our statistical analyses. We 
use monthly ${ }^{23}$ (and annual) data over sixty months (five years) before the merger completion dates and sixty months after the merger completion dates (starting from month 13 to month 72). We skip the first 12 months (i.e. the first year) after the merger completions because Rhoades (1993) notes that sufficient time is required for efficiency improvements to materialize following mergers and acquisitions. One potential issue with using a long time window is the possibility of other confounding factors contaminating the results. However, by controlling for other known determinants of profitability and using all other non-merging WFE member exchanges as the control group, any potential contamination is minimized. As Rhoades (1993) asserted, comparing the merger firms to a large control group should essentially control for other factors that affect the data.

To test our hypotheses, we collected exchange-level data (in US dollars) on several variables including value of share trading, aggregate domestic market capitalization of firms listed on the stock exchanges, revenues, cost of goods sold, total assets - among others - from two main sources. The product market data was collected from the World Federation of Exchanges (WFE) website (http://www.world-exchanges.org/statistics) and the financial statement data was collected from Capital IQ.

\subsubsection{Methodology}

In this essay, we conducted univariate analysis as well as multivariate analysis of the market power hypothesis using both industry-level and stock exchange-level measures of

\footnotetext{
${ }^{23}$ We pooled monthly product market data collected from the WFE website with annual financial statement data downloaded from Capital IQ. Several authors have also used monthly and annual data in regressions including Fama and French (2008) who estimated monthly regressions but some explanatory variables were updated only once a year.
} 
market power. While most studies test the market power doctrine using either firm-level data or industry-level data, this essay uses both exchange-level and industry-level data. Also, given the publicly available data (on stock exchanges) that we can access, the study uses measures that are based on the SCP (structure-conduct-performance) paradigm. Since the new empirical industrial organization (NEIO) models require data that we do not have access to (e.g. elasticity of demand information, prices of factors of production, etc.), we are unable to use these NEIO models in this study. In view of the fact that this study is conducting the market power analysis only in the stock exchange industry, the study is not heir to the main criticism of the SCP paradigm (i.e. that SCP tests based on multiple industries are problematical because they do not consider the industry-specificity that is relevant to tests of market power - see Gallet, 1996).

Methodologically, the study proceeded by first defining the confines of the stock exchange industry/market and then calculating the various measures of market concentration/power which are needed for inferring market power in studies using the SCP paradigm. Once the measures were calculated, we performed univariate analysis including t-tests of means and nonparametric z-tests of medians to determine if the means and medians of the various measures have significantly changed in the post-merger period compared to the pre-merger period. We then undertook multivariate analysis by regressing profits (our measure of firm performance) on a number of variables including measures of industry/market concentration, exchange-level market power measure and a number of control variables. Further details about our methodology are provided below. 


\subsubsection{Market Definition}

While most studies usually adopt a narrower definition of market in the determination of its concentration levels (e.g. Coccorese, 2009), we, in this essay, define market more broadly to include all WFE member stock exchanges. Several authors suggest a broader definition of market (consistent with the broad definition we used in this essay). Landes and Posner (1981) for example propose that output of distant producers (including foreign producers) should be included in figuring out "market shares in a local market even if there are transportation costs or tariffs" (pp. 938) and Kokkoris and OlivaresCaminal (2008) cited a report by the U.K. Competition Commission that suggests that the definition of relevant market for the provisioning of on-book equities trading should include "Europe and the United States, on the basis that exchanges in these regions place a competitive constraint through the threat of head-to-head competition" (pp. 853). Kokkoris and Olivares-Caminal (2008) also identify another source of competition among stock exchanges that support our broader definition of market. The authors argue that investors decide where to invest based on the cash-flow that they want to earn and that "different bundle of shares in two different stock exchanges can induce the same cash-flow, and thus can be substitutable" (pp. 858) - supporting the broadening of the competitive landscape.

\subsubsection{Key Measures}

The key measures used in this study and how they are calculated are briefly discussed below. 


\section{Herfindahl-Hirschman Index (HHI)}

The HHI is the most widely used measure of market concentration. Most market power studies based on the structure-conduct-performance approach have used the HHIincluding White (1987), Kim and Singal (1993), Singal (1996), Fauli-Oller (2002), Walter and Wescott (2008), etc. The HHI, which measures an industry's concentration in a given geographic market, is defined as the sum of squared market shares (Giroud and Mueller, 2011) and is given as:

$H H I=\sum_{i=1}^{N}\left(100 s_{i}\right)^{2}$

where $s_{i}$ represents market share.

\section{Concentration Ratios}

A number of studies have used concentration ratios to measure an industry's concentration level and market power. Some studies that have used concentration ratios include (White, 1987), Chatterjee (1991) and Berger et al. (1999). Concentration ratios, defined as the proportion of an industry's sales accounted for by the largest firms (White, 1987), can be represented as:

$C R=\sum_{i=1}^{N} s_{i}$

where $s_{i}$ represents market share. For the 4-firm and 8-firm concentration ratios, for example, $\mathrm{N}$ will be set equal to 4 and 8 respectively.

\section{Market Share}

Market share is used as our proxy for exchange-level market power. We compute market share using monthly as well as yearly value of share trading. To obtain the market share 
for each month for each exchange, we take the exchange's value of share trading (in USD) and divide it by the sum of all the exchanges' value of share trading (in USD). The market shares for the exchanges involved in the mergers were calculated by summing their individual data to get the data for each combined exchange. To get the market share for the merging and rival portfolios, we averaged the market shares of all the exchanges that make up the portfolio.

\subsubsection{Univariate Analysis Approach}

Once the key measures were calculated, we carried out univariate analysis - using trend analysis and parametric/nonparametric tests of mean/median differentials - to determine if the key measures are significantly different between the pre- and post-merger periods.

\subsubsection{Multivariate Analysis Approach}

For the multivariate analysis, we used Binder's (1985) and Acharya's (1993) dummy variables approach for two main reasons. First, because of the inherently small population of stock exchanges, sample sizes of studies using stock exchanges are naturally small. Using the dummy variables approach allows us to use data over both the event and nonevent windows, which will help increase the number of observations for our regressions. Second, the dummy variables approach is one of the preferred approaches when firms experience the same event more than once in the sample period. Given that NYSE is involved in two of the mergers (i.e. with Archipelago and Euronext), the dummy variables approach is the best approach for our study. 
In view of the fact that mergers and acquisitions in an industry typically tend to cluster in time, the assumption of independence among individual events that is required for ordinary least squares regressions to be the best linear unbiased estimates (BLUE) is most likely violated. Therefore, because of the possibility of contemporaneous correlations in the residuals as a result of the clustering of mergers and acquisitions in an industry, we use Zellner's (1962) seemingly unrelated regression (SUR) methodology to estimate the regression equations.

It has been argued that in order to avoid spurious correlations in structure-conductperformance studies, tests of market power should control for efficiency (Choi and Weiss, 2005). We address this requirement in our regressions by incorporating variables for expense efficiency and revenue efficiency. Given our quest to determine the presence or otherwise of market power effects and the extent to which any potential market power exercise in the stock exchange industry has become inimical to consumer welfare, we regressed our measure of profitability (ROA) for stock exchanges on the measures of market concentration (HHI, 4-firm concentration ratio), proxies for efficiency (ratio of total expenses to total assets, ${ }^{24}$ ratio of revenues to total assets), proxy for exchange-level market power (i.e. market share) and other control variables. The SUR regression models we estimated are of the general form:

${ }^{24}$ See Rhoades (1993). 
Profit $=\propto+\beta_{1}$ Market Share $+\beta_{2}$ Market Concentration Measure +

$\beta_{3}$ Expenses to Assets $+\beta_{4}$ Revenues to Assets $+\beta_{5}$ Post - Merger Dummy +

$\beta_{6}$ Market Share $*$ Post - Merger Dummy +

$\beta_{7}$ Market Concentration Measure $*$ Post - Merger Dummy +

$\beta_{8}$ Expenses to Assets $*$ Post - Merger Dummy $+\beta_{9}$ Revenues to Assets $*$ Post -

Merger Dummy $+\gamma_{k} \sum Z_{k}+\varepsilon_{i}$

where profit represents return on assets (ROA), market concentration being one of the two measures of market concentration (i.e. HHI or CR4), expenses (selling, general and administrative) to assets being a measure of cost efficiency, revenues to assets being a measure of sales efficiency, market share being the proxy for exchange-level market power, post-merger dummy (taking the value of 1 in the post-merger period and zero otherwise) and $Z_{k}$ is a vector of control variables including a linear time trend, long-term debt-equity ratio, capital expenditures (CAPEX) to sales ratio, GDP per capita and domestic market capitalization of firms listed on the exchanges. The post-merger dummy is also interacted with the measures of efficiency, measures of market concentration and measure of market power. The interactions are used to determine whether or not market concentration, market power and/or efficiencies are the main drivers of profitability in the post-merger period for all exchanges, the merging exchanges and/or rivals.

The rationale for our multivariate regression equation is that after controlling for market concentration and efficiency, the coefficient of market share, the market power measure, will reflect market power exercised (Rhoades, 1985; Choi and Weiss, 2005). If industry 
concentration is helping improve the profitability of stock exchanges following the mergers, then the expectation is that the coefficients of the measures of industry concentration (i.e. HHI and CR4) interacted with the post-merger dummy variable will be significantly positive. A significantly positive HHI * post-merger dummy coefficient or $\mathrm{CR} 4 *$ post-merger dummy coefficient provides support for the SCP hypothesis - which postulates that as industry concentration increases as a result of mergers, the conduct of firms may change, for example by undertaking anticompetitive actions such as colluding to restrict output and/or raise prices - so as to improve their performance (e.g. increase profit rate). If there is the exercise of market power at the exchange-level, then we expect the coefficient of the market share variable interacted with the post-merger dummy variable to be significantly positive. However, because we argue that the threat of competition from multiple sources is lowering entry barriers, we expect the coefficient of the post-merger market power proxy to be insignificant. We expect the measure of sales efficiency in the post-merger period, proxied by the sales to assets ratio interacted with the post-merger dummy variable to be significantly positively related to ROA while the measure of cost efficiency in the post-merger period, proxied by the total expenses to assets ratio interacted with the post-merger dummy variable to be significantly negatively related to $\mathrm{ROA}$.

The additional control variables included in our multivariate analyses are motivated by theory and/or empirical evidence. Since most variables tend to trend upwards over time, we follow Arnold et al. (1999) and include a linear time trend variable as a control variable in our regressions. The positive relationship between size and profitability has 
been noted in the literature (e.g. Athanasoglou et al., 2008). As such, we control for exchange size by including the log of domestic market capitalization of firms listed on the exchanges. Short (1979) notes that leverage is a potential determinant of profitability and Angbazo (1997) asserts that leverage is a proxy measure for the risk of insolvency. We therefore control for leverage using the total long term debt-equity ratio. The positive effect of capital/infrastructure investments on profitability in the banking sector has been recognized by authors such as Williams (2003). As a result, we include the CAPEX to sales ratio as a control variable in our regressions. To control for country growth differences, we include GDP per capita. We lag, by one year, financial and macroeconomic variables that are reported with a lag in order to avoid look-ahead bias.

We run several variants of the above regression equation using the two measures of market concentration. We next report the results of our analyses.

\subsection{Results}

\subsubsection{Descriptive Statistics and Correlations}

Presented in Table 4.1 are descriptive statistics of key variables as well as the Pearson's correlations among the variables used in this study. As demonstrated in panel A, the means and medians of the key measures of concentration, market power and efficiencies appear to be reasonable. 
Table 4.1 - Descriptive Statistics and Pearson Correlations

This table presents descriptive statistics and Pearson correlations of key variables. Panel A presents descriptive statistics (mean, median, standard deviation, minimum, maximum and number of observations at the exchange-month level). We report descriptives for all exchanges. Panel B reports the Pearson correlations for all exchanges.

Panel A: Descriptives

\begin{tabular}{lcccccc}
\hline Variable & Mean & Median & Std. Dev. & Min & Max & $\begin{array}{c}\text { Firm- } \\
\text { Month } \\
\text { Obs. }\end{array}$ \\
\hline ROA & 0.0609 & 0.0625 & 0.0380 & 0.0022 & 0.1419 & 15,858 \\
Market Share & 0.0898 & 0.0756 & 0.0831 & 0.0050 & 0.2008 & 31,212 \\
HHI & 2038 & 2059 & 315 & 1510 & 2652 & 37,962 \\
CR4 & 0.7342 & 0.7274 & 0.0564 & 0.6458 & 0.8223 & 37,962 \\
$\begin{array}{l}\text { Expense } \\
\text { Efficiency }\end{array}$ & 0.1145 & 0.0846 & 0.0875 & 0.0372 & 0.3449 & 15,458 \\
$\begin{array}{l}\text { Sales } \\
\text { Efficiency }\end{array}$ & 0.2805 & 0.2627 & 0.0952 & 0.1333 & 0.5052 & 15,858 \\
\hline
\end{tabular}

Panel B: Correlations

\begin{tabular}{|c|c|c|c|c|c|c|c|c|c|c|}
\hline & ROA & $\begin{array}{l}\text { Market } \\
\text { Share }\end{array}$ & HHI & CR4 & $\begin{array}{l}\text { Expense } \\
\text { Efficiency }\end{array}$ & Efficiency & $\begin{array}{l}\text { CAPEX } \\
\text { to Rev }\end{array}$ & $\begin{array}{l}\text { Debt- } \\
\text { Equity }\end{array}$ & $\begin{array}{l}\text { Domestic } \\
\text { Mkt Cap }\end{array}$ & $\begin{array}{l}\text { GDP } \\
\text { per } \\
\text { Capita }\end{array}$ \\
\hline $\mathrm{ROA}$ & 1.0000 & & & & & & & & & \\
\hline Market Share & $\begin{array}{c}-0.8574 \\
(* * *)\end{array}$ & 1.0000 & & & & & & & & \\
\hline HHI & -0.0217 & 0.0729 & 1.0000 & & & & & & & \\
\hline CR4 & -0.0463 & 0.0748 & $\begin{array}{c}0.9818 \\
(* * *)\end{array}$ & 1.0000 & & & & & & \\
\hline $\begin{array}{l}\text { Expense } \\
\text { Efficiency }\end{array}$ & $\begin{array}{c}-0.1825 \\
(* * *)\end{array}$ & $\begin{array}{c}0.4361 \\
(* * *)\end{array}$ & $\begin{array}{l}0.6052 \\
(* * *)\end{array}$ & $\begin{array}{c}0.6235 \\
(* * *)\end{array}$ & 1.0000 & & & & & \\
\hline $\begin{array}{l}\text { Sales } \\
\text { Efficiency }\end{array}$ & $\begin{array}{c}0.1860 \\
(* * *)\end{array}$ & $\begin{array}{c}0.1536 \\
(* *)\end{array}$ & $\begin{array}{l}0.6359 \\
(* * *)\end{array}$ & $\begin{array}{l}0.6462 \\
(* * *)\end{array}$ & $\begin{array}{c}0.8852 \\
(* * *)\end{array}$ & 1.0000 & & & & \\
\hline CAPEX to Rev & 0.0765 & 0.1041 & $\begin{array}{c}0.7782 \\
(* * *)\end{array}$ & $\begin{array}{c}0.7885 \\
(* * *)\end{array}$ & $\begin{array}{c}0.8362 \\
(* * *)\end{array}$ & $\begin{array}{c}0.8614 \\
(* * *)\end{array}$ & 1.0000 & & & \\
\hline Debt- Equity & $\begin{array}{c}-0.6336 \\
(* * *)\end{array}$ & $\begin{array}{c}0.7660 \\
(* * *)\end{array}$ & $\begin{array}{c}0.3883 \\
(* * *)\end{array}$ & $\begin{array}{c}0.3930 \\
(* * *)\end{array}$ & $\begin{array}{c}0.7252 \\
(* * *)\end{array}$ & $\begin{array}{c}0.4469 \\
(* * *)\end{array}$ & $\begin{array}{c}0.3936 \\
(* * *)\end{array}$ & 1.0000 & & \\
\hline $\begin{array}{l}\text { Domestic Mkt } \\
\text { Cap }\end{array}$ & 0.0638 & -0.0577 & $\begin{array}{c}-0.7635 \\
(* * *)\end{array}$ & $\begin{array}{c}-0.7896 \\
(* * *)\end{array}$ & $\begin{array}{c}-0.6028 \\
(* * *)\end{array}$ & $\begin{array}{c}-0.6141 \\
(* * *)\end{array}$ & $\begin{array}{c}-0.8069 \\
(* * *)\end{array}$ & $\begin{array}{c}-0.2176 \\
(* * *)\end{array}$ & 1.0000 & \\
\hline GDP per Capita & $\begin{array}{c}-0.8300 \\
(* * *)\end{array}$ & $\begin{array}{l}0.9260 \\
(* * *)\end{array}$ & $\begin{array}{c}-0.2665 \\
(* * *)\end{array}$ & $\begin{array}{c}-0.2721 \\
(* * *)\end{array}$ & $\begin{array}{c}0.1135 \\
(*)\end{array}$ & $\begin{array}{c}-0.1544 \\
(* *)\end{array}$ & $\begin{array}{c}-0.2521 \\
(* * *)\end{array}$ & $\begin{array}{c}0.5686 \\
(* * *)\end{array}$ & $\begin{array}{c}0.2629 \\
(* * *)\end{array}$ & $\begin{array}{c}1.0000 \\
(* * *)\end{array}$ \\
\hline
\end{tabular}

The return on assets (ROA) of the average exchange is about $6.1 \%$ while the average market share is about $9 \%$. Since White (1987) indicated that four-firm concentration ratios exceeding the $50 \%$ to $60 \%$ range increase the likelihood of anticompetitive behavior, the four-firm concentration ratio (CR4) of $73 \%$ that we report in this study appears to be on the high side. We argue, however, that this is not unexpected when one considers the fact that the stock exchange industry is dominated by a few super exchanges such as NYSE Euronext, NASDAQ OMX, Tokyo Stock Exchange Group, 
London Stock Exchange and Deutsche Boerse. The average HHI of 2038 shows that the industry is moderately concentrated because according to the US Department of Justice and the Federal Trade Commission (2010), HHI lower than 1500 means unconcentrated markets, $\mathrm{HHI}$ greater than 2500 indicates highly concentrated markets while $\mathrm{HHI}$ between 1500 and 2500 represents moderately concentrated markets.

Panel B of Table 4.1 presents the Pearson's correlations between the pairs of variables. Some insights can be deciphered from the relationships between the independent variables and ROA (the dependent variable). The insignificant negative relationships between ROA and the measures of market concentration (HHI and CR4) supports our hypothesis that exchanges will not exploit industry concentration to enhance their bottom-lines. The negative relationship between market share and ROA is suggestive of the fact that exchanges are not exploiting market share for higher profits. The negative (positive) relationship between ROA and expense (sales) efficiency measures (expenses/sales to total assets) demonstrate operational efficiencies in the stock exchange industry - as improved cost management and revenue generation are significantly related to profitability. Capital expenditures are also positively (but insignificantly) related to ROA while the long term debt-equity ratio shows that as the chances of insolvency increases, profitability decreases. In general, the low correlations between the independent variables indicate that multicolinearity is not an issue. The $98 \%$ correlation between HHI and CR4 is indicative of the fact that one can expect very similar results by using any one of these measures of market concentration. 


\subsubsection{Univariate Analysis of Market Power}

To understand the separate behaviors of the key measures of market power in the stock exchange industry, we conducted univariate trend analyses and tests of mean and median differences between the pre-merger period and post-merger period.

\subsubsection{Trend Analysis of Concentration and Profit Measures}

We trended key measures of market concentration and ROA in order to gain further insights into industry concentration levels as well as profitability following the mergers. We present, in Figure 4.1, trend charts of monthly and yearly HHI (based on value of share trading), yearly HHI based on revenue as well as yearly ROA. The trend charts track these measures starting five years before the merger completion dates and ending six years after the merger completions.

Figure 4.1 - Stock Exchange Industry Concentration and Profit

This figure trends monthly and yearly Herfindahl Index (HHI) and yearly return on assets (ROA) from 5 years before the merger completion dates to six years after the merger completion dates. Panel A graphs monthly HHI using value of share trading in US dollars; Panel B trends yearly HHI based on value of share trading (USD) and revenues (USD); and, Panel C plots ROA.

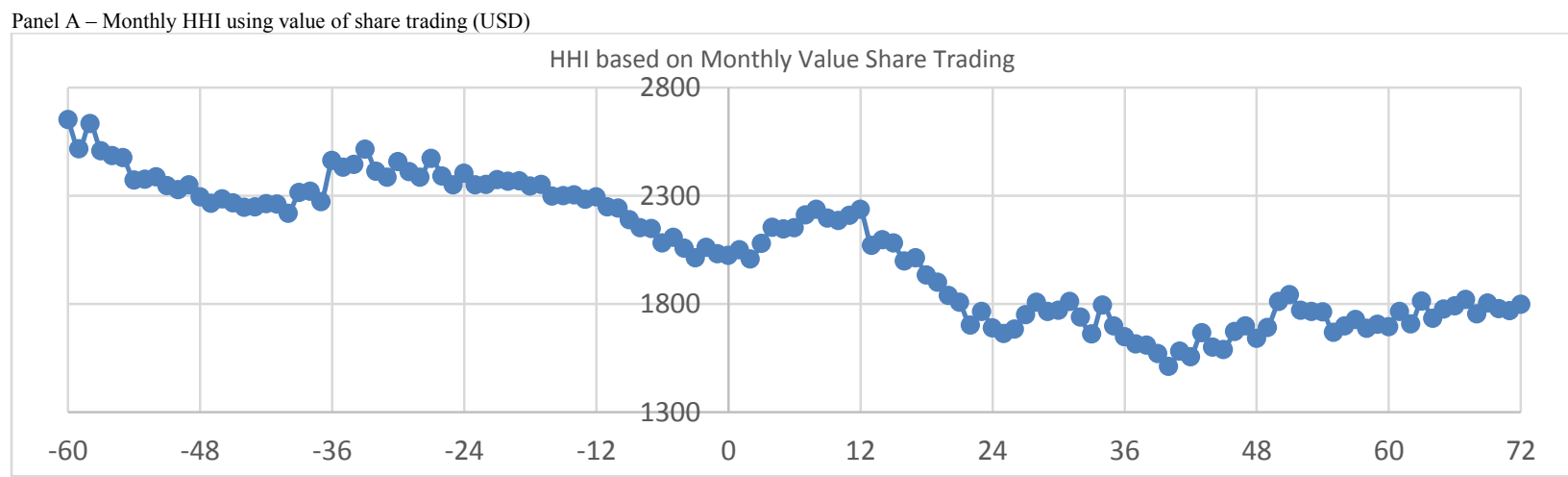



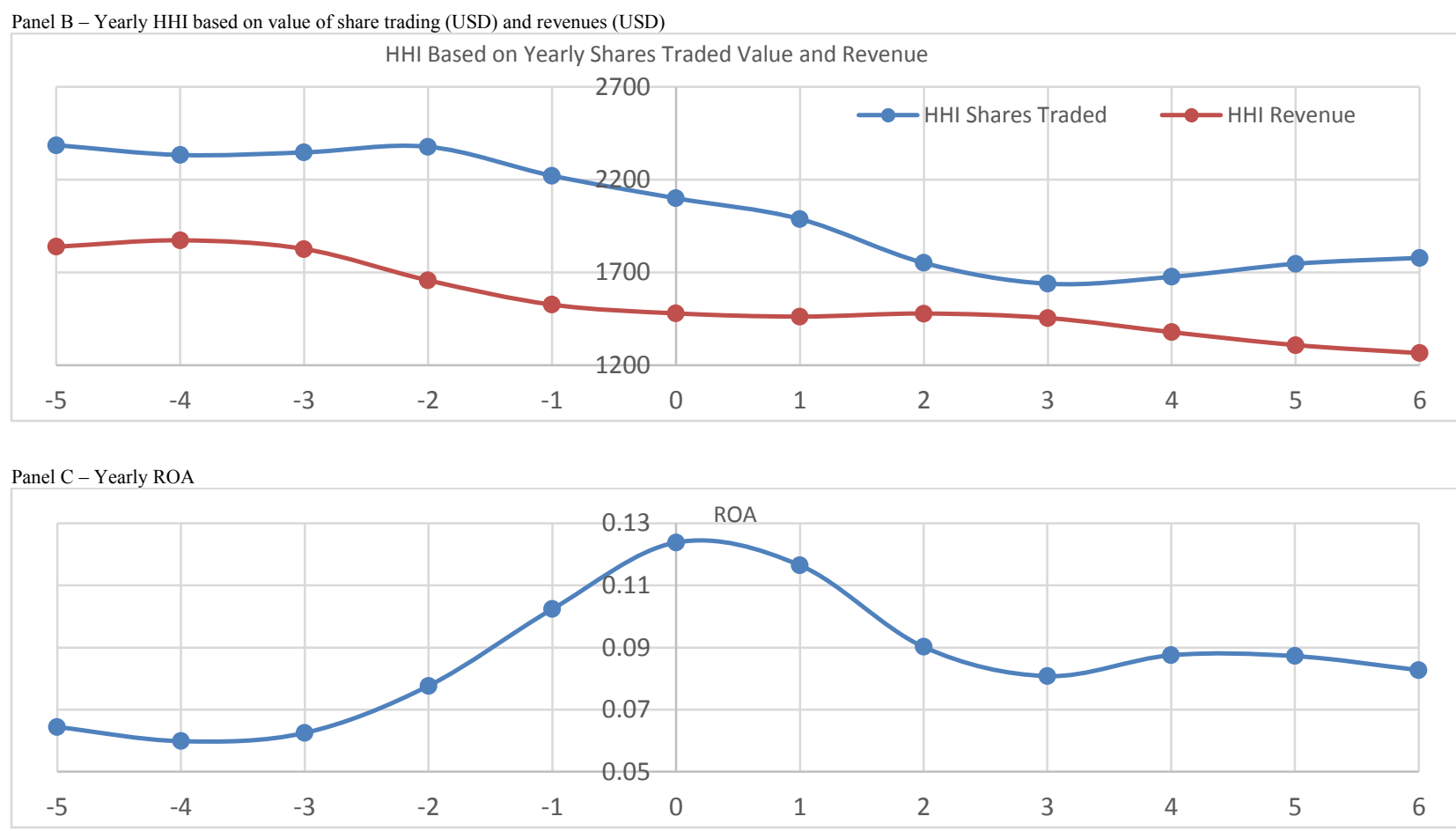

The trend charts above do not indicate any significant increases in market concentration and profitability following the stock exchange mergers. Panel A graphs monthly HHI based on market share derived from monthly value of share trading in US dollars. As evident, while the HHI inched up about 200 points in the first twelve months following mergers' conclusions from 2022 in month zero to 2235 in month twelve, it fell significantly in the next five years to about 1800 in year six. We arrive at the same conclusion of lower HHI in the post-merger period using HHI values derived from yearly revenues and yearly value of share trading (panel B). Finally, panel C shows that ROA, our measure of profitability, has marginally increased in the post-merger period.

From the univariate trend analysis, our results do not appear to highlight the possibility of market power exploitation. We conducted statistical tests to determine whether the 
changes in the key measures of industry concentration and market power are significant from a statistical point of view.

\subsubsection{Pre- and Post-Merger Market Power Analysis}

The trend charts do indicate changes in the post-merger values of the key measures we graphed. To determine whether or not these and other changes are statistically significant, we performed univariate tests of changes in means and medians in the pre- and postmerger periods. The results of our univariate tests of mean and median differences are reported in Table 4.2.

Table 4.2 - Univariate Tests of Means and Medians

This table presents the results of the univariate tests of means and medians 60 months before the date of the mergers compared to 60 months after the mergers' completion dates. The results are presented for all exchanges. (Test statistics are in parentheses)

\begin{tabular}{lrrrrrrrr}
\hline & \multicolumn{3}{c}{ Mean } & \multicolumn{3}{c}{ Median } \\
\hline Portfolio & Before & After & $\begin{array}{c}\% \\
\text { Difference }\end{array}$ & $\begin{array}{c}\text { Paired T- } \\
\text { Test of } \\
\text { Difference }\end{array}$ & Before & After & $\begin{array}{c}\% \\
\text { Difference }\end{array}$ & $\begin{array}{l}\text { Wilcoxon } \\
\text { signed-rank test }\end{array}$ \\
\hline ROA & 0.0596 & 0.0622 & $4.22 \%$ & $(1.18)$ & 0.0604 & 0.0864 & $42.97 \%$ & $(0.90)$ \\
Market Share & 0.0950 & 0.0845 & $-11.06 \%$ & $(-7.70)^{* * *}$ & 0.0880 & 0.0756 & $-14.13 \%$ & $(-4.27)^{* * *}$ \\
HHI & 2324.98 & 1751.77 & $-24.65 \%$ & $(-27.11)^{* * *}$ & 2344.82 & 1751.85 & $-25.29 \%$ & $(-9.44)^{* * *}$ \\
CR4 & 0.7850 & 0.6834 & $-12.94 \%$ & $(-25.17)^{* * *}$ & 0.7946 & 0.6804 & $-14.37 \%$ & $(-9.37)^{* * *}$ \\
Expense & 0.1656 & 0.0634 & $-61.74 \%$ & $(-9.59)^{* * *}$ & 0.0995 & 0.0666 & $-33.08 \%$ & $(-8.32)^{* * *}$ \\
Efficiency & 0.3373 & 0.2236 & $-33.72 \%$ & $(-8.81)^{* * *}$ & 0.2977 & 0.2489 & $-16.39 \%$ & $(-8.11)^{* * *}$ \\
Sales Efficiency & & & & & & & &
\end{tabular}

From the table, although the mean and median ROA increased in the post-merger period, the increases are statistically indistinguishable from zero. We are therefore contending that stock exchanges did not exploit the mergers to reap "supernormal" profits as the profit rate remained essentially the same in the pre- and post-merger periods. Both measures of industry concentration decreased in the post-merger period - with the mean 
(median) HHI decreasing by about $24.7 \%(25.3 \%)$ while the CR4 saw reductions in mean (median) of about $12.9 \%(14.4 \%)$ after the mergers were completed. The mean (median) expense efficiency metric (expenses to assets ratio) significantly improved by $61.7 \%$ (33.1\%) in the post-merger period compared to the pre-merger period. Sales efficiency declined for all exchanges - likely because of the cancelling out effects between the merging firms and rivals.

All in all, the univariate trend analysis and test of mean/median differences do not raise any serious concerns related to increasing concentration and exploitation of market power in the stock exchange industry following the consummation of the six transformational mergers examined in this study.

\subsubsection{Multivariate Analysis of Market Power}

For our multivariate analysis of market power, we use seemingly unrelated regressions (SUR) to determine the extent to which market power, efficiencies and market concentration have contributed to profitability of stock exchanges after controlling for the influence of other important determinants of profitability. We next discuss the results of our multivariate analysis.

\subsubsection{Market Power Effects in the Absence of Efficiency Measures}

It has been noted that models of market power that do not include efficiency measures could (wrongly) signal the presence of market power (Berger, 1995) even when that may not be the case. We first test the extent to which profits are impacted by measures of 


\title{
market concentration and market power when efficiency measures are not explicitly
}

\author{
accounted for.
}

\section{Table 4.3 - Market Power Effects without controlling for Efficiency Effects}

In this table, we present the results of seemingly unrelated regression equations that regress ROA on measures of market power and exchange-level, country-level and other control variables. The variables include exchange market share, HHI (or CR4), domestic market capitalization, long-term debt- equity ratio, CAPEX to revenue ratio, post-merger dummy, GDP per capita and a linear time trend. We estimated the regressions using monthly data that start 60 months before the month of the merger completions, skips one year and end 60 months after the skipped year. (t statistics are in parentheses)

\begin{tabular}{|c|c|c|c|c|c|c|}
\hline & \multicolumn{2}{|c|}{ All Exchanges } & \multicolumn{2}{|c|}{ Merging Exchanges } & \multicolumn{2}{|c|}{ Rivals } \\
\hline & ROA & ROA & ROA & ROA & ROA & ROA \\
\hline \multirow[t]{2}{*}{ Mkt Share } & -0.0987 & -0.0975 & -0.7647 & -0.7590 & 1.1577 & 1.1332 \\
\hline & $(-3.70)^{* * *}$ & $(-3.66)^{* * *}$ & $(-17.70)^{* * *}$ & $(-17.72)^{* * *}$ & $(5.00)^{* * *}$ & $(4.91)^{* * *}$ \\
\hline \multirow[t]{2}{*}{$\begin{array}{l}\text { Mkt Share * Post- } \\
\text { Merger Dummy }\end{array}$} & -0.0234 & -0.0233 & 0.3821 & 0.3887 & -2.5088 & -2.6313 \\
\hline & $(-0.87)$ & $(-0.86)$ & $(10.95)^{* * *}$ & $(11.19)^{* * *}$ & $(-10.30)^{* * *}$ & $(-10.8)^{* * *}$ \\
\hline \multirow[t]{2}{*}{ HHI } & 0.0000 & - & 0.0000 & - & 0.0000 & - \\
\hline & $(1.90)^{*}$ & - & $(4.03)^{* * *}$ & - & $(0.28)$ & - \\
\hline \multirow{2}{*}{$\begin{array}{l}\text { HHI * Post-Merger } \\
\text { Dummy }\end{array}$} & 0.0001 & - & 0.0001 & - & 0.0000 & - \\
\hline & $(7.40)^{* * *}$ & - & $(8.01)^{* * *}$ & - & $(1.43)$ & - \\
\hline \multirow[t]{2}{*}{ CR4 } & - & 0.0335 & - & 0.1804 & - & -0.1541 \\
\hline & - & $(0.69)$ & - & $(3.03)^{* * *}$ & - & $(-3.28)^{* * *}$ \\
\hline \multirow[t]{2}{*}{$\begin{array}{l}\text { CR4 * Post-Merger } \\
\text { Dummy }\end{array}$} & - & 0.4569 & - & 0.6887 & - & 0.1819 \\
\hline & - & $(9.39)^{* * *}$ & - & $(10.68)^{* * *}$ & - & $(3.87)^{* * *}$ \\
\hline \multirow[t]{2}{*}{ GDP per Cap } & 0.0000 & 0.0000 & 0.0000 & 0.0000 & 0.0000 & 0.0000 \\
\hline & $(-6.12)^{* * *}$ & $(-6.30)^{* * *}$ & $(18.14)^{* * *}$ & $(16.64)^{* * *}$ & $(11.82)^{* * *}$ & $(12.43)^{* * *}$ \\
\hline \multirow[t]{2}{*}{ Linear Trend } & 0.0000 & 0.0001 & -0.0002 & 0.0001 & 0.0000 & 0.0000 \\
\hline & $(-0.41)$ & $(1.78)^{*}$ & $(-2.49)^{* *}$ & $(0.87)$ & $(0.01)$ & $(-0.22)$ \\
\hline \multirow[t]{2}{*}{ Post-Merger Dummy } & -0.0872 & -0.3059 & -0.1520 & -0.4967 & 0.0117 & -0.1032 \\
\hline & $(-4.76)^{* * *}$ & $(-8.31)^{* * *}$ & $(-6.60)^{* * *}$ & $(-10.20)^{* * *}$ & $(0.64)$ & $(-2.90)^{* * *}$ \\
\hline \multirow[t]{2}{*}{ CAPEX to Rev } & 0.2512 & 0.2495 & 2.8406 & 2.9452 & 0.1272 & 0.1341 \\
\hline & $(14.43)^{* * *}$ & $(14.32)^{* * *}$ & $(18.60)^{* * *}$ & $(19.18)^{* * *}$ & $(8.66)^{* * *}$ & $(9.12)^{* * *}$ \\
\hline \multirow[t]{2}{*}{ Debt-Equity } & -0.0092 & -0.0091 & -0.0002 & 0.0002 & 0.1833 & 0.1818 \\
\hline & $(-7.40)^{* * *}$ & $(-7.28)^{* * *}$ & $(-0.20)$ & $(0.15)$ & $(12.59)^{* * *}$ & $(12.52)^{* * *}$ \\
\hline \multirow[t]{2}{*}{ Mkt Cap Exch } & 0.0586 & 0.0542 & 0.0779 & 0.0863 & 0.0696 & 0.0567 \\
\hline & $(9.42)^{* * *}$ & $(8.17)^{* * *}$ & $(8.83)^{* * *}$ & $(9.52)^{* * *}$ & $(11.27)^{* * *}$ & $(8.67)^{* * *}$ \\
\hline \multirow[t]{2}{*}{ Constant } & -0.9970 & -0.9186 & -1.6770 & -1.8719 & -1.1928 & -0.8420 \\
\hline & $(-8.67)^{* * *}$ & $(-6.67)^{* * *}$ & $(-10.56)^{* * *}$ & $(-10.48)^{* * *}$ & $(-10.37)^{* * *}$ & $(-6.20)^{* * *}$ \\
\hline $\mathrm{N}$ & 3743 & 3743 & 2035 & 2035 & 1708 & 1708 \\
\hline $\mathrm{R}^{2}$ & 0.2660 & 0.2645 & 0.3410 & 0.3520 & 0.3693 & 0.3716 \\
\hline
\end{tabular}


As evident from Table 4.3, regression models that use only market concentration and market power measures without including efficiency measures show that stock exchanges may have exercised market power as HHI and CR4 in the post-merger period are significantly positive at the $1 \%$ level for all exchanges and the merging exchanges. The significantly positive coefficient of the market share variable in the post-merger period variable (i.e. Mkt Share * Post-Merger Dummy) for the merging firms corroborates this assertion and indicates that profitability of the merging exchanges in the post-merger period is positively influenced by market share (a measure of exchange-level market power).

\subsubsection{Incorporating Efficiency Measures in Market Power Analysis}

Studies of the market power effects of mergers need to incorporate measures of efficiency (Berger, 1995) if the wrong conclusions are to be avoided. The results of our SUR regressions that incorporate measures of efficiency (cost efficiency and sales efficiency) are presented in Table 4.4 .

Table 4.4 - Efficiency and Market Power Effects of Exchange Mergers

We present the results of seemingly unrelated regression equations that regress ROA on measures of market power, exchange-level, country-level and other control variables in this table. The variables include exchange market share, HHI (or CR4), cost efficiency, sales efficiency, domestic market capitalization, long-term debt-equity ratio, CAPEX to revenue ratio, post-merger dummy, GDP per capita and a linear time trend. We estimated the regressions using monthly data that start 60 months (5years) before the month of the merger completions, skips one year and end 60 months (5 years) after the skipped year (i.e. from month 13 to month 72 ). ( $t$ statistics are in parentheses)

\begin{tabular}{lccccccc}
\hline & & \multicolumn{2}{c}{ All Exchanges } & \multicolumn{2}{c}{ Merging Exchanges } & \multicolumn{2}{c}{ Rivals } \\
\hline & $\begin{array}{l}\text { Expected } \\
\text { Sign }\end{array}$ & ROA & ROA & ROA & ROA & ROA & ROA \\
\hline Mkt Share & $?$ & -0.4105 & -0.4145 & 0.0510 & 0.0581 & 0.2014 & -0.2343 \\
& & $(-17.70)^{* * *}$ & $(-17.24)^{* * *}$ & $(1.58)$ & $(1.72)^{*}$ & $(0.88)$ & $(-1.05)$ \\
Mkt Share * Post- & $?$ & 0.0332 & 0.0356 & 0.0362 & 0.0391 & -0.5518 & -0.1469
\end{tabular}




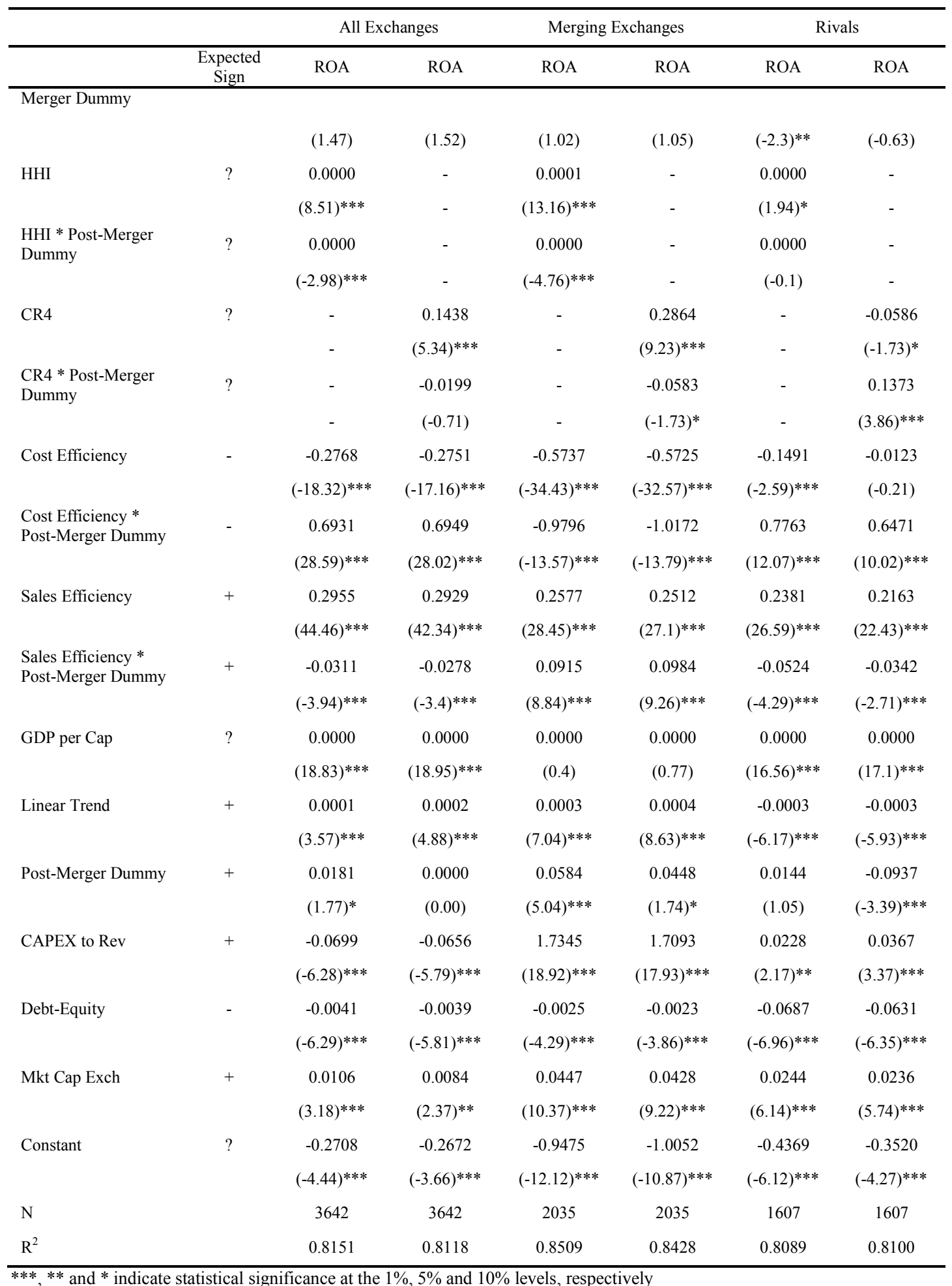

***,** and * indicate statistical significance at the $1 \%, 5 \%$ and $10 \%$ levels, respectively

From Table 4.4, there is no evidence of market power exploitation when efficiency

measures are incorporated into the regression models. The measures of market 
concentration (HHI and CR4) in the post-merger period are both significantly negative at the $1 \%$. Thus, although both HHI and CR4 are significantly positive over the entire period for all exchanges (columns C and D), when these measures are interacted with the post-merger dummy variable, the interaction variables are significantly negative indicating that the exchanges did not leverage market concentration to drive up profitability following the mergers. Exploitation of market concentration for profitability would have resulted in a positive relationship between the interaction variables and ROA. When separate regressions are estimated for merging exchanges and rival exchanges, the measures of market concentration interacted with the post-merger dummy variable are significantly negative at the 1\% level (HHI interaction) and 10\% level (CR4 interaction) for the merging exchanges (columns $\mathrm{E}$ and $\mathrm{F}$ ) and insignificant for $\mathrm{HHI}$ interaction but significantly positive at the $1 \%$ for CR4 interaction for the rival exchanges (see columns G and $\mathrm{H})$.

The exercise of market power in the post-merger period for profitability can be directly inferred from the market share variable interacted with the post-merger dummy variable. If exchanges exercised market power in the post-merger period, the relationship between ROA and the interaction between market share and the post-merger dummy variable should have been significantly positive. For all the exchanges (columns C and D) and merging exchanges (columns E and F), the Mkt Share * Post-Merger Dummy variable is insignificant. For the rival exchanges, the interaction variable is significantly negative at the $5 \%$ level in the regression that uses $\mathrm{HHI}$ as the measure of market concentration but insignificant in the regression that uses CR4 as the measure of industry concentration. 
These results support our hypotheses that stock exchanges would not exercise market power as a result of the mergers. We argue that because technological advancements, internationalization and liberalization are lowering industry entry barriers, stock exchanges that want to succeed in this highly competitive environment are better served by being efficient rather than by exercising market power - since some competitors, especially low-cost competitors such as ECNs, can afford to forgo exercising market power in order to siphon business from rivals.

Given that our results do not provide support for the market power exploitation hypothesis following the mergers, we next turn our attention to the efficiency hypothesis - especially given that the mergers were sold to stakeholders partly on the grounds of efficiency. If the mergers resulted in efficiency improvements, then the measure of cost efficiency in the post-merger period, Cost Efficiency * Post-Merger Dummy, would be negatively related to profitability - indicating that decreasing expenses in the post-merger period resulting from efficiencies in expense management is boosting exchanges' profitability. We would also expect the sales efficiency measure in the post-merger period (Sales Efficiency * Post-Merger Dummy) to be positively related to profits signifying that increasing sales in the post-merger period is positively impacting exchanges' profitability. Examination of our results for all exchanges (columns C and D) shows that while the Cost Efficiency * Post-Merger Dummy is significantly negative (as expected), the coefficient of the Sales Efficiency * Post-Merger Dummy is significantly negative - contrary to our expectations. However, since we argue that the efficiency gains will be disproportionately in favor of the merging exchanges because of synergies 
but punitive for the rivals because they have to compete with better resourced merged entities, the results for all the exchanges is not unexpected (because of the possibility of efficiency gains by merging exchanges being cancelled out by efficiency losses suffered by rivals). Thus, because of the asymmetric nature of the efficiency gains, we would analyze the separate regressions for the merged exchanges and rivals to find the real efficiency gains of the mergers.

As expected, the coefficient of the Cost Efficiency * Post-Merger Dummy variable is significantly negative at the $1 \%$ for the merging exchanges and the Sales Efficiency * Post-Merger Dummy is significantly positively related (at the $1 \%$ level) to ROA (columns $\mathrm{E}$ and $\mathrm{F}$ ). These findings mean that the merging firms improved their competitive standing following the mergers - as improvements in cost management and revenue generation significantly positively impacted profits. On the contrary, the postmerger cost efficiency measure is significantly positive (at the $1 \%$ level) for rival exchanges while the post-merger revenue efficiency measure is significantly negative at the $1 \%$ (columns $\mathrm{G}$ and $\mathrm{H}$ ). In line with our conjecture, these findings signify that rival exchanges suffered competitive disadvantages and were exposed to efficiency losses in the post-merger period. Our results are consistent with Focarelli and Panetta (2003) who find, using a sample of Italian bank mergers, that in the long term, efficiency gains dominate the market power effect. However, our results are inconsistent with other studies that find mergers in the banking industry (e.g. Baltazar and Santos, 2003; Ryan et al., 2014) and airline industry (e.g. Kim and Singal, 1993) to have resulted in the exercise of market power. 
The other control variables in our regressions have coefficients that are intuitive and in line with our expectations. The post-merger dummy variable is positive (and mostly significant) for all exchanges and the merging exchanges but negative and significant in one regression for rivals. This means that profitability has generally increased for the merging exchanges in the post-merger period. The debt-equity ratio is significantly negative for all exchanges, merging exchanges and rivals. We interpret this as indicating that as the risk of insolvency/bankruptcy increases with increasing leverage, profitability declines. Capital expenditures are significantly positively related (at the $1 \%$ level) to profitability for the merging exchanges and rival exchanges. The coefficient of the aggregate domestic market capitalization variable is positive and significant - suggesting that bigger exchanges are generally more profitable.

From our results, we conclude that there is no evidence that the mergers have resulted in the exploitation of market power in the stock exchange industry. This is not unexpected because with technological advancement, globalization and liberalization, we argue that entry barriers in the stock exchange industry are falling. Consequently, stock exchanges are losing the monopoly status some of them enjoyed in the past, and as such, if they exploit market power following mergers, the competition (especially low cost rivals such as ECNs) may get an opportunity to wrestle away some market share and improve their bottom-lines. Therefore, the merging exchanges are better off if they pursue mergers for efficiency reasons. And as our results indicate, the merging exchanges realized improved efficiencies in cost management and revenue generation - at the expense of rivals who 
suffered competitive disadvantages by competing with better resourced and more

efficient merged entities.

\subsubsection{Robustness Tests}

To test the sensitivity of our results to alternative specifications and measures, we conducted a number of robustness tests and discuss the results of these tests in this section.

\subsubsection{Using Yearly (instead of Monthly) Data}

Although we have used monthly data in our main analyses, we also run our regressions using yearly data.

Table 4.5 - Efficiency and Market Power Effects using Yearly Data

Reported in this table are the results of seemingly unrelated regression equations that regress ROA on measures of market power, exchange-level, country-level and other control variables. The variables include market share, HHI (or CR4), cost efficiency, sales efficiency, domestic market capitalization, long-term debt-equity ratio, CAPEX to revenue ratio, post-merger dummy, GDP per capita and a linear time trend. We estimated the regressions using yearly data that start 5years before the year of the merger completions, skips one year and end 5 years after the skipped year. ( $t$ statistics are in parentheses)

\begin{tabular}{|c|c|c|c|c|c|c|}
\hline & \multicolumn{2}{|c|}{ All Exchanges } & \multicolumn{2}{|c|}{ Merging Exchanges } & \multicolumn{2}{|c|}{ Rivals } \\
\hline & ROA & ROA & ROA & ROA & $\mathrm{ROA}$ & ROA \\
\hline \multirow[t]{2}{*}{ Mkt Share } & -0.3906 & -0.4306 & 0.2358 & 0.2431 & 0.5042 & -0.1800 \\
\hline & $(-3.89)^{* * *}$ & $(-3.94)^{* * *}$ & $(1.66)^{*}$ & $(1.49)$ & $(0.51)$ & $(-0.18)$ \\
\hline \multirow{2}{*}{$\begin{array}{l}\text { Mkt Share * Post-Merger } \\
\text { Dummy }\end{array}$} & 0.0308 & 0.0633 & -0.0390 & -0.0506 & -0.6778 & -0.0325 \\
\hline & $(0.32)$ & $(0.60)$ & $(-0.25)$ & $(-0.28)$ & $(-0.69)$ & $(-0.03)$ \\
\hline \multirow[t]{2}{*}{ HHI } & 0.0001 & - & 0.0001 & - & 0.0000 & - \\
\hline & $(3.70)^{* * *}$ & - & $(5.26)^{* * *}$ & - & $(1.35)$ & - \\
\hline \multirow{2}{*}{$\begin{array}{l}\text { HHI * Post-Merger } \\
\text { Dummy }\end{array}$} & -0.0001 & - & 0.0000 & - & -0.0001 & - \\
\hline & $(-2.19)^{* *}$ & - & $(-0.79)$ & - & $(-1.54)$ & - \\
\hline \multirow[t]{2}{*}{ CR4 } & - & 0.1764 & - & 0.4693 & - & -0.0575 \\
\hline & - & $(1.34)$ & - & $(3.17)^{* * *}$ & - & $(-0.33)$ \\
\hline \multirow[t]{2}{*}{$\begin{array}{l}\text { CR4 * Post-Merger } \\
\text { Dummy }\end{array}$} & - & -0.1930 & - & -0.0895 & - & -0.0333 \\
\hline & - & $(-1.22)$ & - & $(-0.48)$ & - & $(-0.17)$ \\
\hline
\end{tabular}




\begin{tabular}{|c|c|c|c|c|c|c|}
\hline & \multicolumn{2}{|c|}{ All Exchanges } & \multicolumn{2}{|c|}{ Merging Exchanges } & \multicolumn{2}{|c|}{ Rivals } \\
\hline & ROA & ROA & ROA & ROA & ROA & ROA \\
\hline \multirow[t]{2}{*}{ Cost Efficiency } & -0.3175 & -0.2827 & -0.6564 & -0.6525 & -0.1407 & 0.0812 \\
\hline & $(-4.59)^{* * *}$ & $(-3.67)^{* * *}$ & $(-8.86)^{* * *}$ & $(-7.61)^{* * *}$ & $(-0.57)$ & $(0.31)$ \\
\hline \multirow[t]{2}{*}{$\begin{array}{l}\text { Cost Efficiency * Post- } \\
\text { Merger Dummy }\end{array}$} & 0.7206 & 0.6694 & -1.3135 & -1.3588 & 0.6785 & 0.4439 \\
\hline & $(7.39)^{* * *}$ & $(6.44)^{* * *}$ & $(-3.96)^{* * *}$ & $(-3.76)^{* * *}$ & $(2.49)^{* *}$ & $(1.57)$ \\
\hline \multirow[t]{2}{*}{ Sales Efficiency } & 0.3315 & 0.3104 & 0.2209 & 0.2081 & 0.2597 & 0.2173 \\
\hline & $(10.44)^{* * *}$ & $(8.97)^{* * *}$ & $(4.89)^{* * *}$ & $(4.28)^{* * *}$ & $(6.13)^{* * *}$ & $(4.51)^{* * *}$ \\
\hline \multirow[t]{2}{*}{$\begin{array}{l}\text { Sales Efficiency * Post- } \\
\text { Merger Dummy }\end{array}$} & -0.0628 & -0.0307 & 0.1089 & 0.1323 & -0.0453 & 0.0007 \\
\hline & $(-1.65)^{*}$ & $(-0.74)$ & $(2.13)^{* *}$ & $(2.38)^{* *}$ & $(-0.80)$ & $(0.01)$ \\
\hline \multirow[t]{2}{*}{ GDP per Cap } & 0.0000 & 0.0000 & 0.0000 & 0.0000 & 0.0000 & 0.0000 \\
\hline & $(4.39)^{* * *}$ & $(4.58)^{* * *}$ & $(0.28)$ & $(0.49)$ & $(2.66)^{* * *}$ & $(2.80)^{* * *}$ \\
\hline \multirow[t]{2}{*}{ Linear Trend } & 0.0001 & 0.0007 & 0.0034 & 0.0055 & -0.0053 & -0.0053 \\
\hline & $(0.04)$ & $(0.39)$ & $(1.79)^{*}$ & $(2.74)^{* * *}$ & $(-2.40)^{* *}$ & $(-2.38)^{* *}$ \\
\hline \multirow[t]{2}{*}{ Post-Merger Dummy } & 0.1355 & 0.1298 & 0.0975 & 0.0838 & 0.1303 & 0.0349 \\
\hline & $(2.31)^{* *}$ & $(1.08)$ & $(1.51)$ & $(0.60)$ & $(1.77)^{*}$ & $(0.23)$ \\
\hline \multirow[t]{2}{*}{ CAPEX to Rev } & -0.1150 & -0.0888 & 2.4791 & 2.5089 & -0.0055 & 0.0303 \\
\hline & $(-2.63)^{* * *}$ & $(-1.93)^{*}$ & $(7.40)^{* * *}$ & $(6.73)^{* * *}$ & $(-0.13)$ & $(0.65)$ \\
\hline \multirow[t]{2}{*}{ Debt-Equity } & -0.0044 & -0.0032 & -0.0034 & -0.0033 & -0.0537 & -0.0508 \\
\hline & $(-1.73)^{*}$ & $(-1.21)$ & $(-1.43)$ & $(-1.26)$ & $(-1.63)$ & $(-1.53)$ \\
\hline \multirow[t]{2}{*}{ Mkt Cap Exch } & 0.0199 & 0.0121 & 0.0682 & 0.0660 & 0.0376 & 0.0336 \\
\hline & $(1.51)$ & $(0.82)$ & $(3.85)^{* * *}$ & $(3.16)^{* * *}$ & $(2.21)^{* *}$ & $(1.89)^{*}$ \\
\hline \multirow[t]{2}{*}{ Constant } & -0.5777 & -0.3836 & -1.6748 & -1.7436 & -0.8185 & -0.6043 \\
\hline & $(-2.08)^{* *}$ & $(-1.08)$ & $(-4.56)^{* * *}$ & $(-3.66)^{* * *}$ & $(-2.38)^{* *}$ & $(-1.47)$ \\
\hline $\mathrm{N}$ & 276 & 276 & 155 & 155 & 121 & 121 \\
\hline $\mathrm{R}^{2}$ & 0.8048 & 0.7960 & 0.7990 & 0.7655 & 0.8328 & 0.8305 \\
\hline
\end{tabular}

As shown in Table 4.5, the yearly results are similar to those based on monthly data.

Market share in the post-merger period, our measure of market power, is insignificant for all exchanges (columns B and C), merging exchanges (columns D and E) and rivals (columns F and G). The measures of industry concentration in the post-merger period (HHI * Post-Merger dummy and CR4 * Post-Merger dummy) are either significantly negative or indistinguishable from zero. On the contrary, expense efficiency ratio is significantly negatively related to profitability for the merging firms but significantly positively related to profitability of rivals. Revenue efficiency in the post-merger period 
is significantly positive for the merging firms at the $5 \%$ level but insignificant for rivals. Thus, whether monthly data or annual data is used, we arrive at the same conclusion that the mergers were undertaken for efficiency reasons but not to exploit market power.

\subsubsection{Not Skipping a Year Following Merger Completion Dates}

While we follow the standard practice of skipping one year after the merger completion dates because of arguments that it takes time for efficiencies to materialize, we also estimated our regression equations without skipping a year following the merger completion dates. The results of these analyses are presented in Table 4.6.

Table 4.6 - Efficiency and Market Power Effects without Skipping a Year

Presented in this table are the results of seemingly unrelated regression equations that regress ROA on measures of market power, exchange-level, country-level and other control variables. The variables include exchange market share, HHI (or CR4), cost efficiency, sales efficiency, domestic market capitalization, long-term debt-equity ratio, CAPEX to revenue ratio, post-merger dummy, GDP per capita and a linear time trend. We estimated the regressions using monthly data that start 60 months before the month of the merger completions and end 60 months after the merger completion dates. ( $\mathrm{t}$ statistics are in parentheses)

\begin{tabular}{lcccccc}
\hline & \multicolumn{2}{c}{ All Exchanges } & \multicolumn{2}{c}{ Merging Exchanges } & \multicolumn{2}{c}{ Rivals } \\
\hline & ROA & ROA & ROA & ROA & ROA & ROA \\
\hline Mkt Share & -0.3617 & -0.3611 & 0.0297 & 0.0305 & -0.2401 & -0.6260 \\
& $(-15.67)^{* * *}$ & $(-15.20)^{* * *}$ & $(0.92)$ & $(0.91)$ & $(-1.10)$ & $(-2.95)^{* * *}$ \\
Mkt Share * Post-Merger & -0.0204 & -0.0223 & -0.0147 & -0.0138 & -0.5985 & -0.2047 \\
Dummy & $(-0.89)$ & $(-0.95)$ & $(-0.43)$ & $(-0.38)$ & $(-2.57)^{* * *}$ & $(-0.90)$ \\
& 0.0000 & - & 0.0001 & - & 0.0000 & - \\
HHI & $(9.06)^{* * *}$ & - & $(12.24)^{* * *}$ & - & $(1.03)$ & - \\
& 0.0000 & - & 0.0000 & - & 0.0000 & - \\
HHI * Post-Merger & $(-3.63)^{* * *}$ & - & $(-2.87)^{* * *}$ & - & $(-0.10)$ & - \\
Dummy & - & 0.1836 & - & 0.2640 & - & -0.0793 \\
CR4 & - & $(6.70)^{* * *}$ & - & $(8.53)^{* * *}$ & - & $(-2.50)^{* *}$ \\
CR4 * Post-Merger & - & -0.0361 & - & 0.0164 & - & 0.1222 \\
Dummy & - & $(-1.31)$ & - & $(0.51)$ & - & $(3.77)^{* * *}$ \\
Cost Efficiency & -0.2887 & -0.2899 & -0.5436 & -0.5396 & -0.1460 & -0.0188 \\
Cost Efficiency * Post- & $(-18.49)^{* * *}$ & $(-17.64)^{* * *}$ & $(-32.27)^{* * *}$ & $(-30.55)^{* * *}$ & $(-2.63)^{* * *}$ & $(-0.34)$ \\
Merger Dummy & 0.6902 & 0.6970 & -0.5772 & -0.5890 & 0.7900 & 0.6647 \\
& $(28.38)^{* * *}$ & $(28.13)^{* * *}$ & $(-11.89)^{* * *}$ & $(-11.79)^{* * *}$ & $(12.76)^{* * *}$ & $(10.72)^{* * *}$
\end{tabular}




\begin{tabular}{|c|c|c|c|c|c|c|}
\hline & \multicolumn{2}{|c|}{ All Exchanges } & \multicolumn{2}{|c|}{ Merging Exchanges } & \multicolumn{2}{|c|}{ Rivals } \\
\hline & ROA & ROA & $\mathrm{ROA}$ & ROA & ROA & ROA \\
\hline \multirow[t]{2}{*}{ Sales Efficiency } & 0.3026 & 0.3014 & 0.2596 & 0.2533 & 0.2259 & 0.2069 \\
\hline & $(45.46)^{* * *}$ & $(43.82)^{* * *}$ & $(28.22)^{* * *}$ & $(27.05)^{* * *}$ & $(27.54)^{* * *}$ & $(23.76)^{* * *}$ \\
\hline \multirow[t]{2}{*}{$\begin{array}{l}\text { Sales Efficiency * Post- } \\
\text { Merger Dummy }\end{array}$} & -0.0388 & -0.0385 & 0.0751 & 0.0799 & -0.0533 & -0.0367 \\
\hline & $(-5.34)^{* * *}$ & $(-5.14)^{* * *}$ & $(7.64)^{* * *}$ & $(7.96)^{* * *}$ & $(-5.61)^{* * *}$ & $(-3.74)^{* * *}$ \\
\hline \multirow[t]{2}{*}{ GDP per Cap } & 0.0000 & 0.0000 & 0.0000 & 0.0000 & 0.0000 & 0.0000 \\
\hline & $(23.55)^{* * *}$ & $(23.51)^{* * *}$ & $(-2.02)^{* *}$ & $(-1.72)^{*}$ & $(28.82)^{* * *}$ & $(28.99)^{* * *}$ \\
\hline \multirow[t]{2}{*}{ Linear Trend } & 0.0002 & 0.0002 & 0.0002 & 0.0003 & -0.0002 & -0.0002 \\
\hline & $(5.00)^{* * *}$ & $(5.98)^{* * *}$ & $(4.78)^{* * *}$ & $(6.01)^{* * *}$ & $(-5.86)^{* * *}$ & $(-5.46)^{* * *}$ \\
\hline \multirow[t]{2}{*}{ Post-Merger Dummy } & 0.0260 & 0.0167 & 0.0463 & 0.0004 & 0.0055 & -0.0911 \\
\hline & $(2.51)^{* *}$ & $(0.78)$ & $(4.02)^{* * *}$ & $(0.02)$ & $(0.43)$ & $(-3.57)^{* * *}$ \\
\hline \multirow[t]{2}{*}{ CAPEX to Rev } & -0.0654 & -0.0635 & 1.3823 & 1.3735 & 0.0308 & 0.0393 \\
\hline & $(-6.30)^{* * *}$ & $(-6.04)^{* * *}$ & $(16.52)^{* * *}$ & $(15.91)^{* * *}$ & $(3.37)^{* * *}$ & $(4.22)^{* * *}$ \\
\hline \multirow[t]{2}{*}{ Debt-Equity } & -0.0079 & -0.0078 & -0.0008 & -0.0006 & -0.0653 & -0.0584 \\
\hline & $(-13.14)^{* * *}$ & $(-12.80)^{* * *}$ & $(-1.50)$ & $(-1.05)$ & $(-6.18)^{* * *}$ & $(-5.49)^{* * *}$ \\
\hline \multirow[t]{2}{*}{ Mkt Cap Exch } & 0.0097 & 0.0110 & 0.0467 & 0.0478 & 0.0179 & 0.0169 \\
\hline & $(3.62)^{* * *}$ & $(3.86)^{* * *}$ & $(13.51)^{* * *}$ & $(12.99)^{* * *}$ & $(6.02)^{* * *}$ & $(5.50)^{* * *}$ \\
\hline \multirow[t]{2}{*}{ Constant } & -0.2699 & -0.3502 & -0.9493 & -1.0492 & -0.3112 & -0.2200 \\
\hline & $(-5.36)^{* * *}$ & $(-5.64)^{* * *}$ & $(-14.95)^{* * *}$ & $(-13.82)^{* * *}$ & $(-5.72)^{* * *}$ & $(-3.38)^{* * *}$ \\
\hline $\mathrm{N}$ & 4002 & 4002 & 2208 & 2208 & 1794 & 1794 \\
\hline $\mathrm{R}^{2}$ & 0.8491 & 0.8474 & 0.9181 & 0.9145 & 0.8074 & 0.8087 \\
\hline
\end{tabular}

Whether we skip a year after the merger completion dates or not, our results remain essentially the same. In the post-merger period, (i) market share is insignificant for all exchanges and the merging exchanges and significantly negative for rival exchanges; (ii) except for CR4 for rivals which is positive at the $1 \%$ level, both measures of post-merger market concentration are either insignificant or negatively significant at the $1 \%$ level; (iii) expense efficiency is significantly negative for merging exchanges but significantly positive for rivals at the $1 \%$ level of significance; and, (iv) sales efficiency is significantly positive for the exchanges engaged in mergers and acquisitions but significantly negative for competitors. 


\subsubsection{Using ROE as an Alternative Measure of Profitability}

Though we have used ROA in our analyses thus far, we also estimated our regression models using return on equity (net income divided by equity). The results of the ROE regressions are presented in Table 4.8 .

\section{Table 4.7 - Efficiency and Market Power Effects using ROE}

Using ROE, this table presents results of the seemingly unrelated regression equations that regress ROE on measures of market power, exchange-level, country-level and other control variables. The variables include market share, HHI (or CR4), cost efficiency, sales efficiency, domestic market capitalization, long-term debt-to-equity ratio, CAPEX to revenue ratio, post-merger dummy, GDP per capita and a linear time trend. We estimated the regressions using monthly data that starts 60 months (5years) before the month of the merger completions, skips one year and ends 60 months (5 years) after the skipped year (i.e. from month 13 to month 72 ). ( $t$ statistics are in parentheses)

\begin{tabular}{|c|c|c|c|c|c|c|}
\hline & \multicolumn{2}{|c|}{ All } & \multicolumn{2}{|c|}{ Merging Companies } & \multicolumn{2}{|c|}{ Others } \\
\hline & ROE & ROE & ROE & ROE & ROE & ROE \\
\hline \multirow[t]{2}{*}{ Mkt Share } & 0.3387 & 0.1338 & -0.4197 & -0.7951 & 3.9622 & 2.4314 \\
\hline & $(1.52)$ & $(0.58)$ & $(-1.07)$ & $(-1.91)^{*}$ & $(7.63)^{* * *}$ & $(4.83)^{* * *}$ \\
\hline \multirow[t]{2}{*}{ Mkt Share * Post Merger } & -1.6796 & -1.5059 & -1.0747 & -0.6261 & -3.1953 & -1.8850 \\
\hline & $(-7.72)^{* * *}$ & $(-6.67)^{* * *}$ & $(-2.48)^{* *}$ & $(-1.37)$ & $(-5.83)^{* * *}$ & $(-3.55)^{* * *}$ \\
\hline \multirow[t]{2}{*}{ HHI } & 0.0004 & - & 0.0008 & - & 0.0000 & - \\
\hline & $(9.64)^{* * *}$ & - & $(13.65)^{* * *}$ & - & $(2.47)^{* *}$ & - \\
\hline \multirow[t]{2}{*}{ HHI * Post Merger } & -0.0003 & - & -0.0004 & - & 0.0000 & - \\
\hline & $(-7.48)^{* * *}$ & - & $(-5.76)^{* * *}$ & - & $(2.86)^{* * *}$ & - \\
\hline \multirow[t]{2}{*}{ CR4 } & - & 0.8432 & - & 2.1612 & - & -0.2264 \\
\hline & - & $(3.25)^{* * *}$ & - & $(5.67)^{* * *}$ & - & $(-2.95)^{* * *}$ \\
\hline \multirow[t]{2}{*}{ CR $4 *$ Post Merger } & - & -0.6253 & - & 0.5903 & - & 0.6884 \\
\hline & - & $(-2.30)^{* *}$ & - & $(1.43)$ & - & $(8.54)^{* * *}$ \\
\hline \multirow[t]{2}{*}{ Cost Efficiency } & -3.4424 & -3.2860 & -6.1827 & -5.9041 & -0.9830 & -0.5165 \\
\hline & $(-23.68)^{* * *}$ & $(-21.25)^{* * *}$ & $(-30.46)^{* * *}$ & $(-27.35)^{* * *}$ & $(-7.49)^{* * *}$ & $(-3.90)^{* * *}$ \\
\hline \multirow[t]{2}{*}{ Cost Efficiency * Post Merger } & 2.6223 & 2.4924 & -4.4457 & -4.9280 & 1.5346 & 1.1074 \\
\hline & $(11.25)^{* * *}$ & $(10.42)^{* * *}$ & $(-5.05)^{* * *}$ & $(-5.44)^{* * *}$ & $(10.46)^{* * *}$ & $(7.56)^{* * *}$ \\
\hline \multirow[t]{2}{*}{ Sales Efficiency } & 0.9816 & 0.8894 & 0.9276 & 0.7900 & 0.3568 & 0.2799 \\
\hline & $(15.35)^{* * *}$ & $(13.34)^{* * *}$ & $(8.41)^{* * *}$ & $(6.94)^{* * *}$ & $(17.47)^{* * *}$ & $(12.80)^{* * *}$ \\
\hline \multirow[t]{2}{*}{ Sales Efficiency * Post Merger } & 0.0591 & 0.1621 & 0.2136 & 0.3344 & -0.3517 & -0.2867 \\
\hline & $(0.78)$ & $(2.05)^{* *}$ & $(1.69)^{*}$ & $(2.56)^{* * *}$ & $(-12.63)^{* * *}$ & $(-10.02)^{* * *}$ \\
\hline \multirow[t]{2}{*}{ GDP per Cap } & 0.0000 & 0.0000 & 0.0000 & 0.0000 & 0.0000 & 0.0000 \\
\hline & $(17.14)^{* * *}$ & $(17.47)^{* * *}$ & $(15.57)^{* * *}$ & $(15.04)^{* * *}$ & $(27.28)^{* * *}$ & $(28.64)^{* * *}$ \\
\hline \multirow[t]{2}{*}{ Linear Trend } & 0.0020 & 0.0022 & 0.0025 & 0.0035 & 0.0001 & 0.0002 \\
\hline & $(5.16)^{* * *}$ & $(5.61)^{* * *}$ & $(4.65)^{* * *}$ & $(6.17)^{* * *}$ & $(0.84)$ & $(1.52)$ \\
\hline Post-Merger Dummy & 0.5872 & 0.3093 & 0.8617 & -0.4424 & 0.0314 & -0.4215 \\
\hline
\end{tabular}




\begin{tabular}{lcccccc}
\hline & \multicolumn{2}{c}{ All } & \multicolumn{2}{c}{ Merging Companies } & \multicolumn{2}{c}{ Others } \\
\hline & ROE & ROE & ROE & ROE & ROE & ROE \\
\hline \multirow{2}{*}{ CAPEX to Rev } & $(5.95)^{* * *}$ & $(1.48)$ & $(6.11)^{* * *}$ & $(-1.40)$ & $(1.00)$ & $(-6.72)^{* * *}$ \\
& -0.4175 & -0.2919 & 31.3251 & 31.3568 & 0.0128 & 0.0600 \\
Debt-Equity & $(-3.9)^{* * *}$ & $(-2.67)^{* * *}$ & $(28.04)^{* * *}$ & $(26.79)^{* * *}$ & $(0.53)$ & $(2.43)^{* *}$ \\
& 0.0167 & 0.0235 & 0.0429 & 0.0535 & 0.1135 & 0.1350 \\
Mkt Cap Exch & $(2.63)^{* * *}$ & $(3.63)^{* * *}$ & $(6.03)^{* * *}$ & $(7.17)^{* * *}$ & $(5.04)^{* * *}$ & $(5.99)^{* * *}$ \\
& -0.1115 & -0.1656 & 0.3689 & 0.3040 & 0.0513 & 0.0468 \\
Constant & $(-3.48)^{* * *}$ & $(-4.85)^{* * *}$ & $(7.03)^{* * *}$ & $(5.34)^{* * *}$ & $(5.65)^{* * *}$ & $(5.02)^{* * *}$ \\
& 0.9604 & 2.1148 & -9.8004 & -8.6266 & -0.9868 & -0.6609 \\
$\mathrm{~N}$ & $(1.64)$ & $(3.00)^{* * *}$ & $(-10.29)^{* * *}$ & $(-7.60)^{* * *}$ & $(-6.06)^{* * *}$ & $(-3.53)^{* * *}$ \\
$\mathrm{R}^{2}$ & 3642 & 3642 & 2035 & 2035 & 1607 & 1607 \\
\hline$* * * * *$ and * indicate statistical significance at the $1 \%, 5 \%$ and & $10 \%$ levels, respectively & & 0.7601 \\
\hline
\end{tabular}

As evident from Table 4.8, our findings are not impacted by using ROE as our measure of profitability. Market share in the post-merger period is either insignificant or significantly negative. If exchanges had exercised market power following the mergers, the coefficient of the market share variable should have been significantly positive in the post-merger period. HHI, one of the measures of market concentration, has been generally significantly negative in the post-merger period (except for the significantly positive coefficient for non-merging rival exchanges). CR4, while significantly positive for non-merging exchanges at the $1 \%$ level and significantly negative for all exchanges at the $5 \%$ level - is insignificant for the merging exchanges. After the merger completion dates, cost efficiency is significantly negative (at the $1 \%$ level) for the merging exchanges but significantly positive (at the $1 \%$ level of significance) for rivals while revenue efficiency is significantly positive for the merging exchanges ( $1 \%$ and $10 \%$ levels of significance) but significantly negative for rivals (at the $1 \%$ level). Thus, Table 4.8 demonstrates that using ROE, an alternative measure of profitability, does not alter the essence of our results. 


\subsubsection{Pretax ROA - An Alternative Definition of ROA}

Having defined ROA as net income divided by total assets in our main analyses, we also estimated our regression models where we use pretax income (instead of net income) to derive pretax ROA. The results of the pretax ROA regressions are presented in Table 4.8.

Table 4.8 - Efficiency and Market Power Effects using Pretax ROA

Using an alternative definition of ROA, this table presents results of seemingly unrelated regression equations that regress pretax ROA on measures of market power, exchange-level, country-level and other control variables. The variables include market share, HHI (or CR4), cost efficiency, sales efficiency, domestic market capitalization, long-term debt-equity ratio, CAPEX to revenue ratio, postmerger dummy, GDP per capita and a linear time trend. We estimated the regressions using monthly data that start 60 months before the month of the merger completions, skips one year and end 60 months after the skipped year. ( $t$ statistics are in parentheses)

\begin{tabular}{|c|c|c|c|c|c|c|}
\hline & \multicolumn{2}{|c|}{ All Exchanges } & \multicolumn{2}{|c|}{ Merging Exchanges } & \multicolumn{2}{|c|}{ Rivals } \\
\hline & Pretax ROA & Pretax ROA & Pretax ROA & Pretax ROA & Pretax ROA & Pretax ROA \\
\hline \multirow[t]{2}{*}{ Mkt Share } & -0.4752 & -0.4804 & 0.1301 & 0.1462 & 1.0198 & 0.4010 \\
\hline & $(-17.59)^{* * *}$ & $(-17.23)^{* * *}$ & $(3.55)^{* * *}$ & $(3.86)^{* * *}$ & $(4.00)^{* * *}$ & $(1.62)$ \\
\hline \multirow{2}{*}{$\begin{array}{l}\text { Mkt Share * Post- } \\
\text { Merger Dummy }\end{array}$} & -0.0288 & -0.0248 & -0.0580 & -0.0584 & -2.0476 & -1.4611 \\
\hline & $(-1.09)$ & $(-0.92)$ & $(-1.43)$ & $(-1.40)$ & $(-7.61)^{* * *}$ & $(-5.59)^{* * *}$ \\
\hline \multirow[t]{2}{*}{ HHI } & 0.0000 & - & 0.0000 & - & 0.0000 & - \\
\hline & $(3.89)^{* * *}$ & - & $(7.49)^{* * *}$ & - & $(1.63)$ & - \\
\hline \multirow[t]{2}{*}{$\begin{array}{l}\text { HHI * Post-Merger } \\
\text { Dummy }\end{array}$} & 0.0000 & - & 0.0000 & - & 0.0000 & - \\
\hline & $(1.48)$ & - & $(0.36)$ & - & $(0.39)$ & - \\
\hline \multirow[t]{2}{*}{ CR4 } & - & 0.0748 & - & 0.2328 & - & -0.1159 \\
\hline & - & $(2.40)^{* *}$ & - & $(6.70)^{* * *}$ & - & $(-3.07)^{* * *}$ \\
\hline \multirow[t]{2}{*}{$\begin{array}{l}\text { CR4 * Post-Merger } \\
\text { Dummy }\end{array}$} & - & 0.0790 & - & 0.0247 & - & 0.2254 \\
\hline & - & $(2.41)^{* *}$ & - & $(0.66)$ & - & $(5.68)^{* * *}$ \\
\hline \multirow[t]{2}{*}{ Cost Efficiency } & -0.2993 & -0.2958 & -0.6456 & -0.6512 & -0.3607 & -0.1584 \\
\hline & $(-17.00)^{* * *}$ & $(-15.91)^{* * *}$ & $(-34.06)^{* * *}$ & $(-33.07)^{* * *}$ & $(-5.59)^{* * *}$ & $(-2.43)^{* *}$ \\
\hline \multirow[t]{2}{*}{$\begin{array}{l}\text { Cost Efficiency * Post- } \\
\text { Merger Dummy }\end{array}$} & 0.8234 & 0.8251 & -1.2156 & -1.2639 & 1.2386 & 1.0479 \\
\hline & $(29.16)^{* * *}$ & $(28.68)^{* * *}$ & $(-14.8)^{* * *}$ & $(-15.30)^{* * *}$ & $(17.17)^{* * *}$ & $(14.55)^{* * *}$ \\
\hline \multirow[t]{2}{*}{ Sales Efficiency } & 0.3818 & 0.3798 & 0.3254 & 0.3231 & 0.3475 & 0.3146 \\
\hline & $(49.30)^{* * *}$ & $(47.34)^{* * *}$ & $(31.58)^{* * *}$ & $(31.12)^{* * *}$ & $(34.62)^{* * *}$ & $(29.25)^{* * *}$ \\
\hline \multirow[t]{2}{*}{$\begin{array}{l}\text { Sales Efficiency * Post- } \\
\text { Merger Dummy }\end{array}$} & 0.0033 & 0.0056 & 0.1795 & 0.1832 & -0.1072 & -0.0806 \\
\hline & $(0.36)$ & $(0.59)$ & $(15.24)^{* * *}$ & $(15.37)^{* * *}$ & $(-7.83)^{* * *}$ & $(-5.72)^{* * *}$ \\
\hline \multirow[t]{2}{*}{ GDP per Cap } & 0.0000 & 0.0000 & 0.0000 & 0.0000 & 0.0000 & 0.0000 \\
\hline & $(22.35)^{* * *}$ & $(22.42)^{* * *}$ & $(-2.77)^{* * *}$ & $(-2.54)^{* *}$ & $(19.63)^{* * *}$ & $(20.32)^{* * *}$ \\
\hline Linear Trend & 0.0001 & 0.0002 & 0.0003 & 0.0004 & -0.0005 & -0.0005 \\
\hline
\end{tabular}




\begin{tabular}{lcccccc}
\hline & \multicolumn{2}{c}{ All Exchanges } & \multicolumn{2}{c}{ Merging Exchanges } & \multicolumn{2}{c}{ Rivals } \\
\hline & Pretax ROA & Pretax ROA & Pretax ROA & Pretax ROA & Pretax ROA & Pretax ROA \\
\hline \multirow{2}{*}{ Post-Merger Dummy } & $(3.11)^{* * *}$ & $(4.31)^{* * *}$ & $(6.51)^{* * *}$ & $(8.15)^{* * *}$ & $(-8.84)^{* * *}$ & $(-8.67)^{* * * *}$ \\
& -0.0312 & -0.0779 & 0.0053 & -0.0126 & 0.0325 & -0.1361 \\
CAPEX to Rev & $(-2.61)^{* * *}$ & $(-3.09)^{* * *}$ & $(0.40)$ & $(-0.44)$ & $(2.11)^{* *}$ & $(-4.41)^{* * *}$ \\
& -0.0592 & -0.0569 & 1.9108 & 1.8942 & 0.0395 & 0.0601 \\
Debt-Equity & $(-4.56)^{* * *}$ & $(-4.32)^{* * *}$ & $(18.32)^{* * *}$ & $(17.74)^{* * *}$ & $(3.35)^{* * *}$ & $(4.95)^{* * *}$ \\
& -0.0064 & -0.0063 & -0.0040 & -0.0042 & -0.1037 & -0.0944 \\
Mkt Cap Exch & $(-8.36)^{* * *}$ & $(-8.05)^{* * *}$ & $(-6.09)^{* * *}$ & $(-6.17)^{* * *}$ & $(-9.38)^{* * *}$ & $(-8.52)^{* * *}$ \\
& 0.0027 & 0.0007 & 0.0346 & 0.0353 & 0.0290 & 0.0279 \\
Constant & $(0.69)$ & $(0.17)$ & $(7.07)^{* * *}$ & $(6.80)^{* * *}$ & $(6.49)^{* * *}$ & $(6.08)^{* * *}$ \\
& -0.0993 & -0.0824 & -0.6954 & -0.8048 & -0.5156 & -0.3824 \\
$\mathrm{~N}$ & $(-1.40)$ & $(-0.97)$ & $(-7.82)^{* * *}$ & $(-7.77)^{* * *}$ & $(-6.44)^{* * *}$ & $(-4.16)^{* * *}$ \\
$\mathrm{R}^{2}$ & 3642 & 3642 & 2035 & 2035 & 1607 & 1607 \\
***** and * indicate statistical significance at the 1\%, 5\% and $10 \%$ levels, respectively & & 0.8651 & 0.8673 \\
\hline
\end{tabular}

As evident from Table 4.8, our findings are not impacted by an alternative definition of profitability. Market share in the post-merger period is either insignificant or significantly negative. If exchanges had used the mergers to exercise market power, the coefficient of the market share variable should have been significantly positive in the post-merger period. HHI, one of the measures of market concentration, has been insignificant in the post-merger period in all regressions. CR4, while significantly positive for all exchanges at the $5 \%$ level and significantly positive for rival exchanges at the $1 \%$ level - is insignificant for the merging exchanges. After the merger completion dates, cost efficiency is significantly negative (at the $1 \%$ level) for the merging exchanges but significantly positive (at the $1 \%$ level of significance) for rivals while revenue efficiency is significantly positive for the merging exchanges ( $1 \%$ level of significance) but significantly negative for rivals (at the $1 \%$ level). Thus, Table 4.8 demonstrates that using an alternative definition of ROA does not alter the essence of our results. 
Given the similarity of our results from the various robustness tests, we conclude that our findings that the six mergers were primarily undertaken for efficiency gains but not for market power exploitation - are robust and are not sensitive to alternative specifications/definitions or frequency of measuring variables.

\subsection{Conclusion}

While creating efficiencies is often the professed motive for mergers and acquisitions, some mergers lead to the exercise of market power and impose detrimental effects (such as increased prices or reduced output or both) on consumer welfare. Despite the possibility that the recent spate of stock exchange mergers could lead to the exercise of market power in the stock exchange industry, there have been no empirical testing of the market power hypothesis in the industry. To fill this gap, this essay tested the market power effects of six major stock exchange mergers using data on 53 stock exchanges over the five years before each merger consummation and five years after each merger completion date (starting from year 2 to year 6).

Our results show that the six transformational mergers we investigated did not result in the exercise of market power. Our measures of industry concentration (HHI and CR4) and market power (market share) are not significantly positively related to profitability in the post-merger period - findings that are inconsistent with market power exploitation. Instead, we find that the mergers resulted in significant gains in efficiencies for the merging firms - with expense efficiency being significantly negative and sales efficiency 
being significantly positive for the merging exchanges. These results are consistent with efficiency gains for the merging exchanges. In univariate tests, for example, mean expenses to total assets fell by more than $60 \%$ after the merger completion dates. We also find evidence that rival exchanges not undertaking mergers and acquisitions suffered some competitive disadvantages. In the post-merger period, rival exchanges experienced significantly positive coefficients for expense efficiency and significantly negative coefficients for the revenue efficiency measure.

As we contended, stock exchange mergers will lead to efficiency gains for the merging entities but will not be exploited for market power gains because of the fact that technological advancements, globalization and liberalization in the industry are lowering entry barriers and stock exchanges are now competing on several dimensions of competition (including price, speed of execution, etc.). As a result, stock exchanges may lose competitive ground if they exploit market power following mergers and acquisitions. Our results, which are robust to different specifications/definitions and frequency of measuring variables, support our contention and ex ante hypotheses.

This essay does have some important limitations. First, given that there are only a few realized stock exchange mergers, the sample size is inherently small. By using all data for which we have access to and documenting confirmatory results from several robustness tests, we believe that our results are robust and can be generalizable to mergers of similar sizes. Second, since we have adopted a broader definition of market (to include all WFE members) in the determination of industry concentration levels, there is the possibility 
that our results are impacted by the broader definition of market. Future research should consider narrowing the definition of a market to say specific regions (e.g. North American exchanges). 


\section{References}

Acharya, S. (1993). Value of Latent Information: Alternative Event Study Methods, Journal of Finance, 48(1), pp. 363-385.

Angbazo, L. (1997). Commercial Bank Net Interest Margins, Default Risk, Interest Rate Risk and Off Balance Sheet Financing, Journal of Banking and Finance, 21, pp. 55-88.

Arnold, T., Hersch, P., Mulherin, J.H. and Netter, J. (1999). Merging Markets, Journal of Finance, 54(3), pp. 1083-1107.

Athanasoglou, P.P., Brissimis, N.S. and Delis, M.D. (2008). Bank-specific, Industryspecific and Macroeconomic Determinants of Bank profitability, Journal of International Financial Markets, Institutions and Money, 18, pp. 121-136.

Bain, J.S. (1951). Relation of Profit Rate to Industry Concentration: American Manufacturing, 1936-1940, Quarterly Journal of Economics, 65(3), pp. 293-324.

Bajtelsmit, V.L. and Bouzouita, R. (1998). Market Structure and Performance in Private Passenger Automobile Insurance, Journal of Risk and Insurance, 65(3), pp. 503-514.

Baltazar, R. and Santos, M. (2003). The Benefits of Banking Mega-Mergers: Event Study Evidence from the 1998 Failed Mega-Merger Attempts in Canada, Canadian Journal of Administrative Sciences, 20(3), pp. 196-208.

Barton, D.M. and Sherman, R. (1984). The Price and Profit Effects of Horizontal Merger: A Case Study, Journal of Industrial Economics, 33(2), pp. 165-177.

Becher, D.A., Mulherin, J.H. and Walkling, R.A. (2012). Sources of Gains in Corporate Mergers: Refined Tests from a Neglected Industry, Journal of Financial and Quantitative Analysis, 47(1), pp. 57-89.

Bendeck, Y.M. and Waller, E.R. (2011). Consolidation, Concentration, and Valuation in the Banking Industry, Journal of Business and Economics Research, 9(8), pp. 41-48.

Berger, A.N. (1995). The Profit-Structure Relationship in Banking. Tests of MarketPower and Efficiency-Structure Hypothesis, Journal of Money, Credit and Banking, 27, pp. 404-431.

Berger, A.N., Demsetz, R.S. and Strahan, P.E. (1999). The Consolidation of the Financial Services Industry: Causes, Consequences, and Implications for the Future, Journal of Banking and Finance, 23, pp. 135-194.

Bhattacharyya, S. and Nain, A. (2011). Horizontal Acquisitions and Buying Power: A Product Market Analysis, Journal of Financial Economics, 99, pp. 97-115. 
Bikker, J.A., and van Leuvensteijn, M. (2008). Competition and Efficiency in the Dutch Life Insurance Industry, Applied Economics, 40(16), pp. 2063-2084.

Binder, J.J. (1985). On the use of Multivariate Regression Model in Event Studies, Journal of Accounting Research, 23, pp. 370-383.

Bloomberg (2012). Deutsche Boerse-NYSE Takeover Vetoed by European Commission, http://www.bloomberg.com/news/2012-02-01/european-commission-blocks-proposeddeutsche-boerse-nyse-euronext-merger.html. (Last accessed 2014/06/27).

Bremus, F. M. (2015). Cross-Border Banking, Bank Market Structures and Market Power: Theory and Cross-Country Evidence, Journal of Banking and Finance, 50, pp. 242-259.

Carlton, D.W. and Gertner, R. (1989). Market Power and Mergers in Durable-Good Industries, Journal of Law and Economics, 32(2), Part 2, Empirical Approaches to Market Power: A Conference Sponsored by the University of Illinois and the Federal Trade Commission, pp. S203-S226.

Cetorelli, N. (1999). Competitive Analysis in Banking: Appraisal of the Methodologies, Economic Perspectives, 23(1), pp. 2-15.

Coase, R.H. (1972). Durability and Monopoly, Journal of Law and Economics, 15, pp. 143-149.

Chatterjee, S. (1991). Gains in Vertical Acquisitions and Market Power: Theory and Evidence, Academy of Management Journal, 34(2), pp. 436-448.

Choi, B.P. and Weiss, M.A. (2005). An Empirical Investigation of Market Structure, Efficiency, and Performance in Property-Liability Insurance, Journal of Risk and Insurance, 72(4), pp. 635-673.

Coase, R. H. (1972). Durability and Monopoly, Journal of Law and Economics, 15(1), pp. 143-150.

Coccorese, P. (2009). Market Power in Local Banking Monopolies, Journal of Banking and Finance, 33, pp. 1196-1210.

Cummins, J.D., Tennyson, S.L., Weiss, M.A. (1999). Consolidation and Efficiency in the US life insurance industry, Journal of Banking and Finance, 23, pp. 325-357.

Datta, S., Iskandar-Datta, M. and Sharma, V. (2011). Product Market Pricing Power, Industry Concentration and Analysts' Earnings Forecasts, Journal of Banking and Finance, 35, pp. 1352-1366.

Delis, M.D. and Tsionas, E.G. (2009). The joint estimation of bank-level market power and efficiency, Journal of Banking and Finance, 33, pp. 1842-1850. 
Demsetz, H. (1973). Industry Structure, Market Rivalry and Public Policy, Journal of Law and Economics, 16, pp. 1-9.

Devos, E., Kadapakkam, P-R. and Krishnamurthy, S. (2009). How Do Mergers Create Value? A Comparison of Taxes, Market Power, and Efficiency Improvements as Explanations for Synergies, Review of Financial Studies, 22(3), pp. 1179-1211.

Di Noia, C. (2001). Competition and Integration among Stock Exchanges in Europe: Network Effects, Implicit Mergers and Remote Access, European Financial Management, 7(1), pp. 39-72.

Eckbo, B.E. (1983). Horizontal Mergers, Collusion, and Stockholder Wealth, Journal of Financial Economics, 11, pp. 241-273.

Eckbo, B.E. (1985). Mergers and the Market Concentration Doctrine: Evidence from the Capital Market, Journal of Business, 58(3), pp. 325-349.

Eckbo, B.E. (1992). Mergers and the Value of Antitrust Deterrence, Journal of Finance, 47(3), pp. 1005-1029.

Eckbo, B.E. and Wier, P. (1985). Antimerger Policy under the Hart-Scott-Rodino Act: A Reexamination of the Market Power Hypothesis, Journal of Law and Economics, 28, pp. 119-149.

Economides, N. (1993). Network Economics with Application to Finance, Financial Markets, Institutions and Instruments, 2(5), pp. 89-97.

Economist (2012). Deutsche Börse and NYSE Euronext: Why the marriage failed, http://www.economist.com/blogs/freexchange/2012/02/deutsche-b\%C3\%B6rse-andnyse-euronext. (Last accessed 2014/06/27).

Efthyvoulou, G. and Yildirim, C. (2014). Market Power in CEE Banking Sectors and the impact of the Global Financial Crisis, Journal of Banking and Finance, 40, pp. 11-27.

Erel, I. (2011). The Effect of Bank Mergers on Loan Prices: Evidence from the United States, Review of Financial Studies, 24(4), pp. 1068-1101.

European Commission (2012). Mergers: Commission blocks proposed merger between Deutsche Börse and NYSE Euronext, Presss Release, http://europa.eu/rapid/pressrelease IP-12-94 en.htm?locale=en. (Last accessed 2014/06/27).

Evanoff, D.D. and Fortier, D.L. (1988). Reevaluation of the Structure-ConductPerformance Paradigm in Banking, Journal of Financial Services Research, 1, pp. 277294. 
Fama, E.F. and French, K.R. (2008). Dissecting Anomalies, Journal of Finance, 63(4), pp. 1653-1678.

Fauli-Oller,R. (2002). Assessing the Anticompetitive Effect of Mergers for Market Power, International Game Theory Review, 4(4), pp. 449-458.

Fee, C.E. and Thomas, S. (2004). Sources of Gains in Horizontal Mergers: Evidence from Customer, Supplier, and Rival Firms, Journal of Financial Economics, 74, pp. 423460 .

Fisher, A.A., Lande, R.H. and Vandaele, W. (1983). Afterword: Could A Merger Lead to Both a Monopoly and a Lower Price, California Law Review, 71, pp. 1697-1706.

Focarelli, D. and Panetta, F. (2003). Are Mergers Beneficial to Consumers? Evidence from the Market for Bank Deposits, American Economic Review, 93(4), pp. 1152-1172.

Fraser, D.R., Kolari, J.W., Pynnonen, S. and Tippens, T.K. (2011). Market Power, Bank Megamergers, and the Welfare of Bank Borrowers, Journal of Financial Research, 34(4), pp. 641-658.

Gallet, C.A. (1996). Mergers and Market Power in the US Steel Industry, Applied Economic Letters, 3, pp. 221-223.

Gan, J. (2004). Banking Market Structure and Financial Stability: Evidence from the Texas Real Estate Crisis in the 1980s, Journal of Financial Economics, 73, pp. 567-601.

Ghosh, A. (2004). Increasing Market Share as a Rationale for Corporate Acquisitions, Journal of Business Finance and Accounting, 31(1) and (2), pp. 209-247.

Giroud, X. and Mueller, H.M. (2011). Corporate Governance, Product Market Competition, and Equity Prices, Journal of Finance, 66(2), pp. 563-600.

Gosnell, T.F., Hudgins, S.C.and MacDonald, J.A. (1993). The Acquisition of Failing Thrifts: Returns to Acquirers, Financial Management, 22(4), pp. 58-68.

Gugler, K. and Siebert, R. (2007). Market Power versus Efficiency Effects of Mergers and Research Joint Ventures: Evidence from the Semiconductor Industry, Review of Economics and Statistics, 89(4), pp. 645-659.

Haleblian, J., Devers, C.E., McNamara, G., Carpenter, M.A. (2009). Taking Stock of What We Know About Mergers and Acquisitions: A Review and Research Agenda, Journal of Management, 35(3), pp. 469-502.

Hankir, Y., Rauch, C. and Umber, M.P. (2011). Bank M\&A: A market power story? Journal of Banking and Finance, 35, pp. 2341-2354. 
Hasan, I., Schmiedel, H. and Song, L. (2012). Growth Strategies and Value Creation: What Works Best for Stock Exchanges? Financial Review, 47, pp. 469-499.

Holt, C.A. (1989). The Exercise of Market Power in Laboratory Experiments, Journal of Law and Economics, 32(2), Part 2, Empirical Approaches to Market Power: A Conference Sponsored by the University of Illinois and the Federal Trade Commission, pp. S107-S130.

Hüschelrath, K. and Müller, K. (2015). Market Power, Efficiencies, and Entry Evidence from an Airline Merger, Managerial and Decision Economics, 36, pp. 239-255.

Jensen, M.C. and Ruback, R.S. (1983). The Market for Corporate Control: The Scientific Evidence, Journal of Financial Economics, 11, pp. 5-50.

Kale, J.R. and Loon, Y.C. (2011). Product Market Power and Stock Market Liquidity, Journal of Financial Markets, 14, pp.376-410.

Kane, E.J. (2000). Incentives for Banking Megamergers: What Motives Might Regulators Infer from Event-Study Evidence? Journal of Money, Credit, and Banking, 32(3), pp. 671-701.

Karceski, J., Ongena, S. and Smith, D.C. (2005). The Impact of Bank Consolidation on Commercial Borrower Welfare, Journal of Finance, 60(4), pp. 2043-2082.

Kim, E.H. and Singal, V. (1993) "Mergers and Market Power: Evidence from the Airline Industry", The American Economic Review, 83(3), pp. 549-569.

Knapp, W. (1990). Event Analysis of Air Carrier Mergers and Acquisitions, Review of Economics and Statistics, 72(4), pp. 703-707.

Kokkoris, I. and Olivares-Caminal, R. (2008) "Lessons from the Recent Stock Exchange Merger Activity, Journal of Competition Law and Economics, 4(3), pp. 837-869.

Kroszner, R.S. and Strahan, P.E. (1996). Regulatory Incentives and the Thrift Crisis: Dividends, Mutual-to-Stock Conversions, and Financial Distress, Journal of Finance, 51(4), pp. 1285-1319.

Landes, W.M. and Posner, R.A. (1981). Market Power in Antitrust Cases, Harvard Law Review, 94(5), pp. 937-996.

Leonard, W.N. (1964). Industrial Concentration and Growing Market Power, Challenge, 13(2), pp. 28-32.

Lerner, A.P. (1934). The Concept of Monopoly and the Measurement of Monopoly Power, Review of Economic Studies, 1(3), pp. 157-175. 
Levin, D. (1990). Horizontal Mergers: The 50 Percent Benchmark, American Economic Review, 80(5), pp. 1238-1245.

Lindenberg, E.B. and Ross, S.A. (1981). Tobin's q Ratio and Industrial Organization, Journal of Business, 54(1), pp. 1-32.

Marlow, M.L. and Wright, G.E. (1987). Measuring Market Power as Competition over Time, Journal of Economics and Business, 39, pp. 171-183.

Maudos, J. and Guevara, J.F. (2007). The Cost of Market Power in Banking: Social Welfare Loss vs. Cost Inefficiency, Journal of Banking and Finance, 31, pp. 2103-2125.

McAfee, R.P. and Williams, M.A. (1988). Can Event Studies Detect Anticompetitive Mergers? Economics Letters, 28, pp. 199-203.

Nielsson, U. (2009). Stock Exchange Merger and Liquidity: The Case of Euronext, Journal of Financial Markets, 12, pp. 229-267.

Osborne, D.K. and Wendel, J. (1980). A Note on Concentration and Checking Account Prices, Journal of Finance, 36(1), pp. 181-186.

Panzar, J. C. and Rosse, J. N. (1987). Testing for 'Monopoly' Equilibrium, Journal of Industrial Economics, 35, pp. 443-456.

Prager, R.A. (1992). The Effects of Horizontal Mergers on Competition: The Case of the Northern Securities Company, RAND Journal of Economics, 23(1), pp. 123-133.

Park, K.H. (2009). Has Bank Consolidation in Korea Lessened Competition? The Quarterly Review of Economics and Finance, 49, pp. 651-667.

Peress, J. (2010). Product Market Competition, Insider Trading, and Stock Market Efficiency, Journal of Finance, 65(1), pp. 1-43.

Prager, R.A. and Hannan, T.H. (1998). Do Substantial Horizontal Mergers Generate Significant Price Effects? Evidence from the Banking Industry, Journal of Industrial Economics, 46(4), pp. 433-452.

Rhoades, S.A. (1985). Market Share as a Source of Market Power: Implications and Some Evidence, Journal of Economics and Business, 37, pp. 343-363.

Rhoades, S.A. (1993). Efficiency Effects of Horizontal (in-market) Bank Mergers, Journal of Banking and Finance, 17, pp. 411-422.

Ryan, R.M., O'Toole, C.M. and McCann, F. (2014). Does Bank Market Power Affect SME Financing Constraints? Journal of Banking and Finance, 49, pp. 495-505. 
Sapienza, P. (2002). The Effects of Banking Mergers on Loan Contracts, Journal of Finance, 57(1), pp. 329-367.

Shaffer, S. (2004). Patterns of competition in banking, Journal of Economics and Business, 56, pp. 287-313.

Shapiro, C. (2010). A Tribute to Oliver Williamson: Antitrust Economics, California Management Review, 52(2), pp. 138-146.

Short, B.K. (1979). The Relation between Commercial Bank Profit Rates and Banking Concentration in Canada, Western Europe, and Japan, Journal of Banking and Finance, 3, pp. 209-219.

Singal, V. (1996) Airline Mergers and Competition: An Integration of Stock and Product Price Effects, Journal of Business, 69(2), pp. 233-268.

Stillman, R. (1983). Examining Antitrust Policy towards Horizontal Mergers, Journal of Financial Economics, 11, pp. 225-240.

Sullivan, T.G. (1974). Market Power, Profitability and Financial Leverage, Journal of Finance, 29(5), pp. 1407-1414.

Tobin, J. and Brainard, W.C. (1977). Asset Markets and the Cost of Capital, in Belassa, B. and Nelson, R. (eds.), Economic Progress Private Values and Public Policies: Essays in Honor of William Fellner, Amsterdam, North-Holland, pp. 235-262.

Turk-Ariss, R. (2010). On the Implications of Market Power in Banking: Evidence from Developing Countries, Journal of Banking and Finance, 34, pp. 765-775.

US Department of Justice and Federal Trade Commission (2010). Horizontal Merger Guidelines, http://www.justice.gov/atr/public/guidelines/hmg-2010.pdf. (Last accessed 2015/07/16).

Walter, J.R. and Wescott, P.E. (2008). Antitrust Analysis in Banking: Goals, Methods, and Justifications in a Changed Environment, Federal Reserve Bank of Richmond Economic Quarterly, 94(1), pp. 45-72.

Weinberg, J.A. (2005). Banking Markets in a Decade of Mergers: A Preliminary Examination of Five North Carolina Markets, Federal Reserve Bank of Richmond Economic Quarterly, 91(1), pp. 55-72.

White, L.J. (1987). Antitrust and Merger Policy: A Review and Critique, Economic Perspectives, 1(2), pp. 13-22.

Williams, B. (2003). Domestic and International Determinants of Bank Profits: Foreign Banks in Australia, Journal of Banking and Finance, 27, pp. 1185-1210. 
Williamson, O.E. (1968). Economies as an Antitrust Defense: The Welfare Trade-Offs, American Economic Review, 58, pp. 18-36.

Zellner, A. (1962) An Efficient Method of Estimating Seemingly Unrelated Regressions and Tests of Aggregation Bias, Journal of American Statistical Association, 57, pp. 348368. 


\section{Summary, Conclusions and Policy Implications}

This thesis probed stock exchange demutualization and mergers from three important angles. The thesis specifically looked at: (i) the stock market and product market performance of stock exchange mergers; (ii) the effects of stock exchange demutualization on market quality; and (iii) the market power implications of stock exchange mergers.

Overall, we find that stock exchange demutualization and mergers are beneficial to the exchanges pursing these strategic initiatives. Concentrating on the stock and product markets effects of stock exchange mergers, essay one demonstrates that the stock market performance of exchange mergers have been beneficial to shareholders of the merging entities - with shareholders of targets and shareholders of the combined exchanges realizing significant abnormal returns. These results are consistent with the general mergers and acquisitions literature. More interestingly, we also find, in essay one, that shareholders of rivals from countries in the same geographical region and rivals at the same stage of development realize significant abnormal returns - highlighting the importance of geography and stage of development in the stock exchange industry. Essay

one additionally shows that on the product market, the merging exchanges increased their market share and experienced reductions in bid-ask spreads whilst non-merging rivals experienced decreased market share and increased bid-ask spreads. The findings in essay one support the contention that stock exchange mergers lead to significant wealth creation on the stock market and considerable value creation on the product market for the merging entities. 
Focusing on the market quality ramifications of stock exchange demutualization, essay two establishes that exchanges undertaking demutualization (especially developed stock exchanges) achieve significant reductions in transaction costs and volatility - two important dimensions of market quality. While the demutualized exchanges see improvements in market quality, a controlled group of mutualized rival stock exchanges which have not undertaken demutualization have experienced increases in spreads and volatility, and have, as a result, seen deterioration in market quality.

Finally, with the objective of enhancing our understanding of the market power consequences of stock exchange mergers, essay three shows that stock exchange mergers have not led to the exercise of market power. Instead, the results of essay three indicate that the profitability of the merging exchanges in the post-merger period is substantially influenced by efficiencies in revenue generation and cost management. As the merging exchanges realized efficiency gains, non-merging rival exchanges suffered efficiency losses in the post-merger period.

This thesis has important implications for policy makers, practitioners and investors. First, since our results do not show that stock exchange mergers are leading to the exercise of market power, we maintain that there is no immediate need for regulatory agencies and policy makers to be concerned about stock exchange mergers leading to the exploitation of market power to the detriment of consumer welfare. On the contrary, the cost and revenue efficiency benefits resulting from the mergers point to the need for 
regulatory agencies to encourage value-enhancing mergers in the stock exchange industry.

Second, the thesis has a number of important takeaways for managers of stock exchanges. Since stock exchange mergers are rewarded on the stock and product markets (e.g. merging entities achieved increased market share, reduced spreads, etc.) and lead to efficiency gains for the merging entities, the message to managers of stock exchanges is to seek out and pursue synergistic mergers and not be overly concerned about breaching antitrust laws since the evidence, at this point, does not support the contention that exchange mergers (including those involving super exchanges like NYSE, Euronext, NASDAQ, etc.) are leading to the exercise of market power. Also, managers of mutualized stock exchanges interested in improving liquidity and reducing transaction costs in order to improve market quality should consider demutualization as a viable option.

Third, investors looking to reduce their transaction costs can consider trading on demutualized stock exchanges (especially developed demutualized stock exchanges) where spreads have reduced as a result of demutualization. Investors can also boost their portfolio returns by adding publicly traded exchanges, especially those that are potential acquisition targets - since shareholders of targets in stock exchange mergers reap significant abnormal returns. 
This thesis has a limitation worth mentioning. Given the limited number of stock exchanges, sample sizes of studies investigating the stock exchange industry are naturally small. As a result, a key limitation of this study is the small sample size - which may potentially impact the generalizability of our results. We somewhat mitigate against some of the issues related to small sample sizes by using all stock exchanges and by using data of a representative sample of firms listed on the stock exchanges in some of the analyses.

All in all, this study provides unique and insightful empirical findings on the performance implications of the key recent governance initiatives being pursued by stock exchanges. 